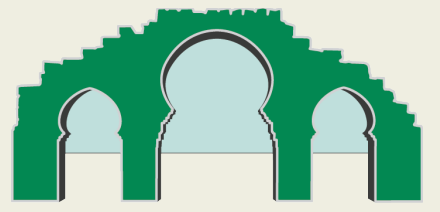

argelina.org
Revista Argelina

Revista semestral de Estudios Argelinos

Otoño 2016

Número 3

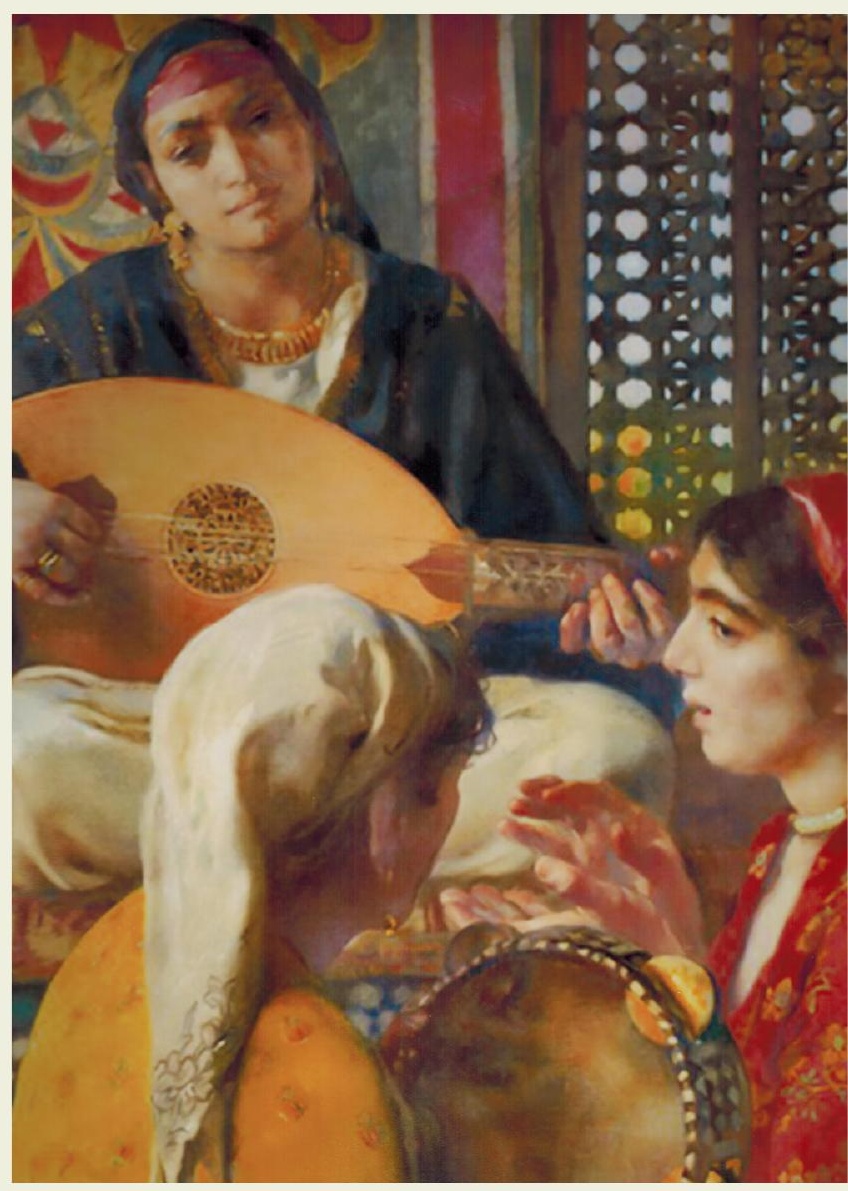


Número 3 • Otoño 2016

\section{Revista Argelina}

Revista semestral de Estudios Argelinos 



\section{Revista Argelina}

Revista semestral de Estudios Argelinos

Número 3

\section{Comité editorial:}

Directora: Naima Benaicha Ziani

Subdirector: Isaac Donoso

Secretario técnico: Didac Conesa

\section{Comité científico:}

Emilio Sola

Universidad de Alcalá de Henares

Abdallah Hammadi

Universidad de Constantina

Juan Martos Quesada

Universidad Complutense de Madrid

CARMEn Barceló

Universidad de Valencia

Miguel Ángel Manzano

Universidad de Salamanca 


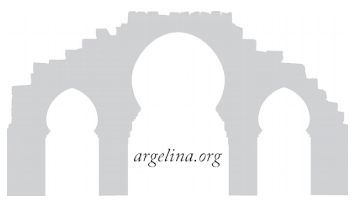

\section{Revista Argelina}

Revista semestral de Estudios Argelinos

Revista Argelina. Revista semestral de Estudios Argelinos es una publicación electrónica semestral editada por el Área de Estudios Árabes e Islámicos de la Universidad de Alicante que edita dos tomos anuales de investigación y reflexión en torno a las letras, cultura, historia y actualidad de Argelia. Una versión extendida de la revista se publica en papel por la Editorial Hispano-Árabe.

\section{Exención de responsabilidad:}

Las opiniones y datos contenidos en cada texto son de exclusiva responsabilidad de sus autores. Revista Argelina no comparte necesariamente las opiniones vertidas por los autores ni se hace responsable de los trabajos.

(C) De los autores de los artículos originales.

(C) Revista Argelina, 2016

ISSN: $2444-4413$

La revista esta disponible a texto completo en internet en la dirección siguiente: http://argelina.ua.es

Portada:

Reproducción de Les musiciennes, óleo sobre lienzo, de Paul Leroy (1860-1942)

Imprime:

Editorial Hispano-Árabe http://www.editorial-hispanoarabe.com

Calle de los Jazmines No 17

Talamanca de Jarama

28160 Madrid

Tel. 639707720 


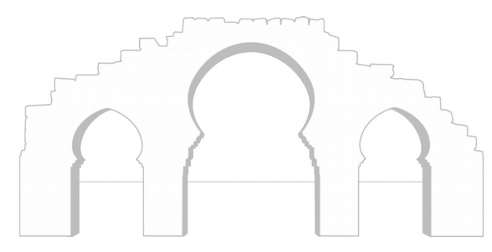

Revista Argelina • Número 3 • Otoño 2016

\section{ÍNDICE}

\section{Ensayo}

Luis F. Bernabé Pons

Música popular y sociedad en la Argelia actual

\section{Artículos y notas}

Azeddine Terbech

Las connotaciones culturales de la música folklórica en Argelia: el grupo musical al-Arfa como modelo en la región de al-Msirda (Tremecén)

Oum Hani Rahmani

Muhammad Benšnab como simbolo de civilización y multiculturalidad ........ 51

LARBi Hocine

La intertextualidad en la crítica literaria argelina moderna: el ejemplo de 'Abd alMãlik Murtäd ............................................................ 65

MuHammad Yousfi

La contradicción del arbitraje internacional y las excepciones generales en la ejecución de la ley en el sistema jurídico argelino 
Dalila Azzi

L'identité hybride des auteurs algériens d'expression française. Le cas d'Assia Djebar

NaIma Benaicha Ziani

Sobre el lenguaje en el teatro árabe argelino (II)

\section{Reseñas y comentarios bibliográficos}

ISAAC DONOSO

Historia textual de la Nueva topografía de Argel de Alonso Cano

Omar Dib, Musique Algérienne. École de Tlemcen. Galerie des grands maîtres (reseña de I. Donoso)

\section{Biblioteca}

Naima Benaicha Ziani

Kaddour el conductor. Escena dramática de la obra Los dichos de Abdelkader Alloula

Reproducción facsimil de Répertoire de musique árabe et maure. Collection de Mélodies, Ouvertures, Noubet, Chansons, Préludes, etc. recueillie par M. Edmond-Nathan Yafil sous la direction de M. Jules Rouanet Ancien Directeur de l'Ecole de Musique du Petit Athénée d'Alger, num. 19, Touchiat Maïa. Touchiat de la nouba Ghernata du mode maïa, Argel, Collection Yafil, 1906. 


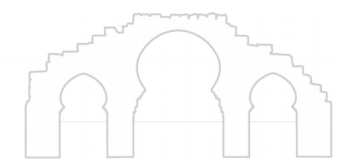

Ensayo 



\title{
MÚSICA POPULAR Y SOCIEDAD EN LA ARGELIA ACTUAL
}

\author{
LUIS F. BERNABÉ PONS
}

\begin{abstract}
El gran profeta Sulaymán tenía poder sobre todos los genios que pueblan la vida de los seres humanos. Esta capacidad, que sólo él atesoraba, le hacía dominar a estos seres de fuego, quienes le obedecían ciegamente para poner en pie todo aquel edificio que el gran rey constructor deseaba. En una ocasión, sin embargo, Salomón les ordenó construir un gran palacio en las tierras de Argel. En aquella ocasión los genios nativos le respondieron: "Irwa, ya nabi! Lakin ancor un bière!".
\end{abstract}

Este chiste, que se puede escuchar con mil formas distintas tanto en la capital de Argelia como en su zona de influencia, ilustra de forma humorísticamente despiadada lo que es una de las características que muchos de los argelinos atribuyen a su propia sociedad y a sí mismos: la pasividad y la inercia cívicas. Muchas son las razones que se pueden dar para ese juicio y muchas son las que ellos mismos dan - a no ser que a tu pregunta respondan con el mismo lema-: degradación social, injusto reparto económico, autarquía de los poderes políticos en manos de castas depredadoras, indigencia intelectual, tensión sociorreligiosa, ausencia de espíritu crítico, etc. La malévola conjunción de estos y más factores ha conducido al común de la población a una suerte de resignación ante la fatalidad, ante la que sólo se puede sobrevivir manteniendo, digamos, un perfil bajo y una inacción protectora. Mantener un proto-espíritu nacionalista, especialmente de puertas hacia fuera, recurrir a las pequeñas triquiñuelas que te beneficien cotidianamente o explotar de júbilo ante los éxitos de la Jadra' en los campos de futbol son algunos de los elementos de supervivencia que pueblan la cotidianeidad argelina, que aún aguarda su retrato literario a ras de suelo. La hogra, palabra y concepto omnipresentes en la vida de Argelia y cuyo arco semántico va desde la injusticia hasta el abuso, siguiendo la trayectoria del 
desprecio del poder hacia el pueblo, aglutina en sí toda esa serie de pensamientos y de características más o menos negativas. El ciudadano argelino en general se siente amenazado y aplastado por la hogra oficial, simbolizada en la burocracia kafkiana y en las arbitrarias decisiones de los chefs, demiurgos a los que sólo ocasionalmente se puede acceder. Estos hagar o tiranuelos sempiternos han abandonado - se les acusa - los ideales de una revolución que costó muchas vidas frente a Francia, y se han fosilizado en el poder, aplastando cualquier foco no ya de posible disidencia, sino de simple molestia.

Vaya por delante que ese retrato que muchos argelinos — de toda clase y extracción - hacen de su país es intencionadamente parcial. En absoluto inverosímil, pero sí moldeado por las numerosas dificultades por las que los ciudadanos pasan en muchas ocasiones en su vida diaria. Incluso los más decepcionados con su gobierno y sus élites guarda tanto un hálito de esperanza en un porvenir mejor como un poso nada desdeñable de aprecio por su país. Y, claro, hay gentes que apuestan por mejorar su país desde todos los puntos de vista, intentado hacer progresar a su sociedad desde dentro. Ya eliminado o muy atenuado el fenómeno harraga, la sociedad argelina asiste a un continuo de voces que desde el exterior pero también desde el interior se enfrentan a los problemas contemporáneos, identificándolos, denunciándolos e intentando sugerir remedios. Aunque las voces exteriores son de ordinario ignoradas por las portavocías oficiales, es innegable que existe en la actualidad una especie de diálogo de aportaciones críticas que intenta remediar, en palabras de Kamel Daoud, una situación de "larbinisme identitaire envers une dune et un croissant".

Pero el inmovilismo - disfrazado de precaución, normalidad o cansancio por el pasado- es el aire que se respira. La obediencia silenciosa y la no posibilidad de discusión de tipo político se han vuelto a instalar de forma cómoda en casi todas las sociedades árabes, que ven, además, cómo a la vigilancia nada discreta de los cuerpos de seguridad se ha añadido la, digamos, supervisión social, menos discreta todavía, de los partidos y grupos religiosos. Instalada en una especie de bipolaridad en la cual las autoridades y los grupos 
religiosos mantienen el orden en las calles, la sociedad argelina intenta buscar, como antes se señalaba, algunos márgenes de expansión.

Es cierto que es una situación que en sus trazos generales y más comunes no es exclusiva de Argelia, sino que la comparte una buena porción de países árabes. Incluso aquellos que no poseen los recursos naturales y económicos tan enormes que ésta atesora y ha utilizado para facilitar la ausencia de protestas. Pero es cierto también que en este campo Argelia ofrece algunas particularidades interesantes en el panorama árabe. Es el único país de su entorno que ha mantenido desde hace años algún periodismo de cariz crítico, especialmente en la zona del Oranesado. Artículos y posiciones que hubieran sido impensables en países como Marruecos o el Túnez de Ben Alí han aparecido en periódicos argelinos, planteando preguntas y reflexiones de calado. Surgido del mismo fondo crítico que sostuvo a Argelia tras la Guerra de la Independencia, este periodismo criticaba la deriva que, primero el poder y después ciertas facciones de la sociedad habían tomado con el paso del tiempo. Ponía el acento igualmente en la brecha cada vez más profunda que en algunos aspectos como el desarrollo cultural y el respeto a los derechos humanos se abría entre Argelia (vide países árabe-islámicos) y los países de Europa. Igualmente, como uno de sus principales temas, se insiste entre el abismo existente entre las élites gubernativas y la sociedad, convertida en simple recipiendario de políticas y acciones que debe asumir acríticamente. Autores como el citado Kamel Daoud, pero también Chawki Amari o Brahim Senouci, por citar algunos de los más relevantes (y que siguen siendo desconocidos en España), han mantenido y mantienen una línea innegociablemente crítica con los poderes en Argelia, sean éstos los que fueren. Y las circunstancias en las que desarrollan su trabajo y su obra son cualquier cosa menos fáciles. Baste recordar el asesinato del periodista de televisión Smail Yefsah a Bab-Ezouar el 18 de octubre de 1993 —días antes de cumplir 31 años - que 22 años después sigue impune, para comprender las circunstancias en las cuales una visión crítica debe desarrollarse en Argelia. Ciertamente las circunstancias ahora no son las mismas que veinte años atrás, pero basta repasar la lista de los intelectuales, escritores, activistas, opositores, etc., que siguen 
viéndose obligados al exilio temporal o definitivo para caer en la cuenta de lo difícil que es a veces para algunos hombres hablar de lo que ven.

Una de las formas en las que esta tensión social e ideológica suele manifestarse en sus diversas facetas es la de la música, especialmente la más alejada de las vertientes clásicas y tradicionales de la música árabe. En Argelia, este alejamiento toma forma, no exclusiva pero sí más conocida en la música raï. En las canciones y en el submundo que conforman las canciones, los cantantes y el público del raï se concentran muchas de las cuestiones que interesan y que traumatizan a la sociedad, especialmente a sus grupos menos favorecidos. Devenido en una suerte de reflejo nacional, el raï se convierte en un espejo deformante que al tiempo que recoge la imagen de quien se pone ante él, devuelve varias imágenes que responden a distintas poses, que a la vez son y no son la persona que posa ante el espejo. El raï argelino vive hoy en día la contradicción de saberse música de éxito intergeneracional y al tiempo espacio social sospechoso, en el que ningún cargo oficial desea ser visto.

No es éste, por supuesto, el espacio para desarrollar la historia de la aparición y desarrollo de la música y la canción raï en la zona de Sidi Bel Abbès y Orán y su expansión a otros lugares, por más que en nuestro país aún se eche de menos la atención crítica que se le ha prestado en otros sitios. Música de raíz popular, en el sentido del término que abarca tanto los estratos más populares de la sociedad como la posibilidad de ir incorporando elementos prestados, el raï y la canción argelina no clásica se caracterizó desde muy pronto, aparte de su uso del árabe argelino (¿podía ser de otra forma?), trufado de palabras francesas y españolas, por incorporar aquellos temas que laceraban a los jóvenes pero que habían sido desterrados de los repertorios musicales por "impropios": el alcohol, el amor y el deseo sexual insatisfecho, la separación, la hipocresía de la sociedad, las normas impuestas, la emigración -dolorosa en principio, grata después al salir del país-. La visión $\left(r{ }^{\prime} i\right)$ de estos temas por parte de los nuevos cantantes sorprendió a unos círculos sociales acostumbrados bien a la repetición de la música tradicional, bien a la importación de la música europeo-norteamericana. Muchas de esas 
canciones surgieron de los locales y cabarets donde el raï se fue formando en boca de hombres y también de mujeres como la poderosa Cheikha Remiti, conquistando poco a poco cada vez más adeptos a estas letras próximas a sus vivencias.

Años más tarde las generaciones siguientes de los jóvenes chebs, especialmente los nacidos en la década de los sesenta, iba a catapultar al raï con tres hechos fundamentales: la introducción de instrumentos electrónicos en sus composiciones, la grabación profesional de sus temas y el tratamiento de sus carreras, con la figura destacada del productor oranés Rachid Baba Ahmed, y la eclosión de esta música en Francia, primero entre los emigrantes magrebíes y después en los circuitos musicales franceses y europeos. Este estilo evolucionado, que fue conocido como "nuevo raï" o "raï sentimental", fue el que consiguió la explosión definitiva del género (por más que algunos puristas lo calificasen de mixtificado) y generó las primeras grandes figuras a nivel internacional, en especial Cheb Khaled (Jaled Hach Ibrahim, Orán, 1960), Cheb Hasni (Hasni Chakrun, Orán, 1968-1994) y Cheb Mami (Ahmad Jelifati, Saida, 1966). No por casualidad los dos primeros fueron catalogados respectivamente como el rey y el príncipe del raï. Junto con ellos, otras grandes figuras que ayudaron a llevar a primera fila el rai fueron Cheb Aziz (Bchiri Buyemaa, Setif, 1968), Cheb Sahraoui (Mohamed Sahraoui, Tlemcen, 1961), su esposa Cheba Fadela (Fadela Salmat, Orán, 1962), o Cheba Zahouania (Halima Mazzi, Orán, 1959).

Sin embargo, la gran oleada de éxito internacional se vio trágicamente truncada por el estallido de la guerra civil que dio en llamarse decenio negro, que llevó a Argelia al abismo hasta la entrada en el siglo XXI. Los cantantes de raï, cuyas vivas letras ofendían a los islamistas, se convirtieron en objetivo de estos y de las acusaciones de impiedad, especialmente en lo referido al protagonismo de la mujer, se pasó pronto a procurar su desaparición. Esta persecución sin piedad suele simbolizarse en el asesinato del "príncipe del raï", Cheb Hasni, en cuyas numerosas canciones puede seguirse sin dificultad el retrato sentimental de varias generaciones de jóvenes argelinos. Hasni, que gozaba y aún goza de una inmensa popularidad a través de las versiones de sus canciones, fue tiroteado cerca de su casa en 
Orán, en el barrio de Gambetta. El cantante oranés había protagonizado un momento especial de enervamiento de los islamistas con la grabación en 1987 a dúo con Cheba Zahouania de la canción "Derna l'amour fi barraka" ("Hicimos el amor en una cabaña"). El franco lenguaje de atracción sexual y alcohol que expresaban dos jóvenes hizo que los islamistas amenazaran a los propietarios de las tiendas de discos para que no pusieran la canción o al menos no fuera audible. El debate se extendió a todos los medios de comunicación, lo que dotó a la canción de una fama instantánea:

Hasni

- Derna l'amour fi barraka mrannika / Ana dditha ou houma yoghdou yrannikou.

-El jabta mine touali / Essakra mine touali.

\section{Zabouania}

- Ana bhare 3liya ou hbabi lla / Qilou blaya ouana maqaditchi.

- Ellila rgadah 3andi / Ellila matafrachi

$H$.

-Endirelha tilifoune outjini lyoum/ Ana bghite zzerga d'origine, mechi mabrounzia.

-El jabta mine touali / Essakra mine touali.

\section{$Z$.}

- Elga3da bel3aqliya ou rana

mgassirine / La ylaha yla Allah, elmahna doubli.

- Ellila sakra fi dari / Ellilila elkbabta fidari
Hasni

-Hicimos el amor en una cabaña de mierda. / Yo la hice mía, que los demás se fastidien.

- Es lo que tiene la juerga / Es lo que trae la bebida.

Zahouania

-Yo, tan mala conmigo, pero no con mis amigos. / Déjame con mis problemas, que no puedo más.

-Esta noche él se acuesta conmigo / ¡Oh que no termine nunca esta noche!

$\mathrm{H}$.

-La llamaré por teléfono y vendrá esta noche / La quiero morena de verdad, nada de bronceado.

- Es lo que tiene la juerga / Es lo que trae la bebida.

Z.

-Nos juntaremos como hay que hacerlo y pasaremos buenos ratos. / La pasión nos desborda, por Dios. -Esta noche beberemos en mi casa. /Esta noche el placer será conmigo. 
$H$.

- Ana bhare 3liya ou mektoubi lla/ Moubal nabra oualli koutni

3ammidète.

-El khabta mine touali / Essakra mine touali.

$Z$.

-Hasnou 3aouni, rani mdammiral Hna sharna ou 3yina,jibou l'auto tjorrina.

-Ellila rgadah 3 andi / Ellila matafrachi.

$H$.

- Ana ditha mene Gambetta ountouma chta hazkoum. -El khabta mine touali / Essakra mine touali.

$Z$.

- Hasnou 3aouni ida hdart ou faltite. - Ellila rgadah 3andi / Ellila matafrachi.

$H$.

-Hna skerna jibou el babor yjorrina / Hna skerna oulla nsina rouahna. -El khabta mine touali / Essakra mine touali.

$Z$.

-Hbebi elli nebghihoume rani
$\mathrm{H}$.

-Yo, tan malo conmigo, pero no con la que el destino me ofrece. / No quiero curarme: ésta que me abrasa ha decidido no recular.

- Es lo que tiene la juerga / Es lo que trae la bebida.

Z.

-Comprende lo que digo, estoy harta de mis problemas. / Ha sido una larga noche, trae el coche para echarnos.

-Esta noche él se acostará conmigo. / Sí, esta noche no se acabará jamás.

H.

-La elegí de Gambetta, así que todos a callar.

-Es lo que tiene la juerga / Es lo que trae la bebida.

Z.

-Comprende lo que digo, si hablo demasiado y si peco. -Esta noche él se acostará conmigo. / Sí, esta noche no se acabará jamás.

H.

-Estamos borrachos: trae un barco que nos arrastre. / Estamos borrachos y sin memoria. -Es lo que tiene la juerga / Es lo que trae la bebida.

Z.

-Estoy con la gente que quiero. / 
3andehoum / Hna skerna ou tohna,jibou l'auto tjorrina. - Ellila rgadah 3 andi / Ellila matafrachi

\section{H. $y$ Z.}

- Hna chorfa ou brare ou rana baynine / Elga3da ou taouil 3and ennass el 3aqline.

- Derna l'amour fi baraka mrannikal Ana diteha ou houma yoghdou yrannikou.
Borrachos, nos hemos desplomado.

Trae el coche que nos lleve.

-Esta noche él se acostará conmigo.

/ Sí, esta noche no se acabará jamás.

H. y Z.

-Libertinos y orgullosos, así nos mostramos. / Intimidad y elocuencia es cosa de sabios. -Hicimos el amor en una cabaña de mierda. / Yo la hice mía, que los demás se fastidien.

De forma similar a lo que sucediera decenios antes con Cheikha Remiti y su "Charrak Gataa" ("Llora, araña"), interpretada por los religiosos como una incitación a las chicas argelinas a perder su virginidad y que conllevó la censura de la cantante de Tessala, la difusión del tema fue paralela a la presión que sufrieron sus intérpretes. E1 24 de septiembre de 1994 Cheb Hasni fue asesinado a tiros cerca de su casa. El príncipe del raï moría en presencia de su hermano y se inauguraba una época de extrema tensión para los compositores e intérpretes que de alguna manera sobresalieran del espeso silencio que se imponía en la sociedad. Cheba Zahouania y muchos otros partieron para el exilio francés, donde se encontraron con algunos cantantes - caso de Remiti- que ya habían iniciado ese camino mucho antes. Pero el destino peor aguadaba a quienes se quedaron. Rachid Baba Ahmed, el gran catalizador del primer gran éxito del raï fue también asesinado a las puertas de su tienda de música en febrero de 1995, mientras que Cheb Aziz, el cantante del estilo chaoui, fue mutilado y asesinado en Constantina en septiembre de 1996. Pese a las condenas más o menos formales del gobierno ante los multitudinarios funerales que se llevaron a cabo para cada una de esas muertes, la situación se enrarecía cada vez más en un marasmo en el que todos sospechaban de los movimientos y las implicaciones de los demás. 
Todo se complicó mucho más en agosto de 1995, cuando la cantante de la Cabilia, Lila Amara apareció asesinada. La muerte fue atribuida a los islamistas, teóricamente por la condición de mujer libre y cabil de la que hacía gala Amara, si bien el silencio en el que a tal respecto se sumió el gobierno hizo circular algo más que sospechas. Pero posiblemente fue el asesinato de Matoub Lounés en Ath Douala en junio de 1998 el acto que produjo un mayor impacto. El gran ídolo de la cultura beréber, militante cabil desde su juventud, militante antigubernamental, pero también anti-islamista y ateo, era un objetivo apetecible para varios poderes. Matoub Lounés poseía la desgraciada distinción de haber sido atacado en su vida tanto por la policía como por los islamistas, y su muerte camino de casa junto con su familia, desató una impresionante manifestación de duelo y protesta en Tizi Ouzou, con acusaciones nada larvadas.

La gigantesca ola de violencia que arrasó la sociedad argelina y su creencia de una reconciliación nacional durante muchos años conllevó la salida de una gran cantidad de escritores, cantantes, periodistas y hombres de cultura de Argelia. Paradójicamente (o no), mientras el raï y otras formas de la canción popular argelina se hacían cada vez más populares en Europa y América, con Khaled a la cabeza de un grupo en el que destacaban Mami, el más joven Faudel o el más versátil Rachid Taha - junto con la sempiterna Cheikha Remiti-, en Argelia el raï, pese a su inacabable difusión popular, pasaba horas bajas.

Tras la guerra civil que supuso el decenio negro, las ganas de ruptura con el terrible pasado inmediato y un cierto movimiento entre aperturista y tolerante por parte de los sucesivos gobiernos llevó a una aceptación del raï por parte de las esferas oficiales, que veían en él tanto la expresión de una cierta idiosincrasia argelina como una forma de manifestación victoriosa contra los grupos islamistas violentos. Los cantantes raï más jóvenes, nacidos en los años ochenta, que junto a los éxitos de sus mayores habían crecido escuchando música "occidental" y sus diversos estilos más contraculturales, se lanzan a la caza del mercado con una afloración extraordinaria de protagonistas y de producción. Es el tiempo del raï-rock, del rap-raï o del cool-raï, diversas denominaciones que recibe un producto que 
todavía está en vigencia y desarrollo junto con un raï más apegado a un estilo tradicional, con versiones incesantes de los grandes clásicos por parte de cantantes más jóvenes como Houari Manar, Cheb Fayçal, Cheba Dalila, Cheb Bilal, Cheb Redda o Cheb Rayan. Esta generación verá cómo varios de los grandes cantantes de la generación anterior que se habían establecido en el exilio comienzan a volver con cierta frecuencia a cantar a Argelia y en más de una ocasión protagonizarán sesiones conjuntas.

No faltan quienes acusan a cantantes y canciones argelinos de la última década de haber edulcorado sus canciones y sus mensajes, habiéndose plegado a una cierta mercantilización de su estilo, a una preponderancia instrumental por encima de la vocal y especialmente a una excesiva y cómoda prudencia. El hecho de que el rai haya sido aceptado oficialmente, sostienen estos críticos, ha contribuido en cierta forma a una cierta "institucionalización" y a la pérdida tanto de voluntad crítica por parte de los nuevos cantantes como de esa atmósfera de producto popular y semiclandestino que tenía originalmente.

Sin embargo, estas acusaciones no tienen en cuenta algunas características en las que se desarrolla esta nueva floración de la música pop argelina. En primer lugar, la digamos esquizofrenia social que al respecto del raï se sigue manteniendo en Argelia. La música más popular del país ha devenido un signo reconocible de la identidad argelina y de esta forma ha sido aceptada por el establishment de la nación a través de ciertas manifestaciones. Sin embargo este mismo establishment no aceptaría encontrarse en una fiesta con música raï, y censuraría a los presentes. No es necesario insistir mucho acerca de la doble moral existente en torno al consumo de alcohol, elemento indispensable en este tipo de festejos. Por otra parte, es necesario diferenciar entre los conciertos raï más o menos establecidos - sean éstos en pabellones deportivos, teatros, cabarets o cualquier tipo de festejo- y el que se desarrolla fuera de los circuitos comerciales, en lugares disfrazados puertas afuera y que acogen en la noche a cantantes raï más o menos desconocidos. Se trata de una clandestinidad que tiene sus propias reglas y su propio ambiente, con jóvenes cantantes de ambos sexos con los que el lenguaje descarnado 
y los temas más tabú de la sociedad árabe-islámica encuentran su vía de escape. Ambos mundos del raï están interconectados en gentes y en canciones y si en el primero podemos hallar canciones de éxito, en el segundo hallamos versiones anónimas de esas mismas canciones — una de las señas de identidad del raï- con difícil salida en un circuito público.

Y evidentemente, como última característica, está el hecho de que la vigilancia sobre los cantantes no ha cesado. $Y$ es una vigilancia que se realiza desde frentes parecidos a los de hace unos años. Una de las cesiones a las tensiones de la sociedad que los sucesivos gobiernos han realizado ha sido la prerrogativa que se ha dado a mezquitas, asociaciones, grupos y grupúsculos musulmanes para controlar la moral de la ciudadanía. A cambio de evitar violencias desestabilizadoras, es permitida sin embargo a estos grupos una cierta violencia de baja intensidad que ayude a reprimir ciertas pulsiones, en especial de la mujer pero en general de los jóvenes. El hecho de que en las principales ciudades de Argelia las tiendas de música no puedan anunciar en la calle sus productos más modernos es un síntoma elocuente. Por otra parte, el gobierno, que se vio sorprendido con las protestas populares de enero y febrero de 2011 — que le valieron el triste record de ser el país árabe con más autoinmolados por fuegointentó apaciguar las protestas volviendo a rebajar el precio de algunos productos básicos, elevando el sueldo de los funcionarios y anunciando una enésima reforme a favor de la población. También esta primavera argelina que fue y no fue trajo un redoble del control político y policial. Aunque los gobiernos tuvieron que seguir lidiando con esa tradición de periodismo crítico ya citada - crítica que, con todo, jamás ha salido gratis-, en general las expresiones de desacuerdo o de discusión fueron acalladas, en especial las dedicadas al ejército o a los cuerpos de seguridad, que devinieron ídolos inatacables de la política de los últimos tiempos.

Ya en 1998 el cantante de Chlef Cheb Azzedine había tenido problemas con la oficialidad con su primer álbum Ach Dani Lal Ghorba dedicado en su integridad al problema de los harraga o emigrantes clandestinos. Problema siempre disminuido o matizado por las autoridades, Cheb Azzedine lo puso incómodamente en la 
primera línea del país, con temas que se harían famosos como El bhar, sobre ese Mediterráneo que separa a sus compatriotas, o Jaya mel Paris, sobre sus vidas difíciles en Francia, huérfanos de un país natal que les proteja. La popularidad de Azzedine se hizo inmensa desde entonces como cantante que apela a la moralidad de su sociedad. Sin embargo, el conflicto estallará en 2005 al grabar la que había de ser su canción estadarte, Chuf El Hogra chuf(título al que en algunas versiones se añade "Président"). La canción, una denuncia de los manejos de ciertos políticos locales, le valió una denuncia del abogado de la wilaya de Chlef por ultraje y una condena - a él y al dueño de la casa Fraternelle, que producía el disco- de un año de prisión y el pago de una multa por daños y perjuicios. El caso, que mereció una condena de Human Rights Watch y su mención en el Comité de derechos humanos de la ONU, no hizo sino agrandar la figura de Azzedine entre sus admiradores (quienes llenaron, por cierto, la sala del juicio, fuertemente vigilada).

Una reedición de este mismo caso se vivió en mayo de 2013 cuando el cantante Cheb Fayçal (Fayçal Bensalah, Aïn Temouchent 1987), uno de los mejores raiman de su generación, fue acusado, al igual que Cheb Azzedine, de "atentar contra un cuerpo constituido". La condena, de seis meses de prisión y pago de 100.000 dinares de multa por ultraje, vino en este caso por cantar en una fiesta privada la canción Mamamia. En ella, canción festiva para los jóvenes de Témouchent y por extensión del Oranesado, se hacía —o se pretendía entender - un malévolo juego de sentidos en uno de los versos con el apellido del Director General de la policía, el general Abdelgani Hamel:

Chicha w papicha w tebla lm3icha ob mama mía.

Raba a la mode, fi jater tout le monde, ob mama mía.

Polisi themel goudam el hamel, ob mama mía.

Burek hrira w ji lvotca.

Ndiru rubla, carti taana.
El hachís y las chicas me ponen tierno ¡oh Mamma mía!

Es la nueva moda para todo el mundo ¡oh Mamma mía!

El policía maricón engendra a otro maricón ¡oh Mamma mía!

Burek, harira y al fin vodka.

Hagamos una fiesta, la calle es nuestra. 
Wlid 46, segir wa artiste

El temouchent, seghir wa blendi.

Laabu laabu, barage bucif, ma andkum ma teddu.
El hijo del 46 es joven y artista. De Temouchent, joven y duro. ¡ugad, jugad! En la frontera de Boucif no pillaréis nada.

El verso en cuestión, que también posee variantes, juega con los sentidos de la policía, la homosexualidad, el alcohol, la delación e inevitablemente con la presencia nominal del militar. La condena del cantante de Témouchent, de gran popularidad en el Oranesado, fue vista como un recordatorio de la vigilancia a la que el poder, especialmente el poder armado, somete a la población. La difusión de este caso por personajes de resonancia como el periodista de France Télévision Ahmed Tazir no sirvió de mucho para el cantante, quien tuvo que purgar su pena. Sin embargo la canción, que nunca había sido grabada oficialmente en un disco, se convirtió en una especie de himno oficioso de los jóvenes oraneses, que la cantaban en cualquier acto en el que se congregaran —una fiesta, partido de fútbol, una sesión de cine- ante la manifiesta irritación de las autoridades. Pese a que Fayçal se ha dedicado en los últimos años, al lado de sus propias composiciones, a versionar con gran éxito las antiguas canciones de Cheb Hasni, Mamamia se ha convertido en una pieza emblemática y obligada de su repertorio.

Pero si algún cantante sabe de verdad de censuras y castigos en Argelia, ese es Baâziz (Abdelaziz Bejti, Cherchell, 1963), el mroufez o contestatario por antonomasia de Argelia. Ajeno al raï, Baaziz se integra de otro modo en el venero popular argelino. A través de la crítica directa y el humor corrosivo de sus letras, tomados directamente de un grande de la canción popular de la primera parte del siglo XX, Rachid Ksentini “el Charlot árabe" (m. 1944), Baaziz va a escoger el modelo de chansonnier de Renaud y Georges Brassens para ir desgranando uno tras otro los grandes males de su sociedad natal. Labor patriótica para él, insoportable crítica para el poder, Baâziz va a sufrir las iras del poder desde casi el principio de su carrera, lo que le acarreará una censura duradera y un exilio no menos largo. Él mismo suele contar con fruición los orígenes de este desencuentro: una de sus composiciones más célebres y más repetidas, 
Algérie mon amour, había sido bien recibida por las autoridades, e incluso el presidente Buteflika la había elogiado, al parecer ajeno a los alcances que la canción, pensada para los que tenían que vivir fuera de Argelia, podía tener:

Depuis mon enfance, je rien finis pas de souffir

De la faim, des privations, des pénuries

La matraque, en permanence au-dessus de ma tête

Pourtant, je rêvais de douceur de vivre,

Et de projets sur cette terre qui est mienne

Le "mektoub» en a décidé autrement

Mais, Ô mon pays, je t'en fais le serment

Un jour je reviendrai

Estribillo

Algérie, mon amour

Algérie pour toujours

Algérie, mon amour

Algérie pour toujours

Malgré ta tragédie et ton sort injuste

Je t'aime, Ô mon pays

Je te porte toujours dans mon cour

Et pour te préserver

Je ne reculerai devant aucun sacrifice

Mon pays, tu as cru en des idéaux

Vidés de leurs sens par quelques uns

Sache que beaucoup de tes enfants

Te sont éternellement dévoués

Ô cher pays, des gens ton projeté

Dans les ténèbres et l'obscurantisme

Ils t'on souilleé, terre nourricière

Et humilié ton peuple

C'est un exil, pas une fuite

Me voilà étranger, exilé

Mon pays ne me blâme pas trop

Si je n'ai pu tout te donner

Des uniformes mal intentionnés 
M'en ont empêché

$[\ldots]$

Invitado en junio de 2000 al programa televisivo "Mesk ellil", transmitido en directo a todo el país, Baâziz calibró la potencia de esta oportunidad única y en lugar de la esperable canción interpretó Waili Waili, una alegre y socarrona canción dedicada a los generales que asfixiaban al país y su moral múltiple, asociada a la rapiña de poder y dinero y a la hipocresía de llenarse la boca con su exigencia de amor y fidelidad a la patria teniendo ellos la doble nacionalidad:

\author{
walli walli \\ walli walli \\ walli walli chik mama boulo boulo \\ walli walli é li fi kalbi nqolo
}

qolou 3lya hadar wache iqol may wassi, had zman el ghadar témchi m3ah étbassi. qolhom c pas fail aji oul3ab démoqrassi, li hab issir issir ana ndir wahe kali rassi. ki nesma3 générale ana ndhak sans pitier, khalatha bles afaires lyoum rja3 personnalité. 3andou l'pouvoir ou lmal ou double nationalité, $i$ dal ichamét frjal hata fel mout yaprofité.

walli walli

walli walli

walli walli chik mama boulo boulo

walli walli é li fi kalbi nqolo

Las represalias contra semejante acto no se hicieron esperar y Baâziz fue prohibido en cualquier actuación radiada y televisada en el país, en primer lugar, y cualquier actuación en vivo más adelante. Para entonces Baâziz ya llevaba dos años viviendo en Francia tras haber gustado las primeras mieles de la censura y las presiones por su cultivo del Maakus o canción satírico-social. Como en otros casos, las censuras y las prohibiciones hacia su persona, no hicieron sino acen- 
tuar su celebridad entre los argelinos de dentro y de fuera de Argelia.

Todas estas presiones no hicieron sino acentuar el perfil comprometido de Baâziz con todas las causas a combatir dentro de su país, en primer lugar, y como ser humano en general. Contra los islamistas, pero también contra el inmovilismo y secretismo gubernamental, él fue uno de los primeros en poner en pie un homenaje al asesinado Matoub Lounés, pero no ha dejado de poner su voz en contra de la situación de la mujer argelina, del drama de los harraga o de la corrupción rampante de su país. Uno de sus temas fetiche, Je mén fou, es quizá uno de los que mejor le retrata en esa lucha anti-establishment y anti-conformismo, siempre relatada con un humor lacerante:

ki nesma3 b'deux parties yeddabzu 3la lkursi, j'men fougir yajtîwli rassi.

ki nesma3 burgeoisi, marcedes meju mekrazi, wana m3a les bus nqâsi,

Ki nchuf télévision kayen la greve des enseignants yezguiwlhuym les fainéants, (...)

anaya l youm jmien fou, ki 3retf lyoum kulchi festi, kulchi khdeb koulchi faut, qulli wiin la vérité?

Ki negra fel Journal, kayen la bagarre bin FLN, j'men fou, anyaa jrejt zman.

yddebzo yella3bu dima binaazum yet7abbu, mazel fil bagra ya 7albu.

ki nsma3 3al lemra, meskina 7asbuba bagra, maa tekteb maa teqra.

ratteb qaanun al ousra, tant pie lyum rej3et 7 urra, jm'en fou ana mzewwaj 3achra. anaya lyoum jm'en fou... (...)
Cuando oigo de dos partes que se pelean por la poltrona, me da igual, si me dejan en paz.

Cuando oigo a los burgueses del Mercedes con su cabeza hueca y yo machacado en el bus,

Cuando veo la televisión la huelga de los maestros y cómo se les llama vagos, (...)

Hoy me da igual, porque sé que todo es falso, que todo es mentira. Dime: ¿dónde está la verdad?

Cuando leo en el periódico una pelea en el FLN, me da igual: hace tiempo que me largué.

Se pelean, disfrutan siempre, se aman y aún siguen ordeñando la vaca.

Cuando oigo hablar de la mujer, pobre, la consideran una vaca que mi lee ni escribe.

Se ajusta el código de familia y ya está libre. Pero me da igual: yo me casé con diez mujeres.

Hoy me da igual...

(...) 
kayen gâchi fel yame3, ness raqed wness yesma3, jm'en fou ana nselli feddar.

(...)

kii nesma3 bel coup d'état, kol 7ouma gareta, nedjul ta $7 t$ lcuverta; w gayti ghayti yalgayta 7atta tajlas I maurvais temps.

qulli wachen hadi la7iyat, ya7akmou fina lmadammat, ya7akmou fina l maddamat tqulchi jlassu rjal rmawna kamel $f$ la pubelle; wach 3 melna fisteqlal?

ki nesma3 bi les intello, kayen menbum bel kilo, la brosse rej3at be'stylo.

arabofone francofone; qahera wella la sorbonne, rajel fihoum qoulli chkun.

ki nesma3 bi satellite, w dzayer jadmet zalamet w tetfarqa3 ki dinamit.

nnas kherjet mel orbite, w $7 n a$ mazel bidun zit, ana krabt ana mellit.

anaya lyum jm'en fou...
Hay gente en la mezquita: la mitad duerme y la mitad escucha. Me da igual, yo rezo en mi casa.

(...)

Cuando oigo del golpe de estado, toda la gente vigila. Yo me meto bajo la manta y toco la gaita hasta que amaine.

Dime, ¿qué es esta vida en la que nos mandan las mujeres?

Desaparecidos los hombres ellas nos echan a la basura. ¿Qué se ha hecho de la independencia?

Cuando oigo de intelectuales, los hay a kilos. Los bolígrafos han reemplazado al borrador. Arabófono, francófono, E1 Cairo y no la Sorbona... Quien se considere un hombre que me lo diga.

Cuando oigo del satélite, Argelia ha fabricado un petardo que explotó como dinamita. La gente pasea por el espacio y nosotros aún con la lata de aceite. No puedo más, estoy harto.

Hoy me da igual...

En la línea de los cantantes comprometidos con los problemas de la gente llana de su país, con una mezcla de sátira genuinamente argelina y tono escéptico e irónico de la escena francesa, Baaziz sigue enarbolando la bandera de una radical contestación al poder. A través de las grabaciones pirata de sus discos, sus canciones circulan por todo el país a la espera de que, más allá de alguna presencia episódica en Orán, las autoridades puedan darle permiso de actuación. Pero su ejemplo ha cundido en otros artistas más jóvenes que se precian de ser amigos suyos. El rapero Lotfi Double Kanon (Lotfi Belamri, Annaba, 1974), uno de los más destacados intérpretes de este estilo junto con los más radicales Apoka, sacudía en marzo de 2014 la 
campaña electoral que había de elegir a Abdelaziz Butefika para un cuarto mandato, con un video en el que denunciaba a "esos carroñeros que joden el ambiente del país". Pocos días después, lanzaba también en Youtube una canción, Klehoua ("Lo han robado"), en la que denunciaba de forma demoledora la rapiña a la cual han sometido a Argelia los miembros del poder establecido. Ya en 2013 Lotfi DK había publicado una polémica canción, Fakakir, dirigida directamente contra el primer ministro Abdelmalek Sellal y su particular gusto por las citas coránicas y literarias en sus ruedas de prensa. Tema que provocó un terrible ataque del oficialismo al rapero, tuvo su contrapunto cómico en una reacción que hubo hacia una de sus estrofas, en la que glosaba la inclinación de los ministros hacia sus jóvenes secretarias. Según una entrevista en El Khabar, el artista afirmaba que las mujeres de varios ministros le habían telefoneado para confirmar sus palabras y para felicitarle por su valentía. Como en otros casos, la inmensa popularidad de las letras de Lotfi Double Kanon, especialmente entre los más jóvenes, le ha valido la censura oficial y la crítica oficialista de Argelia, empujándole a un exilio forzoso.

Acechados por varios poderes que ven en la vigilancia del creador uno de los fundamentos de su permanencia, los compositores y cantantes argelinos - así como los periodistas, cineastas, escritores, activistas... - ven comprometida su libertad de expresión dentro de su país. Obligados a emprender en muchas ocasiones un exilio forzoso, la cercanía física, psicológica y cultural con Francia hace sin embargo que su presencia en el país sea notable a través de sus oyentes. De igual modo, España va ganando poco a poco cierto espacio en las canciones de los nuevos cantantes raï ("Nedi 3omri lespania”, "Naatouha Lespania", "Nehreg Le Spania", etc), como espacio de libertad y disfrute, frente a los fantasmas que de ciertas formas sigue despertando Francia entre los argelinos. Esta situación, paradójica pero tradicional en Argelia, hace que en cierta forma el discurso crítico que algunos sostienen dentro del país se vea reforzado por unas canciones que, en boca de muchos - aunque fuera de los circuitos oficiales - siguen poniendo en cuestión el sistema que busca perpetuarse a sí mismo. 


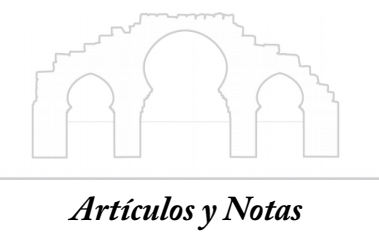



الدلالات الثقافية للمو سيقى الفلكلورية : فرقة العرفة بمنطقة مسيردة أنموذجا

\title{
LAS CONNOTACIONES CULTURALES DE LA MÚSICA FOLKLÓRICA EN ARGELIA: EL GRUPO \\ MUSICAL $A L-A R F A$ COMO MODELO EN LA REGIÓN DE AL-MSIRDA (TREMECÉN)
}

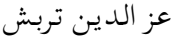

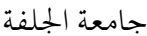 \\ AZEDDINE TERBECH \\ Universidad Zian Achour de Djelfa
}

\begin{abstract}
Resumen
El presente artículo pretende aclarar los conceptos culturales relacionados con la música folklórica argelina. Investiga las raíces del folklore argelino en general y la zona de Tremecén en particular. Estudia las connotaciones culturales del grupo musical al-Arfa y la armonía y el ritmo de los bailes tradicionales en la zona, reflejando y reflexionando sobre la identidad histórica de este arte.
\end{abstract}

Palabras clave: Música folklórica, Argelia, Grupo al-'Arfa, connotaciones culturales, escuela andalusí. 


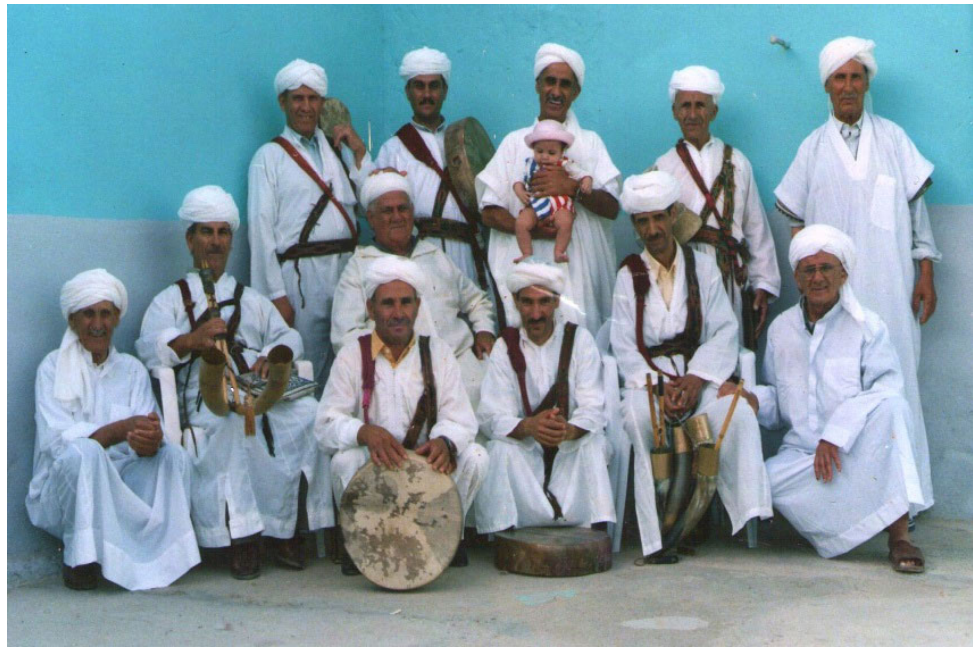

\section{الفرقة الموسيقية " العرفة "}

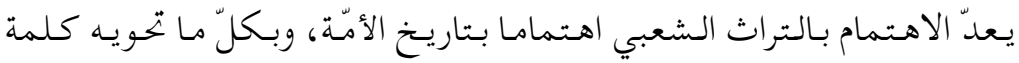
تاريخ من معان، منها : التقاليد والأعراف والعادات والمعاملات الفردية والجماعية،

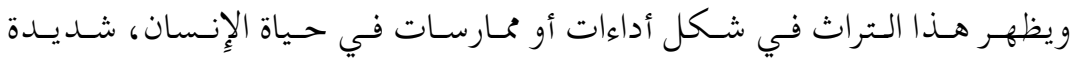
الالتصاق بـه عبر الزّمان و المـكان، وهي بـذلك تمثّل المقوّمات اليومية للثقافة التي

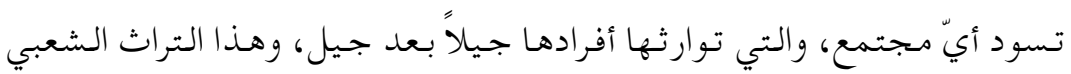

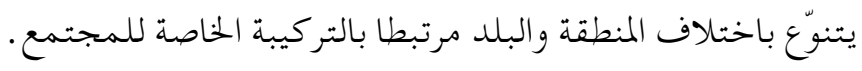

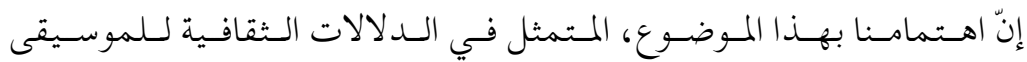
الفلكلورية،التي تهدف إلى تسليط ضَوٍَِ ولو خافتًا على جانب من حضارتنا ذات البعد الشعبي الّذي يبرز لنا حقيقة التعامل والتفكير والتخاطب بين أناس يقيمون في منطقة من مناطق المعمورة، ويقف بنا على عمق النّفس الإِنسانية وخفاياها في تصورّها للحياة و كشف ماضيها. 
وعليه، تظهر أهمية هذه المقالة في الكشف عن المعنى الّذي يكمن وراء تلك الممارسات التي يمارسها أعضاء المجتمع، وتجلية دورها داخل المحتوى الثقافي كافّة

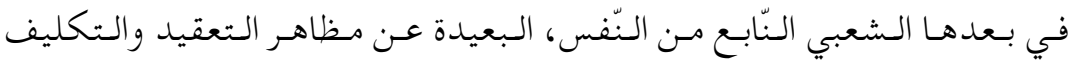

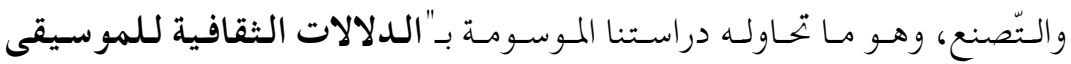
الفلكلورية : فرقة العرفة بمنطقة مسيردة أنموذجا. " إنّ مـا أردنا الوصول إليه بـدراسة هذا الموضوع الّذي امتاز بعراقته و انتقاله عن

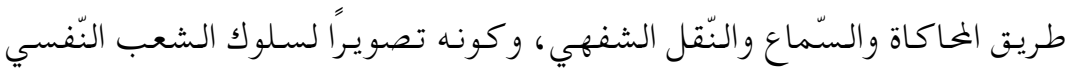
والاجتماعي، ونزوعه إلى التعبير عن روحهه وتقاليده ومعتقده اته دعانا إلى طرح التساؤلات التالية : ماهو موقع الموسيقى في الطّابع الفولكلوري عند فرقة العرفة

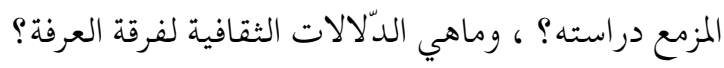

\section{1 تحديد منطقة مسيردة}

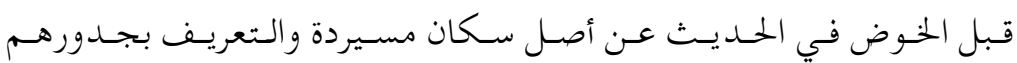
التاريـية والعرقية، ودورهم في رسم المنطقة اقتصاديا واجتماعيا وثقافيا، يـجب أن نحدد موقعهم الجغرافي في الخريطة الجزائرية. إن منطقة مسيردة المعترف بها من السلطات الفرنسية منذ عام1905 إلى غاية

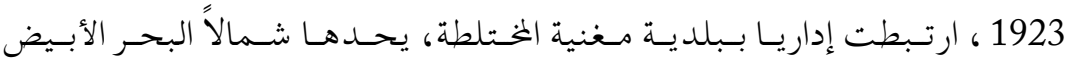
المتوسط، ومـن الشـرق دواويـر السواحسلية، وزاويـة الميرا وتـرنـانـة التابعتين لبلديـة ندرومة الخختلطة، أما جنوبا فتحدها قبائل العشاش والحلدود الجزائرية المغربية، وفق اتفاقية لالة مغنية المؤرخة في 18 مارس 1845 (من المادة الثالثة وتعليلاتها المضافة ببروتو كول أول فبراير1913)، وأمـا غربـا فيحـدهـا كل من دوّار عطية ببو كانون، وواد كـيس، ودوار بــني مـنقوش مـرسى بـن مهـيدي، ومسساحستها تـقدر بـحوالي 
إن مسيردة بمجـموع قراهـا ودواويرهـا تققدم الطابع الجـغرافي الوعر لـشمال

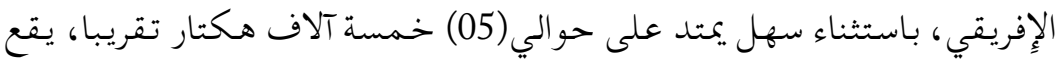

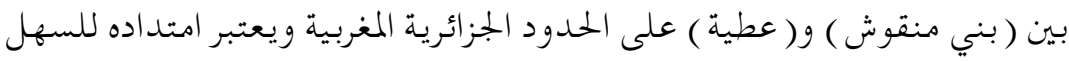
المغربي (تريفة ) وهو على ارتفاع بسيط.

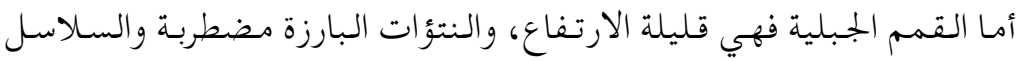
مفرقة بعدد قليل من الأودية الضيقة ذات مداخل صعبة جدلّا، وأهم هذه الأودية، واد الكواردة، ويمكن إحصاء نحو أربعين واديا، وكذا الشعاب التي تجعل الحياة ممرّا

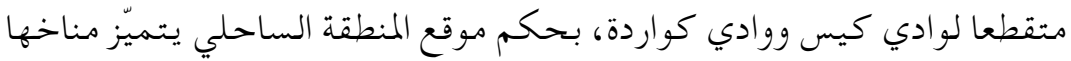
بشتاء بارد وصيف حار وجاف.

\section{2 الجذور التاريخية لسكان منطقة مسيردة}

كما لاشـكّ فيه أن هـذه المنطقة قـد احتفظت بـأثر الأحسداث التي جـرت فيها والخخلفات التي تركتها على تضاريسها، وفي هذا الشأن يقول المستشرق قابريال

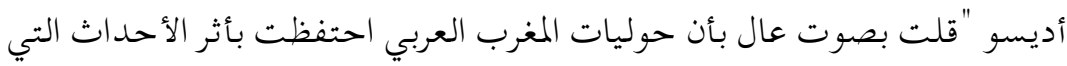

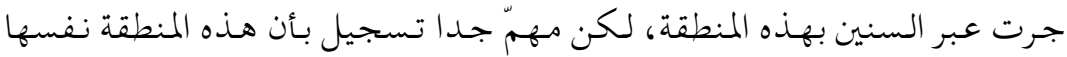
أحدثت أو حملت ذكريات لمراحل قديمة من العصور الوسطى أو ذات أثر قديم" 2.

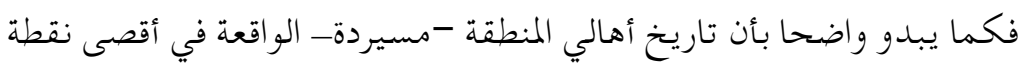

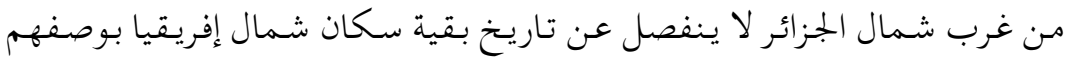

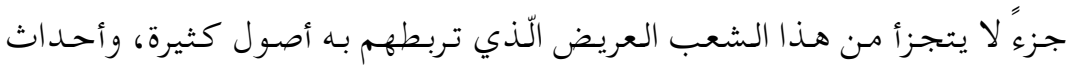

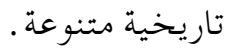

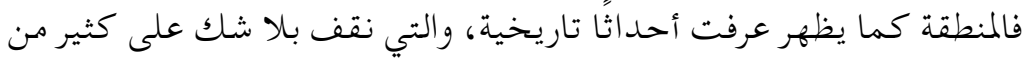

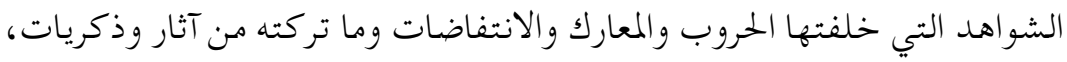

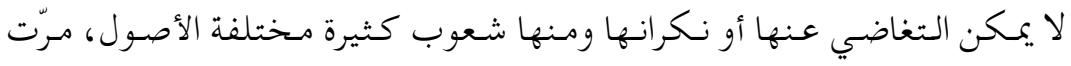


بهذه المنطقة -شمال إفريقيا- نذكر على سبيل المثال الرومان، الوندال الفينيقيين

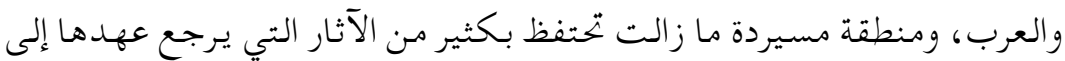
العصور القديمة والمتوسطة، فأما ما يتعلق بـالتسمية -مسيردة- فيروي قابريسيل

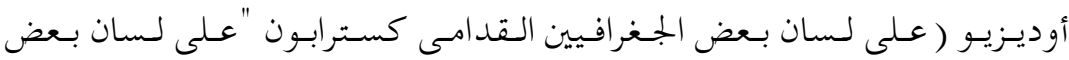
الجغرافيين القدامى كسـترابون "Strabon" ، أن السـكان الّـذيسن يسـتقرون شـرق

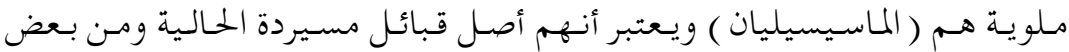
القبائل المجاورة، ويستنتنج الباحـث بـأن المنطقة تعود إلى القرن الثالث مـن عصر موريتانيا القيصرية الرومانية السيزارية 3. ومىن تلك الآثار الرومانية التي لا تزال موجودة في أماكن مختلفة مـن مناطق مسيردة، مثل: باب اللّوح، باب اليهودي، القلعة، وبوزواغي وغير بعيد عن رأس القلعة، في مصب واد الكواردة، في نقطة تسمى ( بلاد تبحريتي )، إنها تعرف كثير من الآثار الرومانية، حيث يظهر بقايا الحي المغربي التبحريتي، والّذي يعنيه البكري في القرن التاسع في بحوثه الجـغرافية، وليون الإِفريقي في وصف إفريقيا و كدا مارمول في كتاباته عن إفريقيا ${ }^{4}$.

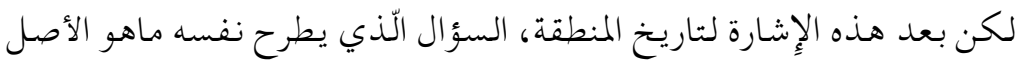
الحقيقي لسكان مسيردة ومن هم؟ في حقيقة الأمر يصعب علينا أن نحدد أصلهم الحقيقي أو إعطاء فكرة مدققة عن هؤلاء السكان من أصليين ولاجئين أو نازحين، فكل ما يلاحظ أنهم يحملون

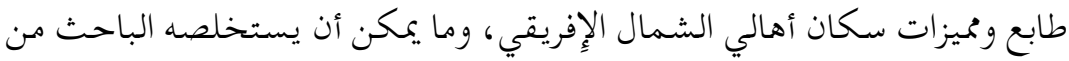
أحاديث المؤرخين ووصف الجغرافيين:" أن هؤلاء السكان برابرة أصلا، وأن القبائل

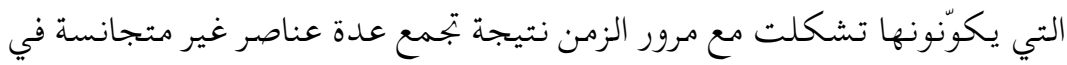

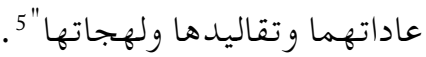


وما يمـكننا أن نميزه اليوم هو عنصريسن مـن سلالتين مختلفتين الأول أصسيل، ويتكون مـن السكان الأصليين لمسيردة والعنابرة والثاني عربي ويتكون مـن أولاد

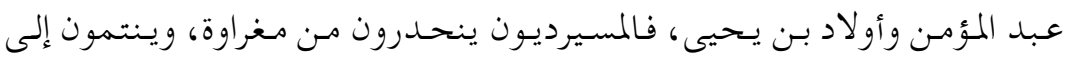
الزيانيين وإلى زيرى بن عطية ومن استقر معه في ضواحي وجدة بالحلدود الجزائرية

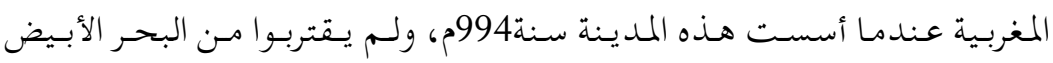
المتوسط إلى في القرن12م، أما العنابرة فينحدرون من يغمراسن مؤسس دولة بني عبد الواد مـن تلمسان، ولم يـضضموا إلى مسـيردة إلاً للتخلص مـن ضغط الأتراك العثمانيين 6

أما في ما يتعلق بالعنصرين العربيين ( أولاد عبد المؤمن،وأولاد بن يحيى ) فِإن ما يربط بينهم هو النسبب الشـيـف أي أحفاد الرسول ( ص ) كما يقال، وأولاد عبد المؤمسن ينسبون إلى إدريس بـينما أولاد بـن يـحيى فينسبون إلى مـولاي عبد القادر الجيلالي.

ومن خلال ما سبق يمكن معرفة الجد الشريف لأحفاد عبد المؤمن الّذي قدم من قرطبة في الـقرن الثالث عشر مارّا بمـدينة سـلا، ومـنطقة ( سوس ) ثم مـنطقة بـن زناسن، حيث خـلف أولادا واستقر كذلك بمـنطقة بـني مـنقوش قرب عجرود ثم نزل بقرية بيدر احدى قرى مسيردة 7. وبالرغم مـن هذه الاحتمالات والاعتقادات فالدارس الباحثث أوديسيو يقول : "قد ثبتت لدى المعرّب الفرنسي والمؤرخ الذي كتب عن تراره ( روني باري ) أن

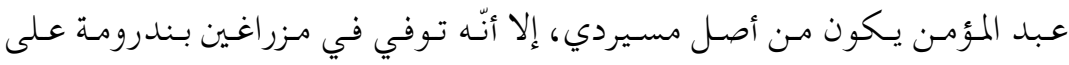
خلاف الاعتقاد الأول ( بـني زنـاسـن ويشـير المؤرخ أن المسجـد الواقع في "بيدر"

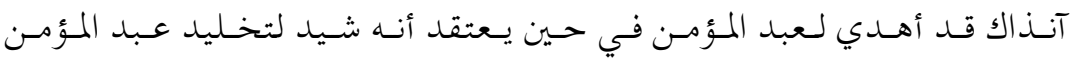

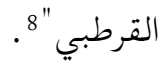




\section{3 مسيردة والاحتلال الفرنسي}

لقد مرت المنطقة بعدة توترات كسائر مناطق أرض الوطن الجزائري، وزاد في

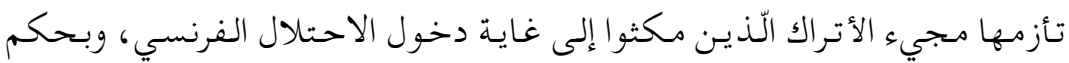

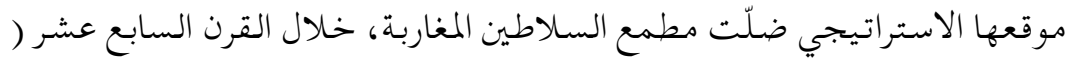

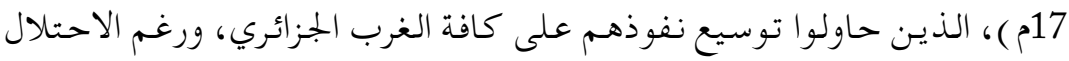

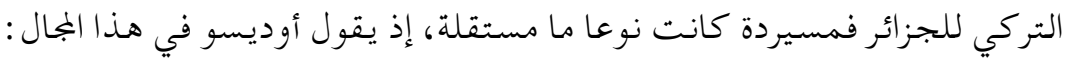

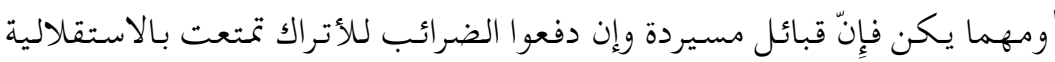

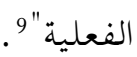

أما الاحتلال الفرنسي لمسيردة، وكما يردد على لسان أهل المنطقة، فلم يكن هينا خصوصا أن هذه القبائل كانت معروفة بنفورها لكل سلطة غير سلطتها،

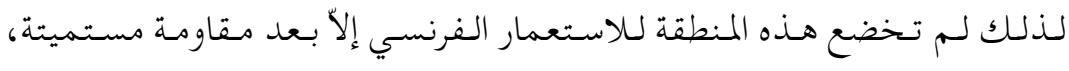

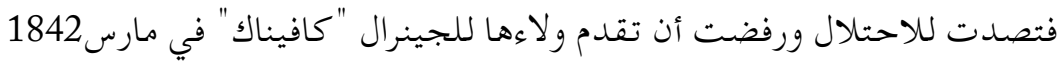

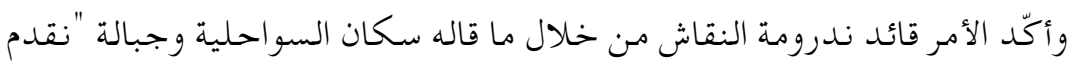
ولاءنا للجنرال ولا ننتظر سكان مسيردة أو غيرهم، ثم إن المنطقة كانت تحت إمارة

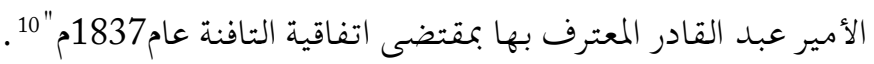

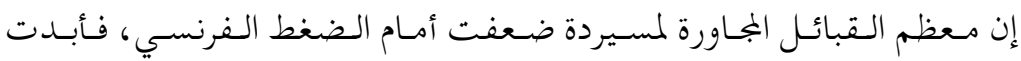

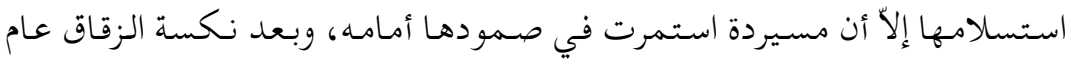

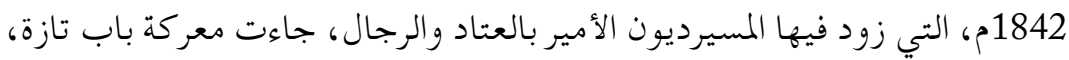

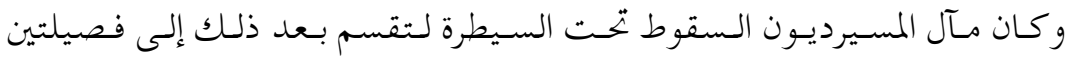
مسيردة التحاتة ومسيردة الفواقة، فسقطت الأولى عام1843 تحت قوات الجنرال

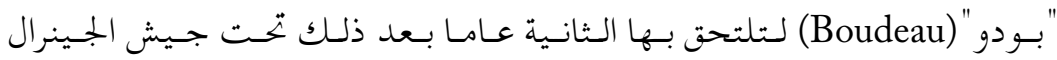
"لامورسيار" (La Morcière). 
في عام1845، وبـعد اتفاقية "لالـة مغنية" الـتي اخضعت القبائسل للسـلطة الجزائرية، التف المسيرديون حول الأمير عبد القادر من جديد، وخاضوا في جبل كركور -ليس بعيدا عن مقام سيدي إبراهيم- أولى العمليات بالمنطقة، وقد أبلوا فيها بالاء حسنا، كما سقطت القوات الفرنسية أسفل من جبل كركور بقليل في 23 سـبتمبر1845، بـقيادة "كـورب دي كـونسيار" ، حسيث انهزم الـفيلق الـثالـث والسادس والسابع، كما انهزمـت بـالقرب مـن مقام سيدي الطاهـر قوات النجـدة بقيادة "برحاو و فرومان" وعلى الرغم من هذه الانتصارات فقد خضع المسيرديون ونهائيا للسيطرة الفرنسية عام1847 11.

\section{4 انقسام مسيردة وتسمياتها}

بعد الخضوع للاستعمار الفرنسي قسمتها إلى قسمين يفصل بينهما الطريق الوطني رقم(7) الّذي يربط بين مغنية وعين عجرود، فالقسم الشمالي وهو ما بين البحر والطريق سمي ( مسـيردة التحاتة ) وقـد وقع تحت الضغط الفرنسي بـقيادة

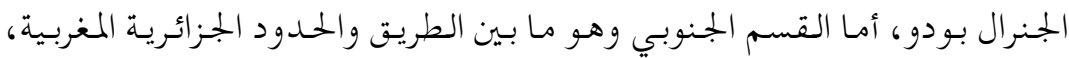
وكانت تحت حكم الجنرال لامورسيار ${ }^{12}$

وبعد استسلام أهل مسيردة نهائيا للاستعمار ، إلاً أن الأهالي بقوا على رفضهم وغضبهـم لكل قانون جـديد تسنه فرنسا وتحاول تطبيقه عليهم، فقد رفضوا دفع الضرائب التي فرضها الاستعمار عليهم، ولم يمتثلو الها إلاً بعد ما تدخلت القوات العسكرية.

لقد عرفنا أن المنطقة قسمت إلى قسمين في ظل الحلكم العسكري، فقد بقيت تتخبط تحت ضغطه إلى غاية1922، حيث خضعت للسلطة المدنية وبعد هـذا، قسمت إلى16 دوارا هي على التوالي : لبخاتة، بـني سـرات، لـقاوة، وريـاش، 
بـيدر، أولاد بـن عـايـد، أولاد سـيدي سـليمان، أولاد بـن يـحيى، لمهادة، أولاد بـن عيد، آغرم، لعنابرة، لهوارن إن كلمة مسيردة ظلت متداولة رسميا بين أهالي المنطقة حتى يومـنا هذا، أما كيف أطلقت التسمية على المنطقة، فتقول إحدى الروايات أنها جاءت نسبة إلى واقعة يحكى عنها البعض وتتمثل في وصول رجل غريـب إلى المنطقة، سئل كيف تمكنت من بلوغها رغم صعوبة المسالك إليها، وكان جوابه : لقد اتبعت المسيرذا، فقالو ا مسيردة414.

\section{5 لدلالات الثقافية للموسيقى لفرقة العرفة}

فرقة العرفة بموسيقاهـا وأغانيها ورقصها ولبسها تشكّل تراثا ثقافيا لمنطقة مسيردة بشكل خاصّ، والجزائر بصفة عامّة، تنقله الذّاكرة الشعبية عبر الأجيال لما

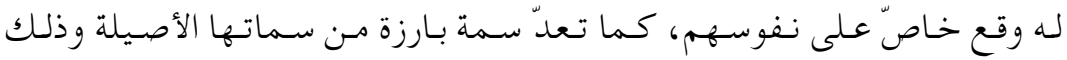
لحفاظها على الموروث الثقافي • إنّ الموسـيقى الـفولـكلوريسة في المـنطقة تـعتمد في انـتقالاتـها عـلى الـتوارث الشفهي، فذاكرتهم هي سجلّ الزّمن الّذي ظلّ يحفظها من الضّياع والتّلف خلال

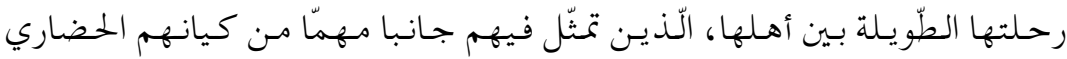

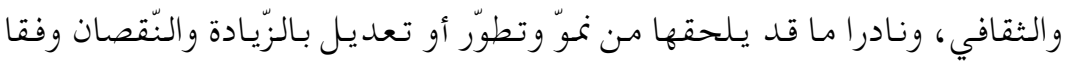

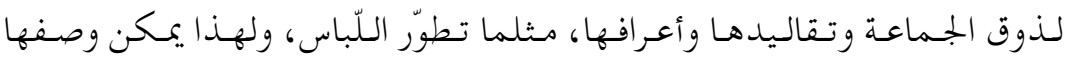
بالأصالة والتأليف الجماعي . وفي تأليفها، لا تستند على أسس علمية دقيقة بقدر ما تعتمد على ضربـة

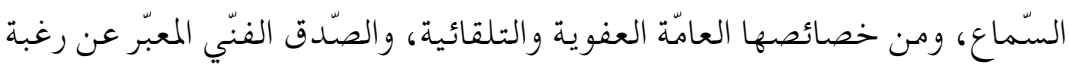

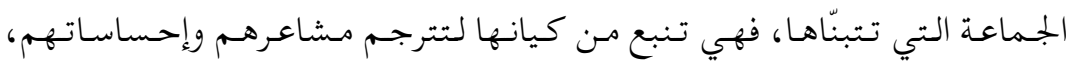
وتحقّق أغراضهم، وتكمل متعتها دون انتظار لشهرة أو كسب مادّي "وإذا قلنا أنّها 
عـفويـة وتـلقائية، فهـذا لا يـنفي عـنها خصائصهها الفنية وقو الـبها الموسيقية في

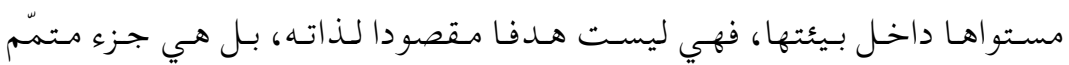

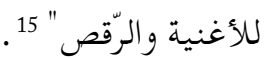

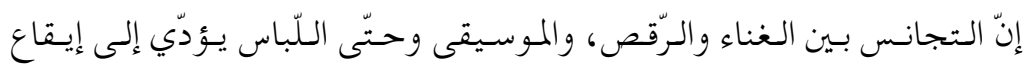

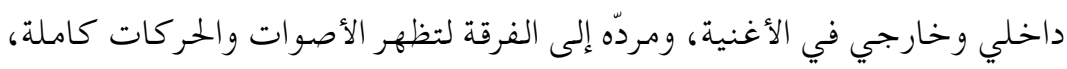

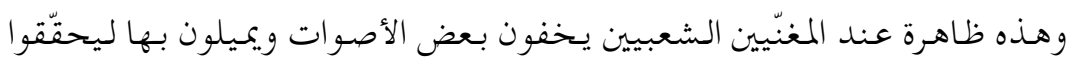
انسجاما وتماثلا في الصّوت والدّلالة بين هذه العناصر.

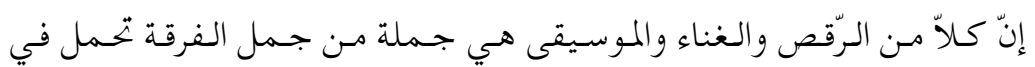

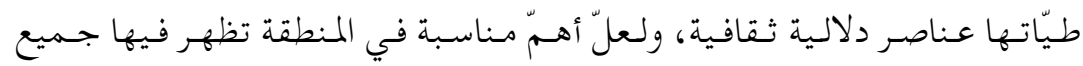

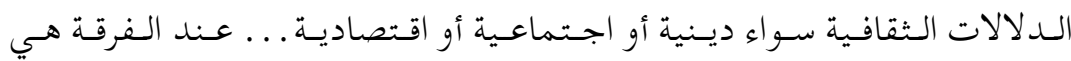

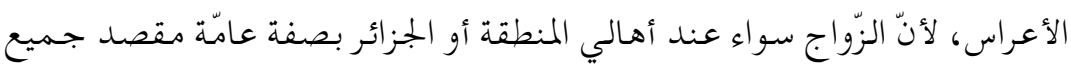

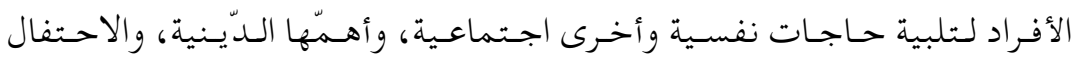
بـالزواج في مـنطقة مسـيردة مـاز ال يـحتفظ بــهـمّ العادات و الـتقاليد وإن غـابـت

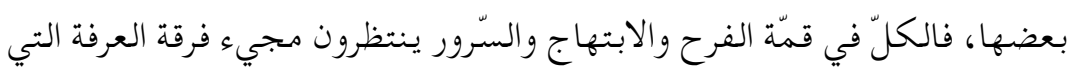
تعطي الفرح نكهته الخاصّة.

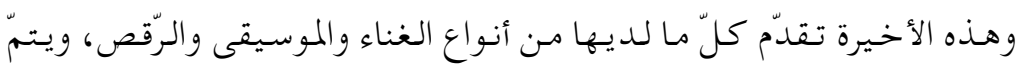
ذلك بطلب من الحاضريـن، وتحرص الفرقة في هـذا على إيصال كلّ عزف وغنـاء وحركات بوضسوح حتّى يصل المعنى واضحا للجهمهور، وهو إدراك تـامّ من دلالة

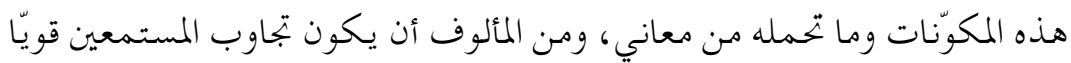

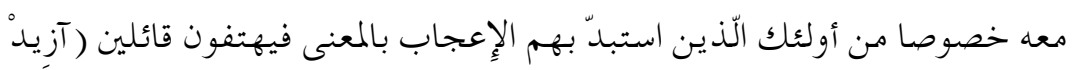

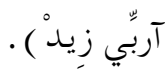


إنّ العناصر المكوّنة للفرقة، كلّ وله دلالته تريـد من خلالها أن تتميّز بها عن بـاقي الـفرق الـفولكلوريـة، لـكن الغناء ( الـكلمات ) هي الـتي يـعطى لـها القدر الكافي في إظهار هذه الدّلالات .

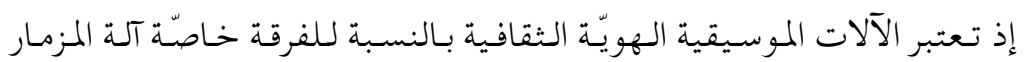

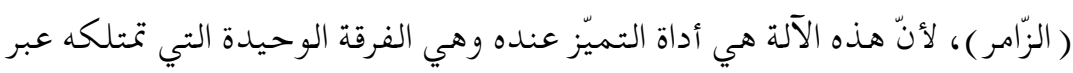

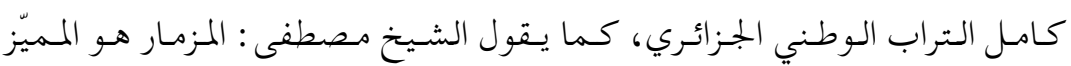
الحقيقي لفرقة العرفة بين الفرق الفولكلوريـة الأخرى، كما تعتبره الفرقة الموروث الحقيقي الّتي تتذ كرّ به أجدادها، وطبعا لا يمكن الاستغناء عن آلة البندير وأقوال. عند حضور الفرقة للحفل التّي وجّهت لها الدّعوة فيما قبل، هذا الحضور يبدأ

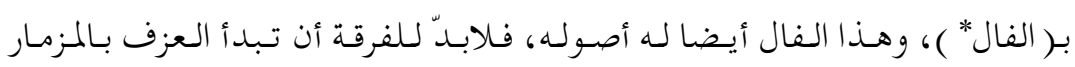

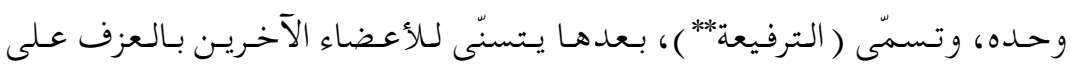

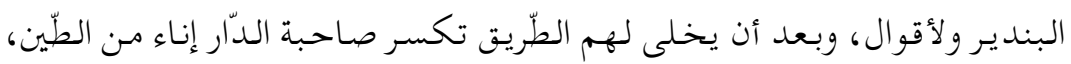
وذلك في اعتقادهم لكسر الشرّ. بعد هذا تباشر الفرقة في الغناء والرّقص، وغالبا ما تبدأ الرّقص والدة العريس، أو واحدة من أهل البيت، وترقص على أنغام رقصة الحميمة والحايطي، لأنّ هاتان

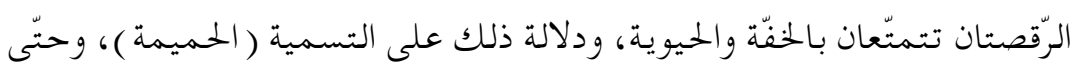

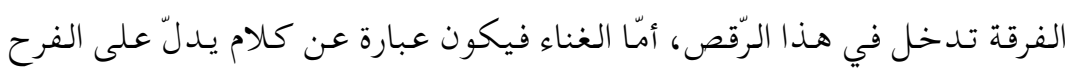

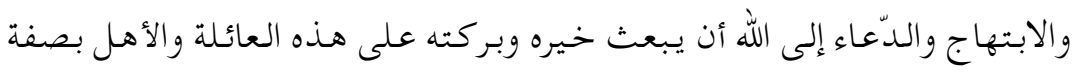

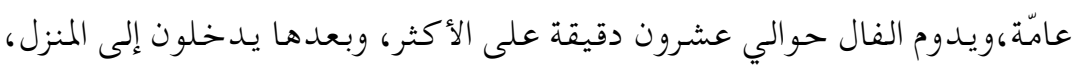

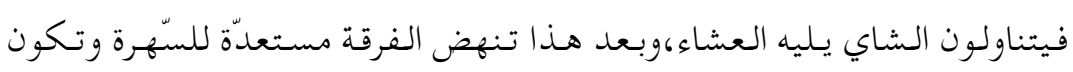

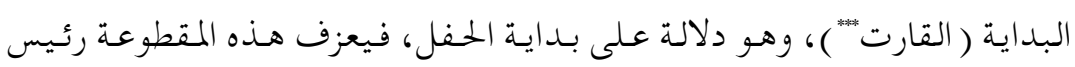
الفرقة النّافخ على آلة المزمار، فهي تقليد لا يمكن الاستغناء عنه بحيث يقوم النّافخ 
بالترحيب و تقديم التحيّة للحاضرين عن طريق هذه المعزوفة، كما يبادله الحضور التحيّة بهزّ الرّّس، وفي نهاية هذه الضرّبة يقدّم صاحب العرس قدرا من المال تعبيرا

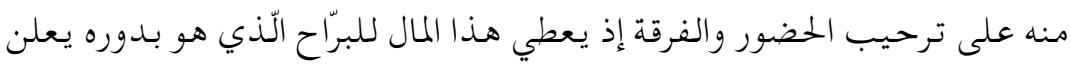
عن هذا علنيا أمام كلّ الحاضرين، وبعدها تدخل الفرقة في الغناء والرّقص لتمتع كل الحاضرين، ثمّ عند انتهاء السّهرة تودّع الجمهـور بالمزمار وحلده ويطلق عليها اسم (ضربة الصّبّاح)، وهي دلالة على نهاية الحفل .

\section{6 الدلالات الثقافية للرّقص}

إنّ الرّقص عنصر مهـمّ عند الفرقة وأغلبية الرّقص عندهم رجالي ما عدا رقصتي الحميمة والحايط، وترافق هذه الرّقصات البنادق أو العصيّ، والرّقص يتمثّل عادة

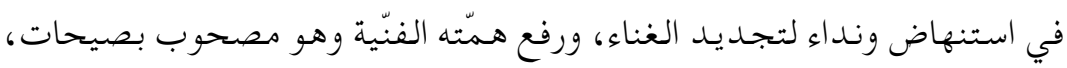
وهي تعتبر خطاب للفرقة للحفاظ عـلى المستوى الجسيّد للعزف ، كقولهـم مـثلا

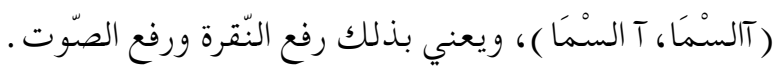

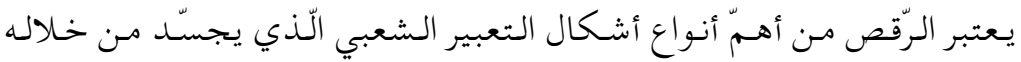

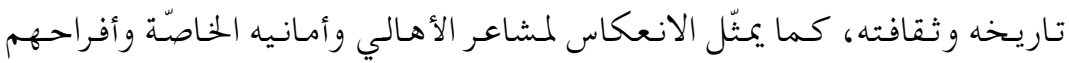

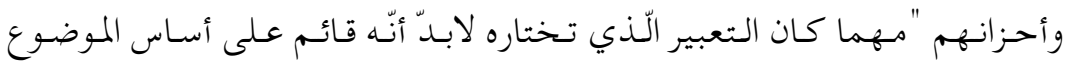

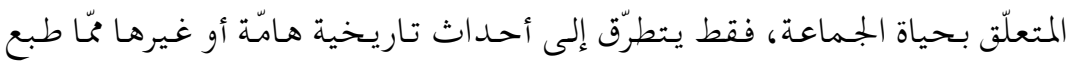

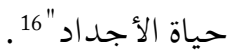

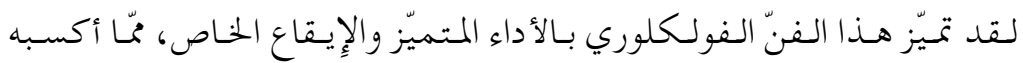

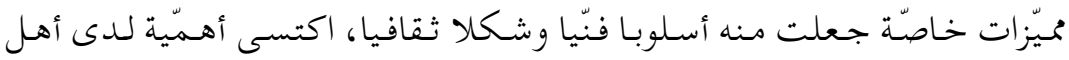
المنطقة عمومـا والفرقة خصوصا، فموضسوعاتها لا تخرج عن احستياجـات أفراد المجتمع ومختلف أذواقهم، وظروف حياتهم "وقد يتمّ التعبير في الرّقص بالحركة أو ما يسمّى بـ: ( الكوليغرافيا ) وهي وسيلة من وسائل التعبير الجسدي اللّني غالبا ما 
يـكون هـادفا، ويـعالج موضـوعات اجـتماعية تخصِ مجتمعهه وأخـرى تاريـخه،

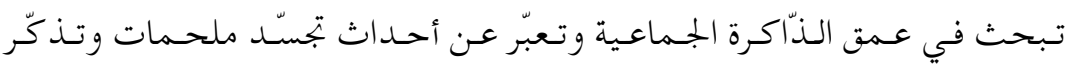

$$
\text { لبطولات ومواقف تاريخية" }
$$

وهكذا يمكن اعتبار الرّقص كلاًّ متكاملا من حياة الفرد كعضو في الجماعة، ودليلا على تششارك أفرادهـا في الأفراح والأحزان، ومـن هـنا كانـت الجماعة سمة أصلية تتميزّ بها الفرقة، اعتبارا لما تنضوي عليه الفرقة من أنواع مختلفة وأشكال

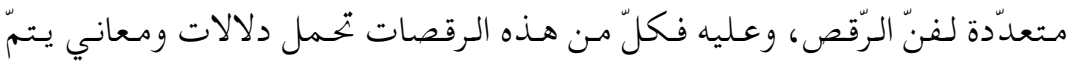

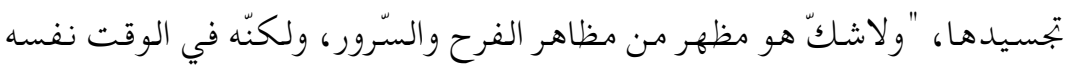
قادر على التعبير عن مظاهر أخرى منها الحماس والتعبّد" 18.

\section{( 7.1 رقصة العلاوي والنهاري}

العلاوي هي رقصة الحساب مثله مثل النهاري، فلها تقنيات موحسّدة إلاً أنّها

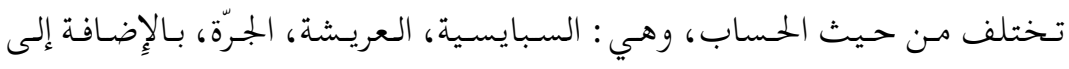
البونت ، ويمكن لهاتين الرّقصتين أن تتوقّف وتبدأ من جـديد ، و الحـركات المرافقة هي حركات الكتف التي تعبّر عن شجاعة الرّجل . كما أنّ الرقصتين تمتاز ان بطابعهما الحربي، ويمارس في نواحي عديدة من غرب

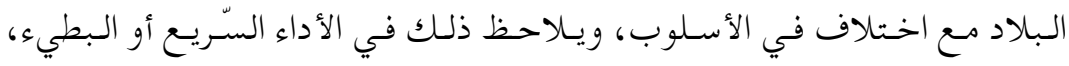

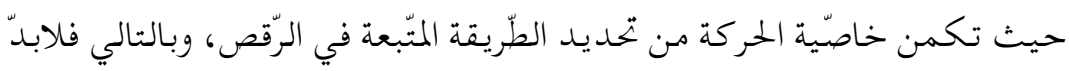
من إصدار أوامر من القائد وتلقّي تعليمات منه و كأنّ الرّاقصين في ميدان الوغى أو

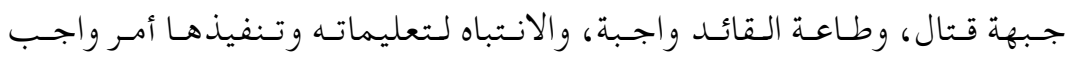
وضروري، ولا يمكن مخالفتها.

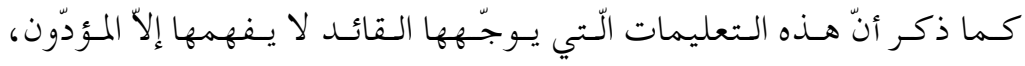
فيغيّرون الصّور والأشكال الحركية مُّا يزيدها جمالا وتعطيها صيغة فنّية غير مملّة ، 
وتببقى رقصة العلاوي والنهاري رقصة عربية لفرسـان محاربـين يـؤدونـها عقبـ الانتصارات التي كانوا يحرزونها على العدوّ، وتبدو هذه الرّقصة للمتفرّج و كأنهّا

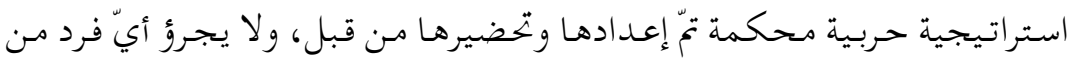
أعضاء الفرقة على القيام بأيّة مبادرة كانت و لا يمكنه أن يفعل ذلك، فالقائد هو الّذي يقوم بالمبادرات داعيا بل آمرا أعضاء فرقته بتنفيذها ويقبلون ذلك.

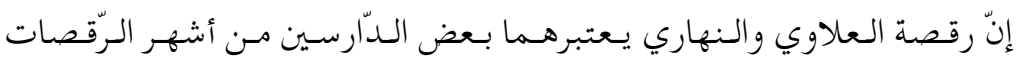
السشبية الفولكلوريـة الجـزائريـة لانتـشارهـا في بـعض المناطق الغربـية مـن الجـزائر

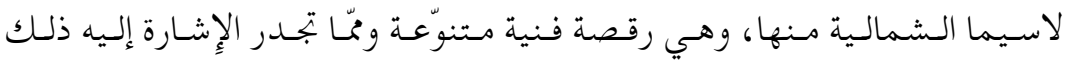
الانسجام الملاحظ بين أعضاء الفرقة والتفاهـم في الأداء، والاحترام والتقدير الّذي

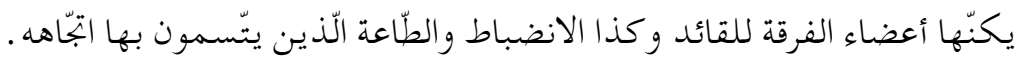
وتبقى رقصة العلاوي "محل اعتزاز الشّبّاب في كافّة غرب البلاد، وتعتبر من

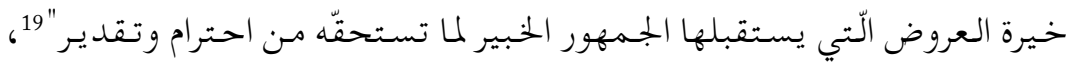
وعلى هذا الأساس فِإنّ رقصة العلاوي أهـمّيتها تكمن في طريقة أدائها الملتصقة

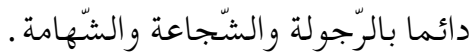

\section{2}

رقصة أحيدوس تبقى من أجمل الرقصات عند فرقة العرفة، وذلك لأنّها من أكثر الرّقصات المذكورة، تعبيرا عن الفرحة والسّرور والابتهاج لمختلف المناسبات، إلاً أنّ تأديتها عند الفرقة تختلف عن باقي الفرق خاصِّة المتواجدة بنواحي جنوب

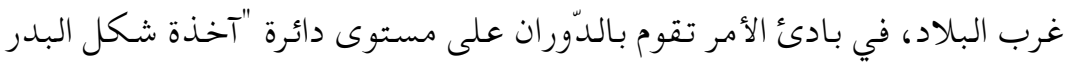

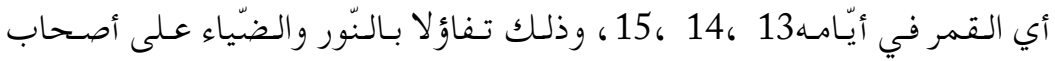


إنّ الدّوران حول الدائرة المرسومة لهم من طرف القائد والّذي هو النافخ على آلة

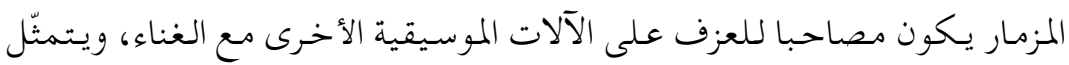
الغناء في ذكر الحبيب المصطفى، بعد هذه الخطوة تصطفّ الفرقة مقابلة للرّئيس

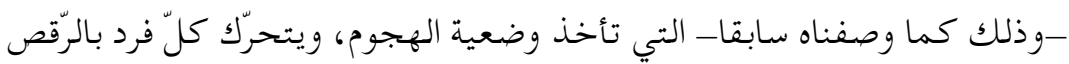

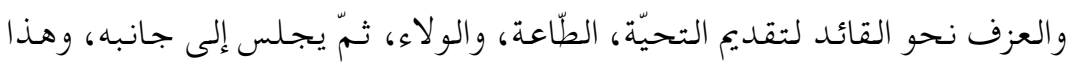
مع باقي عناصر الفرقة، وتسمية هذه الرّقصة بأحيدوس، يوحي بأنّ الفرقة بربرية

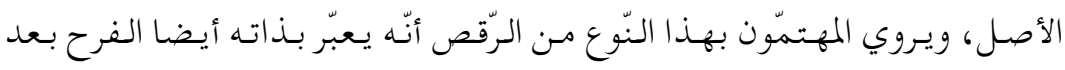
الانتصار . بـعد الانـتهاء مسن وضـعية الـتدريسب لـلهجوم وتـقديم الـتحيّة والـولاء والطظّاعـة

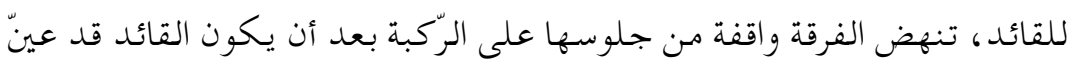

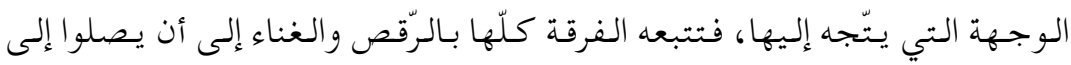

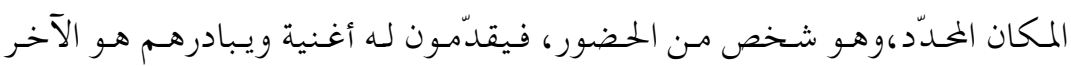
بتقديم مبلغ من المال تقديرا منه إليهم على نجاحهم في تأدية هذه الرّقصة، ويظهر ذلك التعبير الجسـدي المتناغم والمتناسق مع النّغم الموسيقي والكلمات عن مدى استعداد الممارس لخوض غمار الحرب وقدرته على مواجهة العدوّ وثقته في انتزاع

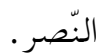
7.3 إنّ لكلمة الصفّ دلالة تتمثّل في ضبط أموره وتنظيمها منذ انتقال الفرد إلى لـ

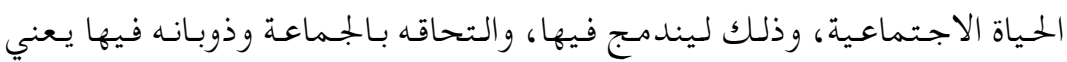

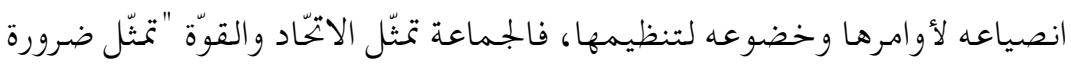
اجتماعية تستمدّ قوّتها من هذه الضّرورة لذلك من الصِّب على الأفراد الخروج

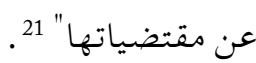




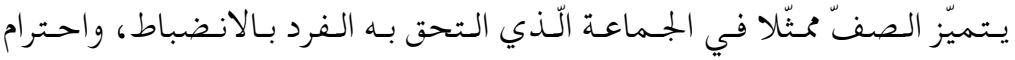
الـقو انـين ضـرورة اجـتماعية وجـــت لـتنظيم العلاقـات بـين الأفراد وتسـيير شـؤون الحياة، وهذا الانتماء يفضي إلى التلاحمى بينهم ( أفراد الجماعة ) من أجل الوحلدة

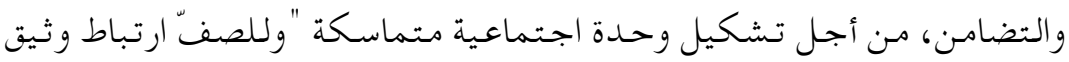
وعالقة حميمة مع الرّقص الشّعبي اللّذي يعتبر أحسد أشكال التعبير الّتي يشترك

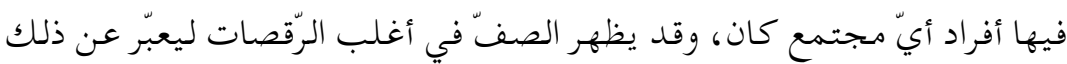
التلاحم و الانسجام، والتّناسق والتّناغم" 22. إنّ رقصة الصفّ منتشرة بصفة كبيرة في مـنطقة مسيردة فلا تعدو أن تمرّ أيّ

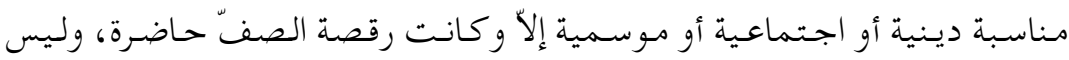
فقط عند فرقة العرفة وإنّا عند نساء المنطقة أيضا، اللّواتي يمتزن بها، وقديما عند بعض العائكلات كانـت تمارس النّساء رقصة الصفّ مع فرقة العرفة، وذلك عند حضورهم للحفل، إنّ هذا الانتشار لرقصة الصفّ في المنطقة ماهو إلآ دلالة على توحِّد أهاليها تحت نسق اجتماعي معينّ، واحترامهم للقيم الجماعية التي وجدلت بين الأهالي، وذلك كما يصفها الباحثث عماد عبد الغني : "أنساق القيم إذهي المستويات التي نحتكم إليها في عرض ذواتنا أمام الآخرين، أو هي الموجهّات التي لتهي

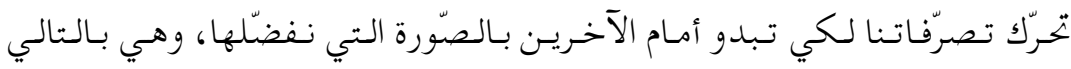
مستويات توجّهنا في إقناع الآخرين والتّأثير فيهم لتبنّي مو اقف أو معتقدات" ورقصة الصفّ كما أطلق عليها سابقا، أو ما اشتهرت بـه هي رقصة جسماعية اكتسبت عن طريق الموهبة الوراثية، كما تعدّ سجلّ لحياة فنيّة شعبية معيّنة أغلبها من القرى والبوادي تعبّر بها عن أفراحها وأحزانها، وقد يرتبط الحديث عن الرّقص

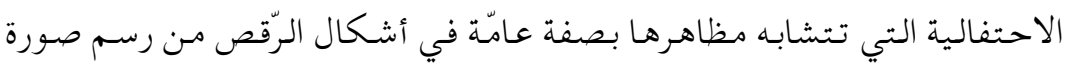
لمقاتل أو مجاهد أو وصف امرأة أو رجل أو التعبير عن حركة عامل ... 
إنّ رقصة الصف عند الفرقة هي شكل تعبيري قائم بشكل أساسي على نظام

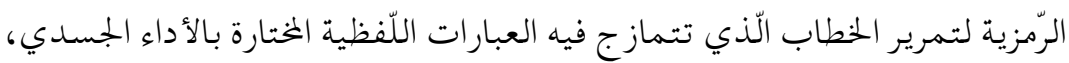

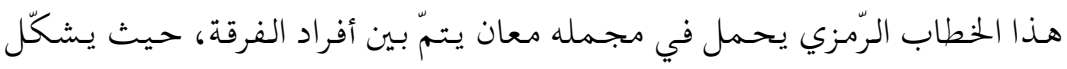
لوحة فنيّة رائعة الجمال. كما ذكرنـا سـالفا هـذه الرقصة تؤُدّى بـكثرة في مواسـم الأعراس والمناسبات الاحتفالية الأخرى ونخصِّ بالذّكر المولد النبوي الشريف، والرقص يتمّ على شكل

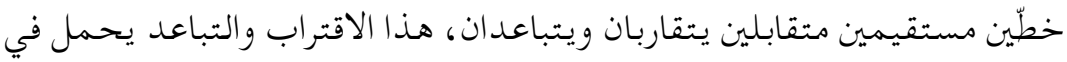

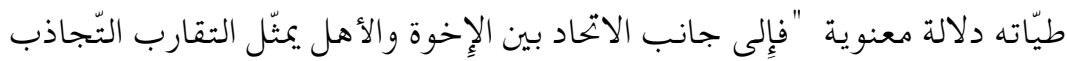
إلى حنين الأخ والأهل بعد أن كان التباعد "24. إنّ هذا الرّقص مورس بكثثرة إبّان الثورة التحريرية بشكل خاصِّ في أيّام الفرحة الكبرى للجزائريين، وهي الاستقلال ، إلاً أنّ تاريخ ظهورها يعود إلى أبعد من ذلك بكثير

\section{8 الدالات الثقافية للغناء}

تمثّل الأغنية الفولكلوريـة تراثـا شعبيا جـزائريـا فرضـت نفسها كثقافة وكفنّ فولكلوري منذ القدم، فهي أغنية متميّزة لما لها من صفات وخصائص خاصّة لا

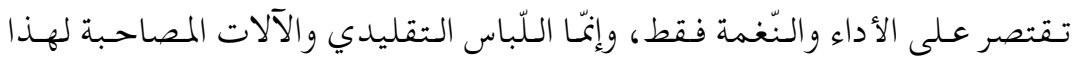
النّوع من الأغاني، يعبّر عن صورة حياة المجتمع

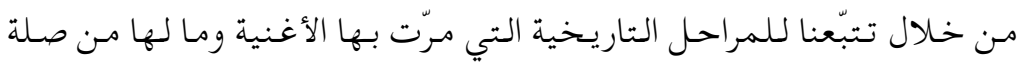
للفنّ القديم "فالكلمات عندما تتكيّف وفق لحن منغّم تشكّل واحدا من الأشكال الشعريـة الـتي هي أكـثر أصـالـة فيما عـرفـناه لأنّها تـكون مـلزمـة عـلى إتّبـاع نظظام محدود، و تضطلع بوظيفة مختلفة كلّ الاختلال عمّا هو دارج من الكلام" "25. 
تحتلّ الأغنية الفولكلورية الاهتمام الأكبر في المناسبات الخختلفة، وأوسع ميدان للأغنية الفولكلوريـة هو الزّفاف، لأنّ الاحتفال بـالزّفاف يحمل في طيّاتهـ أبعادا دينية واجـتماعية وأخلاقية واقتصادية، إذن فالأغنية الفولكلوريـة هي فــ يـتردّد على ألسنة العامّة من النّاس ريفيين وحضاريين، الّتي تستلزم وجود الجماعة، كما أنّ البعض يعتبرها حلقة أساسية من حلقات الثقافة الشعبية، فهي "مرتبطة بحياة الإِنسان في مراحلها الكاملة، كما أنّها ترتبط بمعتقداته وبعمله وبأوقات لهوه، ومسساعدة في إنجاز عمل صعب ومتنفِّس لعاطفة الإنسسان الشعبي "26، وتتجسّـد من خلال الأغنية الفولكلورية عقلية المجتمع وميولاته الفكريـة والأخلاقية، كما أنّها تكشف عن طموحاته وإرادته

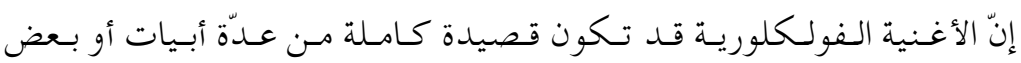
الأبيات منها .فقد احتفظ المغنّون بها لما لها من تأثير في نفوسهم، وتعبير صادق

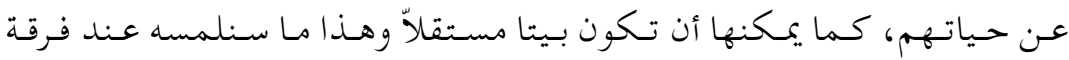
العرفة، فلهم عدّة قصائد تتـكوّن مـن بيت أو بيتين على الأكثر، تنـاقلته الأجيال بالحفظ، فتميّز هذا الغناء بالقدم، و كان دوره هو الحفاظ على الموروثات الثقافية،

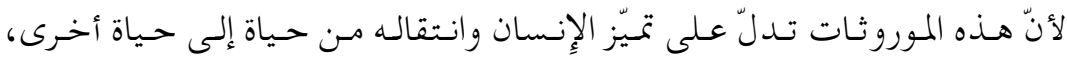

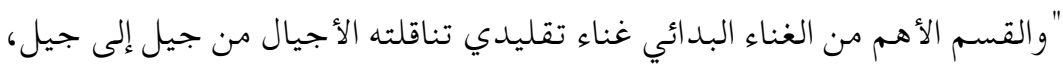
وأنّ البدائيين يؤلّفون أغانيهم دون أن يلجؤو إنبميعة الحال إلى الكتابة"27.

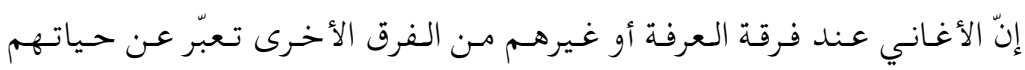

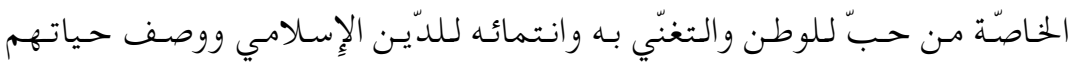

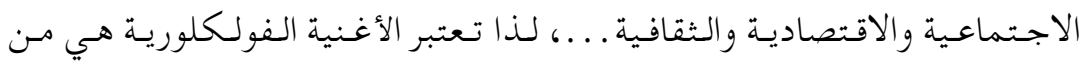
تحمل أكثر الدّلالات الثقافية للفرقة . 
من خلال دراستنا لموضوع "الموسيقى الفولكلورية الجزائرية ودلالاتها الثقافية

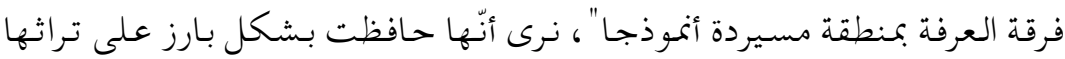
الثقافي كما هو الشأن لمعظم الفرق الفولكلورية الأخرى، في مناطق الوطن، حيث لا تزال بعض المؤشّرات والعادات الثقافية تتعايش مع غزو الثقافات الو افلدة عبر وسائل الإعلام المختلفة، كما أنّها تعتبر المرآة التي تعكس خصائص هذه الأمّة ولغة

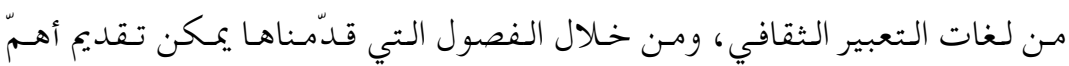
النتائج التي خلص إليها بحثنا هذا فيما يلي :

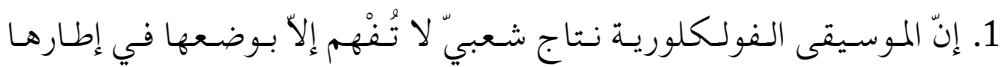
الزماني والمكاني والتاريخي اللّي أحاط بها لتصبح وثيقة هامة معبّرة بصدق، ومن

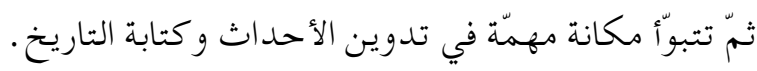
2. ساهمت الموسيقى الفولكلورية بقدر وافر في المحافظة على استمرار الثقافة

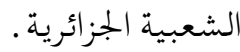
3. تتجلّى القيمة الفنّية للموسيقى الفولكلورية في إيقاظ المشاعر العميقة

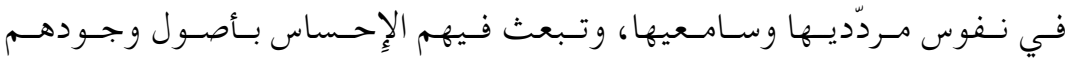
الاجتماعي والثقافي .

4. تتميّز الموسيقى الفولكلورية بالتنوّع في الموسيقى والغناء والرّقص لاسيما من حيث الشّكل والأداء. 5. تؤدي الموسيقى الفولكلوريـة دورا هـاما يـمثّل في التقريسب بـين جـميع طبقات الشعب المثقِف والأمّي والغنيّ والفقير، وهذا بشكل العام. 


\section{المصادر والمراجع}

${ }^{1}$ Revue Africaine, Gabriel Audissio, Société de géographie N68, 1927 Alger, pp. 76-77.

${ }^{2}$ Revue Africaine, Gabriel Audissio, pp. 88.

${ }^{3}$ Revue Africaine, Gabriel Audissio, pp. 79.

${ }^{4}$ Revue Africaine, Gabriel Audissio, pp. 81.

5 التيجاني الزاوي: الأغنية الفولكلورية في مسيردة، مضامينها وفنياتها، رسالة ماجستير، جامعة

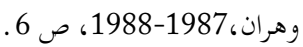

${ }^{6}$ Revue Africaine, Gabriel Audissio N68, pp. 81-82.

${ }^{7}$ Revue Africaine, Gabriel Audissio, pp. 83-84.

${ }^{8}$ Revue Africaine, Gabriel Audissio, pp. 83.

${ }^{9}$ Revue Africaine, Gabriel Audissio, pp. 86.

$$
10 \text { لتيجاني الزاوي :الأغنية الفولكلورية في مسيردة، ص } 8 \text { عن: }
$$

AZAN PAUL Sidi Ibrahim: Récit d'Afrique, Editeur militaire, Io Rue Deuton BdSt Germain 118, Paris, p. 369.

${ }^{11}$ Revue Africaine, Gabriel Audissio, p. 86.

$$
12 \text { عن السيد : محمد تربش : أول كاتب لبلدية مسيردة الفواقة. }
$$

${ }^{13}$ Revue Africaine, Gabriel Audissio, p. 87.

$$
14
$$

15 Tribus et Douard de l'Algerie, P. Acardo, Typographie et lithnographie Adolphe Jourdan, Alger, 1979, p. 103.

$$
\begin{aligned}
& 16 \text { عن السيد : محمد تربش : أول كاتب لبلدية مسيردة الفواقة. } \\
& 17 \text { عن السيد : عبد الهادي هنيني: كاتب ببلدية سوق الثلاثاء. }
\end{aligned}
$$

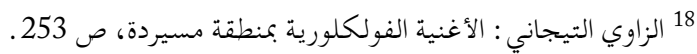

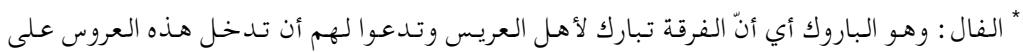

$$
\begin{aligned}
& \text { زوجها بالخير والبركة. } \\
& \text { *** الترفيعة : وهي إعلان عن حضور لفرقة العرفة حتّى يتسنّى لأهل الدّّر بترتيب أمورهم . } \\
& \text { | القارت : مقطوعة موسيقية بآلة المزمار فقط . } \\
& 19 \text { إبراهيم بهـلول: فنّ الرقّص الشعبي في الجزائر، ديوان المطبوعات الجامعية، الجزائر، 1986، ج ج }
\end{aligned}
$$


20 محمدل بوترفاس : الرقص الشعبي أنواعه وخصائصده، رسالة لنيل شهادة الماجستير في الثقافة الشعبية، جامعة تلمسان، 2006-2007، صوسر 18. 21 يسـرى جـوهـري عـرنسيطة : الـفنون الـشعبية في فلسطين، مـنظّمة التحريـر الفلسهينية، مـركز الأبحاث ، 1968، ص 62.

$$
\begin{aligned}
& 22 \text { إبراهيم بهلول : فنّ الرّقص الشعبي، ص } 01 . \\
& 23 \text { لعريف احمد : أحد مشايخ فرقة العرفة . }
\end{aligned}
$$

24 عبد الغني عماد: سوسيولوجيا الثقافة، مركز دراسات الوحدة العربية، بيروت، ط 1 ، 2002،ص صعرده

$$
\begin{aligned}
& 25 \text { محمد بوترفاس : الرّقص الشعبي أنواعه وخصائصه، ص } 94 . \\
& 26 \text { عبد الغني عماد : سوسيولوجيا الثقافة، ص } 147 \text { : } 147 . \\
& 27 \text { ميلود لعريف : عضو فرقة العرفة، ضارب على آلة البندير . }
\end{aligned}
$$

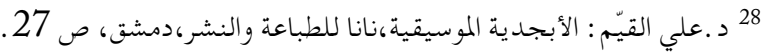

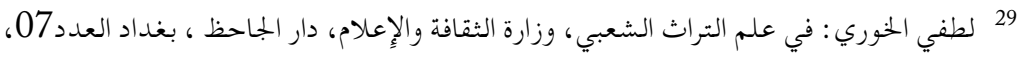

$$
\begin{aligned}
& \text { 1979، ص } 270 . \\
& 30 \text { د. علي القيم: الأبجدية الموسيقية، ص } 30 .
\end{aligned}
$$





\title{
محمد بن شنب رمز الانتماء الحضاري والتعدد الثقافي
}

\section{MUHAMMAD BENŠNAB COMO SÍMBOLO DE CIVILIZACIÓN Y MULTICULTURALIDAD}

\author{
أم هاني رحماني \\ جامعة المدية \\ OUM HANI RAHMANI \\ Universidad de Medea
}

\begin{abstract}
Resumen
El presente artículo trata de arrojar luz sobre una importante figura cultural argelina, la de Muḥammad Benšnab y su papel desempeñado en el ámbito cultural. Se destaca su valor como intelectual árabe y su multiculturalidad en un periodo donde la identidad cultural argelina - $-\mathrm{y}$ árabe en general- vivía un momento crítico bajo la influencia colonizadora francesa. Su presencia tanto a nivel local como internacional fue útil para dar otra imagen sobre la participación de los intelectuales árabes en el desarrollo de la civilización humana. Todo ello lo vamos a reflejar en su biografía y sus esfuerzos intelectuales basándonos en el estado actual de la investigación en torno a la vida y obra de este autor.
\end{abstract}

Palabras clave: Muḥammad Benšnab, identidad argelina, conflicto ideológico, multiculturalidad.

$$
\begin{aligned}
& \text { ملخص } \\
& \text { هـذا المقال يسلط الضوء على شخصية ثقافية جزائريـة مهمة في تاريخخ الجزائر، الأمر يتعلق }
\end{aligned}
$$

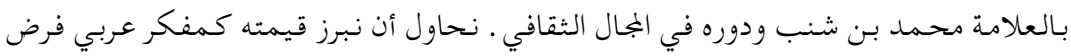

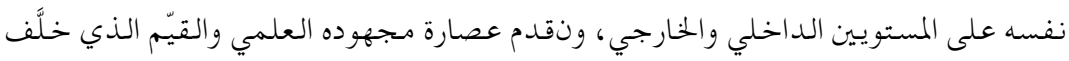

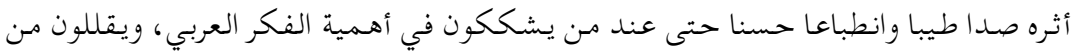

$$
\begin{aligned}
& \text { قيمته كمجهود ثري ومتنوع طال مجالات مختلفة وترك بصمات جلية عليها، وظل رئل رافدا مميزا }
\end{aligned}
$$


للناهلين منها من بعده ـ والذي أضحى محط اهتمام الباحثين من العالم العربي والغربي على حد سواء. الكلمات المفتاحية : محمد بن شنب، الهوية الجزائرية، الصراع الإِيديولوجي، التنوع الثقافي .

\section{مقدمة}

في خضم صراع ثقافي وإيد يولوجي حاد، وفي ظل هيمنة استعمارية فرنسية طاغية حاولت طمس وتزييف الهوية الجزائرية والعربية برز اسم العلامة محمد بن شنب كأحد الأقطاب الهامة التي حررت قواها الفكرية لتذود عنها وتعيد للتراث العربي والإِسالامي حضوره الفاعل على الساحة العلمية، وتمد جسور التواصل مع غيرها مـن الثقافات حتى تنصهر في بوتقة العلم والمعرفة، هـذه الشخصية التي استطاعت في فترة وجيزة من حياتها أن تفرض نفسها على المستويسين الداخلي

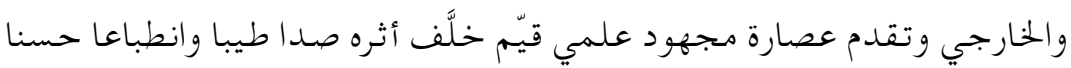

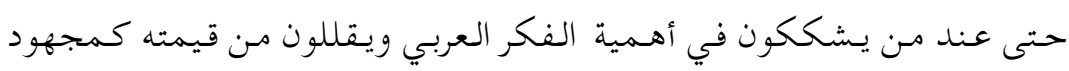
ثري ومتنوع طال مجالات مختلفة وتركك بصمات جـلية عليها، وظل رافـا مميزا للنناهلين منها من بعده .

ولأجل ما تقدم، أردنا أن نخصص هذه الصفحات لهذه الشخصية العبقرية

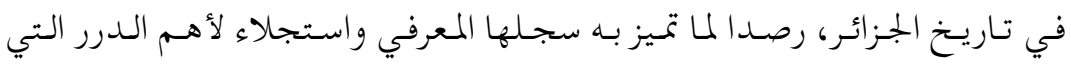
خدمـت بها ميدان البحث العلمي، والتي كانت ولا زالت محط اهتمام الباحثين من العالم العربي والغربي على حد سواء.

\section{نبذة مختصرة من سيرة بن شنبب}

هو محمد بن العربي بن محمد بن شنب، أحد أهم أعلام الجزائر النابهين في العصر الحديث، من مواليد20 رجبـ1286 هـ الموافت لـ26 أكتوبر1896م بمنطقة 
" تاكبو" الواقعة بولاية المدية، نشأ وترعرع في بيت عتيق وفي كنف أسرة عريقة

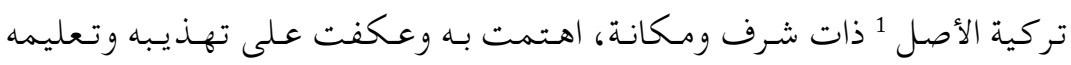

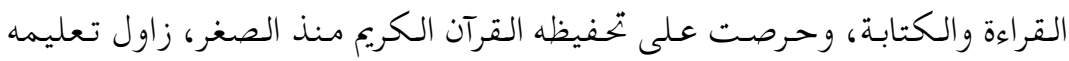
الابتدائي بالمدارس المدنية التي أنشأتها فرنسا آنذاك بالجزائر أين تعلم الفرنسية ونهل من آدابها وخرج منها بالشهادة التي أهلته لمواصلة التعليم الثانوي، ليلتحقق بعلها بـار المعلمين الفرنسية ببوزريعة وعمره لا يتجاوز سبع عشرة عاما، وتخرج مـنها بـعد سـنتين بـشهادة أجـازت لـه تـعليم اللغة العربـية في المـدارس الابــدائسية الوطنية وفي سـنة1894 تقدم للامتحان بالجامعة الجزائريـة الفرنسية فأحرز على الشهادة في اللغة العربية، وفي سنة1896 تحصل على شهادة البكالوريا في القسم

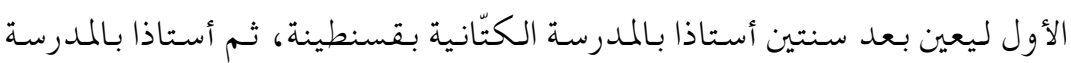
الثعالبية بالعاصمة وقد اشتهر و ذاع صيته عبر ربوع الوطن العربي وحتى الغربي كأحد الأقطاب العلمية الهامـة في الجزائر بعد تعيينه رسميا كأول محاضر جزائري بكلية الآداب بـجامعة الجزائر سنة1924، وقد أهله لاعتلاء هذا المنصب حصب حصوله

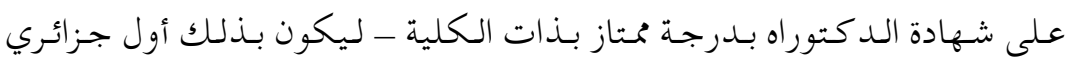
حاصل على شهادة الد كتوراه - عن بحثين متميزين قدمهما في هذا الباب، حيث

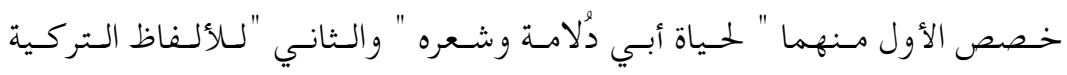

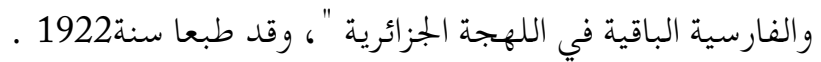

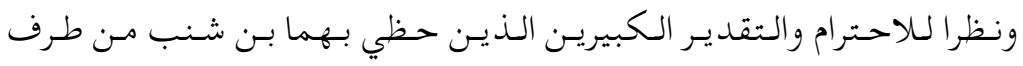
المثقفين العرب و الغرب على حد سواء - لما اتصف به من أخلاق عالية وما أظهره من تمكن علمي ومعرفي كبير- أوكلت اليه العديد من المهام الحساسة، نذكر منها

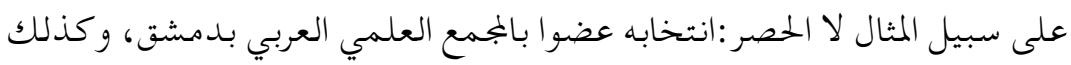
عضوا عـاملا بـالبهمع العلمي الاستعماري بـباريس، أيسن صـار مـندوبـا للمؤتمرات 
العلمية والامـتحانـات الرسمية، وكـذا تعيينه كـاتبا عـامـا لـدى مجـلس الجمعية

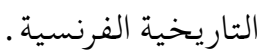
عكف بن شنب طيلة حياته على الدراسة والتدريس والبحث و التأليف الى أن وافته المنية بـتاريخن26 شعبان1347 هـ الموافق لـ5 فيفري1929م بـعد صـراع مـع مرض لمم تجـد يـــ الأطباء سـبيلا الى شـفائه، ودفن بمـقبرة سـيدي عبد الرحسمن الثعالبي بالجزائر العاصمة.

\section{علاقتنه بالثقافات العالمية}

ترعرع بـن شـنب في كـنف المـدارس الـتي أعـدهـا المسـتعمر الـفرنسي بهـدف طمس الهويـة الجزائريـة والثقافة العربية والإِسلامية، وتخريتج أجيال مفرغة منها

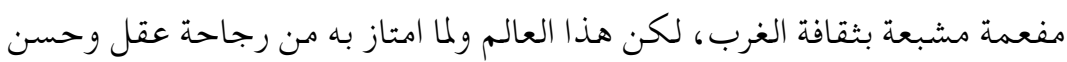
بصيرة قد حصّن نفسه بثقافة عربية أصيلة تشربتها نفسه مـذ الصبى، واستلهم من الغرب - في ذات الوقت -علومهم وطرائقهم ومناهجهم في الدراسة والبحث

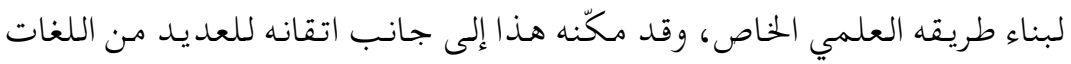
وعلى رأسها الفرنسية - التي كان يتحدث ويـخاطب بها في المحافل الرسمية -

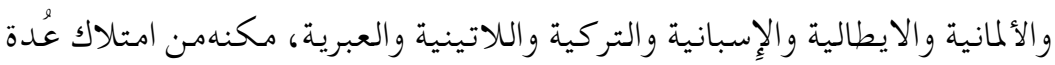

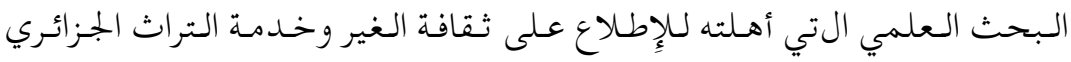
خاصة والعربي عامة على أحسن وجهه.

إلى جـانـب ذلك جـمعت محهمد بـن شــب عـلاقات وطيدة مع أبـرز العلماء والمفكريـن العرب والأوروبـيين في زمـنه، أتـاحـتها الزيـارات العلمية التي قـام بها والندوات والمؤتمرات الدولية التي حضرها والتي شارك فيها، نخص منهم بالذكر "

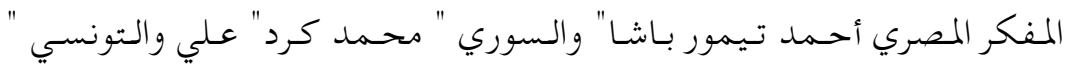

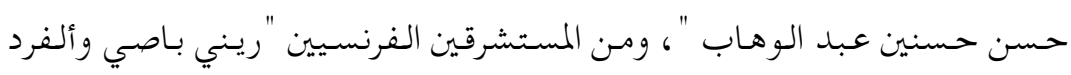




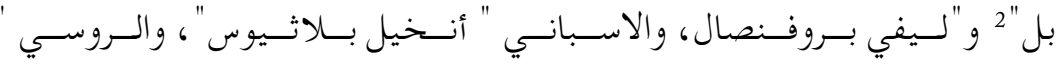

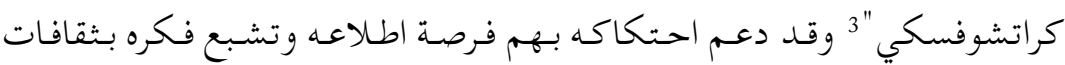
مختلفة متعددة الروافد انعكس ملمحهها على أعماله التي كانت بحق محاولة منه

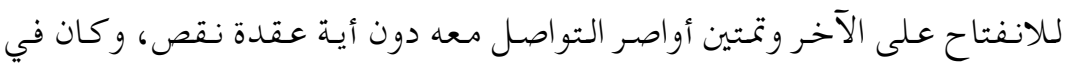
ذلك تجسيد لروح العالم التي أحسنت التأثر والتأثير دون أن تفقد هويتها الوطنية أو مكونات شخصيتها الذاتية أو استقلالها الفكري خدمة لصرح العلم والمعرفة.

\section{أهم مؤلفاته}

يعتبر بن شنب قامة هامة وعلامة شـديدة الوضوح في تاريخ الثقافة الجزائرية واستقراء سيرته والبحث في تكوينه العلمي ونتاجاته المعرفية هو في الحقيقة بحثث في ارهاصات ثقافة معاصرة قائمة على تعددية لغوية وثقافية احتواها ذكاء متميز وحـنكة وثقة عـالية بـالنفس، تجـلت بـوضوح في عـدد كبير مـن الأعمال تـأليفا وتحقيقا وترجمة في ميادين متعددة من لغة وأدب وترجمة ومعاجم وتاريخ، فقد ذكر على لسان تـلميذه عبد الرحمـن الجميلاني أنه قد خلّف ما يزيـد عن أربعين مؤلفا، كما ذُكر في عدد من المصنفات بأنه قد " نشر أربعة وستين بحثا في دائرة المعارف الإِسلامية وخمسا وسبعين دراسة أغلبها باللغة الفرنسية وكتب في المجلة الافريقية ونشر في مجلة الشهاب". لقد فرض بـن شــب نـفسه في ميدان البحتث العلمي بطرحهـ لأعمال جـادة ومتنوعة وخوضه في جملة من الموضوعات التي كان سباقا الى بعضها في وقت لم يكن للمفكرين العرب عامة والجزائريين خاصة أي مجال لممارسة العمل الأكاديمي أو الثقافي 5 لتعكس اجتهاداته ملامح شخصية قوية تميزت بالموضوعية والرزانة استطاعت أن ترسم صورة ايسجابية واضحة المعالم عن العالم العربي والإِسلامي 
قاطبة في زمن تكالبت عليه الأم لتشويهه والحط من قيمته، ولتمثل من ناحية إلته أخرى نافذة واسعة يطل منها المثقفون العرب على الآداب الغربية الغئ. ومن بين أهم مؤلفاته باللغة العربية نذكر:

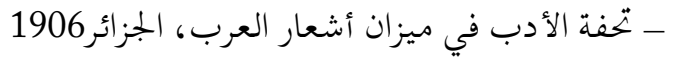

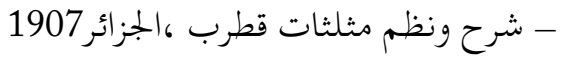
- - رحلة الورثلاني، الجزائر 1908 -

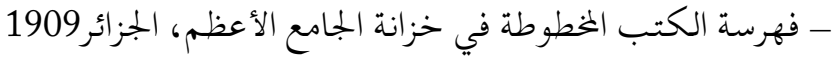

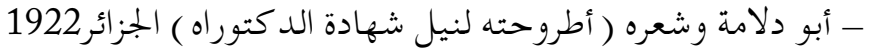
وباللغة الفرنسية :

- مجسموع أمثال العوام في أرض الجزائر والمغرب (في ثناثة أجزاء) باريس $1907 / 1905$

- طبقات علماء افريقية (في جزأين) 1915، باريس / 1920

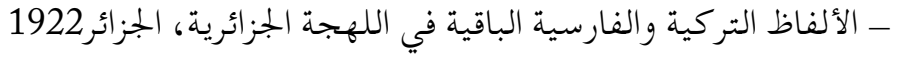
كما صحح وحقق العديد من كتب التراث العربي مثل: - البستان في ذكر الأولياء والعلماء بتلمسان ، لابن مريم التلمساني 1908 - الممتع في شرح المقنع، لأبي سعيد السويسي الجزائر - عنوان الدراية فيمن عرف من علماء المائة السابعة في بـجاية، للغبريني

$$
\text { - شرح ديوان عروة بن الورد، لابن السكيت } 1926
$$

وقد كان أسلوبه في عرض الموضوعات التي كان يطرقها علميا دقيقا مباشرا

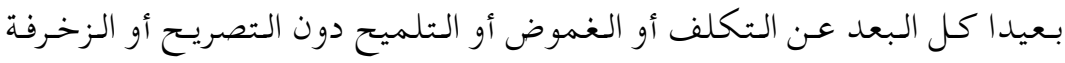

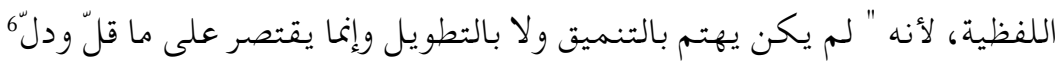

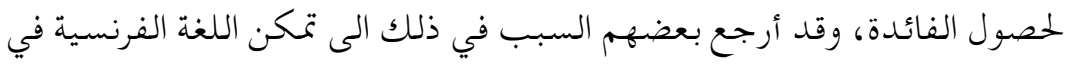


نفسهه أكثر مـن اللغة العربـية نظرا لـتلقى تعليمهه وإلقاء دروسـه ومـحاضـراته في الجـامعة وخطبه في المحافل الرسـمية بـها، في حـين كان للعلامـة عبد الرحسمن

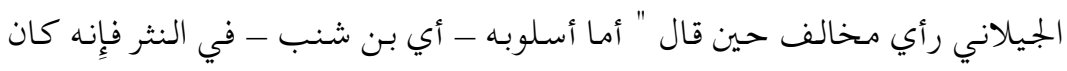

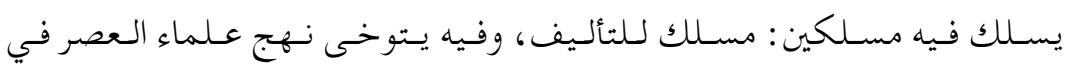
الـوضـيح والـبيان مـع حسن التنسـيق والـترتيب، ومسـلك آخـر لـرسـائله الخـاصـة

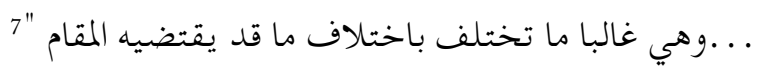

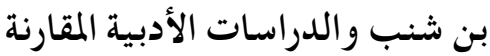

يهتم الأدب المقارن بمقارنة عملين أدبيين - أو أكثر - ينتمي كل واحلد منهما

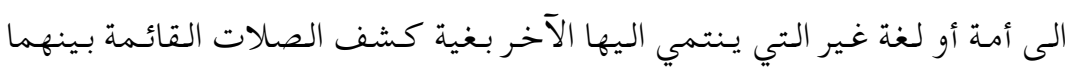

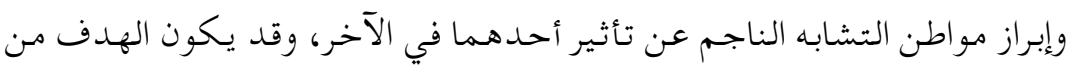
وراء ذلك الموازنة الفنية أو المضمونية، أو كشف الحجاب عن صورة أمهة مـن الأحم في عين الأمة الأخرى من خلال موروثها الأدبي. وقد شق بـن شـب طريقه الى هـذا الميدان - الدراسات الأدبية المقارنة - مـن خلال اهتمامه بقضايا اللغات وتحصيلها والتنقيب في خبايا الثقافات المختلفة وفي ثناياها والخوض في مسائلها، و الترجمة من العربية وإليها، وهو أمر جاد غاية في

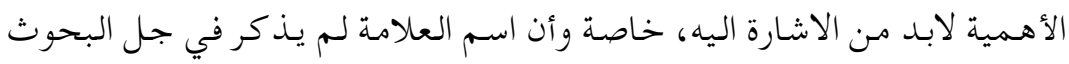
والدراسات الخختلفة التي رصدت بوادر اشتغال العرب بالدراسات المقارنة 8، ويعتبر

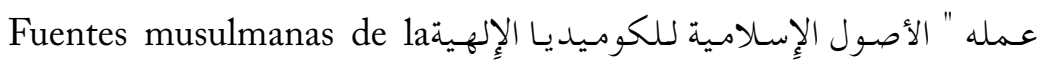
Divina Comedia المقارنة البحتة، كما أن تاريخ صدوره دليل فاصل على أنه قد سبق كل الدراسات

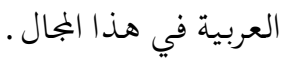


تجسـدت معالم المقارنة في هذا العمل من خلال طرق مسألة التأثير الإِالامي

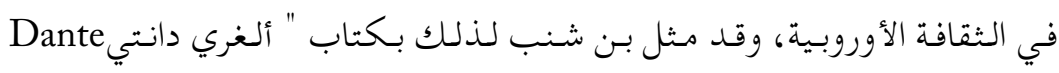

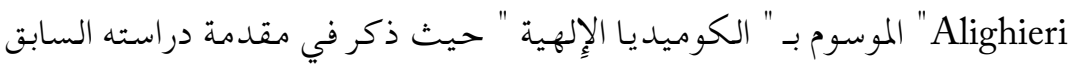

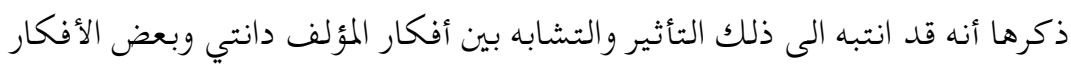

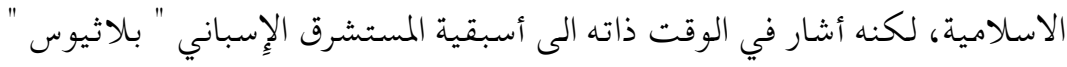

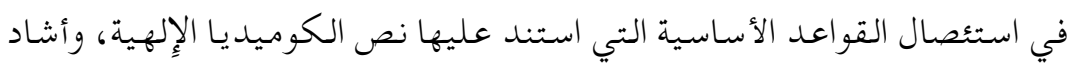

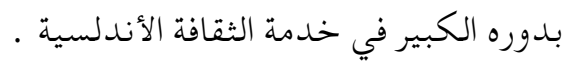

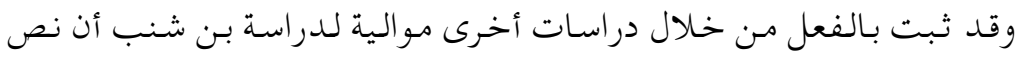

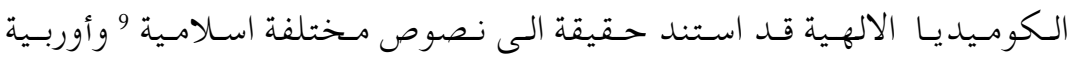

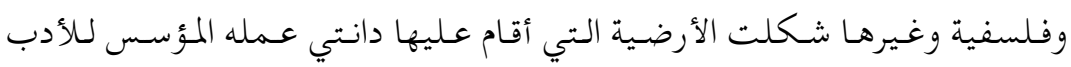

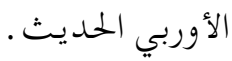

إن خوض بن شنب في هذا الجمال وفي تلك الحقبة الزمنية انما ينم عن اطلاع

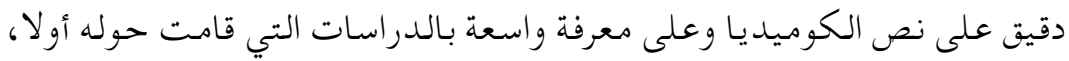

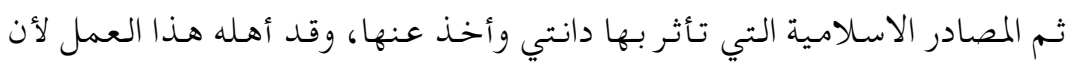
يكون من أوائل الذين خاضوا باب الدراسات المقارنة في البلدان العربية .

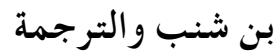

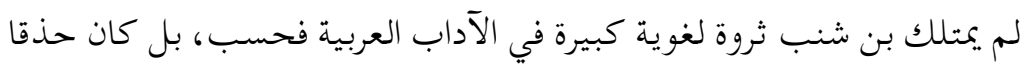

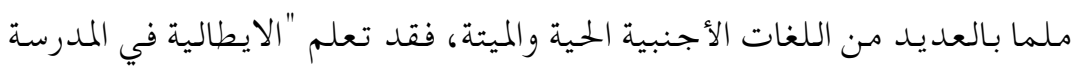

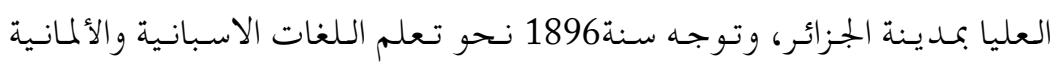

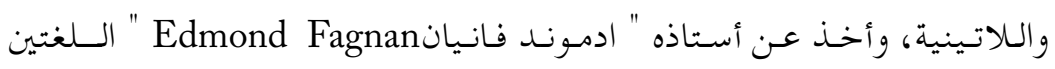

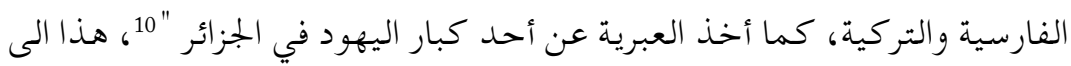


جانب تمكنه الحسن من اللغات الألمانية والابجليزية والإغريقية القديمة والمثبت في الاحالات الواردة في عدد من أعماله. وقد سـاعـده هـذا الالمام بـاللغات على ولوج ميدان الترجمة الذي يعتبر خير مفتاح لمعرفة خبايا الثقافات وتحديثها، وهذا الأمر لا يتأتى إلا لخبير متمكن من اللغتين المترجم منها والمترجم إليها، حتى ينقل المدلولات والمعاني دون تقصير أو زيف أو زيغ، هذه العقبة وإن وقفت حاجزا أهام كثير من المثقفين الذين عاصروه أو سبقوه إلا أنها لم تكن كذلك أمام شخصية بن شنب المقتدرة، وهذا ما عكسه النتاج المترجـم الذـي وصـلنا عـنه مثل ترجـمته لرسالة الإِمام الغزالي في ريـاضـة

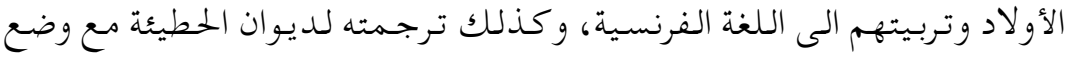
مقدمة تعريفية له، وترجمتهه للقسم الثاني من كتاب فقه اللغة للثعالبي وكذا كتاب متن شذور الذهب في النحو لابن هشام الأنصاري، ترجمته لكتاب التيسير والتسهيل في ذكر ما أغفله الشيخ خليل مـ أحسكام المغارسة* للشيخ أبي عبد القادر الفاسي الى غيرها من الأعمال كما جاء على لسان الكثيرين أن لابن شنب أعمال أخرى مترجمة مفقودة قدمها كمحاضرات الى طلبة الجامعة وأخرى ألقاها في مؤتمرات المستشرقين التي شارك فيها .

\section{بن شنب و التحقيق}

خـاض بـن شـنب مـيدان التحقيق 11 كمهمارس وليس كـمتخصص اعـتناء مـنه بتراث أمته العربي والإِسلامي - على اختلافه وتنوعه - وإيمانا بأهميته وبقدرته على بـناء معارف لغويـة وأدبية ونقـديـة حـديثة، وقد استغل للوصول الى مـبتغاه المناهج العلمية والوسائل المادية المتاحة له في ذلك الوقت ، ليعلن للعالم أنه مثقف مس طراز مـتـلف يحـمل بـين أضـلعه هـموم أمـته ويسعى الى ردم الهوة الثقافية 
والبرهنة على عنصر التكافؤ بينها وبين غيرها من الأمح حتى يزيل عنها ثقل الغبن التاريخي الذي تأصل لدى الأغلبية.

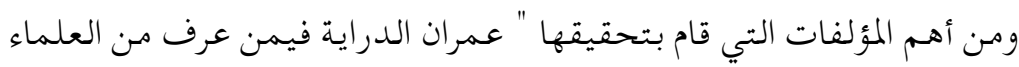

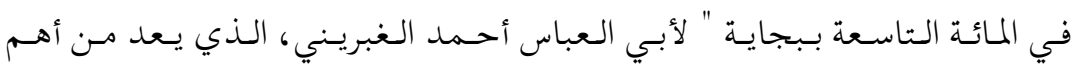

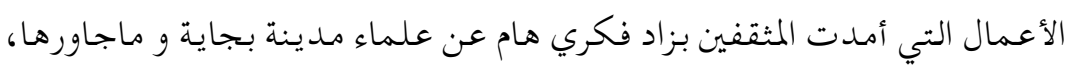

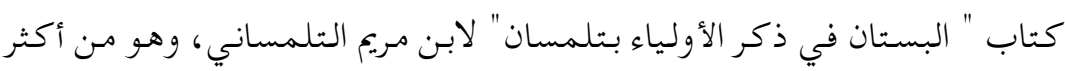
كتب التراجـم غزارة وقيمة، كتـاب "رحسلة الشـيخ الحسـين الورثلاني إلى الحـج" والمسماة بـنزهة الأنظار في فضل علم التاريخ والأخبار أين وصف الحالة الدينية والسياسية والاجتماعية للدول العربية التي مر بها، كتاب " الذخيرة السنية في تاريخ الدولة المرينية " لمؤلف مجهول يتحدث فيه صاحبه عن مفاخر ملوك هذه

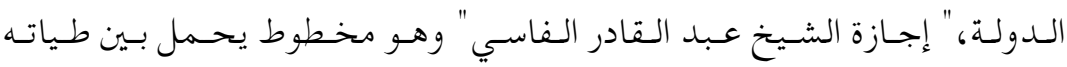

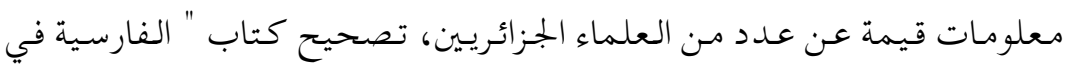

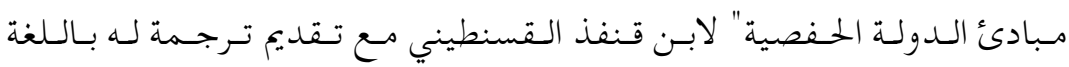

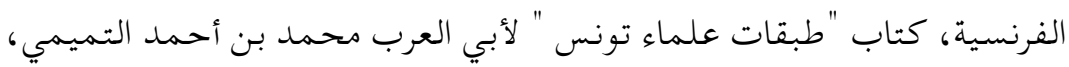

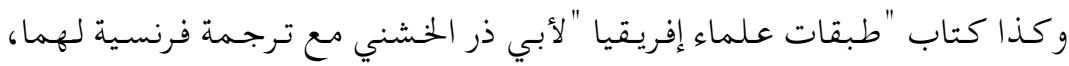
اضافة الى تحقيق عدد معتبر من الكتب التي لا يسعنا المقام لذكرها جميعا . وقد أخذذ أيضا توشيح الكتب بفهارس مساحة خاصة من اهتمام الدكتور بن شـبب حيث قام بفهرسة الكتب الخخطوطة في خزانة الجـامع الأعظم بالجزائر بعد تنظيمها ووصف ما فيها، الى جانب فهرسة مطبوعات مكتبة الرباط بالاشتراك مع المستشرق " ايفارست ليفي بروفنصال Evariste Lévi-Provencal ، كما وضع

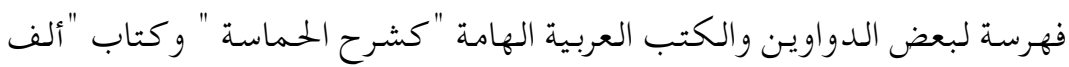
ياء" لأبي الحاج يوسف البلوى . 


\section{بن شنب واللهجة الجزائرية}

تتعدد اللهجات العامية في كل بيئة وتأخذ منحا خاصاًتفرضه الظروف الجغرافية والدينية والسياسية والاجتماعية التي تعيشها شعوبها، غير أن هذه الأخيرة وعلى اختلافها وتلونها في البيئة العربية لم تقطع الصلة بينها وبين اللغة الفصحى، حيث ظلت علاقتها بها هي علاقة العام بالخاص والأصل بالفرع، وظلت تربطها بها أواصر قوية متينة حققها وصانها القرآن الكريم ثم القواعد النحوية التي ظلت حارساً عليها، ثم جهود العلماء المبذولة لحمايتها .

وقد طرق بن شنب باب اللهجات العامية الجزائرية وأظهر عناية فائقة به رغبة مـه في التعريف بالثقافة الجزائرية والكشف عن مكنوناتها وبعض ما تتميز به مـن خصوصية ولأدل على ذلك أطروحته التي قدمها لنيل شهادة الدكتوراه في هـذا

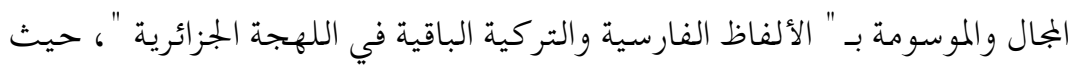

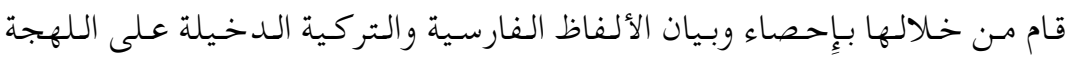
الجزائريـة، فقد تنبه الى وجود بعض من اللغة الفارسية في اللهجة الجزائرية خلفه احتكاك الفرس بالجزائريين إبان تواجدهم بالبلاد في بـاية الحضارة الإِسلامية، وهو الأثر نفسه الذي خلفته اللغة التركية على اللهجة الجزائرية نتيجة الحلكم العثماني الذي عمر طويلا بالجزائر.

وقـد سـار بـن شـنب عـلى نـفس الـنهج في تـأليف كـتابـهـ " الألـفاظ الطليانية

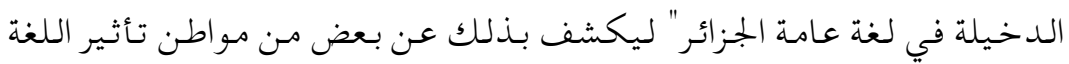
الإِيطالية في العامية الجزائرية، وان لم يكن له السبق في خوض غمار هذا الموضوع حيث وجدت دراسات قبله تحدثت عن تأثير اللغة الايطالية وتأثرها باللغة العربية وبعض لهجاتها، إلا أن عمله كان الأول من نوعه في الكشف عن ذلك التأثير في العامية الجزائرية . 
اضافة الى المجهودات المذكورة، قام بن شنب بجمع كم معتبر من المادة الخام في

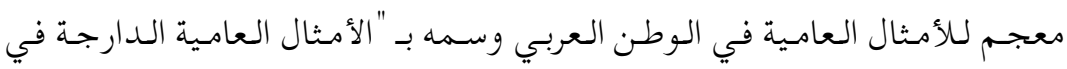

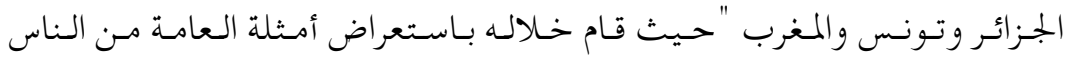
ومقابلتها بأمثلة الأدباء مع التعليق عليها ليدلل بعمله على الوحدة الثقافية بين بلد ان المغرب العربي من جهة وخصوصية الشخصية الوطنية الجزائريـة من جهة، ليؤكد مرة أخرى بأنه مثقف وأكاديمي بـامتياز استطاع السبق إلى انشاء معاجـم متميزة تدـل ضـمن اطار التحول اللغوي وعلاقته باللغة الأم، اعتزازا منه بانتمائه الحضاري العربي والإسلامي.

\section{خاتمة}

تميز العلامة محمد بن شنب بغزارة علمهه وسعة اطلاعه وسعيه الدؤوب لخدمة الثقافة الانسانسية جـمعاء، فتجـلت في مجهوداته تركيبة الشخصية الفذة ذات

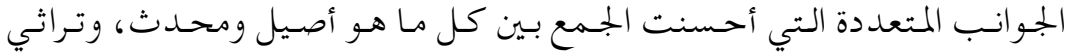
ومعاصر، في حلل لا تنبجس إلا عن فكر مقتدر همه الذوود عن الوطنية والعروبة وتصحيح صورتها وإعلاء مكانتها التي غارت في غيابات زمن مظلم كسى أطرافه

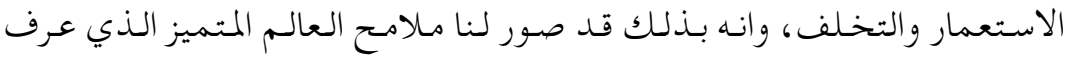
كيف وماذا ينهل من الخختلف والمتعدد حتى يخط لنفسه نهجا ميزا يخدمه ويخدم الأهداف التي حمل القلم من أجلها ،وضمن جميع هذا بين دفات كتبه التي دون التاريخ اسمه عليها بخط من ذهب . 


\section{المراجع والمصادر}

1 انظر :الطيب ولد عروسي ،محمد بن أبي شنب دراسات وشهادات، منشورات مديرية

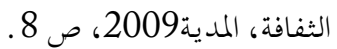

2 فارس كعوان ،بن شنب والمشروع الاستشراقي مسن خلال الاسهام في دائرة المعارف

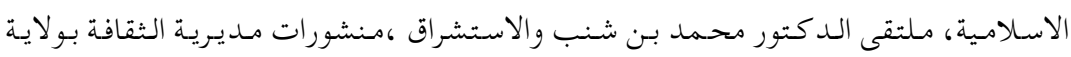

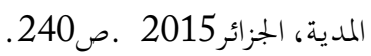

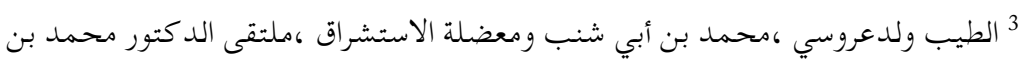
شنب والاستشراق منشورات مديرية الثقافة بولاية المدية ،الجزائر 2015 ـ ص207.

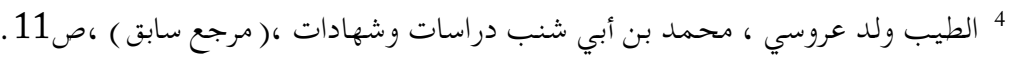

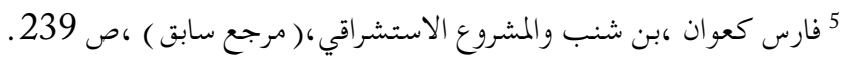

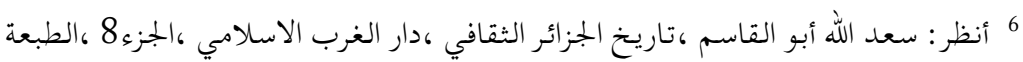

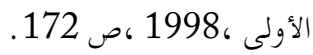
7 الجيلالي عبد الرحمن ،محمد بن شنب حياته وآثاره ،المؤسسة الوطنية للكتاب ،الجزائر ،

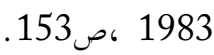
8 لم تشر أي من الدراسات التي حاولت التأريخ لبوادر اشتغال العرب بالدراسات المقارنة

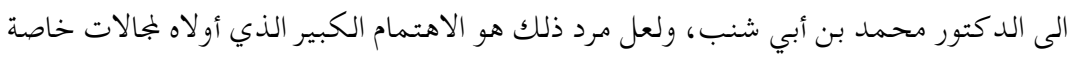

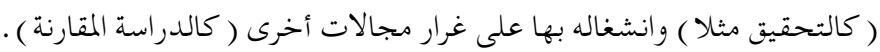

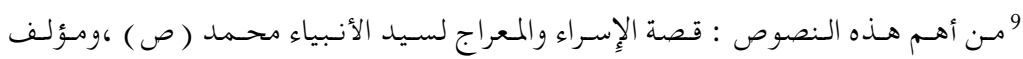

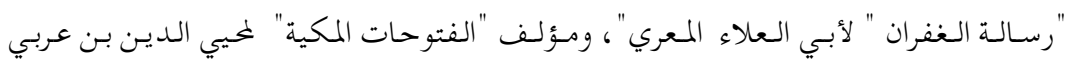

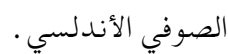

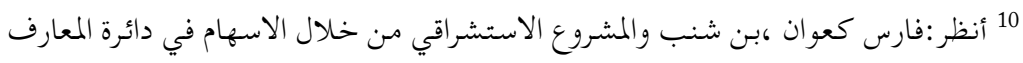

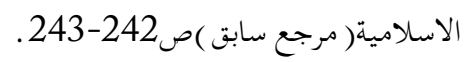

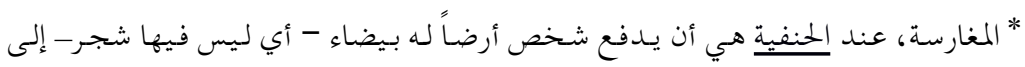

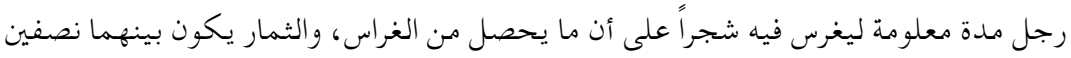

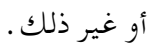




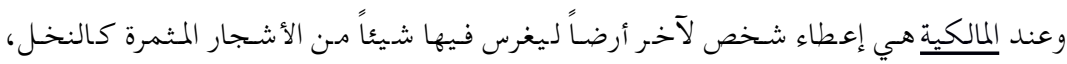

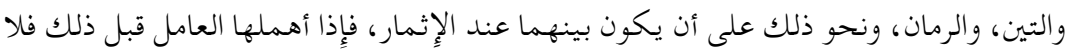

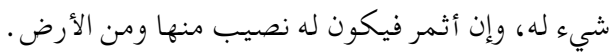

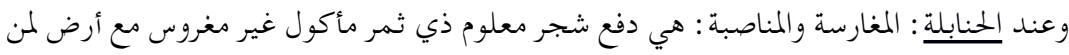

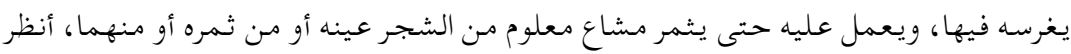
لمزيد الأطلاع : ويكيبيد يا الموسوعة الحرة.

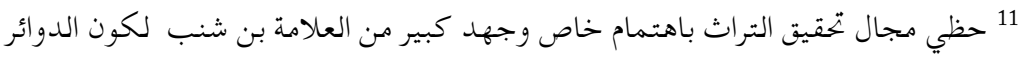
الإستشراقية الفرنسية آنذاك قد رغبت فيه ووجهت جل مجهوداتها صوبه ،ويقصد بالتحقيق

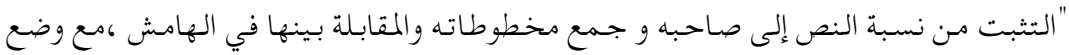

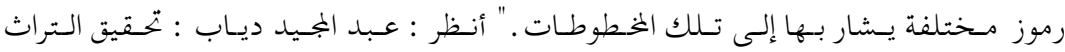

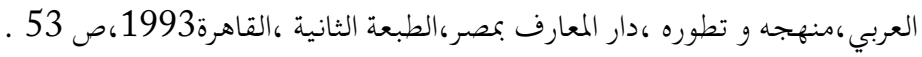




\title{
إشكالية التناص في النقد الجزائري المعاصر عبد المالك مرتاض أنموذجا
}

\section{LA INTERTEXTUALIDAD EN LA CRÍTICA LITERARIA ARGELINA MODERNA: EL EJEMPLO DE ‘ABD AL-MĀLIK MURTĀḌ}

\author{
العربي حسين

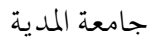 \\ LARBI HOCINE \\ Universidad de Medea
}

\begin{abstract}
Resumen
Esta investigación trata de describir el fenómeno de la intertextualidad en la crítica literaria contemporánea tanto en los estudios occidentales como en los argelinos. El artículo pretende dar al lector una idea general sobre esta teoría, atendiendo especialmente a los trabajos del crítico argelino 'Abd alMālik Murtāọ. Este intelectual argelino ha investigado las bases de la intertextualidad y ha profundizado en sus características. Con ello, ha llegado a demostrar que la literatura árabe medieval empleó el concepto de esta teoría con diferentes usos, de lo cual se abunda en los libros de retórica árabe (balāga), en donde se da una idea muy cercana al concepto tal y como lo conocemos hoy en día.
\end{abstract}

Palabras clave: 'Abd al-Mālik Murtāọ, intertextualidad literaria, crítica literaria occidental, crítica literaria argelina, balaga.

\section{ملخص}

لقد حاول هـا البحث أن يتتبع ظاهرة التناص ويـلم خيوطها في الدراسات النقديـة المعاصرة

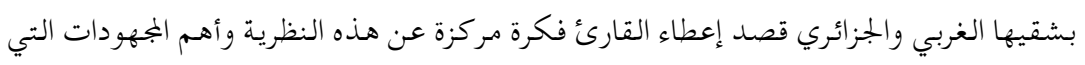

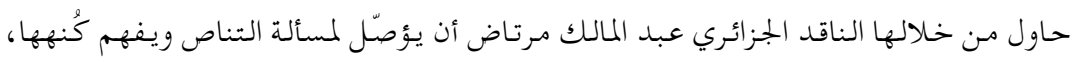

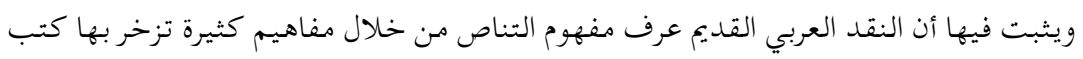

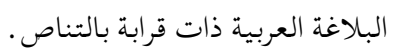


الكلمات المفتاحية : إشكالية ،التناص، النقد الغربي النقد الجزائري، عبد المالك مرتاض، بلاغة

\section{مقدمة}

منذ أن تحدث ميخائيل باختين(1975-Bajtín عن تعدد الأصوات ومـنذ أن صـاغ تـيزفيتان تودروف(1939) Tezveten Todorov مـفهوم المبدأ الحـواري ليجمل القول في نظرية باختين، أصبح الإقبال على التناصIntertextualidad في الدراسات الأدبية أمرا مألوفا، ولم يتوقف البحث على الغربيين، بل أسهم العرب، من موقعهم، في التعريف بالمفهوم، و في البحـث له عن أصول في التراث النقدي العربي وفي اتـخاذه أداة إجـرائسية لتحـليل الـصصوص • وهـكذا أصـبح الـتناص مـن المصطلحات النقدية الحمديثة التي تستدعي منا الرصد والدرس، ومفاده أن النص في بنيته الإنسشائية(discurso o estructura) هو حصيلة تفاعل نصوص سابقة

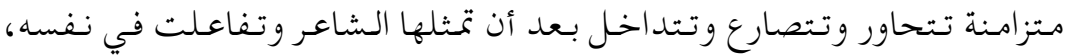

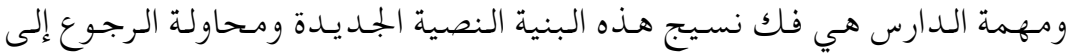
مكوناتها الأولى لمعرفة الطريقة التي تمت من خلالها عملية صياغة النص إنشائيا

ودلاليا.

\section{1 ممارسة التناص في النقد الغربي}

تتجـلى لنـا - في ضوء مسـيرة الحـركة النقديـة الغربية - أن كلّ نظريـة نقدية ذات علاقة وطيدة بأختها تمهد لها دون أن تلغيها، وإن اتجهت اتجاها مغايرا لها في أحيان كثيرة، بل إن كثيرا من النظريات ولدت في أحضان نظرية سابقة فكانت أشبه بالبــت لها، كالتشريحية والتركيبية اللتين ولدتا في قلب البنيوية وهما، ما انتهت إليه الحداثة في مرحلة البنيوية(estructuralismo). 
ومهن بـين نظريـات مـا بـعد الحـداثة بجـد نظريـة التناص التي ولدت في أحضان

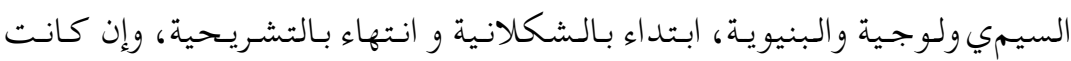
مدينة بكثير من ملامحها لغيرها. فالتناص مصطلح نقـدي حـديـث أريـد بـه تعالق النصوص وتقاطعها، ولإقِامة الحوار بينهما، و هو في أبسط تعريفاته : وجود علاقة بين ملفوظين، و مفهومهـ

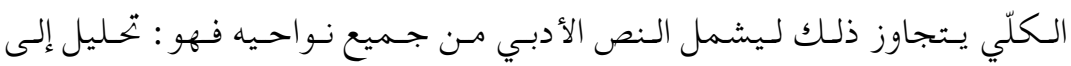

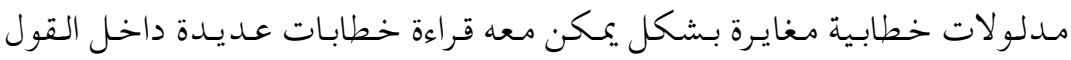
الشعري، و هكذا يتم بعث فضاء نصي متعدد حول المدلول الشعري، و بصورة

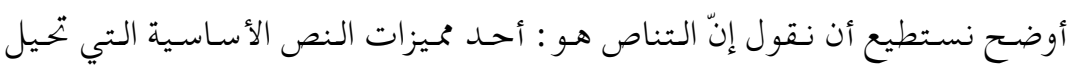

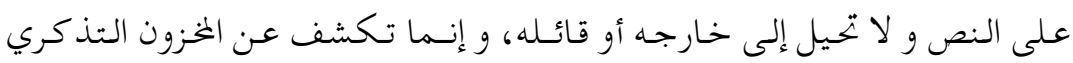
لنصوص مختلفة تشكل حقل التناص 1. وبهذا أصبح مفهوم التناص أحد المفهومات الرئيسية في النقد الحلديث، الذي استمد قيمته النظرية وفاعليته الإِجرائية مـن كونه يقف راهنا في مجال الشعرية الحـديثة في نقطة تقاطع / تـلاقي التحليل البنيوي للنصوص والأعسمال الأدبية بصفة عامة . بصفتها نظامـا مغلقا يـحيل على نفسه مع نظام الإِحالة أو المرجع .

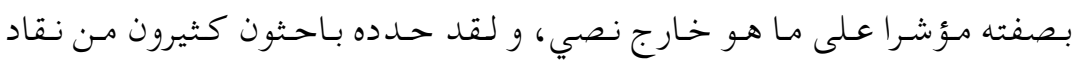

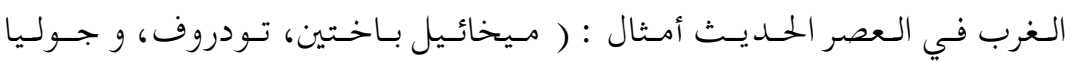
كريسـتيفا، و أريفي ، و لـورانت جيـني ميشال ريفاتيـر، و روبرت شولز، رولان

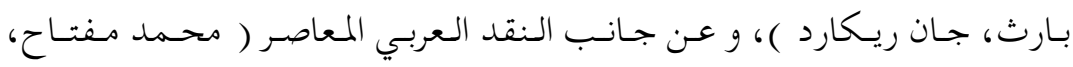

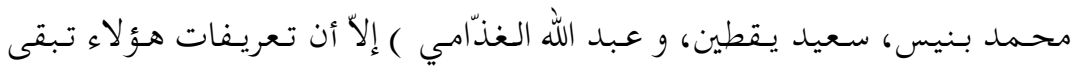
متباينة بعيدة عن تقديم تعريف جامع مانع للنص .

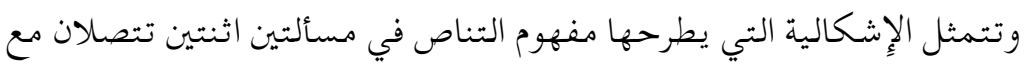

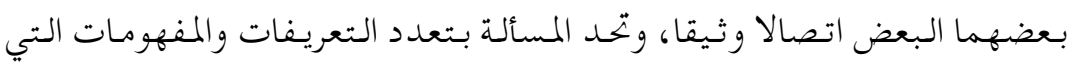


قـدمـت لهـذا المصطلح في مصادره الأولى، والـناجـمة عـن الاختلاف في طبيعة

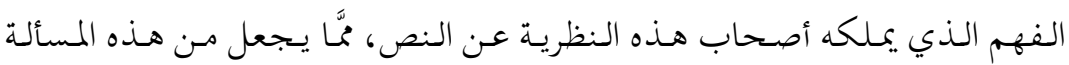
قضية ترتبط بـالحقل المعرفي الذي تسكل فيه هذا المصطلح، في حين أن المسألة

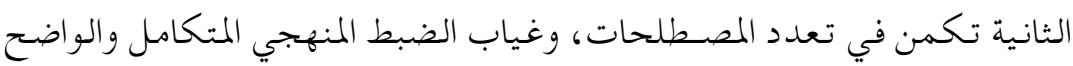
لأسباب تحصل بتعدد الاتجاهات والمساهمات النقدية الأخرى كالبنيوية وغيرهما، حيث أدى كل هـذا إلى عدم وضوح الحـدود الفاصلة، والتحـديدات التي قدمت لـلمفهومـات والمقولات والأنماط الـتي تـشكل الأسـاس الـذي قـامـت عـليه نـظريـة التناص في مدوناتها الخختلفة .

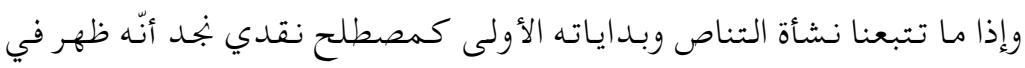

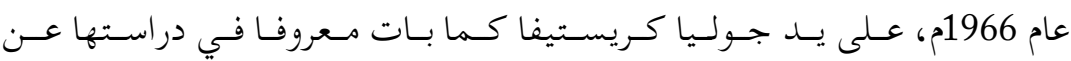
دوستوفسكي ورالي، وكان أول مـن أشار إليه هو شكلوفسكي الذي فتق الفكرة عندما ربط بين مفهوم العمل الفنّي وعالاقته بالأعمال الفنية الأخرى استنادا إلى لى الـترابطات الـقائـمة فيما يسبنها، لـكن الأصـول الأولى تـعود إلى الـناقــ الـروسي ميخائيل باختين الذي أسس له نظريـا في كتابه ( شعرية دوستويفسكي ) وحوله إلى نظرية حقيقية، تعتمد على التداخل القائم بين النصوص ودعاه بالحوارية ².

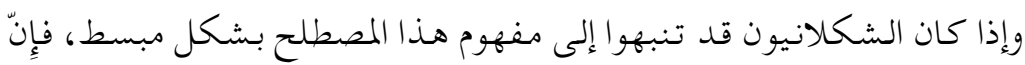

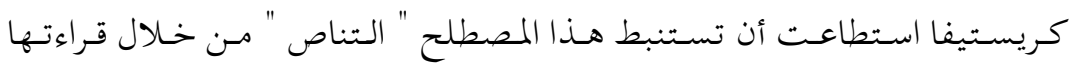
لـباخستين في دراستهـ لأعسمال دوسـتو يـفسكي الـروائية حسيث وضـع مصطلحي تعدديـة الأصـوات الحـواريـة دون أن يسـتخدم مصطلح الـتناص وبــلك المصطلح

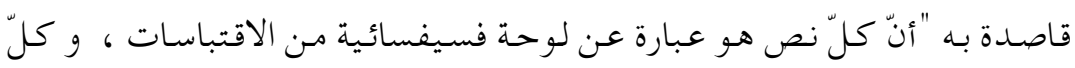
نص هو تشرب و تحو يـل نصوص أخرى "3 وهكذا استوى مفهوم التناص بشكل تام على يد تلميذة باختين الباحثة جوليا كريستسيفا، واتسع مفهومه وأصبح بمثابة ظاهرة نقدية جديدة وجديرة بالدراسة والاهتمام وشاعت في الأدب الغربي، ورغم 


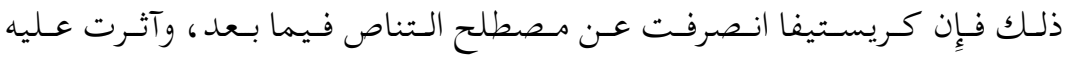

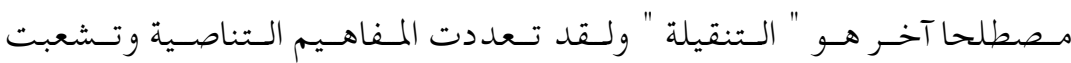
المدلولات، غير أنّ المصطلح ظل حاضرا عبر جميع الاتجاهات الأدبية الحـديثة، وإن

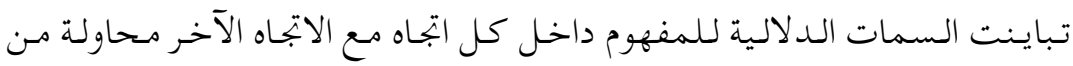
النقاد في تبيين جزيئات هذا المصطلح.

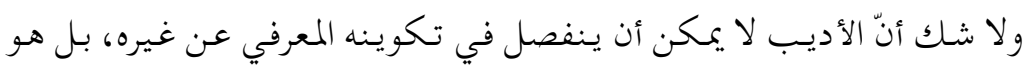

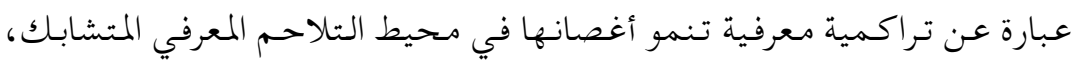
فالخطاب الروائي في نظر باختين " مختمر بالأفكار العامـة، وتداخل أقوال غريبة معقودة بححوارات متعددة، تشترك فيما بينها لتكون في الأخير خطابا هو نسيج عـد كبير مـن الملفوظات المتداولة داخل بـنية اجتماعية يعطيه إمكانيات أدبية

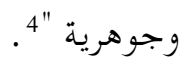

ولنذلك أصبح الأديـب ومـن بعده النص الأدبي بـناء مـتعدد القيم والأصوات، تتوارى خـلف كل نص ذوات أخرى غير ذات المبدع مـن دون حسدود أو فواصل، ومن ثم فالنص الجمديد هو إعادة لنصوص سابـقة لا تـعرف إلا بالخهبرة و التدقيق ،

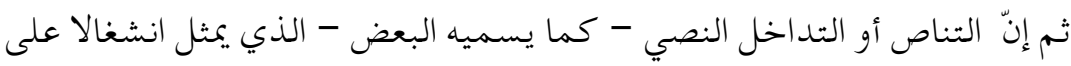
نصوص أخرى لا يقلل من أهمية النص الذي ينهض 5 على تخوم نصوص فهو لا يلغي خصوصسيته الإِبـداعية بـل على العكس يؤكد سماته المتميزة ، بوصفه نصا قائما بذاته تجاوز غيره أو تخطاه 6.

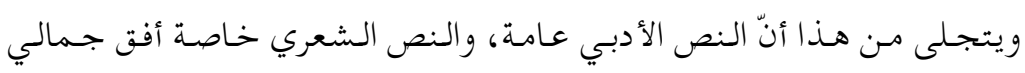

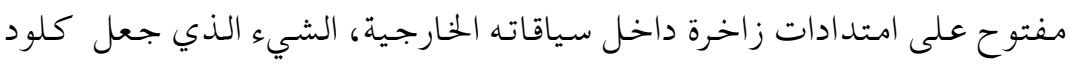
بريفو يقول : " إن النص الأدبي لا ينبت في المطلق إتّه يـدخل في لعبة التوازن بين

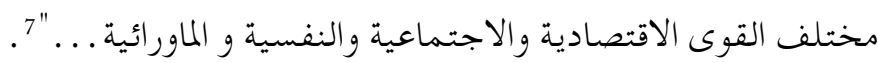


والنص في رأي ليتش:" ليس ذاتا مستقلة أو مادة موحدة ولكنّه سلسلة من

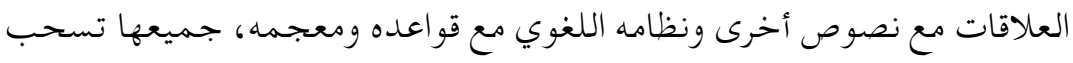

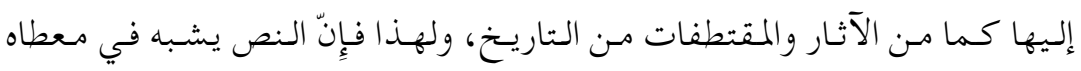

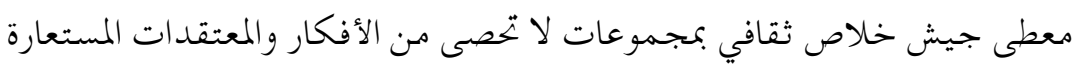

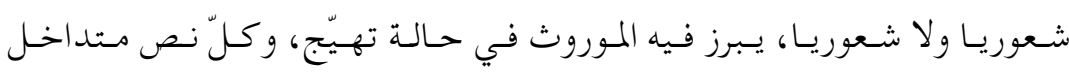

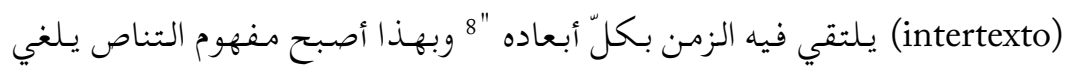

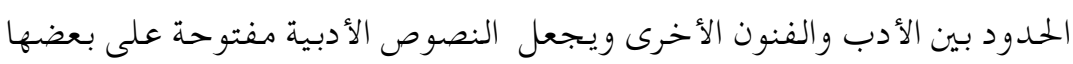

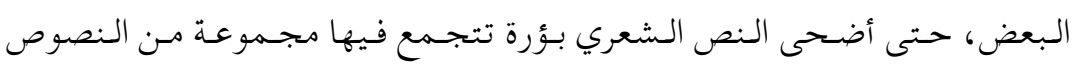

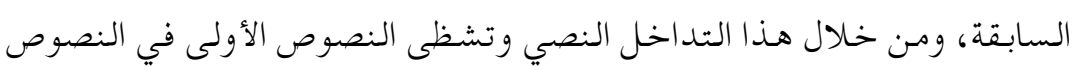
اللاحقة يترقرق التناص(intertextualidad) بشتى أنواعه ومستو ياته .

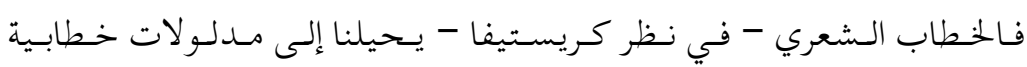

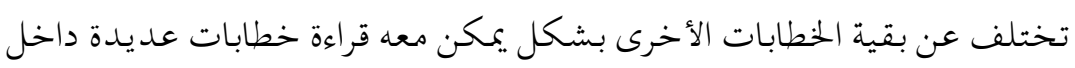

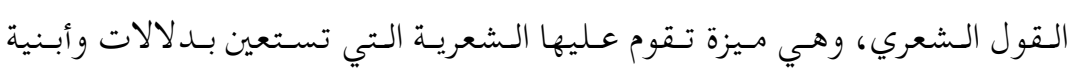

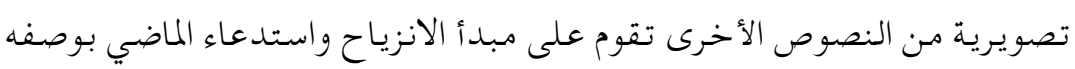

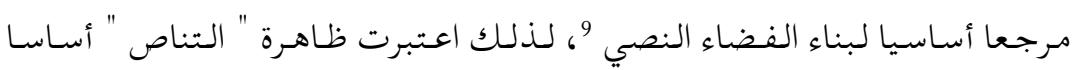

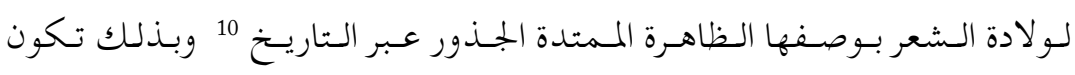

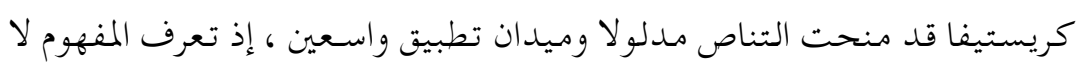

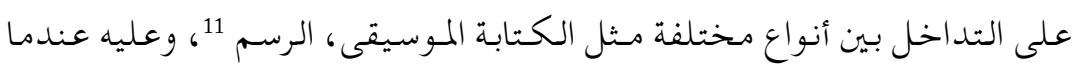

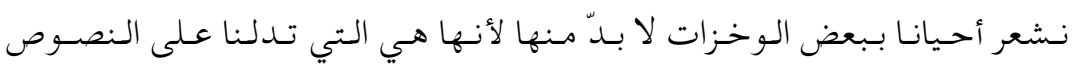

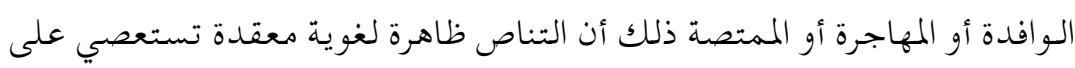

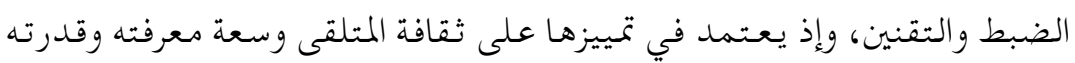
على الترجيح 
ويـكاد هـذا التعريـف يـكون نفسه الـذي نجـده عـند كوربـرات أركسيوني في تعريفها للتناص بقولها :" إن التناص حوار يقيمه النص مع نصوص أخرى، و مع أشكال أدبية ومضامين ثقافية"13.

وهـذه الحواريـة تـنبثق مـن رغبة أكيدة في التجـديــ وتجاوز الآخر, حستى ولو كـان

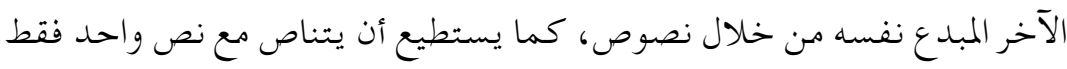

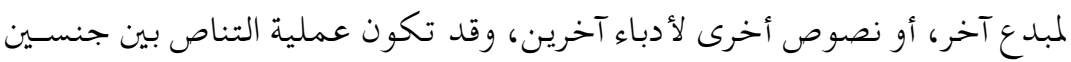
أدبيين .لا على مستوى جنس أدبي واحد .

وقد اقترح ل .جينى إعادة تعريف التناص في العبارات التالية :" عمل تحويل جل وتمثيل عـدة نصوص يـقوم بـها نص مركزي يـحتفظ بـريـادة المعنى 14 ويسرى رولان بارث أن كل نص تناص، يظهر في عالم مليء بالنصوص ( نصوص قبله، نصوص تطوقه، نصوص حاضرة فيه ) وننبه هـنا على أنّ مصطلح التناص كان في بـدايته يتسم بعدم القصدية والمباشرة، فالنصوص تتقاطع فيما بينها بشكل عفوي غير واع ولا شعوري، وكذا هو عند أغلب أصحاب نظريـة التناص مـن بعد، علما أن بعضهم الآخر لـم يمـنع فيه القصدية و الوعي فاقترب من مفهوم التأثر و التأثير و

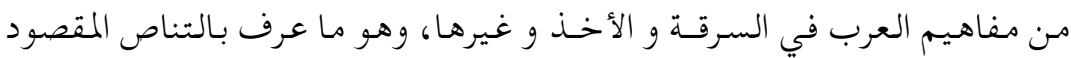
والمباشر و الظاهر . وكان " بارث " قد بـدأ سيميولوجيا في كتابه عن راسين1963 و ذكر عناصر

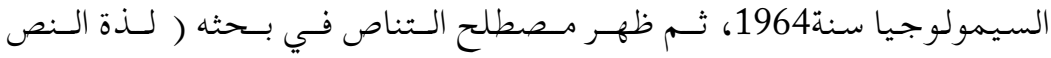
1973 )، ويـقول بـارت :" لـيس الـنص مـقترن الـوجــود بــالـعنى ولـكن بمـروره

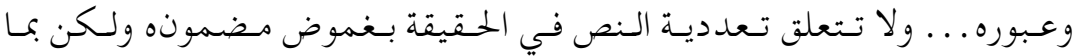
نستطيع تسميته بالتعددية المضخمة التي تنسجه "15. وقـد مسيز بـارث بـين العمل الأدبي والـنص، وهـو يسـير على خطى كريستيفا حيث يؤيد مفهوم الإِنتاجية، ويرفض مفهوم إعادة الإنتاج، فحسب بارت كل نص 
ليس إلا نسيـجا جـد يـدا مـن استشهادات سابقة، وكانـت كريستيفا قد اعتمددت على مفهوم الحوارية لباختين1929 الذي رأى ضرورة قراءة خطاب الآخر وخطاب الأنا، وأشار إلى مفهوم التفاعل النصي وتعدديـة الأصوات، في حين ركز " لوران جيني " في شرحه لمفهوم التناص على ( الهضم والتحويل والحرق ) ، النص الذي يشرب عددا من النصوص مع بقائه ممركزا بمعنى .

2 ماهية التناص عند عبد المالك مرتاض

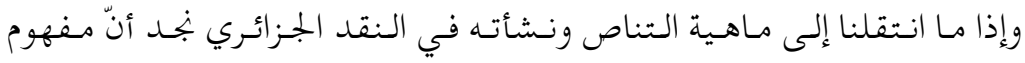
التناص هو مصطلح جـديد لظاهـرة أدبية نقدية قديمة " فظاهرة تـداخل النصوص هي سـمة جـوهريـة في الثقافة العربية حيث تـتشكل العوامل الثقافية في ذاكرة الإِنسان العربي ممتزجة ومتداخلة في تشابك عجيب مذهل "16. فالمتأمل في طبيعة التأليفات النقدية العرب ية القديمـة يـعطينا صورة واضحة جـدا لـوجـود أصـول لـقضية الـتناص في الأدب الـقديم،و ظهـر وجـوده فيها تحـت مسميات أخرى وبأشكال تقترب بمسافة كبيرة من المصطلح الحمديـث، على غرار ما قام بـه محمد بـنيس ، محمد مفتاح، صببحي الطعان،وعبد المالك مرتاض في

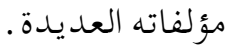

ولقد تنبه النقاد العرب إلى التناص وإلى دوره ووظيفته، واستحسنه شعراؤهم

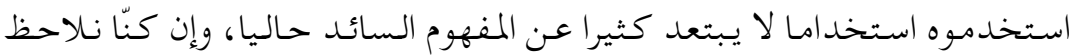
توسـيعا في المفهوم لاستخدامه اليوم ولكن العرب لـم يقعوا على الاسم نفسه " التناص " فكان اقترابهم من اسم آخر هو " التضمين "17.

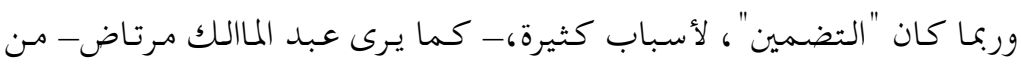
أعرق صور التناص على الإِطسلاق ، سواء على المستوى الإِبداعي، أو على المستوى

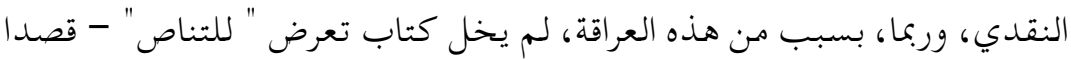


أو عـرضـا - مـن احـتفال بـه وركون إليه بـاعتباره أصـل الظاهـرة، خـاصـة والـتراث النقدي يطالعنا في بعض صفحات خطابه بطــرق ، أو بطرائق، من خبره. ولقد كان تطور النظر النقدي في ظاهرة " التضمين " القديمة راجعا الفضل فيه إلى الإِبـاع الأدبي وتعتقد آليات تضمنه للنصوص والخطابات الأخرى، فبينما

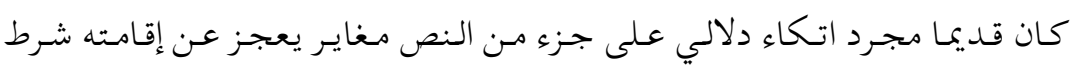
التفاعلية للتناص بوجهه عام، إذا بالحـداثة تطور من وظيفته وطرائق أدائها، فتنفخ فيه من تمرد روحها لينقلب من سكونيته السابقة متحولا إلى حوارية فاعلة تبني نص الحـداثـة في الوقت الذذي تستدعى خطابـاتها ونصوصهـا التي كانـت لها، فتنقسم أبعاد النص ليمتلك من دلالات النص دلاليا 18. وإذا تـتبعنا قـليلا أصسول التناص في أدبـنا القديم، نجــ أنّ الموازنـة التي أقـامها الآمدي بين أبي تمام والبحتري تعكس شكلا من أشكال التناص، و كذلك المفاضلة كما هو عند المنجم، والوساطة بين المتنبي وخصومه عند الجرجاني .

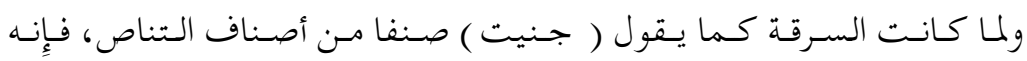

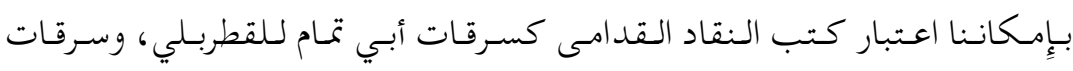
البحتري مـن أبي تمـام للنصصيبي والإِبانـة عن سرقات المتنبي للحميدي، شكلا

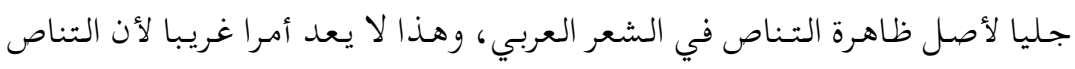
أمر لا بد منه و " ذلك لأن العمل الأدبي يدخل في شجرة نسب عريقة وممتدة تماما

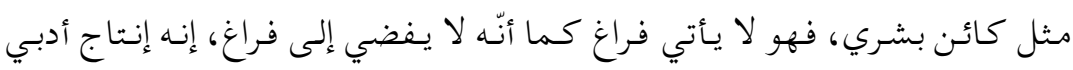

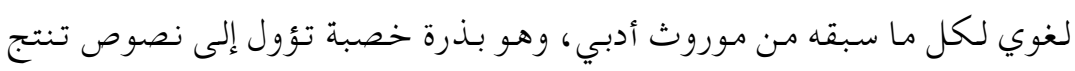

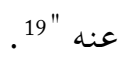

وهـا الجهـد المتمثل في هذه الموازنات والسرقات والمعارضات والجـدل الطويل دار بين النقاد القدامى الذيـن درسوا هـذه الظواهـر التي تـتفاوت فيها الصلة بـين

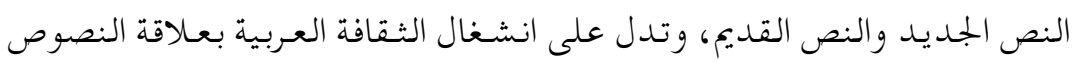


بعضها ببعض ، وإدراك النقاد القدامى " للغة والأسلوب من جهة وبين الخطاب من جهة أخرى، وهكذا أنزلوا الأولى منزلة السرقة والثانية منزلة الإجبار الذي هو شرط

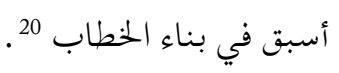
وهذا الأمر ولد لدينا رغبة في التساؤل عن علاقة السرقات الأدبية في البلاغة الحمديثة بالتناص، وقد اهتدينا إلى إجابة مقاربة بفضل الناقد عبد المالك مرتاض إذ

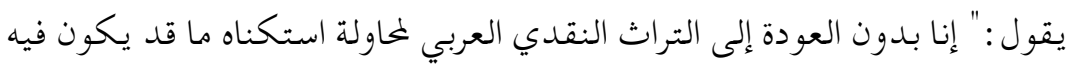

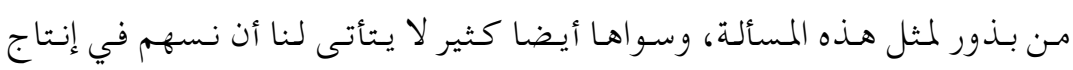

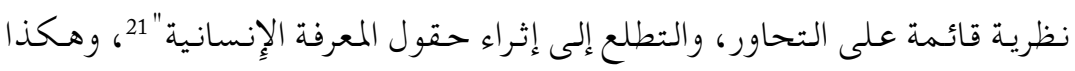

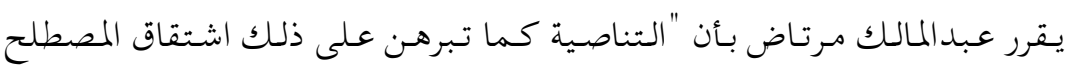
نفسه ، هي تبادل التأثر والعلاقات بين نص أدبي ما، ونصوص أدبية أخرى، وهذه

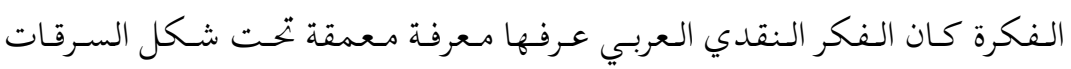
الأدبية"22، و و في ذلكك إثـارة إلى أن هـذا الـتراث -مــادام - حسافـلا بـالـنظريـات

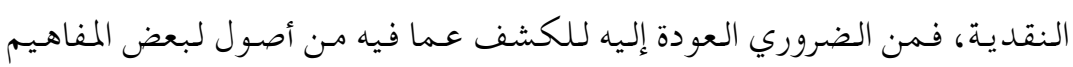

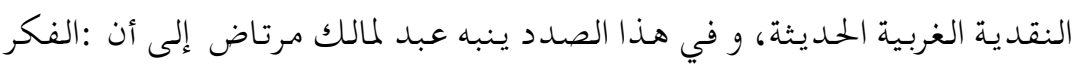
النقدي العربي حافل بالنظريات ، ومن الاستحذاء و العقوق أن نضرب صفحا عن الكشف عما قد يكون فيه من أصول لنظريات نقدية غربية تبدو لنا الآن في ثوب مبهرج بالعصرنة، فننبهر أمامها، و هي في حقيقتها لا تعدم أصولا لها في تراثنا الفكري مع اختلاف المصطلح و المنهج " . لقد بـذل عبد المالك مرتاض جهـدا في استنطاق التراث العربي القديم و ذلك من خلال البحث الدؤوب عن أصول النظريات الغربية.

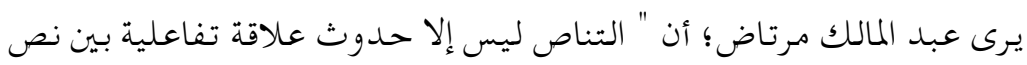
سابق و نص حاضر و نص لاحق، و هو ليس إلا تضمين بغير تنصيص "23، كما أنّه

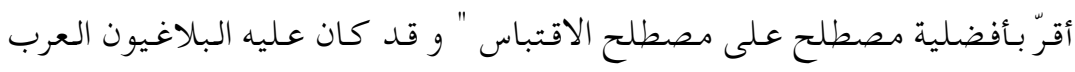


( الاقتباس ) و أحسب أن المصطلح المعاصر الذي هو ثمرة من ثمرات الترجمة من

$$
\text { الغربيين هو أدقّ و أدلّ على الحال" }
$$

كما أن مرتاض يسوي بين التناص و السرقة الشعرية ، إذ يقول : "والتناصية إن شـئت اقـتباس، و هــا المـصطلح بـاغـي صـرف، و ولـكنه الآن مسـطو عـليه مسن السيميائية التي بادرت إلى إلحاقه بالتناصيات و استراحت ، بل إنها ألحقت الأدب

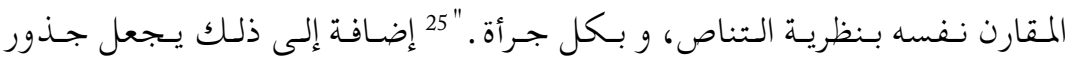
التناص تعود إلى علي بن عبد العزيز الجرجاني 26، لكن بمصطلح السرقات الأدبية الذي استهجنه في الوقت نفسه كونه" يقتضي عقوبة قانونية"27، ويعتبره" إهانة للشعراء والأدباء وأنه لايحمل الحقيقة في بعديها الأدبي والأخلاقي "28، و رغم أنّه إعترف باختلاف المصطلحين السرقة و التناص إلاً أنّه يذهـب في موضع آخر إلى أنّ القضية في رأيه " مسألة مصطلح لا مسألة الفكرة في حد ذاتها فهي قد وردت في النقد العربي القديم" "29، بـل يعتبر أنّ " التناص المعاصـر يـحاول في خـذلقة مائسية

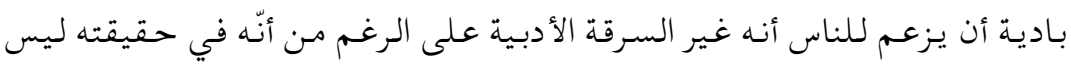

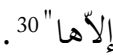

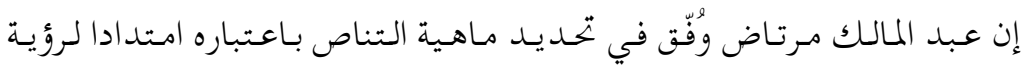
ثقافية غربية و عربية معا لكن من المستبعد حصر نظرية التناص كلها في الاقتباس أو السرقة 31، لأنه من غير المعقول لمصطلح بلاغي واحد أن يقابل نظرية بكاملها و وكريه بكل مصطلحاتها وأنماطها 32. كمـا يـذهـب إلى أن عـدم تمكـن النقد العربي مـن الإِلمام الجـيّد بـنظريـة التناص والولوج إلى صميمها من سوء حظ هذا النقد ، رغم اقتناعه بأن النقد العربي عرف فكرة التناص في ماهـيته و وظائفه و إنّما لـم يصطنع بطبيعة الحال هـذا المصطلح الغربي و إعادة إدماجه في النقد الحديث . 
و الحقيقة أنّ التعاريف الدقيقة لمفهوم التناص تؤكد أنّ مرتاض على بيّنة من

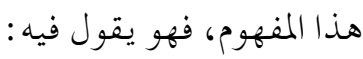

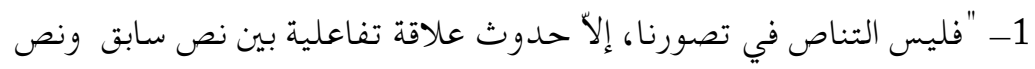

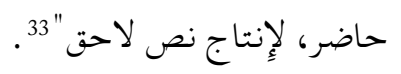

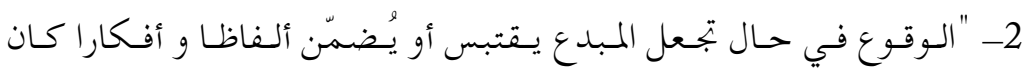

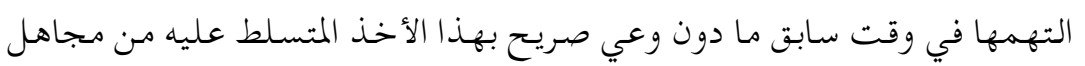

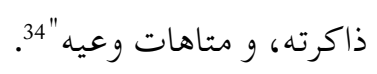

3- "التناص نظرية تقوم على افتراض شيء غائب داخل شيء غائب، هو هو النص الذي يقع بين أيدي الناس في صورته الأدبية النهائية" 35. 4-" هو استبدال نصوص سابقة بنص حاضر دون قصد "36.

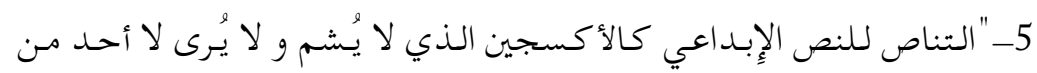

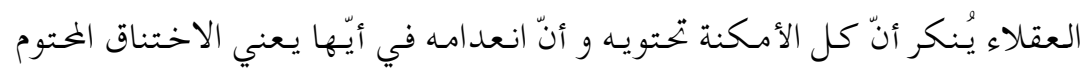

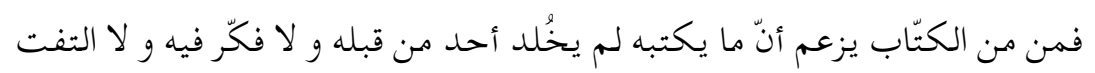

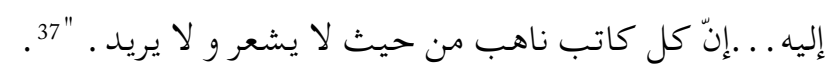

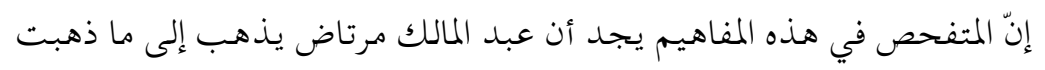

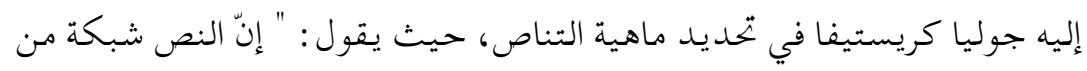

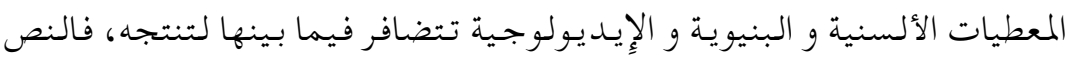

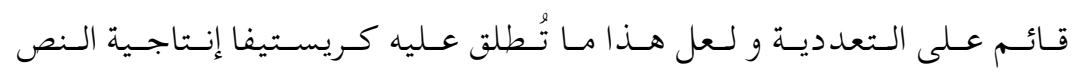
.${ }^{38}$ producción de texto

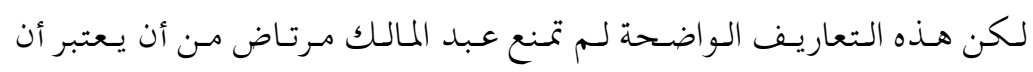

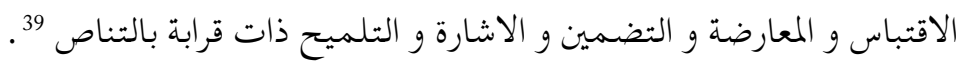

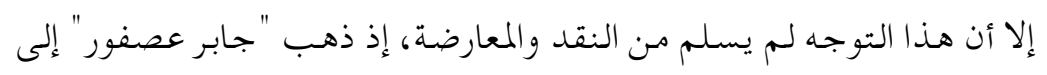

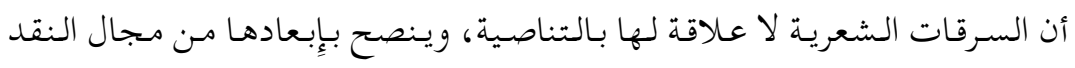


العربي 40 ـ وهـا أيضا وجه من أوجه الحوار الهادف الذي من شأنه أن يثري المعرفة

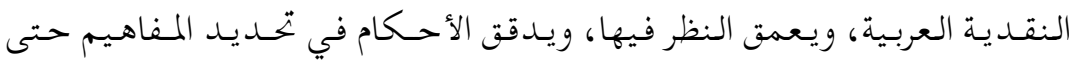
يحصل التطور، والتقدم، فيكون العطاء، وهو النهج الذي اتبعه حافظ صبري ؛ إذ

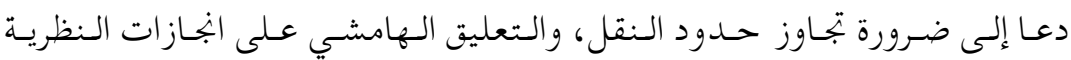
النقدية الحمديثة في الغرب، لعقد نوع من الحوار الجلدلي الخلاق بين الجازات النقد

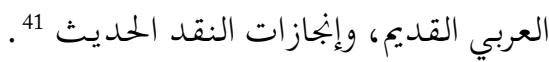
لقد أشـار الناقـد الجـزائري عبد المالك مـرتاض إلى أنّ مصطلح التناص بمعناه

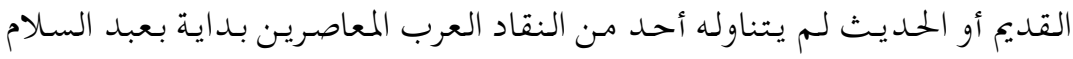
المسدي من خلال كتابه" الأسلوبية و الأسلوب" سنة 1975 وصولا إلى كمال أبو ديب من خلال كتابيه " جدلية الخفاء و التجلي" سنة 1979 و "في الشعرية" سنة

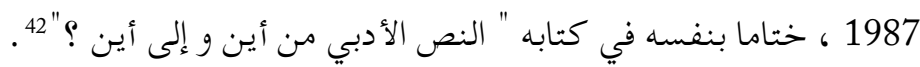

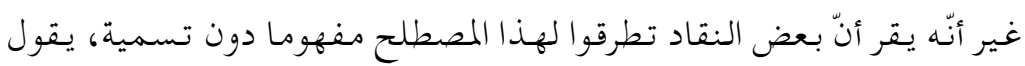

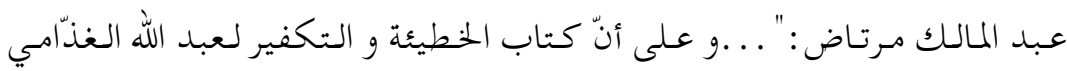
الذي صـدر عـام1985 و هـو مـن أحسـن الكتب الأولى التي ظهرت في الحـداثـة

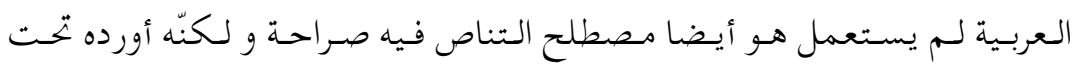

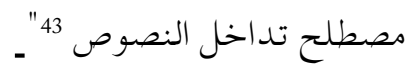

وفي السياق نفسه نجد أنّ عبد المالك مرتاض يورد مصطلحات متعدّدة للتناص

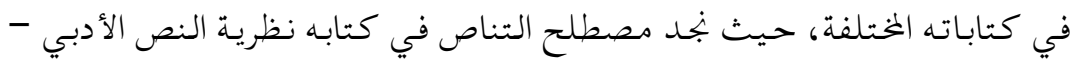
تحليل الخطاب السردي- و مصطلح التناصية في كتابه في نظريـة النص الأدبي السبع المعلقات- في حين يورد مصطلح التكاتب في مقال له بعنوان بين التناص و التكاتب، كما يقترح مصطلحا آخر للتناص هو المقارءة في كتابه نظريـة النقد ، أمّا مصطلح السرقات الشعرية فقد استخدمه في كتاب نظرية النص الأدبي. 
وإذا كان التناص في الأدب العربي قد مر ببدايات غنية تحت مسميات نقدية تناسب عصوره القديمة، وعاد من جديد للظهور متأثرا بالدراسات اللّسانية الغربية الحديثة كمصطلح مستقل له أصوله ونظرياته وتداعياته، و كانت دراسة التناص، في بـداياتها قد اتخذت شكل الدراسة المقارنة , و انصرفت عن الأشكال اللفظية

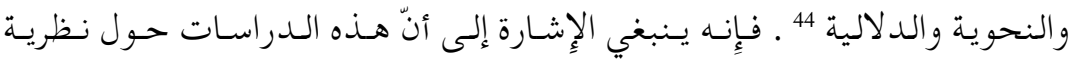
التناص التي انتقلت من النقد الغربي المعاصر إلى النقد الجزائري عن طريق التأثير خاصة من الناحية النظرية لا نكاد نلمس فيها فروقا ذات شأن من هذه الناحية بل الشيء الذي نلاحظه هو دخول النقاد الجزائريين والعرب بصفة عامة في إشكالية المصطلح نتيجة اختلاف الترجمات والمدارس النقدية.

خاتمة

إن التناص من المفاهيم التي نجد لها جذورا وبذورا في نقدنا العربي القديم، من خلال مفهوم السرقات رغم وجود بعض المعارضات التي ترى بأن السرقات الشعرية لا علاقة لها بالتناصية.

كما أن هـناك مجـموعـة مـن المصطلحات البديعية التي يمـكنها أن تسهمم في بلورة هذا المفهوم كالتوليد والتلميح والإِشارة والاقتباس، أما التضمين فِإنه عد من أعرق صور التناص باعتباره أنه لم يخل كتاب تعرض للتناص إلاً وأورده. إن النص الغائب أحمد مكونات النص الحاضر، وهو يعمل وينبض في العمق، ويسبين مصطلح التناص أن حـركية النص مـن مـكونـات نصسوص سـابـقة عـليه أو معاصرة له، وهـذا يعني أن عمل المؤلف في تكويـن نصوص جـديدة من نصوص كثيرة، بـعضها مـن جـنس النص الجـلديـد، وبـعضها مـن أجـناس مـختلفة، إن عمله هذا نصوصي و النصوص الغائبة سابقة على المؤلف ودوره في صنعها ثانوي، أما الـدور الأولسى فـهو لـلنصوص نـفسها، ولـم تـكـن آفـاق هـذه الــصوص تـتحاور 
وتتجاذب والنص الجـديــ لما تشكل هـذا النص على هذه التناصـية، ولـذلك فِِان مؤلف أي نص متعدد، وهو لازماني ولامكاني ولا أجناسي، وهذا يستدعي إلى لي الذهن مقولة "موت المؤلف" عند بارت، وأهم ما فيها أن اللغة هي التي تتكلم في

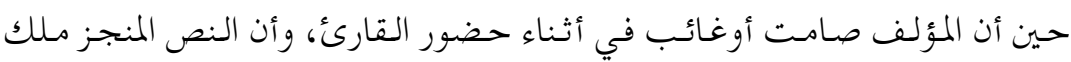

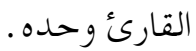




\section{الهو امش}

1 صلاح فضل .التوشيح بين الانحراف و التناص _قراءة جديدة لتراثنا النقدي -طبع النادي الأدبي الثقافي بجدة . 1990 . ص 983.

2 تيزفيتان تودوروف . في أصول الخطاب النقدي الجمديد (مفهوم التناص في الخطاب

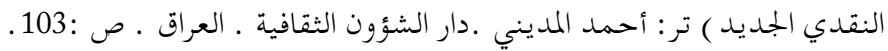

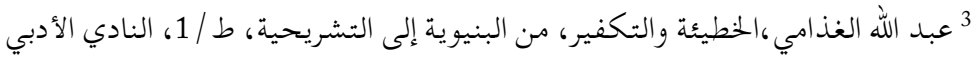

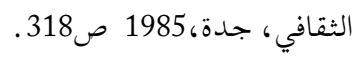

T. Todorov, Mikhaïl Bakhtine. Le principe dialogique. Suivi de: Ecrits du Cercle 4 .de Bakbtine, Paris, Le Seuil, 1981, p. 41 5 ماجد ياسين الجعافرة: التناص والتلقي دراسات في الشعر العباسي دار الكندي للنشر

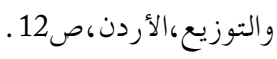
6 نجم مفيد : التناص و مفهوم التحويل من شعر محمد عمران، موقف الأدبي العدد319، 1997 مدرد 1997 7 عبد القادر فيدوح، الرؤيا والتأويل، ط 1، ديوان المطبوعات الجامعية للدراسات والنشر،

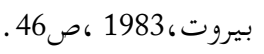
8 8 جمال مباركي التناص وجمالياتهاته في الشعر الجزائري المعاصر،رابطة الإِبداع الأدبية الثقافية

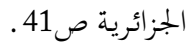
9 ماجد ياسين الجعافرة، التناص و التلقى، ص12. 12.

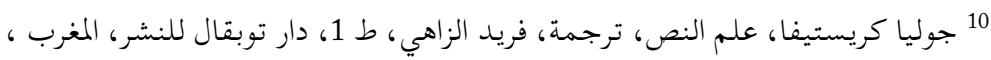
.79، 1991

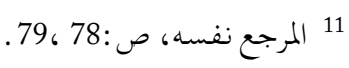
12 محمد خطابي، لسانيات النص( مدخل إلى انسجام الخطاب )، ط3 3 ، دار توبقال

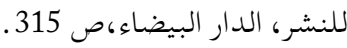

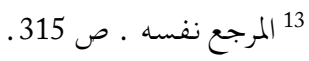
14 تيزفيتان تودروف ،وآخرون في أصول الخطاب النقدي الجلديد ، ( مفهوم التناص في ماكي

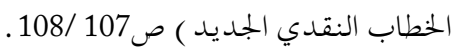


15 حسين جمعة، المسيار في النقد الأدبي، ط 1، دراسة من منشورات اتحاد الكتاب العرب،

$$
\text { دمشق سوريا2003، ص } 20 .
$$

16 عبد الله الغذامي، ثقافة الأسئلة " مقالات في النقد والنظرية "،ط 2، النادي الأدبي صلي

$$
\text { الثقافي جدة، } 1992 \text { ، ص119. } 119 .
$$

17 ماجد ياسين الجعافرة، التناص والتلقي، ص21.

18 فكري الجزار، لسانيات الاختلاف ، الخصائص الجالية لمستويات النص في شعر الحداثة،

ط / 1 ، ايتراك للطباعة والنشر والتوزيع، القاهرة مصر، ، 2001 ، ص343.

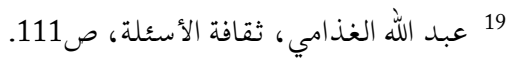

20 محمد بنيس، الشعر العربي الحديث بنياته وابدالاتها، ج 3 الشعر المعاصر، دار توبقال،

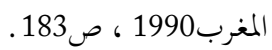

21 عبد المالك مرتاض، فكرة السرقات الأدبية ونظرية التناص، مجلة علامات في النقد الأدبي، البجلد الأول النادي الأدبي الثقافي بجدة السعودية،1991 ، ص84.

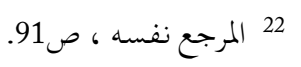

23 عبد المالك مرتاض، تحليل الخطاب السردي، ديوان المطبوعات الجزائرية، الجزائر، 1995،

$$
\text { ص248. } 248
$$

25 حسين جمعة، نظرية التناص صك جديد لعملة قديمة، مجلة مجمع اللغة العربية،

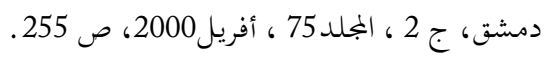

$$
\begin{aligned}
& 26 \text { عبد المالك مرتاض، نظرية النص الأدبي ، ص197. } \\
& 27 \text { المرجع نفسه، ص203. } \\
& 28 \text { المرجع نفسه، ص203. }
\end{aligned}
$$

29 عبد المالك مرتاض، نظرية النص الأدبي دار هومة للنشر و التوزيع الجزائر،2007، ص

$$
31 \text { المرجع نفسه ، ص264 المرجع نفسه ، ص264. }
$$




$$
\begin{aligned}
& 33 \text { عبد المالك مرتاض، فكرة السرقات الأدبية ص88. }
\end{aligned}
$$

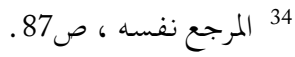

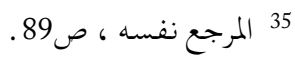

$$
\begin{aligned}
& 36 \text { عبد المالك مرتاض، نظرية النص الأدبي، ص199. } \\
& 37 \text { عبد المالك مرتاض، تحليل الخطاب السردي، ص278. } \\
& 38 \text { نور الدين السد، الأسلوبية و تحليل الخطاب، ص103. }
\end{aligned}
$$

39 عبد المالك مرتاض، فكرة السرقات الأدبية و نظرية التناص، ص 85. 40 رابح بوحوش، اللسانيات وتطبيقاتها على الخطاب الشعري، دار العلوم للنشر والتوزيع،

$$
\begin{aligned}
& \text { عنابة، الجزائر2006 ، ص28. } \\
& 41 \text { انظر المرجع نفسه ، ص20 كانس } 42 \\
& 42 \text { عبد المالك مرتاض، نظرية التناص الأدبي، ص254. }
\end{aligned}
$$$$
43 \text { المرجع نفسه، ص254. }
$$

44 داغر شربل، التناص سبيلا إلى دراسة النص الشعري، مجله فصول الهيئة المصرية العامة

$$
\text { للكتاب، القاهرة ع-1 ، 1997 ، مج16 ، ص130 130-131. }
$$




\title{
تعارض فكرة النظام العام والاستثناءات العامة مع تنفيذ الحكم الأجنبي في النظم المقارنة والنظام القانوني الجزائري
}

\author{
LA CONTRADICCIÓN DEL ARBITRAJE \\ INTERNACIONAL Y LAS EXCEPCIONES \\ GENERALES EN LA EJECUCIÓN DE LA LEY EN EL \\ SISTEMA JURÍDICO ARGELINO
}

\author{
يوسفي محمد \\ جامعة عبد الحميد بن باديس مستغانم \\ MUHAMMAD YOUSFI \\ Universidad Abd al-Hamid Ben Badis \\ Mostaganem
}

\begin{abstract}
Resumen
La capacidad de rechazar la aplicación de laudos — resoluciones dictadas en arbitraje internacional一, no debería resolverse atendiendo a la ley interna del país que debe aplicar dicho dictamen. $\mathrm{El}$ mismo régimen general desafía la naturaleza del arbitraje internacional. Puede decirse, simple y llanamente, que en aras de mantener el orden público debe preservarse el interés público, bien sea político, social o económico. Hasta qué punto se atenta contra la idea del "orden público", en ambos sistemas jurídicos, el nacional y el internacional, con la aplicación de resoluciones y laudos internacionales. E1 presente trabajo estudia las contradicciones del derecho internacional y las excepciones para su puesta en ejecución, estudiando el caso del sistema legal argelino.
\end{abstract}

Palabras clave: derecho internacional, arbitraje, laudo, sistema jurídico argelino, La idea del sistema público. 


\section{ملخص}

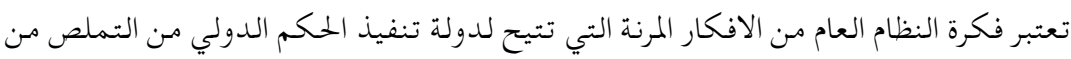

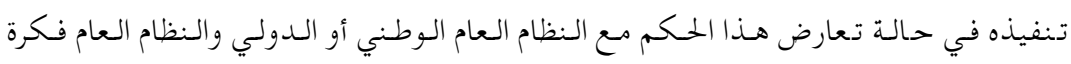

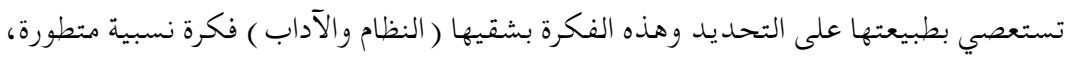

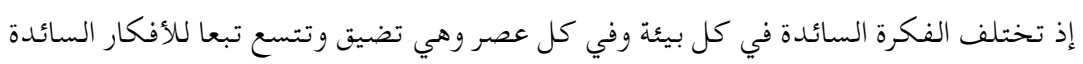

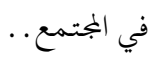
والدفع بالنظام العام هو عبارة عن أسلوب احتجاج يعبر من خلاله القاضي عن اعتراضه على

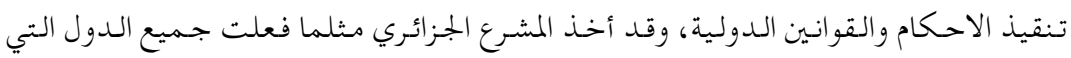

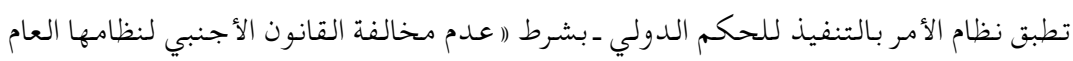

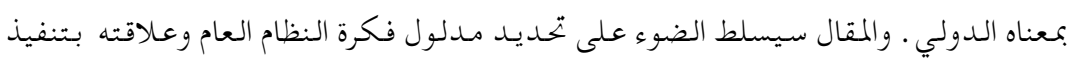

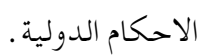

الكلمات المفتاحية: التحكيم التجاري الدولي، النظام العام، تنفيذ الأحكام، الاستثناءات العامة النظام العام الجزائري.

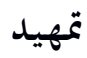

يعتبر التحكيم بمثابة القضاء الخاص الذي يتمتع بخصوصية معينة، تميزه عن

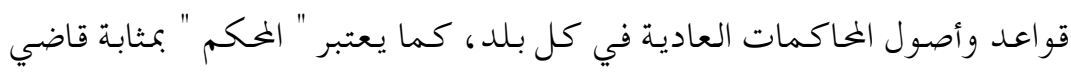
خاص تعهد للحصوم بـتنفيذ مهمة تحكيمية، تكون مسحلا للنزواع فيما بسينهم خلال فترة زمـية معينة، لقاء أتعاب تحدد بموجـب اتفاقية التحكيم، سواء كانت

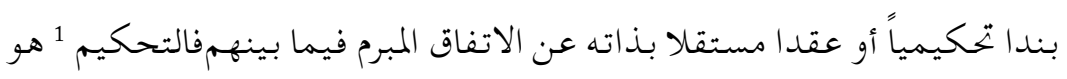
طريق خاص لحل المنازعات ، ولقد التهت النظم القانونية الحلديثة لدعم هذا النظام

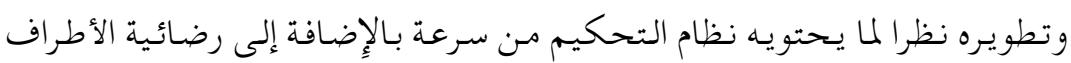

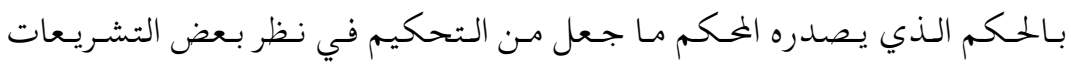


نموذجا يـجب الأخذذ به خاصة في مجال التجارة الدولية نظراً لملائمة التحكيم

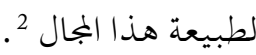

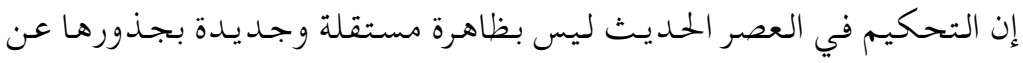

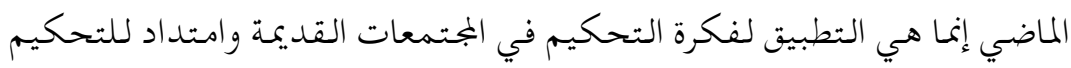
التجاري الدولي في العصور الوسطى، فهذا التحكيم شكل بدائي لإقامة العدالة .

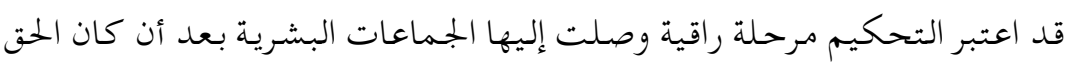
هو قوة والقوة هي حق. ولعل أن مـن الأمور الضروريـة لـنمو وتطور التعاون الاقتصادي الدولي دون

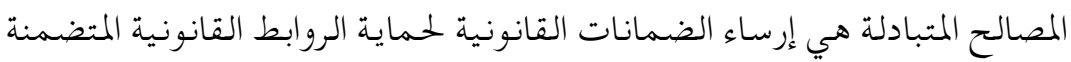

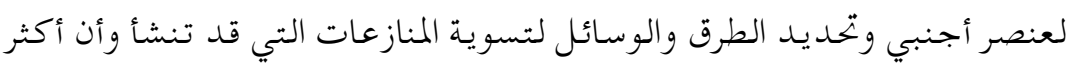

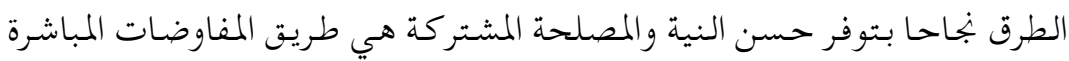

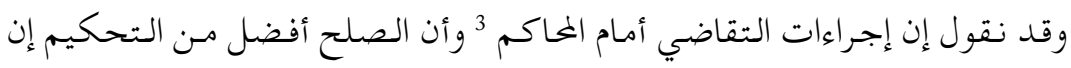
انتفاء وتفادي نشوب المنازعات أفضل من الصلح.

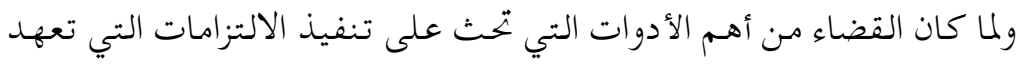

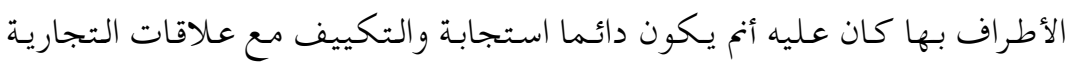

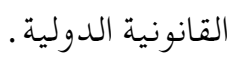
للسلطة الختصة أن ترفض تنفيذ القرارات التحكيمية من تلقاء نفسها في حال

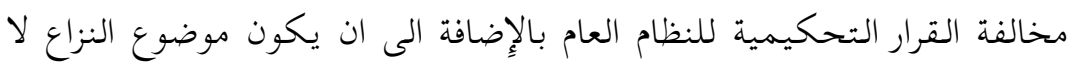

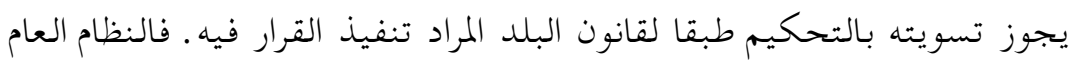

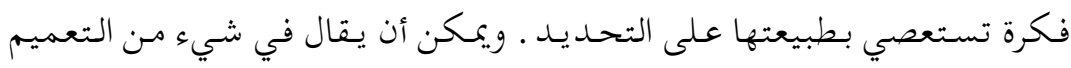

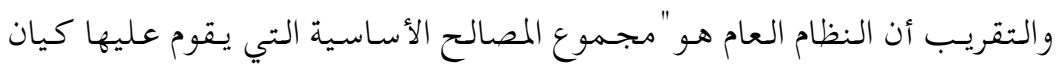

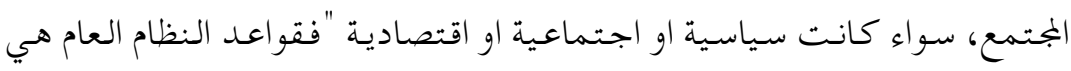


تـلك التي يـقصد بـها تحقيق مصلحة عـامـة، سياسية أو اجتماعية أو اقتصاديـة، ويراد بالمصلحة العام كل أمر يتعلق بالنظام الأساسي للمجتمع بحيث يرجح على كل مصلحة فردية ـ فما مدى تعارض فكرة النظام العام سواء كان نظام عام دولي أو وطني مع تنفيذ الأحكام الدولية؟

\section{1 رفض تنفيذ القرار التحكيمي استنادا للنظام العام}

لقد أوردت بعض التشريعات الأسباب التي تؤدي إلى رفض تنفيذ القرار التحكيمية 4 منه :عدم وجود اتفاق تحكيم صحيح طبقا للقانون الواجب التطبيق على اتفاق التحكيم، أو أن يـكون تشكيل الهيئة مخالفًا للقواعد الواجبة التطبيق، أو أن هيئة التحكيم لم تقم بدورها بشكل صحيح، أو أن القرار قد تم إبطاله من قبل جهة مختصة في البلد الذي صدر فيه حيث أن القرار الخاص برفض تنفيذ القرار التحكمي يصدر من السلطة الخختصة في البلد المراد فيه التنفيذ وفي الغالب المحكمة الخختصة بنظر النزاع في ذلك البلد، وقد بينت اتفاقية نيويورك لعام 1958 حول الاعتراف وتنفيذ قرارات التحكيم الأجنبية الأسباب التي يمكن بموجبها رفض التنفيذ إذا تمكن طالب الرفض من إثبات وجودها وهـذه الأسباب هي -أ-نقص أهلية إحدى الأطراف أو عدم صحة اتفاق التحكيم ب -عدم احترام حق الدفاع (خماع

للخصم وعدم إباغه بإِجراءات التحكيم ج-تجاوز هيئة التحكيم لاختصاصها

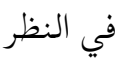
بالنزاع المعروض عليها د-عدم سلامة الإجراءات التحكمية د-حالة عدم اكتساب القرار صفة الإلزام 5. 
_للسلطة الختصحة أن ترفض تنفيذ القرارات التحكيمية من تلقاء نفسها في حال مخالفة القرار التحكيمية للنظام العام بالإِافة الى ان يكون موضوع النزاع لا يجوز تسويته بالتحكيم طبقا لقانون البلد المراد تنفيذ القرار فيه. -إن رفض تنفيذ القرار التحكيمي في إحدى الدول لا يؤدي إلى رفضه من قبل الدول

الأخرى ويترك لكل دوله إن تقرر سلطتها الخختصة كما انه في المقابل فان تنفيذ

القرار

التحكيمي6 في إحدى البلدان لا يعني إلزام الدول الأخرى بالتنفيذ في إقليمها ـ أيضا إبطال القرار التحكيمي أو وقف العمل به تقرره السلطة في البلد الذي صدر في هـا القرار التحكيمي أو البلد الذي صدر القرار التحكيمي بموجب قانونه، وإبطال القرار التحكيمي من قبل السلطة المختصة في البلد الذي صدر فيه القرار هو البلد الذي صدر فيه القرار بموجب قانونه يعتبر سبابا كافيا لرفض التنفيذ في البلد المراد تنفيذ القرار فيه. وهناك أسباب يمكن للسلطة الخختصة في البلد المراد تنفيذ القرار التحكيمي فيه أن ترفض تنفيذه من تلقاء نفسها، وهذا ما نصت عليه اتفاقية نيويورك حيث جاء فيها أن موضوع النزاع الذي صدر بشأنه القرار التحكيمي لا يمكن تسويته بالتحكيم طبقا لقانون ذلك البلد بالإضافة إلى أن تنفيذ القرار المذكور يشكل خرقا لقواعد النظام العام في ذلك البلد أو قواعد النظام العام الدولي ${ }^{7}$ بالنسبة لتشريعات بعض البلدان . ت ل 
لهذا سنتناول النظام العام وأثره على عملية التنفيذ بشيىء من التفصيل في هذا المبحث مسلطين الضوء على الدفع بالنظام العام لتجنب تنفيذ أحكام المحاكم

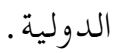

\section{2 مفهوم النظام العام وعلاقته بتنفيذ الأحكام}

النظام العام فكرة تستعصي بطبيعتها على التحديد ـ و ويمكن أن يقال في شيء

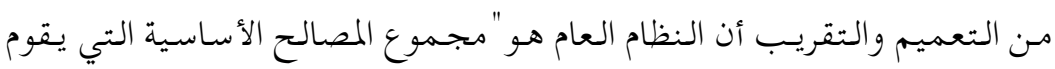

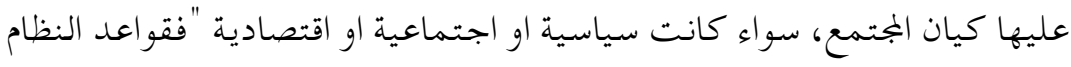

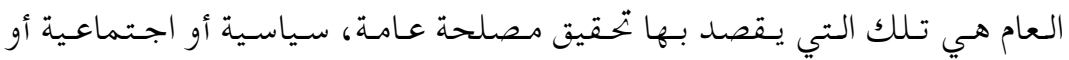

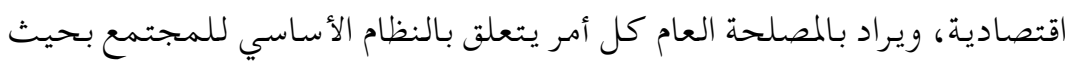

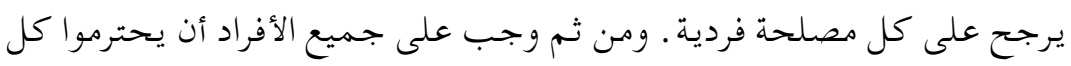

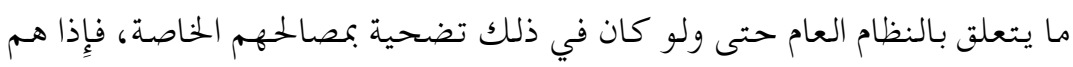

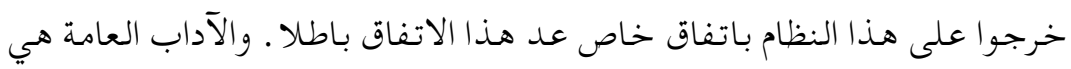
مجموعة القواعد الخلقية التي تدين بها الجمماعة في بيئة معيشة وعصر معين فهي

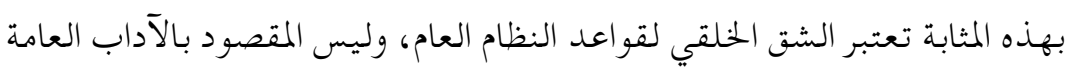

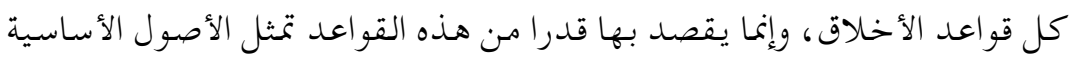
لأأخلاق في الجماعة.

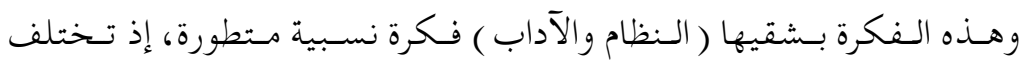
الفكرة السائدة في كل بيئة وفي كل عصر، فكثير من ضروب التعامل التي كانت

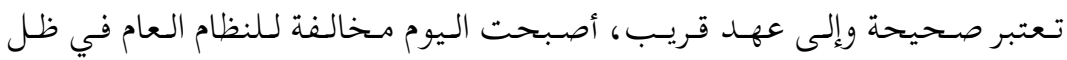

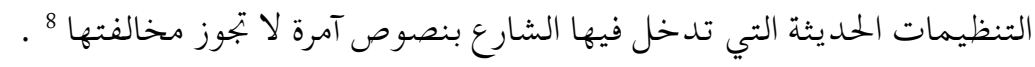

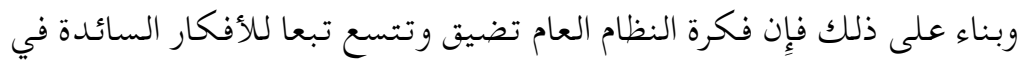

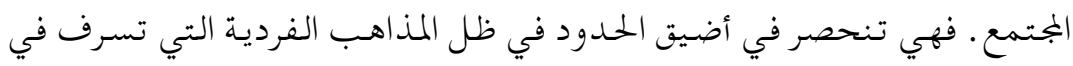


الاعتد اد بحرية الفرد وتغفل الصالح العام • بينما تتسع في ظل المبادئ الاشتراكية التي تسرف في مصلحة المجموع وتضحي في سبيلها بـالمصلحة الفرديـة 9. . وإذا

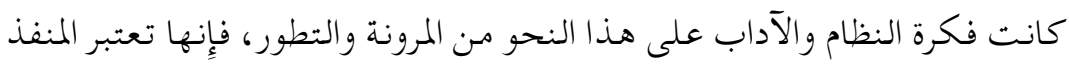
التي تدخل منه العوامل الاجتماعية والاقتصادية والخلقية في النظام القانوني، كي تلاءم بينه وبين التطور الذي يتعرض له المجتمع في وقت واحد .

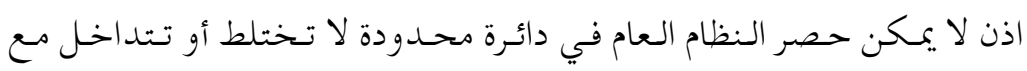
غيرها ذلك أن هذه الفكرة مرنة وتضييق و تتسع بحسب ظروف كل مجتمع . فلا

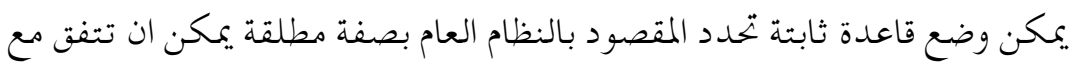
كل زمان ومكان . ومرد ذلك أنها فكرة مرنة وأنها مسألة نسبية، فالمصلحة العامة هي أساس فكرة النظام العام، هذا الأساس مـتغير بحسب مفهوم كل دولة ولة لفكرة المصلحة العامة ومصددرها بداية ونهاية.

\section{المقصرود بالآداب العامة}

الآداب في زمن معين ومـكان معين هي مجمموعة مـن القواعد و المبادئ وجـد الناس أنفسهم ملزمين بإتباعهام10 طبقا لناموس أدبي يسود علاقاتهم الاجتماعية،

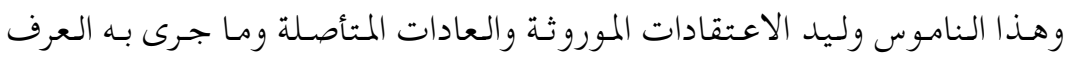
وتواتر الناس عليه ـ و يعتبر الديـن أهـم العوامل التي تـؤثر في الناموس الأدبي 11 للأمهة، يضاف إليه العرف و العادات والتقاليد التي يسير عليها المجتمع . ولمعرفة ما

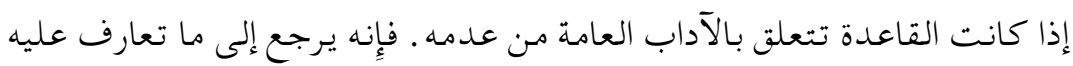

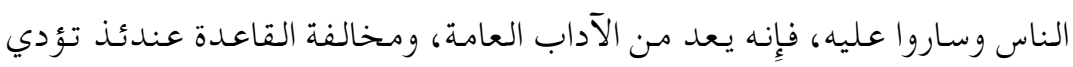
إلى جزاء البطلان . فالمعيار إذن معيار اجتماعي عام وليس معيار ذاتي خاص، وإن كان غير ثابـت بـل ومتتطور طبقا للبيئة الاجتماعية . فلو نظرنـا إلى أمـة مـن زمـن

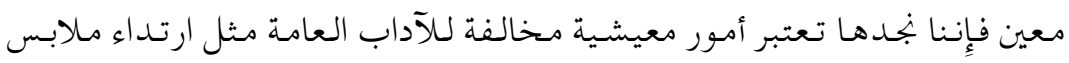


البحر على الشاطئ أو بيع الخمور في الأماكن العامة ولكن في فترة لاحقة ونظرا لحدوث تطور اجتماعي اصبحت هذه العادات لا تخالف الآداب العامة. ومما يجدر بنا قوله إن فكرة النظام العام تقوم على أساس معيار موضوعي وهو المصلحة العامة فمعيارها هو الناموس الأدبي وما تعارف عليه الناس وصار جزءا من أخلاقهم وهو أيضا معيار موضوعي غير ذاتي وإن كان المعيار سالف الذكر مـن المعايير النسبية التي أن صلحت لأمة فِإنها لا تصلح لأخرى، وقد يقال إن القاضي

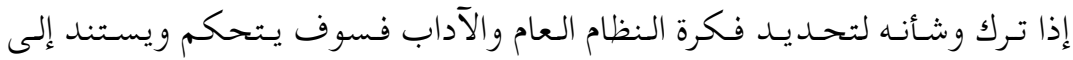
12 هـواه. لكـن الـرد عـلى ذلك يـنحصر في حسن اخـتيار القضاة وتعدد درجـات التقاضي ما يكفل درء هذه المخاوف أما عن فكرة النظام العام العالمي - فهي فكرة متسعة جدا لتحوي العالم أجمع بأنظمته الخختلفة ومصالحة المختلفة وتطلعاته والتي في كثير من الأحيان تصطدم مع الكيان الواحد المتمثل في الدولة والذي يختلف من زمن لآخر . فضلا عن غموض هذه الفكرة من ناحية أهدافها. فترى الأستاذ الدكتور مختار البريري 13 في مؤلفة التحكيم التجاري الدولي يقول : "أن القواعد الآمرة التي ببتغي بها المشرع حماية

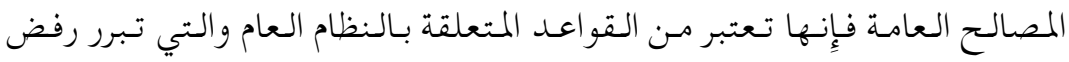
الاعتراف14 وتنفيذ الأحكام التي تصدر إخلالا بها .

ولا نجد مقبو لا محاولة افتعال تفرقة مصطنعة بين النظام العام الد اخلي والنظام العام الدولي في ميدان المعاملات الاقتصادية، فالنظام العام يصطبغ دائما بصبغة وطنية لا يصح تجاهلها تحت ستار فكرة غامضة -تتوسل بها الدول المتقدمة لإهدار مصالح الدول النامية . استنادا إلى عدم تعلق نصوصها الوطنية الآمرة بالنظام العام الدولي الذي يعلو على النظام العام الداخلي • ولن يتسنى القول بوجود نظام عام 
دولي حقيقي إلا عندما تتـلاشى هذه الهوة التي تفصل بين دول العالم المتقدم

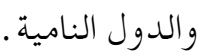

ونحن نصادق على هـذا القول ونعتقد أنه حتى بـعد تلاشي هـذه الهوة-

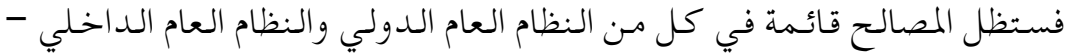

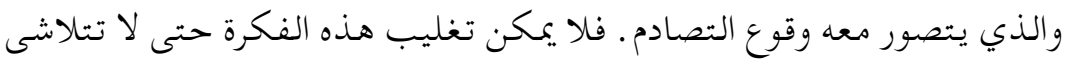
فكرة النظام العام الداخلي الذي تحدد هوية وكيان الدولة والذي يمكن تصوره هو التوازن بين الفكرتين في إطار يغلب فكرة النظام العام الداخلي عند اللزوم.

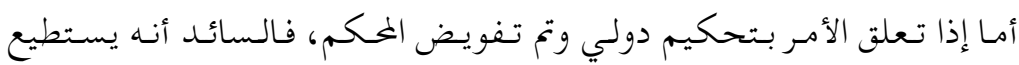
تجاهل القواعد الآمرة المتعلقة بالنظام العام الداخلي، ولا يقف امسامه سوى النظام العام الدولي وقد سبق بيان ان فكرة النظام العام هي بطبيعتها ذات طابع وطني،

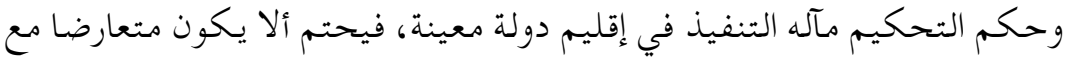

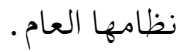
ولا يخفي تمايز وتغاير فكرة النظام العام 15 من دولة لأخرى، مما يضع فكرة نظام

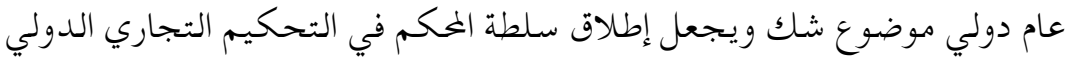

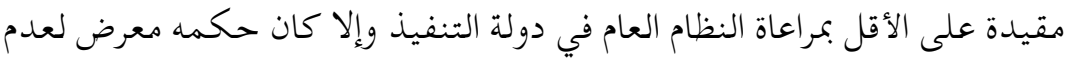
التنفيذ لمخالفته للنظام العام في مثل هذه الدولة. خصائص النظام العام في نطاق تنازع القو انين 1-متغير ونسبي:16 2-وطني: 3 -متنوعو قضائي :

\section{علاقة فكرة النظام العام وبطلان حكم التحكيم وتنفيذه}

تبرز فكرة النظام العام عندما تصطدم بحكم تحكيم يمس الأسس والمصالح

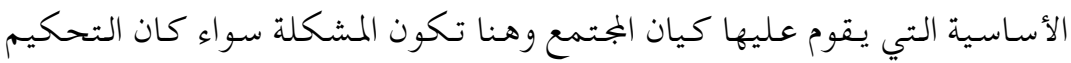


وطنيا أو اجنبيا - حيث يؤدي ذلك إلى منع تنفيذ حكم التحكيم كليا أو جزئيا أو يؤدي إلى عرقلة الوصول إلى الغاية التي تبتغيها الأطراف وهي اللجوء الى الى التحكيم كطريق أسرع لحل المنازعات. أول من استعمل فكرة النظام العام كأداة لاستبعاد القانون الأجنبي هو الفقيه الفيه

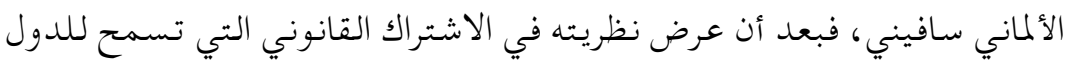
الأوروبية بتطبيق قوانين بعضها البعض، أشار إلى استثناء هام خول بموجبه لقاضي

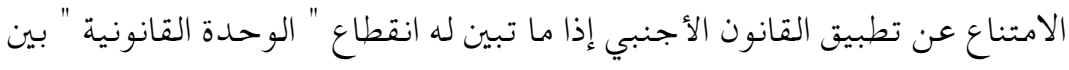
قانونه والقانون الأجنبي الختصص.

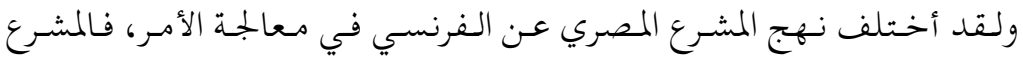

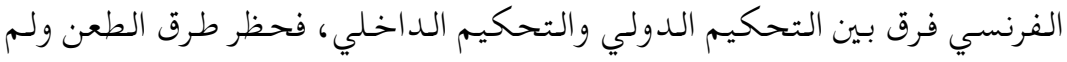

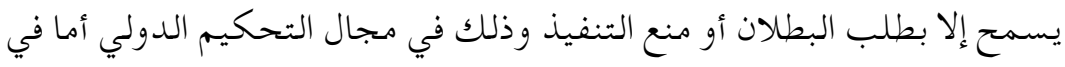

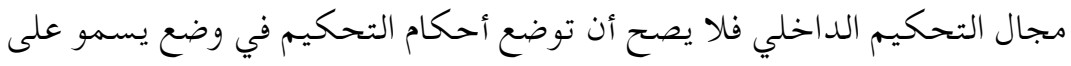

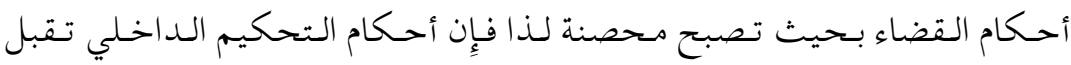
الطعن بالاستئناف أو كان المكمم مفوضا بالحكم وفقا لقواعد العدالة والأنصاف 17

\section{3 عدم تعارض الحكم الأجنبي مع النظام العام في الجزائر}

التزم المشرع الجزائري 18 السكوت عن تعريف النظام العام، واكتفى بالإشارة

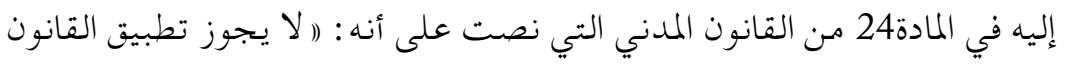

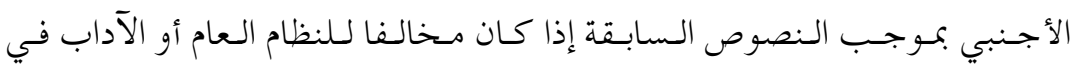
الجزائر ) . أما مهمة تحديد مفهومه فتركها المشرع للقاضي المطروح أمامه النزاع.

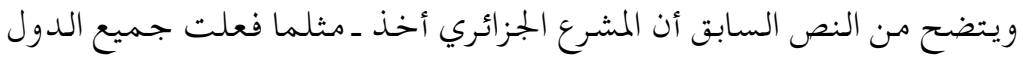
التي تطبق نظام الأمر بالتنفيذ ــشرط (اعدم مخالفة القانون الأجنبي لنظامها العام

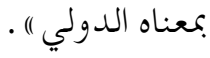


وهذا الشـرط الذي يطبق على القانون الأجنبي هو نفسه يطبق على الحهم

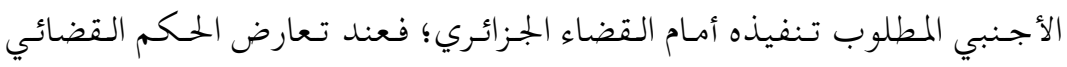

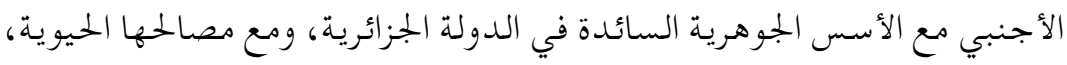
يمتنع القاضي الجزائري عن إصدار الأمر بتنفيذه الحسه

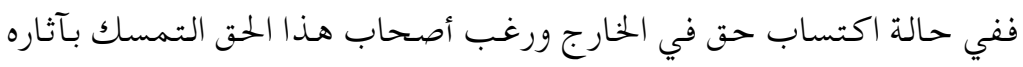

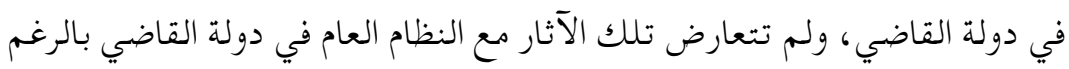
من تعارض نشوء ذلك الحق أو المركز القانوني مع ذلك ذلك النظام العام ـ فِإنه يـجوز

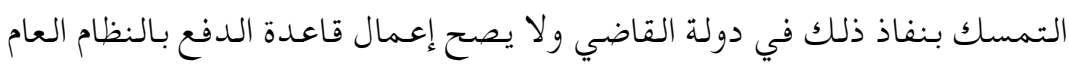

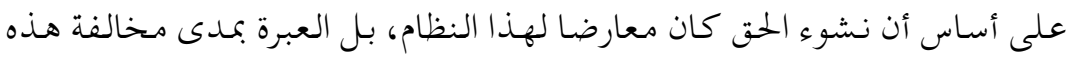

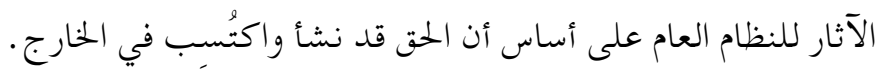

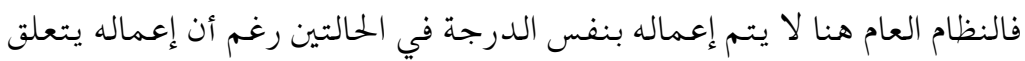

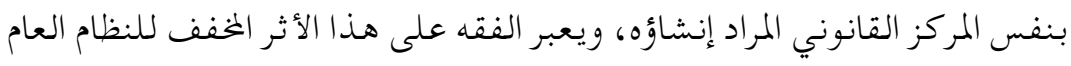

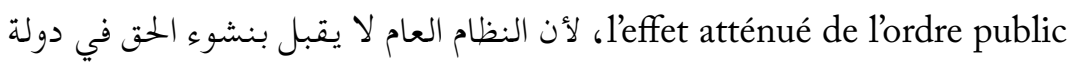

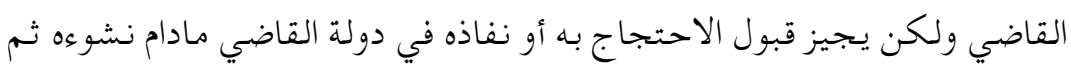

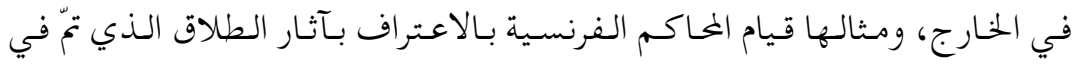

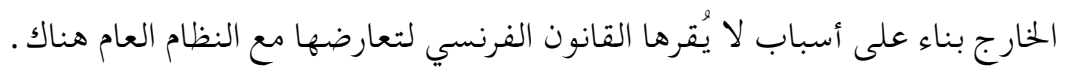

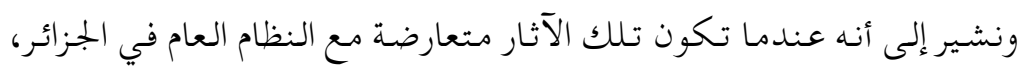

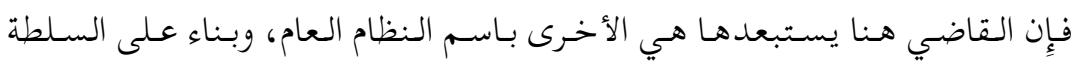

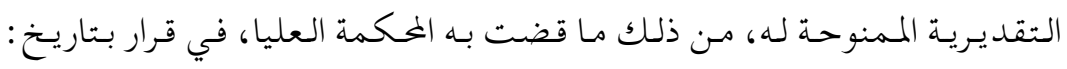

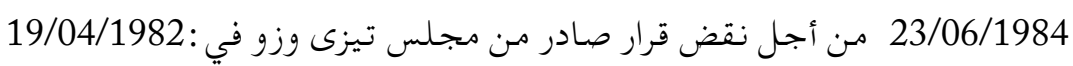

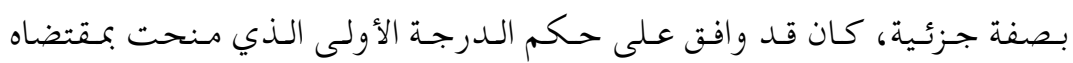

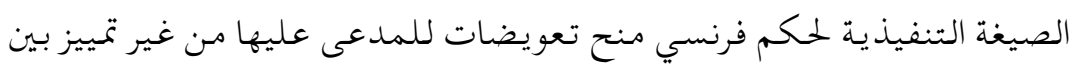


التعويض المستحق عن أصل الحق المطالب به طبقا لاتفاق الطرفين، ومبلغ الفائدة المتفق عليها بنسبة معينة، رغم جوازها في القانون الأجنبي المختص، لكنها مخالفة للنظام العام في الجزائر بنص المادة453 ق مدني 19. لهـذا عمددت المعكمة العليا إلى نقض القرار المطعون فيه جـزئيا فيما يـتعلق

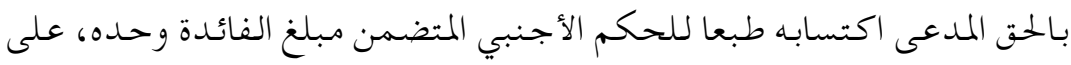
أساس أن تنفيذ الحكم الأجنبي بهذا الشكل في الجزائر يخالف النظام العام فيها فيما يـعلق بهـذا المسألة وما تجـدر الإِشارة إليه في آخر هـذا الفرع أن هـناك فكرة أحرى لها علاقة بهذا الحالة الأخيرة وتتمثل في حالة نشوء حق في دولة أجنبية

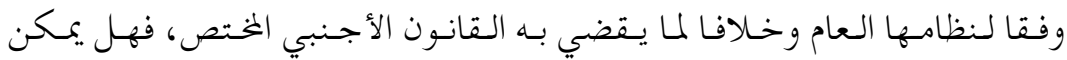
الاحتجاج بسـريـان هـذا الحـق في دولة القاضي؟ حسيث وبـالاستـناد الى أن فكرة النظام العام فكرة وطنية وبالتالي فقانون الدولة الذي يطبق إعمالا لفكرة النظام العام لا يسـري أثره إلى إقليم دولة أخرى، حستى ولو كان مفهوم النظام العام في كلتيهما غير مختلف ، إلا أن الراجـح فقها هو التمييز بين حالة كون النظام العام للدولة الأجنبية متطابقا مع النظام العام في دولة القاضي، و الحالة التي لا يكون فيها متطابقا معده20 حيث يمـكن التمسك بآثار ذلك الحق المكتسبب في دولهة أجـنبية طالما وافق نظامها العام رغم تعارضه مع ما يقضي به القانون الأجنبي الآخر الختتص، ولنضرب

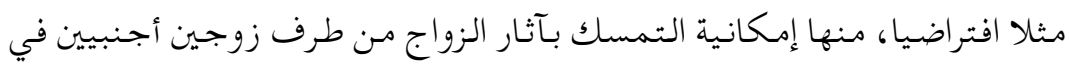
فرنسا من خلال زواجهما الذي تم وفقا لمقتضيات النظام العام الإِيطالي والتي . هي نفسها في فرنسا، حيث أن القانون المختص أصلا لتنظيم هذا الزواج وهو قانون جنسية الزوجين الأجنبيين قد أستبعد من تنظيم هذه العلاقة لمخالفته النظام العام في إيطاليا لأن قانونهما لا يسمح مثلا بالزواج بين مختلفي اللون أو الديانة. 
- أما في حالة عدم تطابق مقتضيات النظام العام لدولة القاضي مع مقتضيات النظام العام للدولة التي أكتسب فيها ذلك الحقى، فِانه لا يججوز هنا التمسك بآثار ذلك الحق في دولة القاضي والمكتسب في لخارج، ويعبَّر عن الأثر المشار إليه سلفا

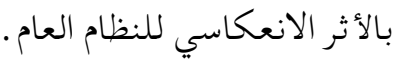

\section{بعض الاتفاقيات التي تناولت النظام العام}

فقد نصـت اتفاقية الرياض العربية على هذا الشرط بالنسبة للدولة المتعاقدة المطلوب منها تنفيذ الحهم الصادر عن دولة متعاقدة أخرى، بل وأضافت بأن لا يكون الحكم الأجنبي مخالفا أيضا للشريعة الإِسلامية أو أحكام الدستور . كما نصت الاتفاقية الثنائية لتنفيذ الأحكام بين الجزائر وفرنسا لعام1964م أن من شروط حيازة الحكم الصادر من إحدى الدولتين لقوة القضية المقضي بها في بلد الدولة الأخرى، ألا يتضمن القرار ما يخالف النظام العام الخاص بالدولة المنوط بها تنفيذ القرار، أو لمبادئ الحقوق العمومية المطبقة في تلك الدولة. النظام العام ومضمون الحكمى الأجنبي ( الحليم، 2014) لم يقدم المشرع الجزائري سواء في القانون رقم(66/157)22 أو القانون(208 09) المتضمن قانون الإِجراءات المدنية والإِدارية الجمديد بتعريف الاعتراف بأحكام التحكيم الأجنبية، لكنه قام فقط بتبيان أهم الشروط الواجب توافرها حتى يعترف بها، وعليه نصت المادة1051 من قانون(08/09) على أنه ":يتم الاعتراف بأحكام التحكيم الدولي في الجزائر إذا أثبت من تمسك بها وجودها، وكان هذا الاعتراف غير مخالف للنظام العام الدولي .

وتعتبر قابلة للتنفيذ في الجزائر وبنفس الشروط، بأمر صادر عن رئيس المحكمة 
أحكام التحكيم في دائرة اختصاصها أو محكمة محل التنفيذ إذا كان مقر كإ محكمة التحكيم موجودا خارج الإقليم الوطني" ، كما نصت كذلك المادة 1052 من نفس القانون على ما يلي " :يثبت حكم التحكيم بتقديم الأصل مرفقا باتفاقية التحكيم أو بنسخ عنهما، تستوفي شروط صحتها" ، والمادة 1053 بقولها: "تودع الوثائق المذكورة في المادة 1052 أعلاه، بأمانة ضبط الجهة القضائية المختصة من الطرف المعني بالتعجيل.

وعليه يخضع الاعتراف بأحكام التحكيم الدولية في الجزائر إلى مدى توفر مجموعة شروط هي : مجي 01 -ضـرورة قيام المتمسك بأحكام التحكيم الدولية بِِتبات صحة وجودها حسب الكيفية التي حددتها ال مادة 1052، وفي هذه الحالة يجب على المعني أو

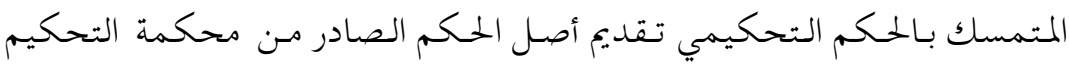

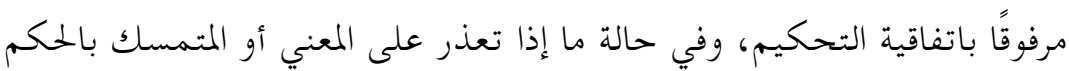
تقديم الأصل، فانه يجوز له الاقتصار على نسخة من كليهما تستوفيان صحتهما، وتودع مباشرة بأمانة ضبط الجهة القضائية المختصة من طرف الذي يهمه التعجيل . 02 - أن يكون الاعتراف الممنوح لهذه الأحكام غير مخالف للنظام العام الدولي 23، وتعتبر قابلة للتنفيذ في الجزائر وبنفس الشروط في حدود دائرة اختصاص المكمة التي أصدرت الحلكم، أو من رئيس محكمة محل التنفيذ في حالة ما إذا كان الحكمى قد صدر في خارج التراب الوطني. إن فكرة النظام العام في إطارها الـدولي تحول دون تـنفيذ الحـكم الأجـنبي إذا كان مضمونه يتعارض مع المبادئ والمثل السائدة في الدولة المطلوب تنفيذ الحكم 
وبناء على ذلك لا يججوز تنفيذ الحكم الأجنبي إذا تضمن مثلا تجسيدا لفكرة

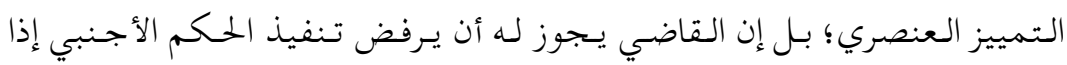

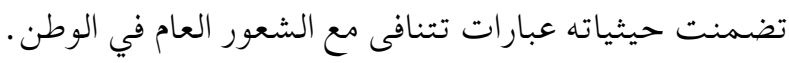

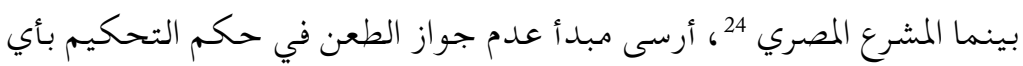

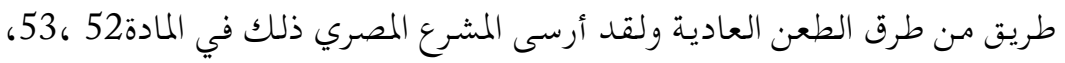

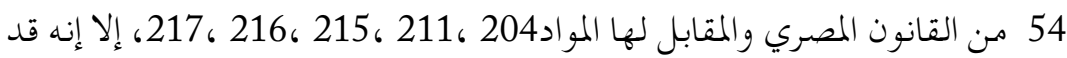

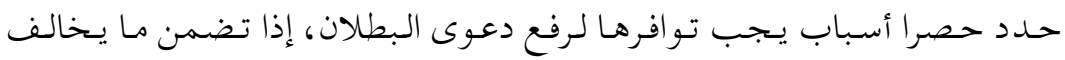
النظام العام في مصر.

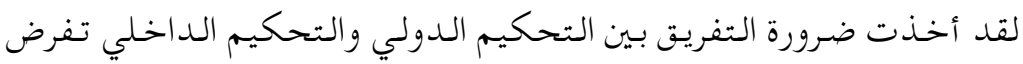

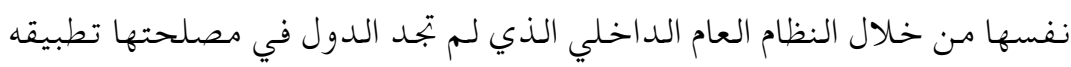

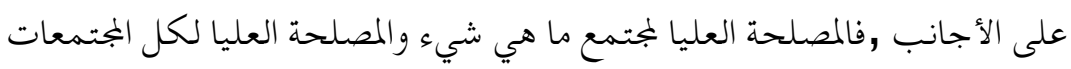
الدولية في العالم شيء آخر.

فالنظام العام الدولي أبو ابه عريضة ونو الخر افذه مشرعة وهو يترفع عن نسبية المكان

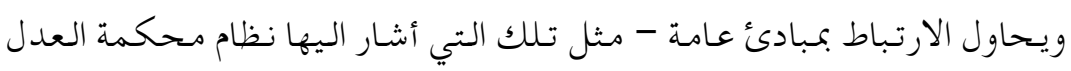

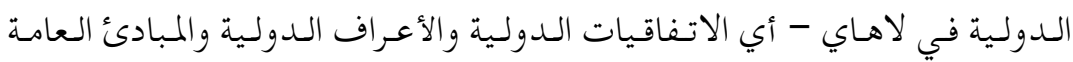

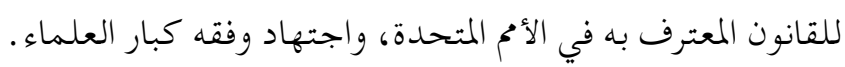

\section{4 أثر النظام العام على الدفع بعدم تنفيذ أحكام الخاكم الدولية}

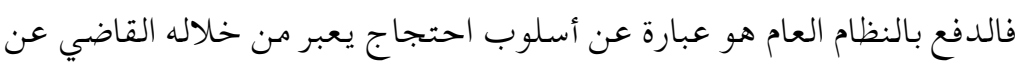

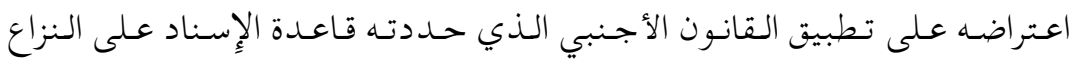

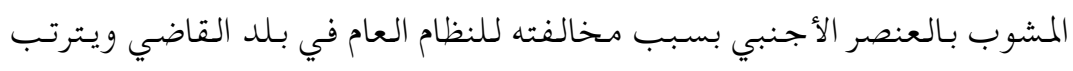

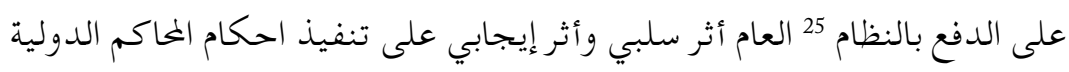
أولا : الأثر السلبي . استبعاد تنفيذ الحكم التحكيمي الدولي 
يترتب على اعمال الدفع بالنظام العام أثر سلبي يقتضي استبعاد تنفيذ الحكم الأجـنبي المتعارض وفقا لقانون القاضي الوطني مع النظام العام، ولإعـمال الدفع بالنظام العام يقتضي عدم السماح للحكم الدولي بالاندماج في النظام القانوني الوطني بسبب التضاد الحاصل بين الحكم الأجنبي والنظام العام الوطني.

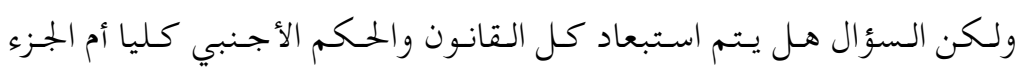
الخخالف لقواعد النظام العام في بلد القاضي ـ ؟؟ هناك رأيين في الفقه.

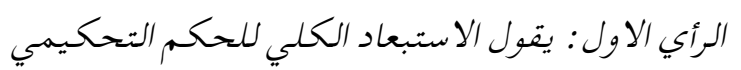
على أساس أن تجزئة الحلكم الأجنبي يؤدي من جهة إلى تطبيقه بشكل مخالف

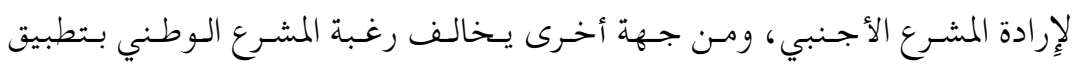
القانون الأجنبي المحدد في قاعدة الإِسناد بشكل كامل . الرأي الثاني: يقول الاستبعاد الجنئي للقانون الأجنبي (الرأي الراجح) يعني استبعاد ذلك الجزء من القانون الأجنبي الذي يتعارض مع النظام العام في بلد القاضي، وتطبيق الجزء الأخر طالما لا يتعارض مع النظام العام في دولته. ثانيًا : الأثر الإِيجابي . تطبيق قانون القاضي الجيقي

ويعني أنه في حالة استبعاد القانون الأجنبي أو الجزء الخخالف منه، يقوم القاضي

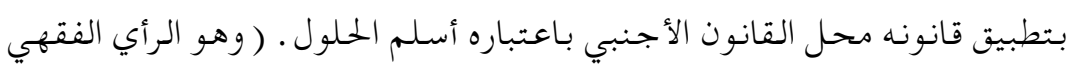
الغالب المعمول به في غالبية الدول )

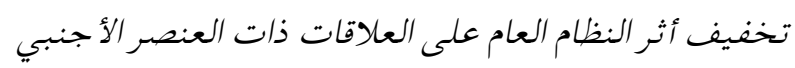
ان التساؤل الذي يطرح دائما نفسه ما الموقف إذا حدث تعارض بارك بين قاعدة آمرة واجبة الإتباع وتحقق الاستقرار القضائي مع حكم تحكيم لا يتضمن إخلالا بالنظام

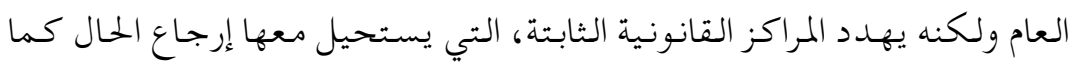


كـان عـليه؟؟! وواقع الأمـر أن الاسـتقرار التشــيـعي يـتطلب مــاصـرة الاتجـاه الـذي يقضي بالموائمة بينها كـما يـبنغي لـلمحاكــم دات الـبعد الإِسـلامسي انـطلاقـا مـن مـبادئ الشـريـعة الإِسـلامسية وكـلما تـعلق الأمـر بـطرف مسـلم أن تـقرر العزوف عـن تطبيق قانون

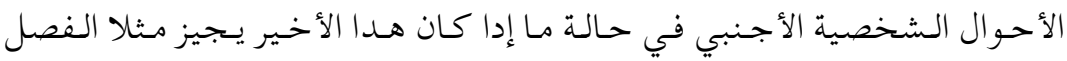
الجسماني بين الزوجين 26. فمسائل الأحهوال الشخصية من أخصب المسائل التي يستبعد فيها القانون الأجنبي الواجب التطبيق نتيجة استخدام تقنية النظام27 سواء في قضايا الزواج أو الطلاق أو الميراث ا واثبات النسب وهدا يرجع إلى أن تلك المسائل يرتكز تنظيمها أساسـا على المفاهيم الـدينية و الأخلاقية أما المسائل الأخرى كمسائل الأحوال العينية و العقود و الوقائع القانونية فلا يثار النظام العام إلا 28 نادرا 29. للذلك فبإن عـددا مـن أحسكام التتحكيم التي صـدرت في إطـار نظام التحكيم التابع لغرفة التجارة الـدولية قـد قضى بـصحة شروط الضمان ضـد تقلبات سعر الصرف، وإن كان ذلك قد جاء بطريقة ضـمنية، الأمر الذي يكشف كما يقول الأسـتاذ جـولـدمـان عـن اتجـاه قضاء الـتحكيم إلى اعـتبار قـاعـدة " العقد شـريسعة المتعاقديـن" مـن النظام العام الـدولي، بمـا يـنيه ذلك مـن ضـرورة إعمال الشـروط العقدية وتغليبها على الأحكام الآمرة المخالفة في قانون الدولة الواجـب التطبيق على العقد وأيـا كانـت تطبيقات قضاء التحكيم" لمفهوم النظام العام الدولي، فِإن الذي يـعنينا هـنا التأكيد عـليه هـو أولا أن مفهوم النظام العام الـدولي لا يستقيم إلا إذا اعترفنا مقدما بوجود قانون التجارة الدولية كنسق قانوني مستقل وبوجود قضاء

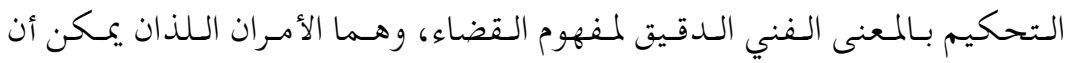


يوفرهما مجرد وجود تشريع وطني خاص بـالتحكيم يعترف بشرعيته ويكرسه

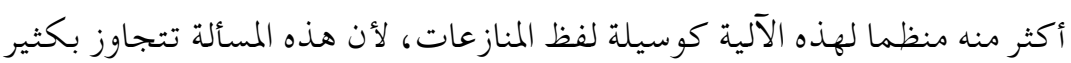

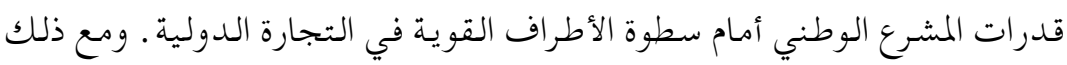
فحتى لو قبلنا كل مسلمات نظريـة قانون التجارة الدولية فمن الصعب القبول

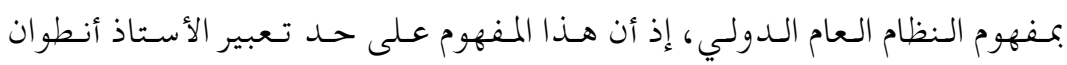
كاسيس "هو مفهوم مستحيل 31 (concepto imposible) إذ أنه يقوم ابتداء وانتهاء على تناقض منطقي يستحيل تجاوزه. ويقول إن أي قراءة متأنية لكتابـات فقهاء القانون التجاري الدولي مـن أنصار هذه النظرية Lex. Mercataria تبين لنا أن هؤلاء الفقهاء يعترفون بأنه أيا كانت درجة اكتمال هذا التنسيق القانوني الدولي فِِان هـناك من القضايا المرتبطة بعقود التجارة الدولية التي مازال تنظيمها يخضع لقانون الدولة، مثل مسائل الأهـلية وعيوب الرضا . وبعبارة أخرى فِإن تدويل النظام القانوني لعقود التجارة الدولية ليس كـامـلا، إذ أن قـانون الـتجارة الـدولية لا يـحكمى في نهـايـة الأمـر إلا المسائـل المتعلقة بتفسير و تنفيذ عقود التجارة الدولية، ونحن نعرف جيدا أن أحكام قانون التجارة الدولية كلها ذات أصل تعاقدي، فهي نتاج ممارسات أطراف عقود التجارة

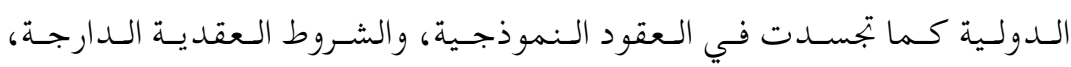
والأشكال العقدية الجديدة، خاصة منها تلك المركبة أو التوليفات العقدية. " وبناء عليه لم يكن غريبا أن يكون المبدأ الأساسي الذي يشكل المحور 32 الذي ترتكز عليه كل أحسكام هـا النسق القانوني هو مبدأ العقد شريعة المتعاقدين .

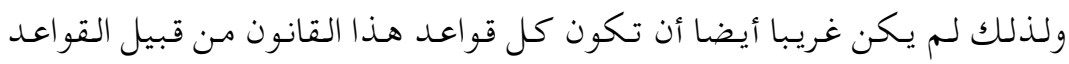
المكملة لإِرادة أطراف العقد، فلا يمكـن لهذه القواعد أن تستبعد نصا في العقد الدولي، فالعبرة أولا بأحكام العقد ولو خالفت قواعد قانون التجارة الدولية . 
بو اسطة أشخاص ( محكمين) 33 خـارج إطلار السلطة القضائية المفوضـة أصلاً بفصل المنازعات ، مما يؤدي بالنتيجة إلى إكساء التحكيم صفة قانونية لاعتباره وسيلة ناجعة لفض المنازعات ـ وبخلاف ذلك يفقد التحكيم كافة ميزاته ويصبح مجرد إضاعة للوقت والجهد والمال. لهـذا التجهت الجهـود على المستوى الدولي إلى إيـجاد وسائل قانونية واتفاقية

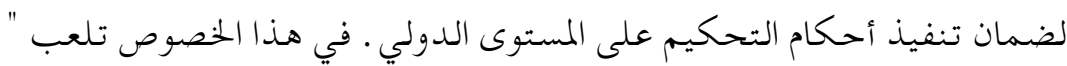
اتفاقية نـيويـورك الخـاصـة بـالاعتراف وتـنفيذ أحسكام التحكيم الأجـنبية "1958

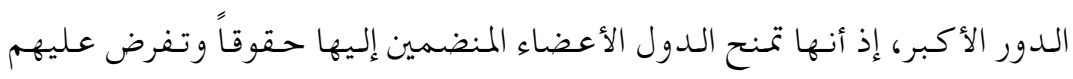
التزامات من خلال نصوص الاتفاقية الواجبة التطبيق في تلك الدول.

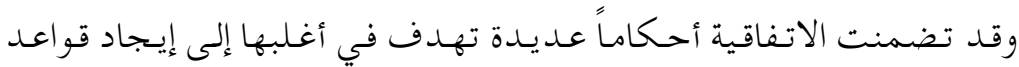
وتعريفات موحسدة لتحكمى عملية الاعتراف بـاتفاقات التحكيم الجماريـة الدولية وتنفيذ أحكام التحكيم الأجنبية ولأن مبدأ النظام العام هو مـبدأ مـرن يصعب ضـبطه 34 وتحديد نطاقه، حيث يمكن تفسيره بطرق عديدة تشمل المسائل ذات الصلة بالإجراءات التي تم اتباعها أثناء نظر النزاع أمام هيئة التحكيم بالإضافة للمسائل التي تتعلق بموضوع النزاع،

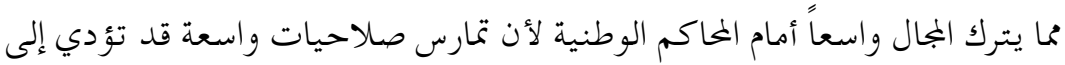

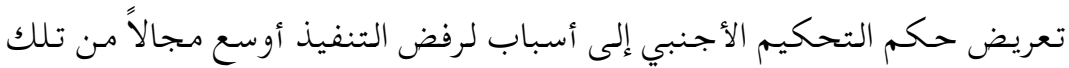

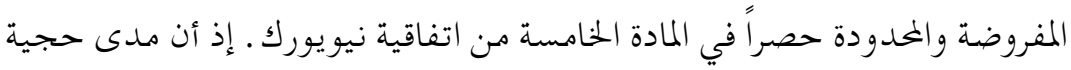
استخدام مبدأ النظام العام كسبب لرفض تنفيذ حكم التحكيم الأجـنبي يعتمد في النهاية على السلطات التقديرية الواسعة التي تتمتع بها المحاكم الوطنية عند تعريفها وتفسيرها لهذا المبدأ وتحديد نطاق تطبيقه وذلك وفقاً لظروف كل حالة. 


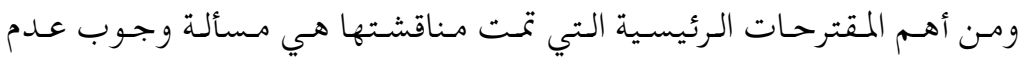
التوسع في تفسير المادة5 /2 فقرة ( ب ) من اتفاقية نيويوركك35 وذلك من خلال تـضيق نـطاق تطبيق المبادئ المعتبرة مسن الـنظام الـعام في الـدولـة المطلوب مـنها التنفيذ، بالإضافة للتفرقة الواجب أخذها بعين الاعتبار بين ما يسمى بمبدأ النظام العام الدولي وبين قواعـد النظام العام الداخلية أو الوطنية الخـاصـة بـدولة معينة. (الأنجلوسكسوني )

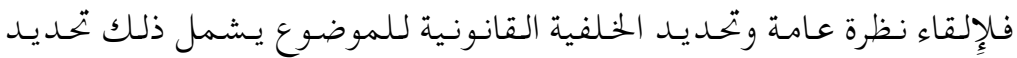

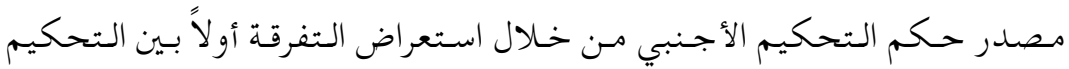
التجاري الوطني وبـين التحكيم التجاري الـدولي ثـم توضسيح الفرق بـين أحسكام التحكيم الوطنية والأجنبية وطرق تنفيذها والقواعد التي تحكم الأسباب الموجبة لـرفض تـنفيذ مـثل هـذه الأحـكام، ويسناقـش هـذا الفضصل وجـوب مـعامـلة أحسكام التحكيم الأجـنبية معامـلة أكثر مـرونـة عـنها في الأحسكام الوطنية وذلك بسـبـب طبيعة عمليات التحكيم التجاري الدولي الذي ترتبط عـناصـره بأكثر مـن دولـة واحدة. تنبع أهمية هذه المسألة من واجـب والتزام المحكم 37 ببذل كل الجههود اللازمة

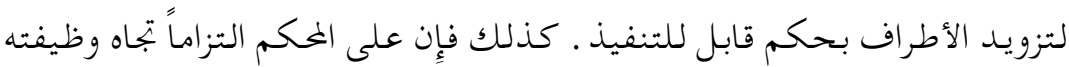
كمحكمم تجاري دولي . فلكي يـتمتع التحكيم التجاري الدولي بـفعالية واحترام للأحكام الصادرة في منازعات التجارة الدولية، لا بـد من أن يأخذ المكممين بعين

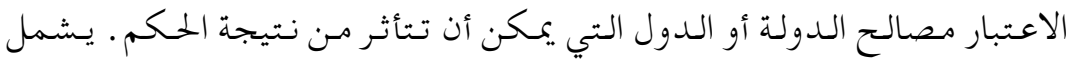
ذلك مـراعاة قواعد النظام العام لقانون الـدولة التي صـدر فيها حـكم التحكيم، والنظام العام للدولة التي سيتم فيها تنفيذ الجزء الرئيسي من العقد محل النزاع،

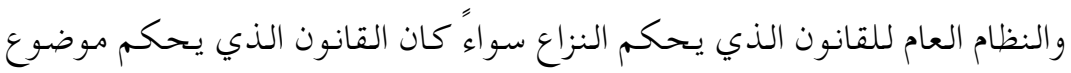


النزاع أو الإجراءات، بالإضـافة لاحترام قواعد النظام العام للدولة التي سيطلب فيها تنفيذ حكم التحكيم إذا كان تحديد تلك الدولة ممكناً خلال إجراءات التحكيم . مما يؤدي بـالنتيجة إلى زيـادة فرصة تنفيذ حـكم التحكيم في الدول الأخرى التي ستتعامل مع الحلكم بصفته الأجنبية 38. إن نضرة تحـليلية على المادة 5 /2/ ب المتعلقة بـرفض تـنفيذ حكـم التحكيم الأجنبي لمخالفته للنظام العام في الدولة المطلوب منها تنفيذ ذلك الحكىم بصفته حكم تحكيم أجنبي 39 . توضح أن مسألة تطبيق قواعد النظام العام من حيث احتمالية رفض تنفيذ

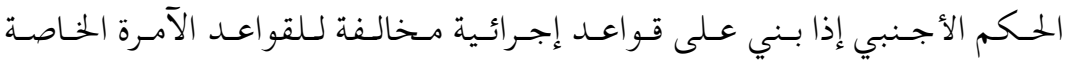
بالإِجراءات الواجب اتباعها في دولة التنفيذ .

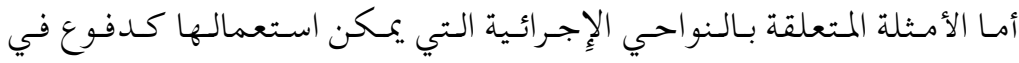
مواجهة التنفيذ . أما الحالات التي يمكن اعتمادها للادعاء بمخالفة حكم التحكيم 40 من الناحية الموضوعية للنظام العام وذلك بـخصوص المسائل المرتبطة بموضوع النزاع • ومن الأمثلة التي تمت دراستها : أولاً: مخالفة حكم التحكيم الأجنبي للمبادئ الأخلاقية 41 المستقرة في دولة التنفيذ(cuestiones morales) حيث يحيط هـذه المسألة مسشاكل عديـدة، فمن ناحية بجد أن المبادئ الأخلاقية متباينة تختلف من مكان لآخر ومن ناحية أخرى سيكون من الصعب على محكمة التنفيذ أن تحدد مدى مخالفة الحلكم الأجنبي لقواعـد الأخلاق المتعلقة بـدولة أخرى حتى وإن كانت ذات صـلة وثيقة بموضوع النزاع. ثـانياً: مـخالـفة حـكم الـتحكيم الأجـنبي لـلـهج السـياسي لـدولـة الـتنفيذ ويـحيط بهـذه المسألمة موضسوعات في غـايـة مـن الأهمية (cuestiones politicas) 
والحساسية إذ أنها ترتبط بسياسة الدولة وعالاقاتها بغيرها من الدول . فقد تجد محكمة التنفيذ بأن تنفيذ حكم التحكيم الأجنبي قد يؤدي إلى تهديد مصالح الدولة السياسية وعلاقاتها مع الدول الصديقة . مثل : وجود حالة حرب، الاتجار مع الأعداء أو الأموال التي يتـم الاتفاق على دفعها للعمليات الإرهابية وغيرها. ويركز هـذا الموضوع على مسألة قرارات المقاطعة التي تصدر بـقرار سياسي مـن الدولة بحيث تؤثر على العلاقات التجارية القائمة بين أطراف التجارة الدولية .

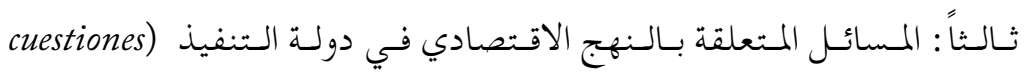
(económicas ، فالتقسيم الدارج للسياسات الاقتصادية يميز بشكل عام بين سياسة السوق المفتوحسة وبـين سـياسـة الـباب المغلق، حسيث يـؤدي اخـتلاف السـياسـات

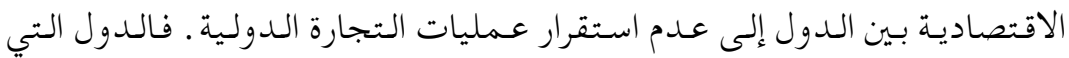
تنتهج سياسة الباب المغلق قد تفرض على إرادة أطراف عقود التجارة الدولية قيوداً عديدة بحجة وجود العديد من النشاطات الاقتصادية التي يمكـن أن تؤثر سلبياً عـلى الـنهج الاقـتصادي المتبع في تـلك الـدولـة، وبـالـتالي رفض تــفيذ أحـكام

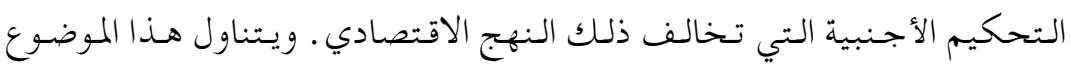
بشيء من التفصيل المشاكل التي قد تواجه تنفيذ أحكام التحكيم المتعلقة ببعض

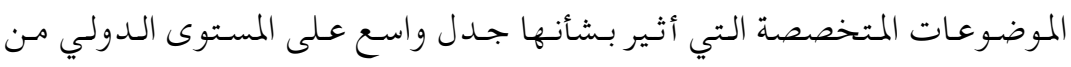
حيث قابليتها للتحكيم. وبـالـتالي إمـكانسية تـنفيذ أحسكام الـتحكيم الأجـنبية الـتي تـفصل بمـثل هـذه

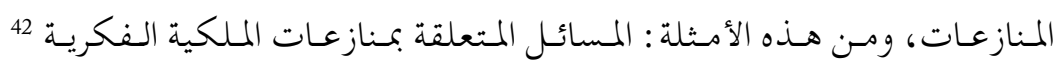
pago de) (derechos de propiedad intelectual)

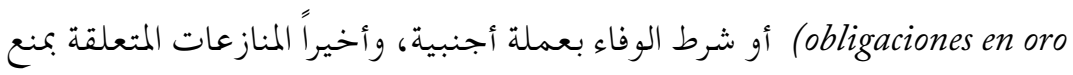
ال منافسة / anti-trust 
وجميع هذه الأمثلة تشرح أسباب المشاكل المرتبطة بضرورة سيطرة الدولة على النهج الاقتصادي المتبع فيها ومدى حدود تلك الحماية عند تطبيقها على أحكام التحكيم الأجنبية لمنع مخالفتها للمصالح الاقتصادية العليا في الدولة.

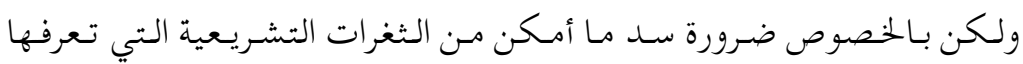
مواضـيع التتجارة الـدولية بشـتى افرعها حستى لا تظل مـرتعا لاجـتهاد لـيس أهـل القانون الخختصين وإنما اصحاب المصالح الكبرى فيها. اذن يـجب الوضع في الاعتبار الموازنـة بين اعتبارات صسيانـة قيم المجـمع وآدابـه وبين اعتبارات نمو التجارة الدولية والداخلية وازدهارها، وأنه يـجب في ظل مرونة فكرة النظام العام ونسـبتها أن تكون هـناك ضـوابط أو معايير محـددة تضع هـذه الفكرة الهلامية في إطار انضباطي، ويمكن ان يضع هذا الإِطار أما محكمة النقض

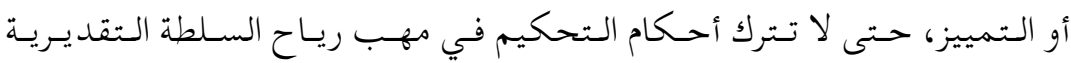
لقاضي الموضوع او قاضي التنفيذ . ونوصي أيضا بأن يـتم الفصل بين التحكيم الداخلي والتحكيم الخارجي وضع قواعد خاصة لكل منهما تتفق وطبيعتها.

\section{5 والاستثناءات العامةكدفع بعدم الامتثال في أحكام محاكم التجارة الدولية} ان الدخول في التجارة الدولي والتوقيع على اتفاقيات تحريـر التجارة العالمية يـفرض عـدة الـتزامـات وكـذا أحسكام وقرارات تـوجـب التنفيذ عـل المخاطبين بـها كالسماح بالإنفاذ للأسوق وتحرير التجارة .

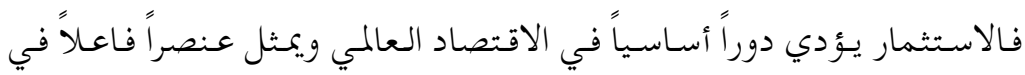
تـنمية دول العالمب، وبـخاصـة تـلك التي يـتيح لـها فرص الوصـول إلى رؤوس المال والتكنولوجيا والمعرفة والانفتاح على الأسواق العالمية وحل مشكلة البطالة. ولكن لا يمكن أن يتحقق الدور الفاعل للاستثمار الدولي، على مستوى الواقع إلا بضمان احترام معاملته . فجل معاهدات الاستثمار تضمن هذا الاحترام، وذلك 
بتخصيصها لنوعية مميزة من المعاملات التي يحظى بها المستثمر الأجنبي سواء

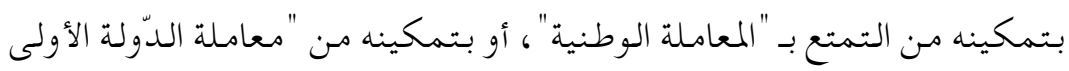

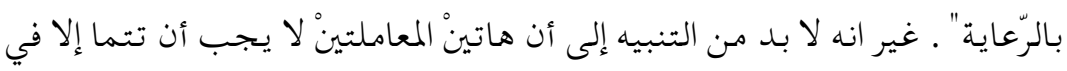
ظل الاحترام الذي يفرضه معيار المعاملة العادلة والمنصفة.

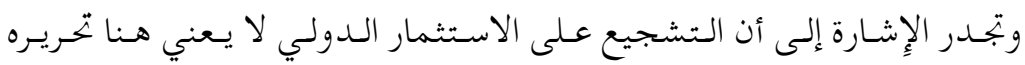

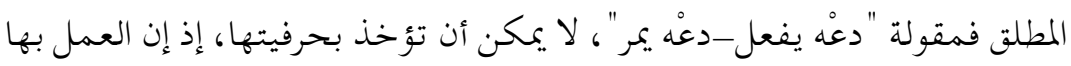

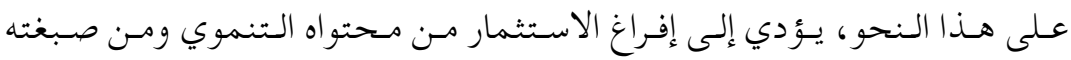

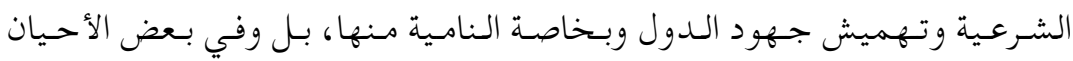

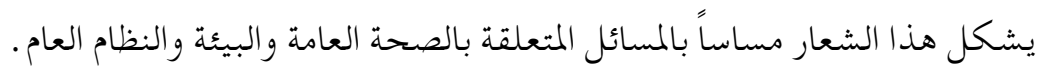

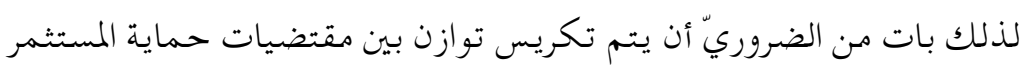

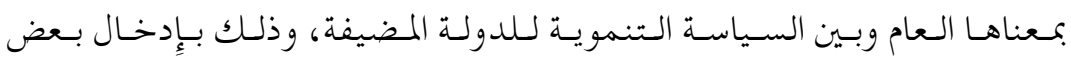

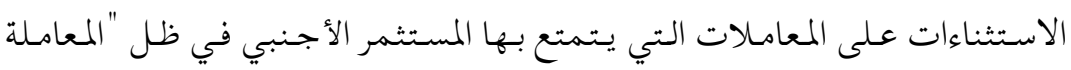
الوطنية" أو "معاملة الدولة الأولى بالرعاية. و كما هو معروف يجب على أعضاء منظمة التجارة العالمية احترام العديد من الالتزامات العامة بموجب 43 الاتفاق العام بشأن التعريفات الجمركية والتجارة لعام 1994 ( اللغات1994 ) . مبدأ الدولة الأكثر رعاية (شرط الدولة الأكثر رعاية) 44

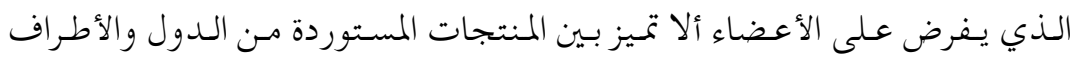

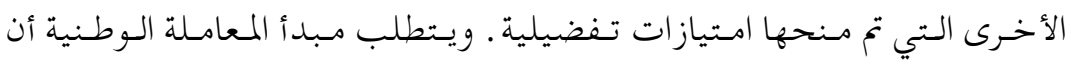

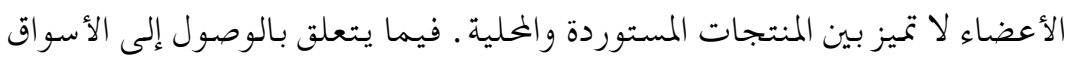

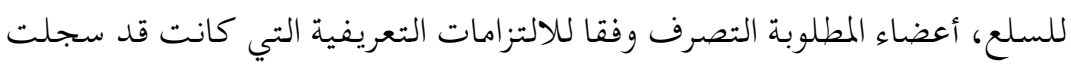

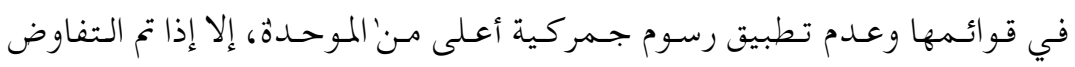


بشأنها ـ وبإٍافة إلى ذلك، فالأعضاء عموما لا يسمحون بفرض قيود كمية على الوصول إلى الأسو اق وعلى السلع.

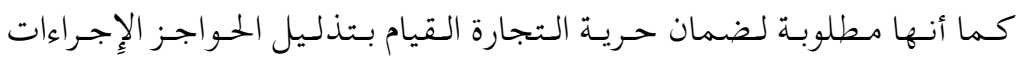
الجمركية وغير الجمركية أي عقبات التي تعترض التجارة.

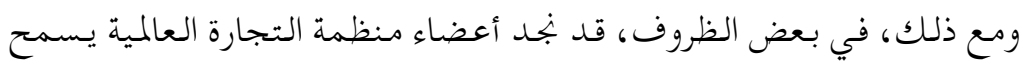

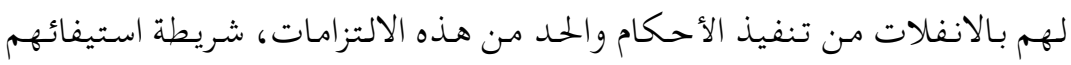

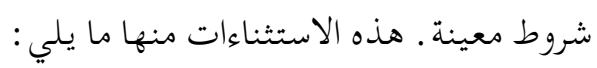

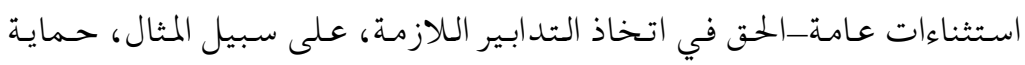

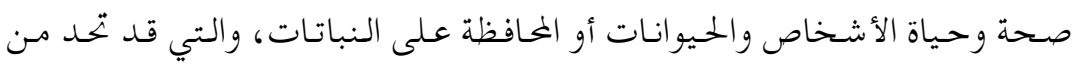

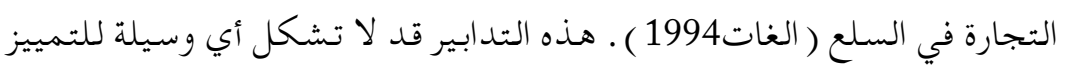

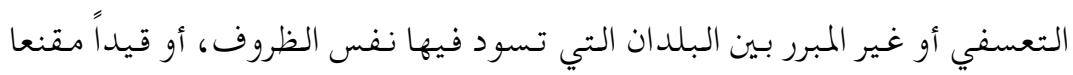

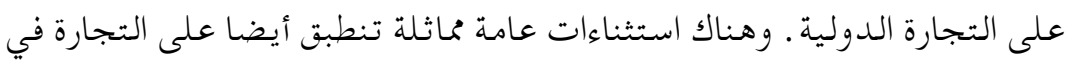

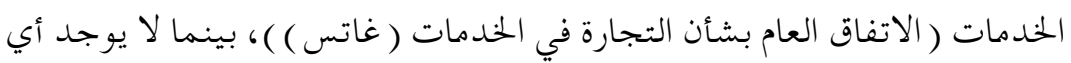

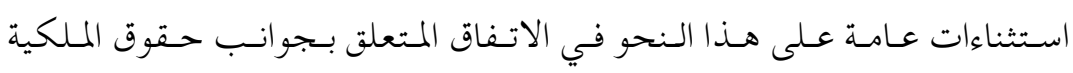

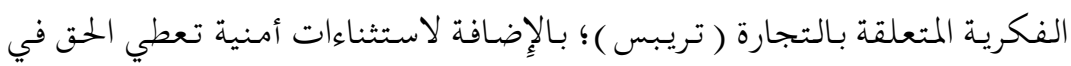

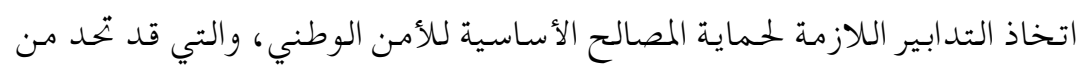

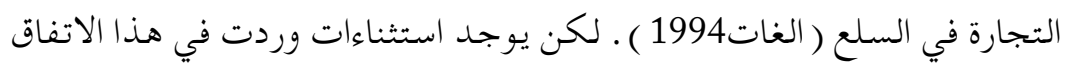

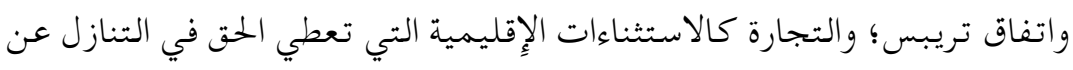

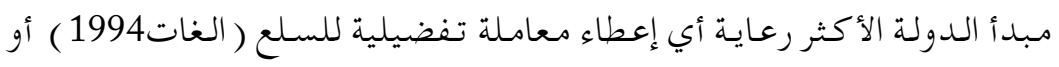

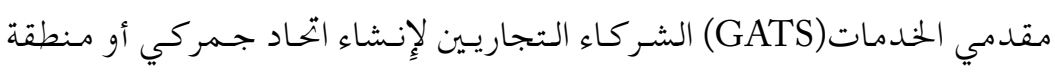
تجارة حرة دون إعطاء هذا الامتياز لجميع أعضاء منظمة التجارة العالمية؛ 
إن العلاقة بـين أحـكام الاستثناء في الاتفاق العام بشأن التعريـفات الجمركية و التجارة واتفاق غات وبين الاتفاقات الأخرى المتعددة الأطراف المتعلقة بـتجارة السلع، غير واضحة. فالمادة • ب تـنص على "ألا يفسر أي شيء في هــا الاتفاق لمنع أي طرف في الاتفاق مـن اعتماد أو إنفاذ التدابير الضروريـة مـن أجل حماية الأخلاق العامة "، ، وما إلى ذلك ـ بـيد أن الاتفاقات المتعددة الأطراف المتعلقة بتجارة السـلع تـنص على ما يلي : "إذا كان هناك تنازع بين حكم من أحكام الاتفاق . العام بشأن التعريفات الجمركية والتجارة لسنة1994وحكمم مـ أحكام اتفاق آخر مـدرج في المرفق ألف لاتفاق إنشاء مـنظمة التجارة العالمية ( المحال إليه في الاتفاقات في المرفق1 ألف بعبارة "اتفاق . منظمة التجارة العالمية ")، فِإن حسمى الاتفاق الآخر يسري في حالة التنازع هذه " . وبالتالي فِإن قابلية تطبيق أحكام الاستثناءات العامة على الاتفاق بشأن

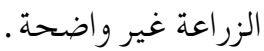

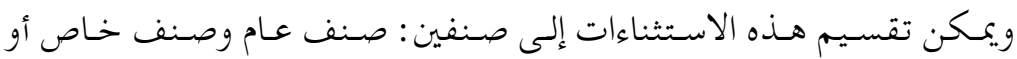
خصوصي · ألف-الاستثناءات العامة

تـطبق هـذه الاسـتثناءات عـلى جـميع الـتزامـات المـعاهـدة ولا تـقتصر عـلى المعامـلتين الوطنية أو الأكثر رعـايـة فقطط ـ وهـي بـــورهـا تـنقسم إلى استتثناءات

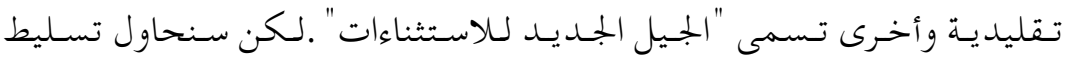
الضوء فقط على الاستثناءات العامة التقليدية . 


\section{الاستثناءات التقليدية}

تركز اتفاقات الاستثمار الدولية 45 تركيزاً كبيراً على شواغل السياسة العامة الـتي تـتضمن اسـتثناءات ذات طـبيعة تـقليديـة تـنص عـليها الاتـفاقيات وتـتصل خـصوصـا بـعدة مسياديـن وهـي حسمايـة الـنظام العام -حسمايـة حـقوق الإنسسانوحفظ / حماية الصحة العامة-و الحفاظ على الأمن الوطني / القومي.

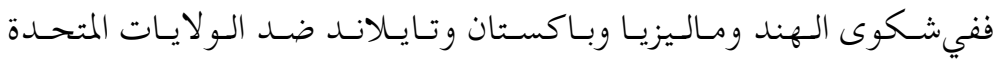
الأمريكية في شأن حظر استيراد الربيان :

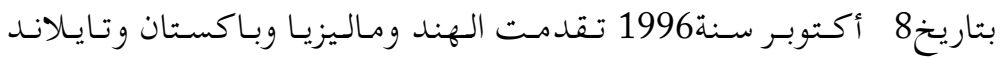
بشكوى ضـد الولايات المتحدة زعمت فيها أن حظر تلك الدولـة لاستيراد الربيان

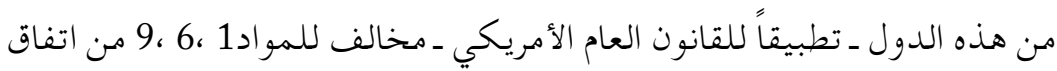
GATT 1994 كما أن هذا الحظر يحرمها ويعوقها عن جنى الفوائد الناتجة عن

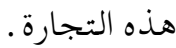
- أصدر فريق الخبراء(PANEL) تقريره لمصلحة الدول الشاكية على سند من

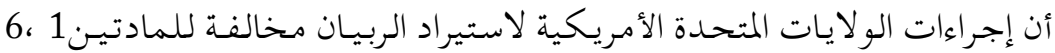
من اتفاق1994 GATT ولا يمكن تبريرها على هدى من حكام المادة10 من ذات الاتفاق .

- استأنفت الولايات المتحدة قرار فريق الخبراء في 13 يوليو سنة1998 إلا أن جهاز الاستئناف أيد ما توصل إليه فريق الخبراء.

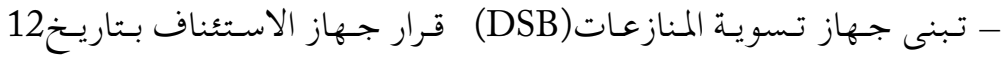
أكتوبر سنة 1998 (20 - 20. 
خاتمة

ظل مصطلح النظام العام، على الرغـم من أهـيته، مـن بين المفاهيم التي مـن الصعب أن نـفلح في تـعريـفها بـصفة دقيقة وشـامـلة ومـوحسدة، بـاعتبار طبيعته

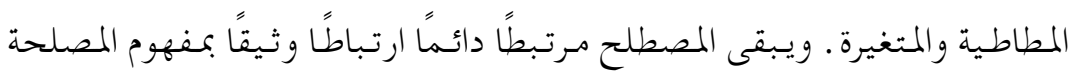
العامـة التي هي بـدورها مـن بين المفاهيم الغامضة ـ فمـن المشاغل الأساسية التي

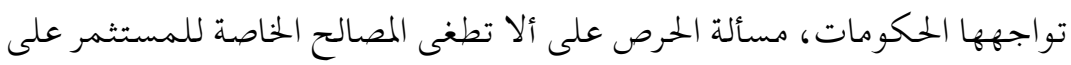

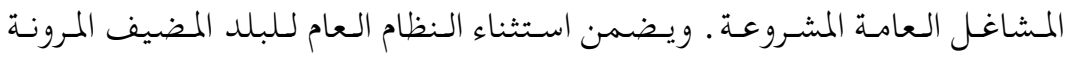

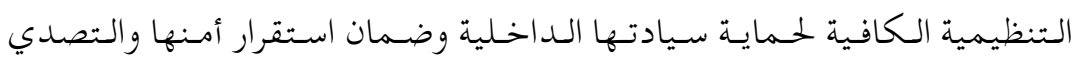

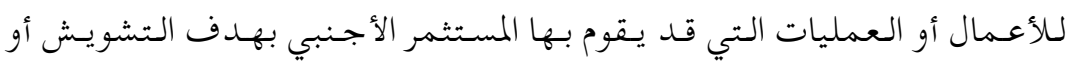

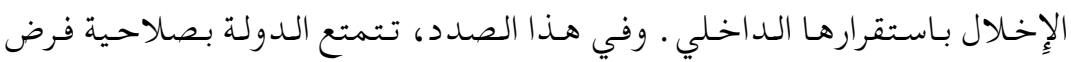
عقوبات على المستثمر الأجنبي المخل بالنظام العام. غـير أن هـذه الإِجـراءات لا تـتيح لـلدولـة الـتصرف المطلق مـن نـاحسية اتـخاذ

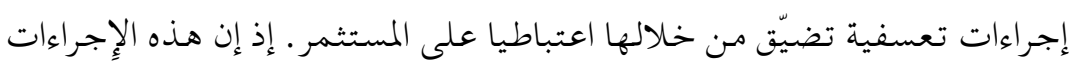
ترد في صلب الشرعية الدولية فلا تتسبب بـأي ضـرر أو أذى. ولا يمكـن للدولة المضيفة أن تـتصرّف على أساس التمييز لاعتبارات دينية أو سياسية أو لخلفيات تاريخية غير مبرّرة أساسا.

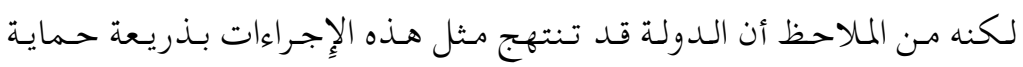
النظام العام، وهي تـؤدي في الغالب إلى تعطيل الاستثمار، وقـد تـكون بـدورهـا

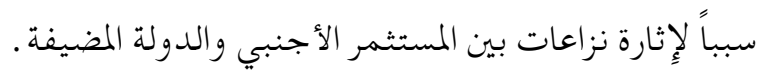
وقد استخدمت الدول نظام الأفضليات المعمم لتعزيز حقوق الإِنسان، في محاولة منها، مثلاً، للقضاء على العمل الجبري وعمل الأطفال أو لجعل الاستفادة من هذا النظام مشروطة بالتصديق على معايير منظمة العمل الدولية .فمن جهة، 
يؤكد ربط التجارة بحقوق الإِنسان على هذا النحو الأبعاد الاجتماعية للتجارة

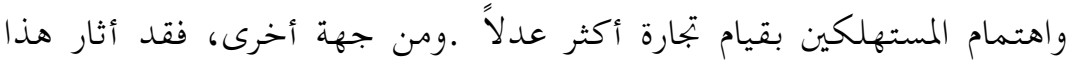
الموضوع مخاوف من استخدام حقوق الإنسان لحجب أهداف حمائية أو سياسية ضيقة مؤدياً في الوقت نفسه إلى تقليل فرص التجارة في البلدان الأكثر فقراً والتسبب فعلاً في تأزم حالة حقوق الإنسان للعمال في تلك البلدان 47 ـوبناء عليه، يبقى استخدام التجارة من أجل تحقيق أهداف حقوق الإِنسان في بلدان أخرى موضوعاً مثيراً للدجدل . ويتوقف الكثير على الأسلوب الذي يمكن أن تعزز به الدول التأثير الإِيجابي للتجارة على حقوق الإِنسان وتحترز من الانعكاسات السلبية لها . وهناك مسبقاً بعض المرونة في قواعد التجارة لتحقيق أهداف حقوق الإنسان في مجال الإصلاح التجاري، على سبيل المثال الترخيص الإلزامي لبراءات الاختراع بشأن الأدوية الأساسية .كما تتيح أحكام الاستثناءات العامة آلية للاحتجاج بحقوق الإِنسان داخل منظمة التجارة العالمية إذا تبين أن إحدى الدول الأعضاء انتهكت القواعد الرئيسية لأحد اتفاقات المنظمة .فهذه الأحكام إذن وسيلة لضمان تفسير قانون منظمة التجارة العالمية وتنفيذه مع إيلاء المراعاة الواجبة للقواعد والمعايير الدولية المتعلقة بحقوق الإِنسان، في الحالات التي يمكن، لولا ذلك، أن تتعارض فيها القواعد والمعايير. 


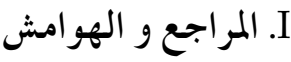

1 د / جعفر مشيمش ، التحكيم في العقود الإدارية و المدنية و التجارية ، دراسة مقارنة ،

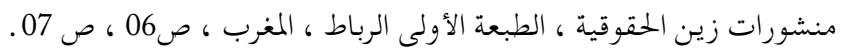

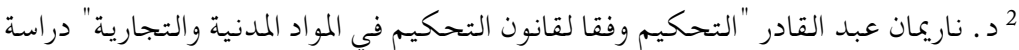

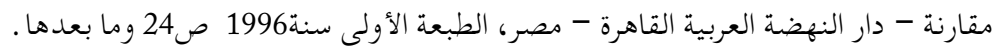
3

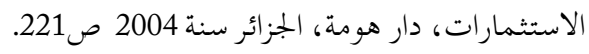

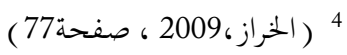

5 سامي، فوزي محمد :التحكيم التجاري الدولي .الجزء الخامس دون طبعة .عمان.

$$
\begin{aligned}
& \text { مكتبة دار الثقافة .1997 صب388. }
\end{aligned}
$$

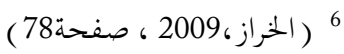

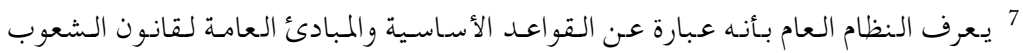

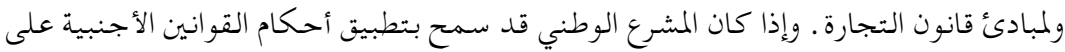

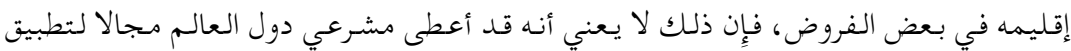
أحكام قو انينهم على إقليمهـ ـ يتبع ل...

فالنظام العام يعد من أهم الدفوع التي قد يستخدمهـا القاضي الوطني لأستبعاد تطبيق

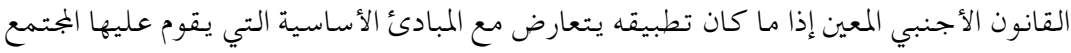

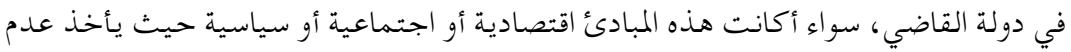
احترام قواعد النظام العام ذات الأثر المترتب على عده عدم اهدي احترام كفالة حقوق الدفاع، فالأنظمة القانونية للدول تشتمل على قواعد خاصة تسمى قواعد النظام العام التي يـراد مـنها تحقيق

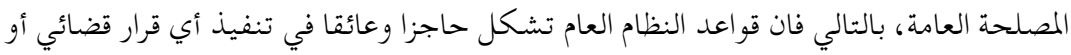

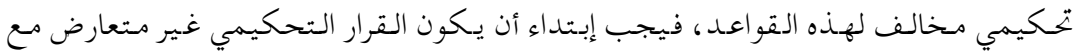

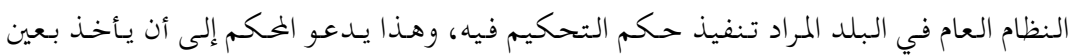

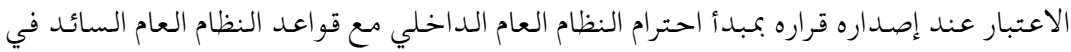




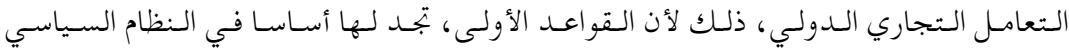

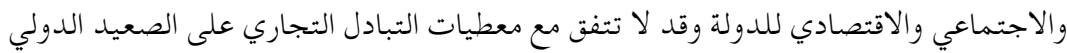

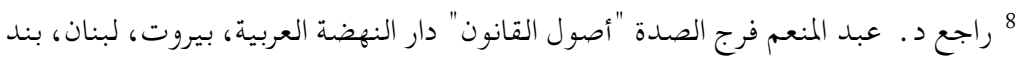
52

$$
9 \text { ( الصدة، صفحة } 77 \text { نفس المرجع السابق ) }
$$

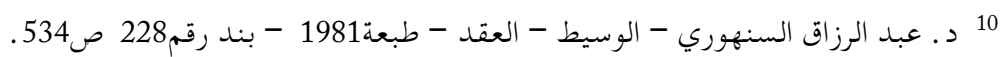

$$
12 \text { 12 }{ }^{11} \text { (السنهوري، دالدسوقي،2014) }
$$

13 الد كتور / مختار أحمد بريري "التحكيم التجاري الدولي" دراسة خاصة في القانون

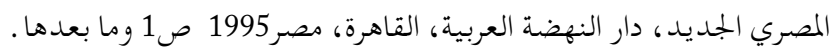

$$
\begin{aligned}
& 14
\end{aligned}
$$

$$
15 \text { (الدسوقي مرجع سابق، } 14 \text { (بريري،2014) }
$$

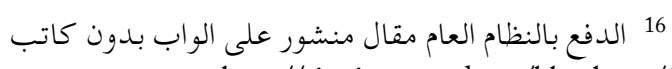

http://site.iugaza.edu.ps/bboshnaq/files

) النظام العام في النزاعات الدولية الخاصة المتعلقة بالأحوال الشخصية. ZAIR, F. (2013)

. (Doctoral dissertation

17 راجع المادة1481 مس قانون المرافعات الفرنسي والتي تنص على عدم جواز الطعن في

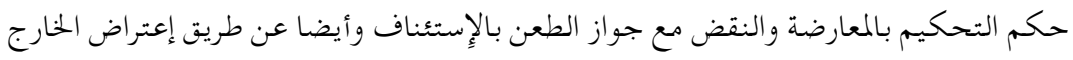

18 - See more at:

عن الخصومة.

http://www.mohamah.net/answer/31594/\%D9\%85\%D9\%82\%D8\%A7\%D9\%84\#sth ash.6BeC8dLe.dpuf

$$
\begin{aligned}
& \text { 19 زروتي الطيب، القانون الدولي الخاص الجزائري مقارنا بالقوانين العربية، تنازع القوانين }
\end{aligned}
$$

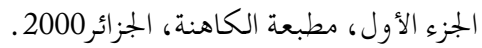

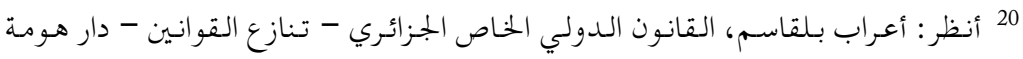

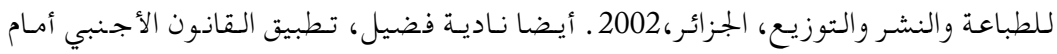

$$
\begin{aligned}
& \text { القضاء الوطني، دار هومة للطباعة و النشر والتوزيع، الجزائر، } 2002 .
\end{aligned}
$$

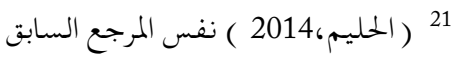


22 المادة (458 مـكرر17 )مسن القانون رقـم ( 66/157) المتعلق بقانون الإجـراءات المدنية

$$
\begin{aligned}
& \text { القديم. } \\
& \text { (عنفوسي،2015 } 23
\end{aligned}
$$

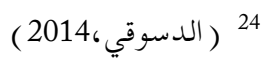

$$
\begin{aligned}
& 25 \text { انظرد .غالب الداودي و د .حسن الهداوي، القانون الدولي الخاص، القسم الثاني، }
\end{aligned}
$$

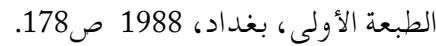

$$
\begin{aligned}
& 26 \text { أحمد زوكاغي: أحكام القانون الدولي الخاص في التشريع المغربي، تنازع القوانين2 } \\
& \text { لطبعة الأولى } 1992 \text { ص91. } \\
& \text { (عبادي،2013) }
\end{aligned}
$$

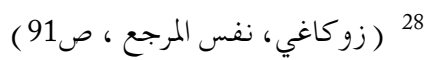

$$
\begin{aligned}
& 29 \text { (إكدر،2002) (زوكاعي، نغسر) } \\
& 30 \text { (عيسى،1988) }
\end{aligned}
$$

31 (Kassis, L.G.D.J Paris 1984)

32 (Kassis, L.G.D.J Paris 1984)

33 (B.Goldman, la lex mecatoria dans les contrats et l'arbitrage international, réalité et perspective, Clunet, 1979)

$$
\text { (العيسى،2009 ، صفحة318) }
$$

35 (Rolin, Colloge Paris 1960.)

36 (B.Goldman, les conflits des lois dans l'arbitrage international revue académique, LAHAY 1956.)

37 (CH. Cavabiber, revue de l'arbitrage 1956.)

38 (Rolin, Colloge Paris 1960.)

39 (Lenze, 1977)

40 (R.Boubles, 1962/1676)

${ }^{41}$ À cet égard, l'Organe d'appel a indiqué dans son rapport que les exceptions énumérées à l'article XX - alinéas a) à j) - se rapportent à toutes les obligations découlant du GATT de 1994 (et pas seulement aux principes du traitement de la nation la plus favorisée et du traitement national) (États-Unis - Essence, rapport de l'Organe d'appel, page 27; États-Unis - Crevettes, rapport de l'Organe d'appel, paragraphe 121.

42 (Lenze, 1977) (Salacus.w, vol XXVII spring 1980N²2) (F, 1986)

$$
43
$$


Exceptions aux règles de l'OMC: Exceptions générales, exceptions concernant la sécurité, accords commerciaux régionaux (ACR), balances des paiements et dérogations.

$$
\begin{aligned}
& \text { (44 } 14 \text { المادة2 معاملة الدولة الأكثر رعاية }
\end{aligned}
$$

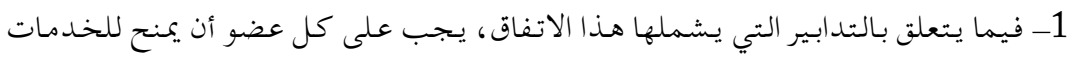

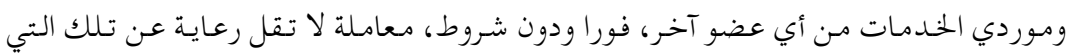

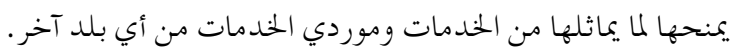

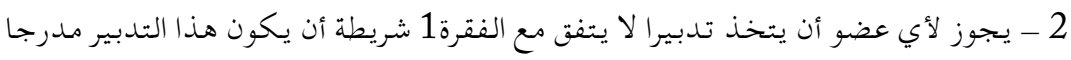

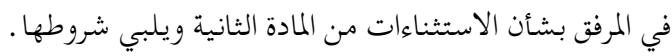

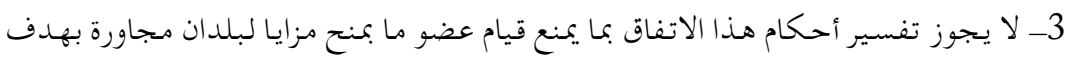

$$
\begin{aligned}
& \text { تيسير تبادل الحندمات التي تنتج وتستهلك محليا ضمن المناطق الحدودية المتجاورة فقط. } \\
& \text { 2011 }
\end{aligned}
$$

${ }^{46}$ L'article XX du GATT de 1994 régit le recours aux exceptions générales pour le commerce des marchandises. Il reconnaît que les Membres peuvent avoir besoin d'appliquer des mesures à des fins telles que la protection de la moralité publique, la protection de la santé et de la vie des personnes et des animaux ou la préservation des végétaux, et la conservation des ressources naturelles épuisables.

Cependant, toute mesure adoptée au titre de la disposition relative aux exceptions générales doit satisfaire aux conditions énoncées dans les alinéas de l'article XX - selon l'objectif de la mesure - et dans son "texte introductif". Aux termes du texte introductif de l'article XX, la mesure ne doit pas être appliquée de façon à constituer soit un moyen de discrimination arbitraire ou injustifiable entre les pays où les mêmes conditions existent, soit une restriction déguisée au commerce international

$$
47 \text { درست مـنظمة التجارة العالمية مؤخرًا استخدام الشـروط المتعلقة بـالـترتيبات بـشأن }
$$

European Communities - Conditions: for the granting of tariff preferences to developing countries, Report of the Panel (WT/DS246/R), 1 December 2003 and EC-Tariff preferences, Report of the Appellate Body (WT/DS246/AB/R), 7 April 2004. 
- الهام عزام وحيد الخراز .(2009) .التحكيم التجاري الدولي في إطار منهج التنازع. غزة، فلسطين : جامعة النجاح الوطنية.

- نادية فضيل، تطبيق القانون الأجنبي أمام القضاء الوطني، دار هومة للطباعة و النشر والتوزيع، الجزائر، 2002.

- مروان عبادي. (2013, 26 محدادات النظام العام في المغرب ـ تم الاسترداد من . marocdroit: http://www.marocdroit.com/\%D9\%85\%D8\%AD\%D8\%AF - مختار أحمد بريري.(1995). " التحكيم التجاري الدولي" دراسة خاصة في القانون

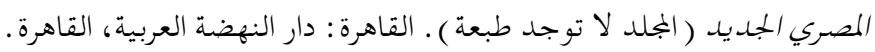
- المادة (458 مكرر17) من القانون رقم (66/157 ) المتعلق بقانون الإجراءات المدنية القديم.

$$
\text { - قانون المرافعات الفرنسي }
$$

- فضلي إكدر . (2002) ـ الإِطار القانوني للتحكيم التجاري بالمغرب الواقع وسبل

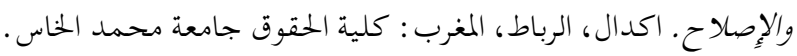

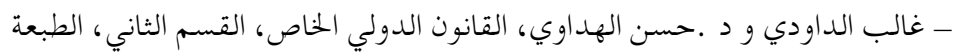
الأولى،

- عبد العزيز عنفوسي • ( جانفي ،2015) . القواعد الإِجرائية التي تحكم مسألة الاعتراف بأحكام - طلال ياسين العيسى .(2009) . دراسة قانونية "في علاقة الاختصاص القضائي الدولي

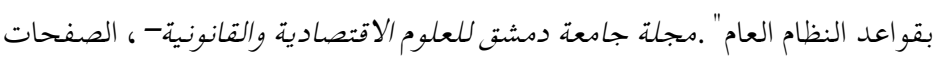
$.337-305$

- سامي، فوزي محمد :التحكيم التجاري الدولي .الجزء الخامس دون طبعة .عمان.

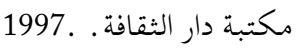

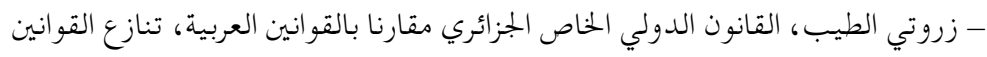

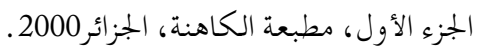


- الد كتور ممدوح عبد الحميد عبد المطلب و الأستاذة إنعام السيد الدسوقي .(25 ديسمبر, 2014) . محماة نت . تم الاسترداد من محاماة نت : http://www.mohamah.net/answer/23004/\%D8\%A8\%D8\%A ـ الدكتور / مختار أحمد بريري "التحكيم التجاري الدولي" دراسة خاصة في القانون المصري الجديد، دار النهضة العربية، القاهرة، مصرب 1995 - الدفع بالنظام العام مقال منشور على الواب بدون كاتب site.iugaza.edu.ps/bboshnaq/files

- د ـ عبد المنعهم فرج الصدة . ( بلا تاريخ ) .أصول القانون" . بيروت، لبنان : "دار النهضة

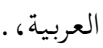

ـ د ـ ناريمان عبد القادر "التحكيم وفقا لقانون التحكيم في المواد المدنية والتجارية" دراسة مقارنة - دار النهضة العربية القاهرة - مصر، الطبعة الأولى سنة 1996 ص24 وما بعدها - د. عبد الرزاق السنهوري - الوسيط - العقد - طبعة1981 - بند رقم228 ص534. - د / قادري عبد العزيز، الاستثمارات الدولية التحكيم التجاري الدولي ضمان الاستثمارات، دار هومة، الجزائر سنة2004.

- د / جعفر مشيمش ، التحكيم في العقود الإدارية و المدنية و التجارية ، دراسة مقارنة ، منشورات زين الحقوقية ، الطبعة الأولى الرباط ، المغرب . - حسام محمد عيسى .(1988) . الأسس العامة في التحكيم التجاري الدولي. . القاهرة : •? - التحكيم وإنفاذها وتوجب الطعن .دفاتر السياسة و القانون ، الصفحات225-248. - بوشكيوه عبد الحليم .26 مارس,2014) . شروط تنفيذ الحكـم الأجنبي أمام القاضي الجزائري . تم الاسترداد من محاماة نت : http://www.mohamah.net/answer/31594/\%D9\%85\%D9\%82 - أعراب بلقاسم، القانون الدولي الخاص الجزائري - تنازع القوانين - دار هومة للطباعة

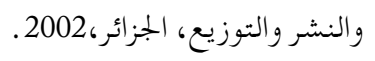

- أحمد زوكاغي : أحكام القانون الدولي الخاص في التشريع المغربي، تنازع القوانين2 لطبعة الأولى 1992 


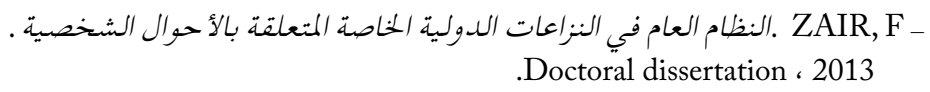

http://www.mohamah.net/answer/31594/\%D9\%85\%D9\%82\%D8\%A7\%D9\%84 \#sthash.6BeC8dLe.dpuf

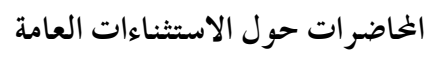

Exceptions aux règles de l'OMC :

Exceptions générales, exceptions concernant la sécurité, accords commerciaux régionaux (ACR), balances des paiements et dérogations.

\section{المراجع باللغة الأجنبية}

- (États-Unis - Essence, rapport de l'Organe d'appel, page 27; États-Unis Crevettes, rapport de l'Organe d'appel, paragraphe 121.

a. (Kassis, L.G.D.J Paris 1984 )

- (WT/DS246/R), 1 December 2003 and EC - Tariff preferences, Report of the

- Appellate Body (WT/DS246/AB/R), 7 April 2004.

- B.Goldman. (LAHAY 1956). les conflits des lois dans l'arbitrage international revue académique.

- CH.Cavabiber. (revue de l'arbitrage 1956.). l'arbitrage international et la réserve de l'ordre public.

- European Communities - Conditions:

- F, R. (1986). la nature de Contrôle de la cour de cassation revue d'arbitrage.

- For the granting of tariff preferences to developing countries, Report of the Panel.

- L'article XX du GATT de 1994.

- Lenze, J. (1977). évolution des contrats de transfert de processus technologique, ou Knowhow, in droit et pratique du commerce international.

- R.Boubles. (1962/1676). violation de lordre public moyen de nullité du compromis d'arbitragesJ.C.P.

a. Rolin, H. (Colloge Paris 1960.). Vers un ordre public réellement international. (B.Goldman, la lex mecatoria dans les contrats et l'arbitrage international, réalité et perspective, clunet 1979. 


\title{
L'IDENTITÉ HYBRIDE DES AUTEURS ALGÉRIENS D'EXPRESSION FRANÇAISE. LE CAS D'ASSIA DJEBAR
}

\author{
DALILA AZZI \\ Romancière \\ "Je ne suis pas un symbole. Ma seule activité consiste à \\ écrire. Chacun de mes livres est un pas vers la \\ compréhension de l'identité maghrébine, et une tentative \\ d'entrer dans la modernité. Comme tous les écrivains, \\ j'utilise ma culture et je rassemble plusieurs imaginaires». \\ Assia Djebar
}

Alors qu'autrefois, l'identité était reçue à la naissance d'une manière presque naturelle, il semblerait que de nos jours, cette attribution ne soit plus une tâche aussi aisée et que la vie de chaque individu gravite autour de la nécessité de se construire une identité. Mais qu'est-ce que l'identité?

C'est en effet un concept bien difficile à définir, ambivalent, fluctuent et polysémique. L'identité est une prise de conscience de soi-même qui se révèle à travers sa propre reconnaissance de la différence. C'est une création de l'imaginaire individuel et un sentiment d'appartenance à une collectivité. Elle se situe à la frontière entre le particulier et l'universel entre l'individuel et le communautaire. Le paradoxe de l'identité réside au sens où celle-ci implique l'affirmation d'une différence par rapport à l'autre en même temps qu'elle signifie son appartenance à un clan ou à un groupe social. D'un point de vue purement psychologique, l'identité découle de l'héritage culturel transmis de génération en génération, auquel se conjugue notre propre vécu émotionnel, linguistique et social. C'est en fait notre propre histoire dans toutes ses nuances et durant toute notre vie, qui est le résultat d'une identité en construction continue. Dans son fameux livre, les identités meurtrières, Amine Maalouf en donnait entre autres définitions, celle-ci «L'identité ne se compartimente pas, elle ne se répartit pas ni par moitiés, ni par tiers, ni par plages cloisonnées. Je n'ai pas plusieurs identités, j’en ai une seule, faite de tous les éléments qui 
l'ont façonné, selon un dosage particulier qui n'est jamais le même d'une personne à l'autre» ${ }^{1}$.

Le concept identitaire est bien ancré dans la littérature algérienne d'expression française, une littérature de l'entre-deux. Le terme en luimême évoque un flottement, un va-et-vient constant entre deux rives. N'est-elle pas nommée la littérature de l'impossible, celle du choix impossible à faire. La dénomination de la littérature algérienne d'expression française ou francophone, renferme un double message d'appartenance et d'exclusion à la fois. Lécriture identitaire crée des attaches, juxtapose des réalités et des imaginaires, dont l'intertextualité qui se décline sous toutes ses formes, implicites ou explicites, littéraires, historiques, sociales ou culturelles. L'écriture de l'entre-deux, raconte une société avec une langue qui n'est pas la sienne. A ce sujet, Kateb Yacine s'exprimait en 1966 sur la francophonie de la sorte:

J'écris en Français parce que la France a envahi mon pays et qu'elle s'y est taillée une position de force telle qu'il fallait écrire en français pour survivre ; mais en écrivant en français, $j$ 'ai mes racines arabes ou berbères qui sont vivantes, par conséquent tous les jugements que l'on portera sur moi, en ce qui concerne la langue française, risquent d'être faux si on oublie que j'exprime en français quelque chose qui n'est pas français. ${ }^{2}$

Mais peut-on résumer l'identité littéraire à une simple nationalité? Nous avons choisi d'aborder le cas Assia Djebar, qui reste l'auteure algérienne et maghrébine la plus internationale. L'écriture djebarienne s'installe dans un contexte culturel hybride ballottée entre la culture française et la culture arabo-musulmane, ainsi que berbère. Assia Djebar écrit en français, pourtant, ce français est «assiégé» par deux autres langues, l'arabe et le berbère formant ainsi l'identité de l'auteure. Rappelons que la langue française ne devint problématique pour la romancière qu'après une absence littéraire de douze années que la propre Djebar nommait «ma longue période de silence». Elle commençait alors à se définir comme auteure francophone et non plus comme une écrivaine en langue française. Cette rupture momentanée avec la littérature, Djebar en avait profité pour se tourner vers la réalisation

1 Cf. A. Maalouf, Les identités meurtrières, Paris, Editions Grasset \& Fasquelle, 1998, p.10.

2 Interview à Kateb Yacine sur Jeune Afrique, núm. 324. 
cinématographique. A ce moment-là, elle commençait à concevoir le français comme la langue de l'ancien colonisateur. Après plusieurs années d'absence, Assia Djebar publie en 1980 un recueil de nouvelles, Femmes d'Alger dans leur appartement, puis en 1985 le premier volet du Quatuor : L'amour, la fantasia. Le tournage de ses films «La Nouba des femmes du Mont Chenoua» en 1978 et «La zerda ou les chants de l'oubli» en 1982 fut une expérience cruciale pour les œuvres littéraires de cette deuxième phase. Elles ont permis à l'auteure d'être en contact avec l'algérien et le berbère, le parler des femmes algériennes ${ }^{3}$. Elle reconnait toutes ces voix de femmes comme faisant partie intégrante de son identité longuement refoulée sous le diktat du parler et de l'écriture français. Son écriture dès lors a inséré ses autres langues dans l'écriture française qui devient de ce fait une écriture francophone et non pas une écriture en langue française. Le français est constamment habité par la culture algérienne, il devient, dans l'écriture presque une langue étrangère. Car dans les récits de Djebar, il y a un bruit de fond avec des voix et des accents de l'Algérie.

C'est principalement à travers la langue qu'Assia Djebar manifeste son identité hybride. Ce thème se retrouve d'ailleurs au centre de la majorité de ses écrits. Dans son quatuor inachevé et à travers ses trois œuvres L'amour, la fantasia (1985), Ombre sultane (1987) et Vaste est la prison (1995). Dans L'amour, la fantasia par le biais de sa narratrice, Djebar nous parle de son identité hybride, de sa culture et de ses deux langues. Le passage entre les langues est de plus représenté symboliquement dans la scène, montrant le père accompagnant sa fille à l'école française. En traçant son chemin vers l'école, la petite fille entame aussi un voyage vers la langue française. Cette scène lourde de sens représente la rupture du cordon ombilical entre la petite fille et sa mère ainsi que le voyage de la langue maternelle vers la langue française. Dans Vaste est la prison, elle est en quête de la langue berbère, sa langue perdue. Ces trois langues sont liées dans la psyché de l'auteure au travers de l'oral et de l'écrit. La langue française lui octroie une liberté intellectuelle que les autres femmes de son époque n'avaient pas, alors qu'elle est incapable d'exprimer l'amour. Le français lui permet aussi de s'exprimer à la première personne du singulier, fait impensable dans sa langue maternelle. Il lui accorde une liberté personnelle et corporelle, mais reste la

3 Cf. M. Segarra, Mujeres magrebies: la voz y la mirada en la literatura norteafricana, Barcelona, Icaria Editorial, 1997. 
langue du colonisateur, une langue marquée par une histoire entachée de sang. L'arabe est par contre la langue de la résistance, de l'affect, de la mère et de toutes ces femmes qui représentent son univers féminin. C'est aussi la langue des tabous, des interdits et de l'impossibilité de s'exprimer dans l'espace public. Quant au berbère, il faut préciser qu'Assia Djebar ne parlait pas cette langue et ses rapports avec le berbère ne pouvaient être que des rapports de manque. Cette absence provoqua une nécessité irrésistible de l'auteure de se rapprocher de sa grand-mère maternelle et de sa mère. Son identité langagière ne se situait finalement dans aucune des trois langues mais plutôt dans l'espace hybride, au carrefour de ses trois langues.

L'histoire de l'Algérie nous installe devant un système sociolinguistique de rencontre des langues et de contact entre elles. L'arabe classique, les dialectes algériens et les parlers berbères sont en contact avec la langue de l'ancien colonisateur. C'est pour cette raison qu'à travers ses écrits, Djebar nous offre une littérature «pont» qui unit non pas deux espaces seulement, mais aussi deux voire trois mondes différents à la fois sur le plan littéraire, linguistique et culturel. Les chemins empruntés et les enjeux de ces trois mondes linguistiques sont parfois corrélatifs, et souvent évoluent de façon parallèle, côte à côte. Ces langues et ces cultures sont les essences de presque toutes ses œuvres littéraires, qui offrent diverses lectures de la société algérienne, qui dépeignent les rapports entre des êtres, des vécus, des expériences et des imaginaires communs partagés, inventés et réinventés.

Assia Djebar dans son livre Ces voix qui m'assiègent...en marge de ma francophonie, expliquait ainsi la littérature de l'entre-deux:

L'entre-deux-langues et l'alphabet perdu, c'est ce qui sépare, ce qui lie et divise à la fois, dans chaque langue, l'écrit et l'oral. Entre-deux-langues, pour un écrivain ne pouvant être autrement quécrivain, c'est se placer dans l'aire nerveuse, énervée, désénervée, douloureuse et mystérieuse de toute langue : situation souvent fréquente pour les écrivains ex-colonisés, des terres de l'un des anciens Empires Européens ${ }^{4}$.

L'identité d'Assia Djebar est donc un brassage de langues et de lieux. $\mathrm{Au}$ travers de ses récits, transperce une sorte d'aliénation, d'exil linguis-

4 A. Djebar. Ces voix qui massiègent... en marge de ma francophonie, Montréal, Éditions Pum, 1999, p. 30. 
tique. Renoncer à la langue maternelle pour adopter et se faire adopter par la langue française. La langue de l'ancien colon. Léternel antagonisme langue arabe / langue française, les conflits identitaires et la crainte de la dépossession de soi, planent en permanence comme une menace au-dessus de sa tête. Cette inquiétude et ces rivalités intérieures sont transportées dans les textes et brouillent pour ainsi dire l'acte d'écriture. L'auteure à travers son œuvre est en perpétuelle négociation de sa propre identité, principalement à cause des blessures causées par l'ancien colonisateur. Alami et Martini-Valat dans La francophonie arabe: pour une approche de la littérature arabe francophone, mettent clairement en exergue le déchirement identitaire de l'auteur de la littérature de l'entre-deux:

Dès lors, toute atteinte à la langue maternelle, toute mise en concurrence de cette langue, dans un écart diglossique, sont ressenties comme une atteinte à l'identité $[\ldots]$ Si toute agression contre la langue maternelle est ressentie comme une opération de déstructuration du sujet $t^{5}$.

Même si ces lésions sont moins douloureuses et moins visibles auprès des auteurs de la nouvelle génération. La notion de l'entre-deux identitaire se caractérise, par sa nature insaisissable, voilée et exhibée à la fois. C'est une identité en filigrane, fragile et coriace en même temps. La langue française n'est plus «un butin de guerre» comme aimait la définir Kateb Yacine mais bien une composante de l'identité collective et individuelle. Il ne s'agit plus d'une situation schizophrénique, d'un dédoublement identitaire douloureux. L'identité des auteurs de la nouvelle génération, de la littérature de l'entre-deux est le produit d'un mariage consenti, une réconciliation du passé et du présent ${ }^{6}$. L'entre-deux identitaire est désormais et plus que jamais un espace de création, de naissance et de renaissance même où se questionne la rencontre des cultures, des imaginaires et de leurs conséquences. Sans animosité et avec une maturité acquise à travers le temps et les précurseurs que sont les générations précédentes d'auteurs.

5 A. O. Alami et C. Martini-Valat, La francophonie arabe: pour une approche de la littérature arabe francophone, Toulouse, Presses Université du Mirail, 2005, p. 39.

6 Cf. AA. VV., Assia Djebar, littérature et transmission, Paris, Presses Sorbonne Nouvelle, 2010. 



\title{
SOBRE EL LENGUAJE EN EL TEATRO ÁRABE ARGELINO (II)
}

\author{
NAIMA BENAICHA ZIANI \\ Universidad de Alicante
}

Desde su creación desde la época de la colonización, el teatro argelino ha conocido una evolución notable. A lo largo de la historia nacieron varias troupes $^{1}$, se crearon muchas obras para representar la Argelia colonial, la revolucionaria, luego la independiente, para narrar la Argelia desencantada, la Argelia que sufre el terrorismo y por fin para mostrar la Argelia contemporánea que se esfuerza por salir de los dogmas, de la censura y del discurso oficialmente impuesto.

En este mismo contexto se muestra, igualmente, valiente, y trata temas espinosos que conciernen a todas las capas sociales. Tiene por lema defender la causa de la libertad individual, las injusticias sociales, la desigualdad entre hombres y mujeres, la corrupción, la educación, los dogmas religiosos y también el papel de la mujer en la sociedad argelina. Son por excelencia temas que todos los dramaturgos argelinos abordan en sus textos. Unos en francés y otros en árabe dialectal argelino o en tamazight ${ }^{2}$, las dos, lenguas autóctonas del norte de África.

Durante largas décadas, especialmente las que siguieron a la independencia de Argelia, figuras como Assia Djebar o Kateb Yacine, continuaban escribiendo los textos dramatúrgicos en la única lengua que manejaban: el francés. Entrada ya la década de los 70 y por la necesidad y urgencia por construir una sociedad civil consolidada, un grupo de intelectuales decide abrir el debate y hablar sobre el porvenir de las lenguas en este país. La identidad del pueblo argelino peligraba y, por estar estrechamente relacionada con el uso de la lengua, había que tomar decisiones apresuradamente.

Liderados por el premiado escritor Kateb Yacine, en 1970 un grupo de intelectuales y dramaturgos crea una troupe de teatro a la que le pone

1 Según la RAE, son una compañía de artistas, especialmente de teatro, danza, cine o circo que trabajan juntos, desplazándose de un lugar a otro.

2 Según el Diccionaire berbère, es la lengua de una franja geográfica que va desde Marruecos hasta Egipto. Cuarenta variedades derivan de este idioma, siendo su alfabeto el llamado tafinagh. 
el nombre de "l'Action Cultuelle des Travailleurs" (ACT), acción cultural de los trabajadores, queriendo así implicar a la masa obrera, siempre la más afligida. Aprovechando que la troupe creada estaba avalada por el Ministerio de Trabajo de entonces, los intelectuales reunidos proponen convertir tanto el árabe argelino como el tamazight en lenguas de la expresión dramática, por ser estas dos últimas lenguas las que maneja en su día a día la mayoría de la población argelina. Eran y siguen siendo, por excelencia, el vehículo de comunicación más usado.

Más allá de la escritura, y a pesar de las controversias que podían generar, los dramaturgos insistían en expresar su deseo de recopilar y traducir al árabe argelino y al tamazight todas las obras escritas en francés por dramaturgos argelinos, antes, durante y después de la colonización. Ver traducidas a las dos lenguas vernáculas todas las obras escritas en la lengua de Baudelaire era un sueño que todos quisieron convertir en realidad. Y así lo hicieron, empezando por traducir L'Homme aux sandales de caoutchouc, del dramaturgo Kateb Yacine.

El teatro, a través de sus textos dramatúrgicos escritos en francés, especialmente los que tratan temas afectados por el postcolonialismo, deja claro lo difícil e incómodo que es expresar en un idioma prestado inquietudes y sentimientos de una cultura con lengua propia. La identidad híbrida de estos autores queda más que reflejada. Tanto el teatro como la literatura escritos en francés, han conocido y siguen conociendo este malestar, el de vivir entre dos o tres lenguas y, por ende, culturas. En sus inicios, los dramaturgos se limitaban a traducir textos pensados en argelino pero escritos en francés. Y, aprovechando que la hibridación es un proceso de interacción entre lo local y lo global, los dramaturgos argelinos, como Allalou, Bachtarzi, Kateb Yacine y Abdelkader Alloula, durante las décadas 60, 70, 80 y 90 pusieron un especial interés en compartir sus obras escritas en francés con el público argelino, traduciéndolas a la lengua de este último.

En cambio, hoy en día y bajo los escombros de una crisis que sopla sobre el país, textos nuevos ven la luz, escritos por dramaturgos que encuentran su sitio en la herencia de los autores citados, convertidos ya en clásicos. No obstante, se desmarcan de éstos aportando un estilo, una escritura nueva, usando indistintamente, el árabe argelino, el tamazight o el francés. 


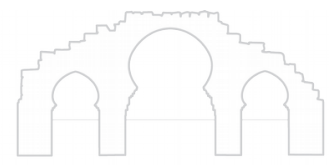

Reseñas y comentarios bibliográficos 



\section{HISTORIA TEXTUAL DE LA \\ NUEVA TOPOGRAFÍA DE ARGEL DE ALONSO CANO}

ISAAC DONOSO

Universidad de Alicante

Alonso CAno, La Regencia de Argel en el siglo XVIII. Nuevo aspecto, topografía de la ciudad y su Estado, sus fuerzas y su gobierno actual computado con el antiguo, manuscrito presentado, traducido y transcrito por Ismet Terki-Hassaine, Orán, Dār al-Qūds, 2010, 176 pp. [9789947-927-31-1]

Alonso CANO, La Regence d'Alger au XVIIIe siècle. Nouvel aspect topographique de la ville son Etat ses forces et son gouvernement actuel comparé avec l'ancien, manuscrit présenté et traduit de l'espagnol par Ismet Terki-Hassaine, Orán, Dār al-Qūds, 2010, 196 pp. [978-9947927-30-4]

José Miguel Escribano y RicARDo CASTILlO LARRIBA, Argel Delenda Est. El "Nuevo Aspecto de la Topografía de la Ciudad y Regencia de Argel" de Fray Alonso Cano y Nieto, Archivo de la Frontera, 2010, $134 \mathrm{pp}$.

[http://www.archivodelafrontera.com/wp-content/uploads/2010/03/GFUENTES-02.pdf]

EMILIO SOLA, La redención de cautivos de 1769 y la nueva topografía de Argel de Alonso Cano de 1770. Versión versiculada del documento Argel Delenda Est. El "Nuevo Aspecto de la Topografía de la Ciudad y Regencia de Argel' de Fray Alonso Cano, Archivo de la Frontera, 2010, $164 \mathrm{pp}$.

[http://www.archivodelafrontera.com/wp-content/uploads/2010/03/GFUENTES-02versiculada.pdf]

Fr. Alonso Cano y Nieto, Nueva topografía de Argel, edición de Mireia Llopis Susierra, composición y diseño de Ana Enmicucx y estudio y notas de Andrés Díaz Borrás, Valencia, Gallo de Fuego, 2014, 264 pp. [978-84-943089-0-1] 
En los últimos años han aparecido numerosas publicaciones, electrónicas, monográficas, versiculadas y traducciones, que tenían por objeto la edición de un texto, hasta entonces inédito, de singular valor. El texto había sobrevivido en diferentes manuscritos, al menos cinco, en apariencia copias desde una redacción original de 1770. La obra tenía su origen en la empresa regia de Carlos III para la redención general de cautivos en Argel, desde el 9 de octubre de 1768 a febrero de 1769, encargada a fray Alonso Cano Nieto, trinitario calzado, fray Antonio Manuel de Cantalejo, de la Real y Militar Orden de la Merced, y fray Juan de la Virgen, trinitario descalzo ${ }^{1}$. Tras cinco meses de presencia en la Regencia otomana de Argel, los redentores enviados por el monarca español consiguieron rescatar a centenares de cautivos cristianos, a cambio de miles de pesos y bastantes "moros de canje". En la operación se rescataron los tabarquinos que habían sido apresados por el bey de Túnez en 1741, y que permanecían retenidos y esclavizados en la Regencia:

En Argel los padres redentores han ido reuniendo al grupo de tabarquinos, así el diecinueve de diciembre de 1768 han agrupado un total de doscientas cuarenta personas de toda edad y estado que se encontraban distribuidas entres Constantina, Moscava y Tenez teniendo que pagar a razón de seiscientos pesos de plata. Ya que a causa del temporal los barcos de la marina española hubieron de volver antes de lo previsto, trayendo por un lado parte de los moros que se querían canjear y por otro, teniendo el conocimiento de la existencia del grupo tabarquino, los padres redentores eran conscientes de que debía intentarse actuar con la máxima rapidez para obtener un resultado positivo ${ }^{2}$.

Este contingente de población de origen ligur y vínculos con la República de Génova dio forma a la ciudad de Nueva Tabarca en la isla Plana de Santa Pola, en las costas alicantinas, ciudad creada de nueva planta por Carlos III. Al tiempo que se permitía continuar la vida marinera de esta población mediterránea, se defendía la costa de Alicante

1 "Redempzion General Que de Orden de S. M. que (Dios Guarde) se hà executado en la Ciudad de Argel, en Los Años de 1768. y 1769. por Las tres Religiones Trinidad Calzada, Merced Calzada, y Trinidad Descalza", Archivo Histórico Nacional, Madrid, 1768-69: [ES.28079.AHN/5.1.3//CODICES,L.150]. 106.

${ }^{2}$ José Luis González Arpide, Los tabarquinos, Alicante, Instituto Juan Gil-Albert, 2002, p. 
con gente escarmentada y experta en las operaciones del corso norteafricano ${ }^{3}$.

Los meses pasados en la ciudad de Argel no fueron desaprovechados por el trinitario calzado fray Alonso Cano Nieto, conquense nacido en Mota del Cuervo en 1711, para emular a Diego de Haedo y realizar una relación exhaustiva e historia general de la república norteafricana, objeto de deseo eterno para la monarquía hispánica. De este modo recaba datos de forma clandestina y observa el funcionamiento de la Regencia para componer su Nuevo aspecto de la Topografía de la Ciudad y Regencia de Argel. Su Estado, fuerzas y gobierno actual, computado con el antiguo, obra que queda manuscrita en 1770. El texto, dividido en tres libros y un apéndice, describe la topografía y las defensas militares de Argel, su estructura administrativa, y los derechos de España a los territorios argelinos. La idea última de la obra es legitimar la soberanía histórica de la monarquía hispánica sobre la plaza de Argel, como así manifestaba el control sobre la ciudad de Orán. Alonso Cano exhortaba a continuar el proyecto frustrado de conquista del norte africano, y parecía delinear un plan entusiasta sobre la facilidad de conquistar "el nido de piratas".

Lo cierto es que informes y relaciones debieron de llegar a la corte, y se organizó rápidamente un proyecto de conquista de Argel, encomendado al irlandés Alejandro O’Reilly. En julio de 1775 la armada española desembarcó en las proximidades de la medina argelina, en una batalla cruenta que causó miles de bajas en el bando español, antes de que la escuadra huyera en retirada hacia Alicante. Sin duda este lamentable acontecimiento, el último de los intentos españoles por conquistar Argel, sentenció definitivamente la fortuna editorial del manuscrito de Alonso Cano, que nunca vio la luz, al tiempo que cedía el futuro de la Regencia a otras potencias coloniales ${ }^{4}$.

\footnotetext{
${ }^{3}$ Puede verse edición parcial de la relación del rescate, Relación puntual de los acaecimientos ocurridos en la comisión del canje y rescate de cristianos cautivos de Argel y transporte de moros que se puso al cargo del capitán de navio don José Díaz de Veañes con el mando de la escuadra de los navios de Su Majestad nombrados San Isidro, Santa Isabel, San Vicente y fragata Santa Teresa, desde la salida del puerto de Cartagena hasta el arribo al de Mallorca, en José Luis González Arpide, "La expedición de Argel y el rescate de los tabarquinos”, en María Antonia Morán Suárez y María del Carmen Rodríguez López (coords.), La documentación para la investigación: homenaje a José Antonio Martín Fuertes, León, Universidad de León, 2002, vol. 1, pp. 255-276.

${ }^{4}$ Véase Frank Lambert, The Barbary Wars: American Independence in the Atlantic World, Nueva York, Hill \& Wang, 2005.
} 
Las nuevas tecnologías permiten hoy en día que el acceso sea inmediato a los manuscritos existentes, al menos tres, cuyo texto completo se encuentra digitalizado y de libre acceso a través de la red $^{5}$. Este acceso inmediato explica en parte que, ahora sí, el texto haya recibido la atención que los siglos le habían negado, y en los últimos años se haya producido una vertiginosa actividad por restituir la obra del trinitario como pieza importante dentro de la historiografía sobre Argel. Habría que destacar en primer lugar los dos volúmenes de Ismet Terki-Hassaine, uno en español (con tapa gris) y otro en francés (con tapa dorada), editando y traduciendo al francés respectivamente el texto del manuscrito Gayangos, con un valioso estudio introductorio de veinte páginas, donde reivindica el valor de las fuentes españolas para la historia de Argelia. Ciertamente esta empresa representa una contribución significativa, no sólo a la historiografía y el hispanismo argelino, sino sobre todo, a la producción en lengua española por parte de autores argelinos y la aparición de libros en español en Argelia, un fenómeno escaso, pero no anecdótico, que pone de manifiesto la tradición argelina con la lengua de Cervantes. Insistimos, creemos que es un verdadero regalo poder ir a librerías de Orán o Argel y encontrar en la sección de actualidad libros argelinos publicados en lengua española. Y como regalo entendemos los libros de Terki-Hassaine, un esfuerzo filológico laudable que disculpa la complejidad de la empresa y los rigores que toda edición sufre.

Desde el manuscrito conservado en la Universidad de Alcalá - copia de 1778- se realiza la siguiente edición completa del texto, labor de José Miguel Escribano y Ricardo Castillo. El resultado aparece de forma electrónica en el portal «Archivo de la frontera», iniciativa de la misma universidad que inició su andadura en 1999 y que posee, en el momento

\footnotetext{
5 Nuevo aspecto de la topografía de Árgel [manuscrito]: su estado, fuerzas y govierno actual comparado con el antiguo / Su author el M.R.P.M. fray Alonso Cano, trinitario calzado y actualmente obispo de Segorbe, año de 1770. Manuscrito digitalizado de la Real Academia de la Historia: [http://bibliotecadigital.rah.es/dgbrah/es/consulta/registro.cmd?id=5982]; Nuebo aspecto de la topografía de la ciudad y regencia de Argel : su estado, fuerzas, y govierno actual, computado con el antiguo / su author el M.R.P.M.F. Alonso Cáno, trinitario calzado, y actualmente obispo de Segorve, año de 1770; trasladado aqui desde su manoescrito original, año de 1778. Manuscrito de la Universidad de Alcalá de Henares: [http://dspace.uah.es/dspace/handle/10017/7233]; Nuevo aspecto de la topografía de la ciudad y regencia de Argel : su estado, fuerzas y gobierno actual, computado con el antiguo su autor Fr. Alonso Cano, Trinitario calzado y, actualmente, Obispo de Segorbe. Manuscrito de la Colección Gayangos de la Biblioteca Nacional:

[http://bdh.bne.es/bnesearch/detalle/bdh0000010991].
} 
presente, un ingente repositorio de textos, ediciones y estudios originales, una verdadera biblioteca que ofrece material de elaboración propia sobre múltiples temas, entre ellos el Mediterráneo otomano. El estudio de Escribano y Castillo relaciona por primera vez la lista de manuscritos existentes (pp. 11-12), las fuentes de la obra, y recupera un retrato de Alonso Cano conservado en la catedral de Segorbe, de la cual fue obispo desde 1770 hasta su muerte en 1780. Desde este texto el siempre sorprendente Emilio Sola realiza una magnífica versión versiculada, en verso, entendiendo agudamente la estructura interna del texto del trinitario, como obra perfectamente manufacturada dentro de los patrones de la retórica ilustrada, y del docere et delectare. No se quedan aquí las ediciones del texto sino que en 2014 aparece en Valencia otra empresa de recuperación textual de la Nueva topografía de Argel, a varias manos, edición de Mireia Llopis, composición y diseño de Ana Enmicucx, y estudio y notas de Andrés Díaz Borrás.

En fin, Alonso Cano aprovechó el privilegio de estar unos meses en la Argel de mediados del siglo XVIII para redactar un texto que emulase la histórica topografía de Haedo y, como 'nuevo aspecto', culminase la empresa de anexión militar a la par que ruina del corso. El corsarismo argelino se arruinó, pero también lo hicieron los sueños españoles de conquistar Argel, beneficiándose de todo ello potencias emergentes ante el vacío de poder de los reinos que habían gobernado el Mediterráneo, España y el Imperio otomano. La Nueva topografía de Argel acabó formando parte del mundo antiguo; serían ya los franceses quienes con ahínco delineasen los mapas norteafricanos. 


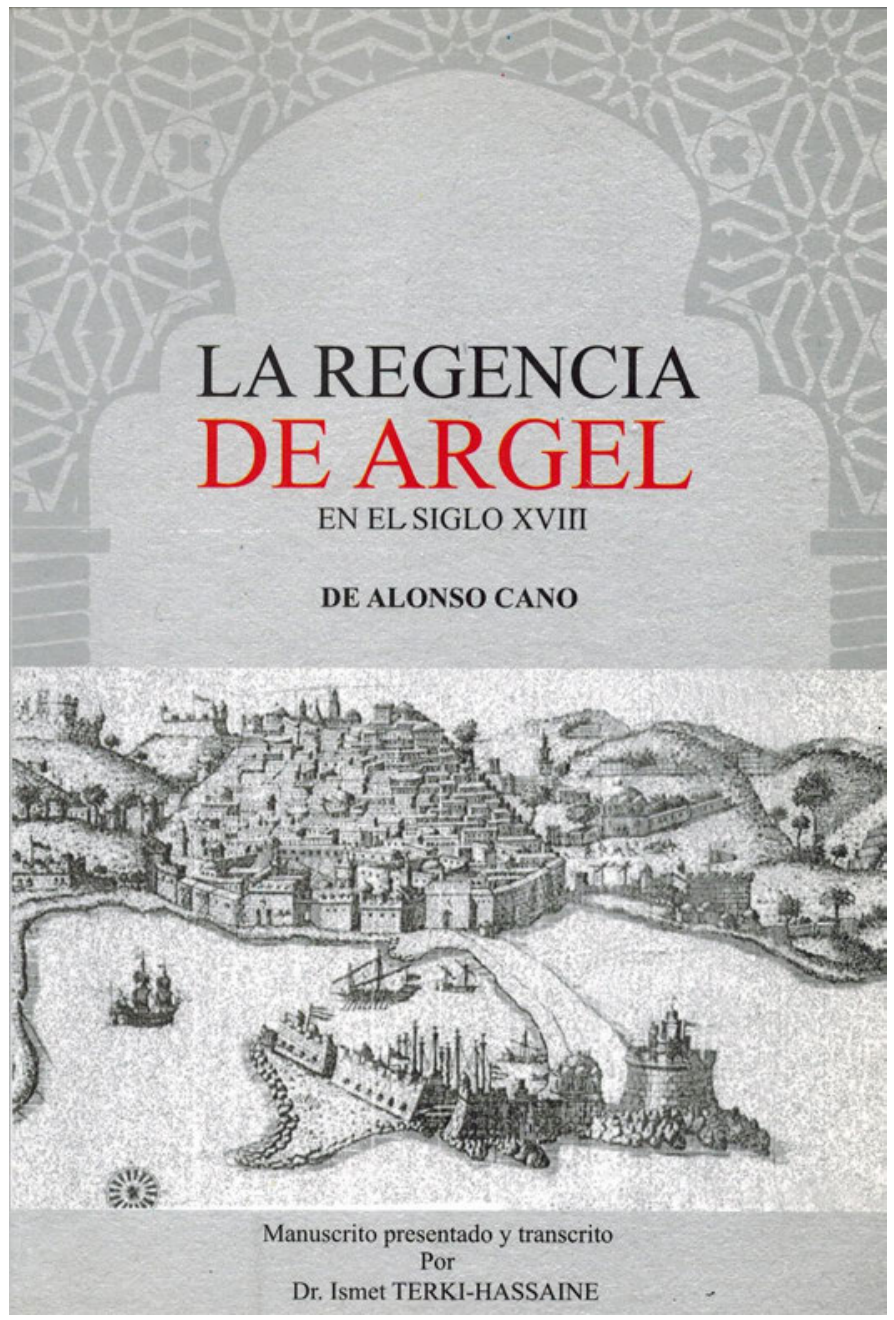



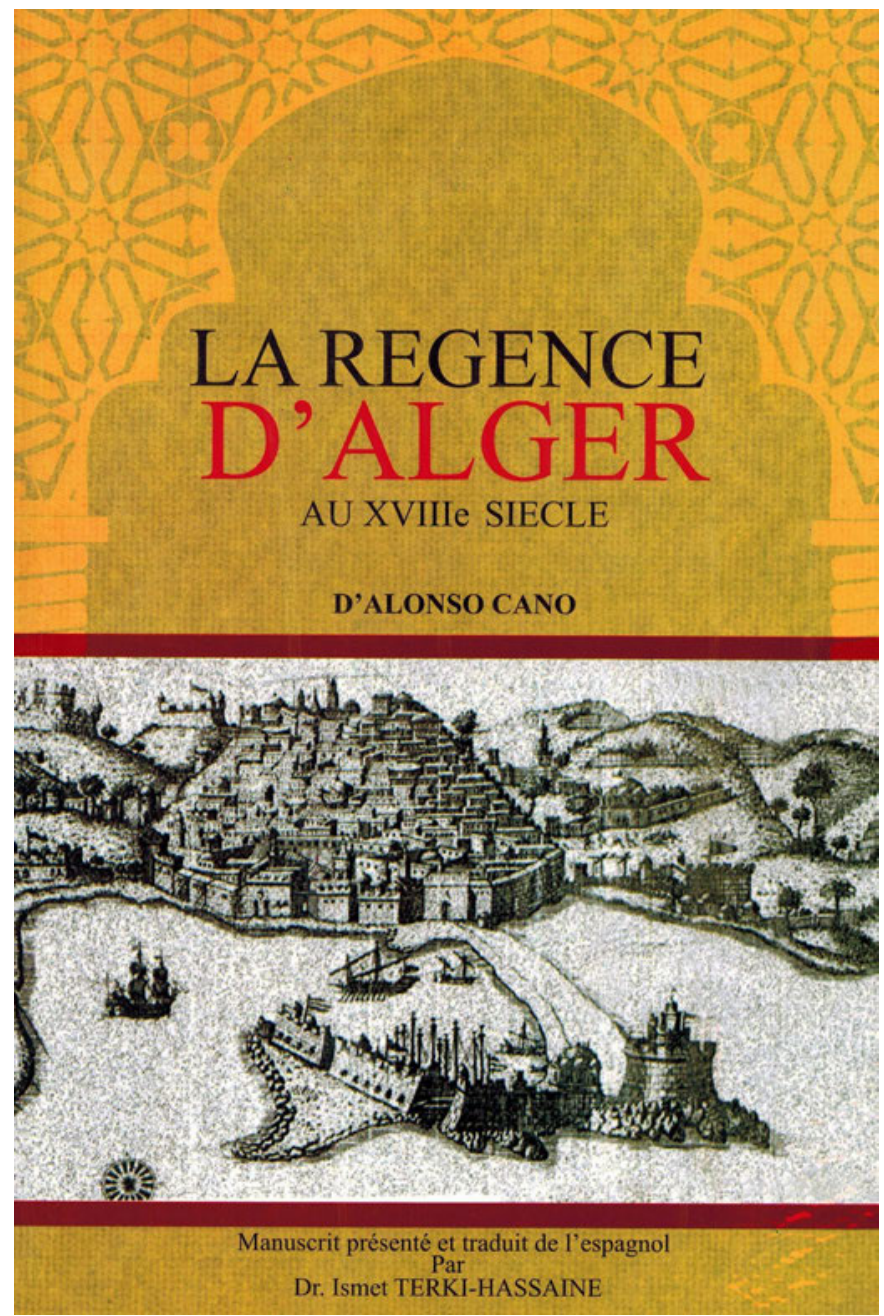


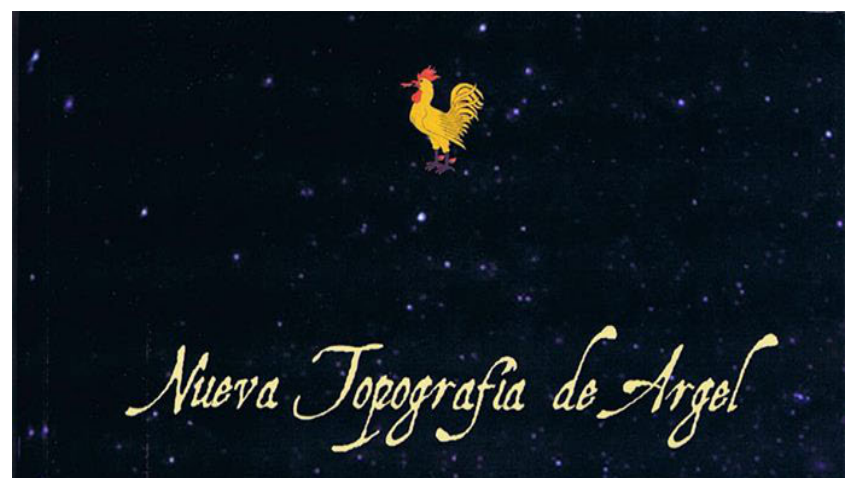

Fr. Alonso Cano y Nieto

Edición de Mireia Llopis Susierra,

Composición y Diseño Ana Enmicucx,

Estudio y Notas Andrés Díaz Borrás 
Omar Dib, Musique Algérienne. École de Tlemcen. Galerie des grands maîtres, Argel, El Othmania, 2015, 216 pp. [978-9947-810-89-7]

Existe una notable bibliografía en torno a la música andalusí en el norte de África. Recordemos por ejemplo el histórico y bellísimo volumen del padre Patrocinio García Barriuso, La música bispano-musulmana en Marruecos, publicado por primera vez en Larache en 1941, y reimpreso en Sevilla en el 2001. No es tanto sin embargo lo que se conoce sobre la música andalusí en Argelia, aunque se pueden destacar aportaciones recientes, por citar una, quizá poco conocida, la de Julián Rabadán Bujalance, Música andalusí, Alicante, Editorial Club Universitario, 2012. No obstante, los textos suelen centrarse por lo general en los modos y estilos musicales, ritmos e instrumentación, y no tanto en la propia historia de su pervivencia, desarrollo y transmisión. Creemos que es éste el valor principal del libro de Omar Dib, un verdadero descubrimiento de músicos, poetas, vidas y trabajos de los que hicieron posible, durante los últimos dos siglos, la escuela tremecení de música andalusí. En efecto, es Tremecén el corazón de la herencia de al-Andalus en Argelia, también en su música, aunque a lo largo de los siglos la escuela que se ha ido forjando en su seno no sólo preserva una música peninsular, sino que, indudablemente, evoluciona a la par que sus maestros.

Los hermanos Dib, Mohammad (1852-1915) y Ghouti (18541817), son los primeros testimonios que emergen en el libro, dos personalidades dibujadas al detalle, en sus matrimonios, exilios y luchas contra el colonizador. El autor reproduce testimonios directos y cartas familiares de los dos grandes maestros, creadores de la orquesta de la cual surgirán los maestros posteriores, Hadj Larbi Bensari (1872-1964) y su hijo Ahmed Bensari, llamado Reduán (1914-2002). Éstos son los cuatro grandes maestros que darán forma a la moderna escuela de Tremecén de música andalusí. De todos ellos existe al final del libro un extenso apartado de ilustraciones donde se recogen fotografías antiguas explicadas con pie de foto (pp. 195-214).

Un segundo apartado del libro lo compone un capítulo teórico que sigue a continuación de la biografía de los grandes maestros, titulado "De la nouba” (pp.111-123). En él se tratan de las secciones de una composi- 
ción, de la nomenclatura de las clases de noubas, y se describe cada una de las doce completas y las cuatro incompletas noubas. De este modo se conoce el léxico técnico y las características de las principales piezas de música andalusí de Tremecén.

Finalmente se dedica un último apartado en el libro a la poesía popular desde el siglo XVI al XIX, poesía que es material cantable y forma parte de los repertorios de los grandes maestros. Son cuatro los personajes de los que se trata en esta sección: al-Mandacī al-Tilimsānī (s. XVI), Ahmad ben Triqī (s. XVII), Ahmad ben M'Sa'īd (s. XVIII), Bū Madyan ben Sahlà (s. XIX). De cada autor se citan poemas directamente en árabe, sin traducción, y al final de cada uno de ellos se da una detallada lista numérica de poemas en árabe. Sin duda el estudio detallado de estos autores permitirá conocer mejor esos siglos poco atendidos de la creación literaria árabe, como son los siglos del periodo postclásico.

La obra de Omar Dib no es sólo por lo tanto un recorrido por las vidas, pensamiento y trayectoria de los grandes maestros de la escuela de Tremecén, sino también por la poesía y la literatura de un periodo que es imprescindible recuperar si queremos aproximarnos con garantías a la creación de un pueblo, Tremecén, heredero de las gentes de al-Andalus que han construido su modernidad lejos de la península.

ISAAC DONOSO 


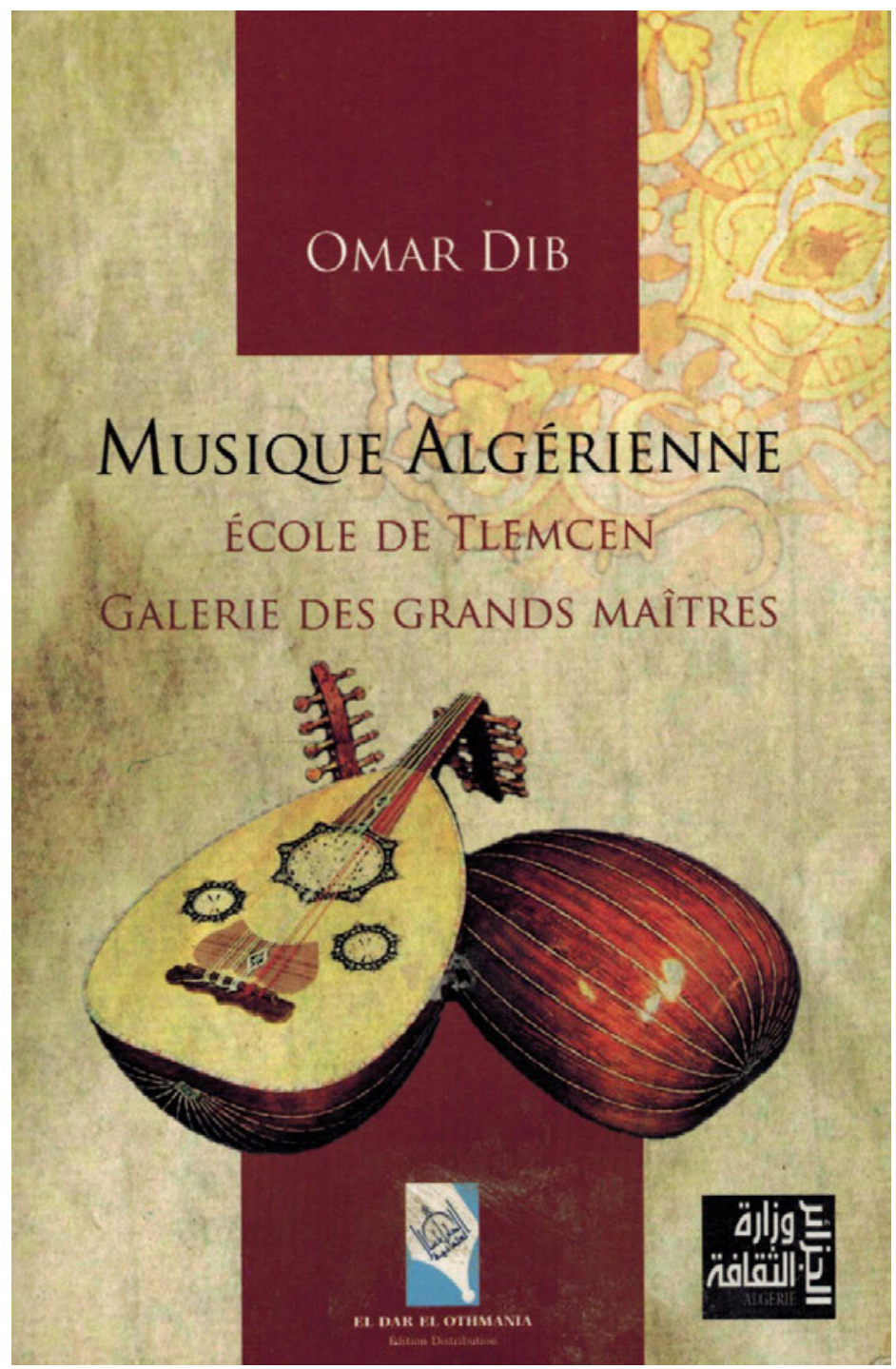





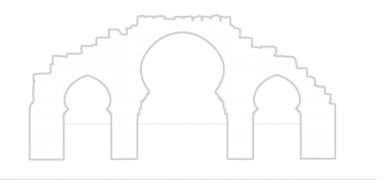

Biblioteca 



\title{
KADDOUR EL CONDUCTOR. \\ ESCENA DRAMÁTICA DE LA OBRA LOS DICHOS \\ DE ABDELKADER ALLOULA
}

\author{
NAIMA BENAICHA ZIANI \\ Universidad de Alicante
}

\section{NOTA INTRODUCTORIA}

El papel de la Halqa y de el goual en el teatro argelino, igual que en la Commedia dell'arte, son omnipresentes en todas las plazas públicas de las diferentes ciudades de Argelia. Tradicionalmente es el estilo más popular para expresar las turbaciones sociales. A través de esta forma, Alloula consiguió transmitir ideas imposibles de expresar en la vida de todos los días. Lo hacía para los que no tenían la posibilidad de escribir, de decir o de hacer.

El personaje que aquí presentamos desarrolla su narrativa en torno a los dos elementos que Abdelkader Alloula consiguió enraizar para siempre en el teatro argelino. Hoy en día hablar de teatro argelino es hacer referencia a los conceptos de halqa y goual y, por ende, a Abdelkader Alloula.

Kaddour es el chófer, el trabajador fiel, honesto y leal, padre de cinco hijos, es un personaje de la obra el Agoual. Viene decidido a presentar su renuncia a su puesto de trabajo. Un puesto que, arduamente, consiguió en 1962, justo después de la independencia de Argelia. Durante la colonia francesa y, mientras luchaba por la libertad y la dignidad, Kaddour soñaba con un trabajo decente en una empresa estatal.

Nos habla de corrupción, de abuso de bienes sociales, de la distancia que separa irremediablemente la gente del poder. Lo hace sin cólera y sin odio, gracias a una voz liberadora, una palabra que anhela la verdad, subrayada por la música que acompaña la emoción, en un eco fiel a las palabras y a los sentimientos. La balqa es el escenario óptimo para tal fin. 
Kaddour, el conductor

Señor Naser, tome, lea esta carta... es una carta para Usted, Señor Director...

Lea... léala...Sí, es mi dimisión

Pido que me eche ahora... quiero dimitir ahora mismo...

No hace falta que hable Señor Naser, Sr Director... hoy, hablo yo...

llevo callado, sigiloso casi quince años, pero hoy hablaré...

deseo que me escuche bien y no intente cortarme...

se estará preguntando y diciendo ¿Qué le pasa a Kaddour, se ha vuelto loco?... ¿No estará borracho?... ¿¿no será un malentendido?...

Pues, no... Kaddour hoy ajustó cuentas consigo mismo y está decidido...

Kaddour hoy decidió actuar, después de un largo y profundo análisis...

Kaddour hoy rompió el hilo que le unía al Sr. Naser, lo rompió intencionadamente...

Esta carta es administrativa y no manifiesta las verdaderas causas, es por eso que se la entrego yo mismo en mano...

es por eso que he venido expresamente...

entonces, si me extiendo no intente interrumpirme o pararme...

es más, no le dejaré hablar...

y cuando me haya marchado de aquí, no intente buscarme, Sr. Naser. 
A partir de hoy se separan nuestros caminos... y puede que lo hagan para siempre... dimito de la empresa, Sr. Naser, porque el camino que hemos escogido los dos juntos hasta ahora no nos lleva a ninguna parte...

cuando digo el camino que hemos escogido, a decir verdad, yo aquí ni pincho ni corto...

pues eso, el camino que ha cogido usted y yo detrás de usted no sirve para nada...

me he cansado mientras me lo recorría y me harté de mí mismo...

me harté de mí mismo y de usted más que de nada...

entonces hoy vengo para dimitir de esta empresa nacional y a la vez de la relación de amistad que nos unía...

Kaddour el conductor, hoy se marcha de la empresa nacional y hoy mismo sepultará...

sí, enterrará definitivamente la amistad que le unió durante dieciocho años al Sr. Naser, el Director...

no es una gran pérdida ni la empresa perdió un directivo... no soy más que un conductor, ¿a quién le importará?...

no importa... Kaddour, el conductor, está contento hoy...

Kaddour, el conductor, el examigo del director, está feliz hoy...

Kaddour está hoy como si hubiera atravesado mares, montañas y ríos...

Kaddour, el energúmeno, está hoy en armonía consigo mismo: encontró la paz, la sencillez, la humildad de antaño, las virtudes con las que antes vivía... 



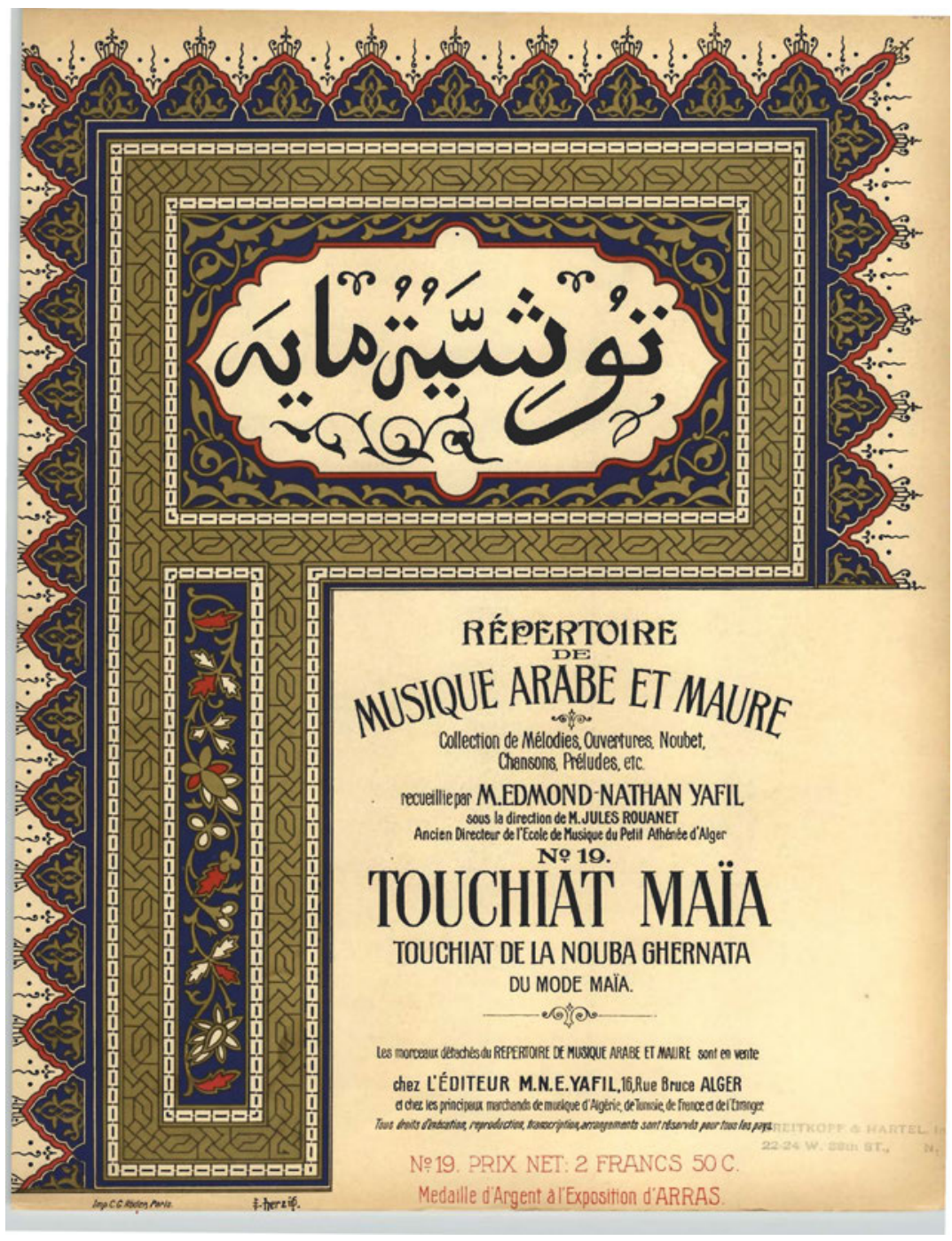





\section{REPERTOIRE DE MUSIQUE ARABE ET MAURE}

La collection que nous présentons au public se 0 recommande à lat à divers titres.

On connait la merveilleuse floraison des arts musulmans du VIle au Xle Siècle et ce qui nous est resté de leur archifecturc, de la sculpture, de la céramique, te la damasquinerie, de la décoration des manuscrits, nous montre à quelle perfoction étaient parvenucs ces manilestations d'une civilisation avancée.

Aujourd'hui, après de trop longues annes d'indifférence, rous essayons, on Agérie et en Tunisie, de sauver d'un oubli définitif les traditions d'art qui avaicnt créé tant de chefs d'cuvres. Mais cette sollicitude et cette curiosité n'étaient pas encore ailées à la musique. Cependant la musique, au temps des Kalites aussi bien qu'aux époques moderires, a ćtć très cn honneur et a toujours joué un rôle important dans la vie publique et privée des Musulmans. Elte méritait done qu'on songeât à la sauver, elle aussi, de la disparition; d'autant plus que, n'ayant jamais été écrite, elle ne survivait que par ta transmission auditive, par des traditions qui s'altéraient et pouvaient finir par se perdre totalement.

Elle le méritait encore par sa valeur propre, par la richesse de ses modes et par la place qu'on lui doit, dans l'histoire, entre la musique grecque ef la musique grégorienne. Et on s'étome vraiment qu'une pareille cuvre de conscrvation n'ait pas cncore étć tentée sérieusement.

C'est cette euvre que M. F. N. Yafit a essaye de réaliser et à laquelle nous avons été heureux de collaborer. Nous avons voulu: fixer, avant qu'ciles sc perdent totalement, les mélodies de tout ordre qui constituent le répertoire si riche des musiciens indigènes; sauver de l'oubli ce qui nous est resté d'un art autrefois trìs florissant; consigner, en notation moderne et mettre ainsi a la disposition des amateurs, une musique originale à peu près inconnue; soumettre attx musicologutes des éléments, nouveaux pour eux, de 'lyistoire musicalc des peuples d'Orient et transcrire définitivement pour les Musulmans le recueil des mélodies typiques dc leur race el de leur religion qui ont suivi partoút le peuple de Mahomet et constituent aujourd bui les seuls vestiges de sa grandeur artistique.

Les mêmes considérations qui nous ont poussés à nous adonner a cette entreprise nous créaicnt l'obiiga- tion formelle de conserver aux pièces de notre Répertoire de Musique Arabe et Maure leur caractère propre, leur physionomie réclle.

Nous n'avons donc recherché ri adaptation de cette musique au sens musical moderne, ni harmonisation ni orchestration plus ou moins savantes.

La science des sons simulianés n'existe pas chez les Arabes; il en est de même de l'accompignement qui est constitué, tous les instruments jouant à l'unisson, par le rythme d'accompagnement donné par les divers instruments de percussion.

Il importait pour cela de recueillir la musique arabe telle qu'elle se joue ou se chante, sans chercher autre chose qu'une transcription scrupuleuse, une écriture sincère des mélodies que les musiciens modernes ont reçues de leurs aînés et dont la plupart ont une origine fort lointaine.

Pour accomplit ce travail it a fallu d'abord, par de longues années d'observation, nous habituer à enteridre cette musique, arriver à la comprendre en écoutant tous les jours les exécutants les plus réputés parmi ceux qui sont restés fidìles aux formes traditionnelles. Après cette préparation, nous avons noté les mélodies àl'audition répétée, cn disséquant, en quelque sorte, l'cuvre enteridue, en la dépouillant des artifices et des ornements que chaque exécutart ajoute suivant le degré de sa virtuosité et au milieu desquels il fallait reconnaître la ligne mélodique à conserver.

C'est le fruif de ce travail, pour lequel nous avons mis à contribution les meilleurs artistes indigènes, que nous oftrons au public.

Notre programme ne comporte pas seulement quelques morceaux choisis au hasard; il embrasse, dans une traduction fidèle et consciencicuse, tous les genres de musique arabe et maure, depuis les chansons ef les touchiat légères jusqu'aux graves mélopées de la grande époque des Kalifes, qui portent le nom de musique andalouse ou de Grenade.

Les amateurs qui voudront bien nous suivre dans notre publication posséderont ainsi, avant quc le temps ait fait son ceuve, un recucil unique, une sorte de compendium d'une musique resté immuable depuis le VII' siècle ef qui ne manquera pas de les intéresser comme elle passionne tous ceux qui arrivent à ta connaitre.

I:rss Rounkt.

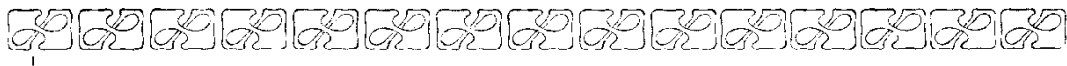


$\mathrm{N}^{0} 19$.

\title{
TOUCHIAT MAÏA.
}

nouba maĩa, dont la pièce publiéc icj est l'ouverture instrumentale, est une de celles qui s'exécutent vors la fin d'unc fête indigenc, entre trois heures du matin et le plein jour.

Cette particularité repose assurément sur le sens général des poesics appartenant a cette nouba; presque toutes parient du matin, du réveil de la nature. Voci dailleurs quelques spécimens des paroles:

(Nessraf) -Sois le bienvenu, 0 10i, qui m’as visité au lever de laurore - Le Zephir matinal a doucement agité les plantes en sève-Ei les rayons du soleil se sont penchés sur la valléc. 0 ! lexquis matin! $\hat{o}$ le meilfeur des matins... Les roses, ce matin, se sont eveillées tout ouvertes - sur les joues de celui qui est venu me voir dans mon jardin.

(Messeder)-Reveille-toi de ton sommeil, toi, qui dors encore à la clarté de la bougie!-Tends-mo; mon verre, car voici que le rossignol se met à réciter des vers -.- verse à boire, $\hat{o}$ mon échanson: les ćtojles viennent de disparaitre - La brise a souffié ct la bougie a coule... Mon vin est vicux et voici que le rossignol dit: $O$ toi qui as des accrochecocur, mon amour pour tai venait sans cesse.

(Mutre Messeder.) O étoite du matin! donne de mes nouvefles à celfo qui est la lumière de mes yeux $O$ beauté des beautés! Toutes les beautés elle les a accaparées Sa démarche est rythmique comme celle des lances en marche; Won amie est la lumièrc du matin - Elle vaut plus que le trésor le plus précieux et la beauté, elle s'en est emparée. (Littéralement: elle l'a prise en un tas tout embrouillé.)

Le mode maĩa se présente à nous, dans sa forme actuelle, avec la gamme suivante: re, mi, faj, solz, la, si, dot, re; ou, ce qui revient au même: do, re, mi, faj, sol, la, si, do; ou encore: la, sol, la, si, do, re, mi, fa.

Il correspondrait, ainsi construit, à l'hypolydien de Grecs, avec applications alternatives du systeme conjoint ef du systeme disjoint.

Les masiciens arabes confondent er un seul mode le maĩa, le dil et le moual. Il semble cependant que chacun de ces modes a dû, autrefois, avoir unc gamme particulière.

Salvador Daniel, qui écrivait en 1862-1863, distinguait te maĭa auquel il attribuait la gamme: do, re, mi, fa, sol, la, si, do, de l'edzeil ow dil, quil avait entendu ainsi: fa, sol, la, si, do, re, mi, fa. Il ne parlait pas du mode moual.

Actuellement fi gamme majeure moderne porte chez les Arabes le nom de mode mesmoun et les modes dil, maïa et moual somt représentés par une seule gamme ayant sa première quarte tantốt juste, tantôt augmentée.

Le mot maïa désigne sur le Kanoun, la Kouitra, le Rebeb et les autres insiruments fa note Ia; dil disigne le sol; mesmoun le do.

Il sembie qu'il faille renoncer à identifier ces divers modes et à retrouver leurs formes anciennes: les très rares documents que nous avons sur la matière sont tous sujets à caution et les survivants les plus âgés des musiciens indigènes d'Alger n'ont plus la notion des différences qui devaient exister entre ces gammes: ils chantent bien une nouba dil quits ne confondent pas avec la nouba maïa; mais les deux nouba ont depuis longtemps la même gamme.
\end{abstract}




\section{Touchiat maïa.}
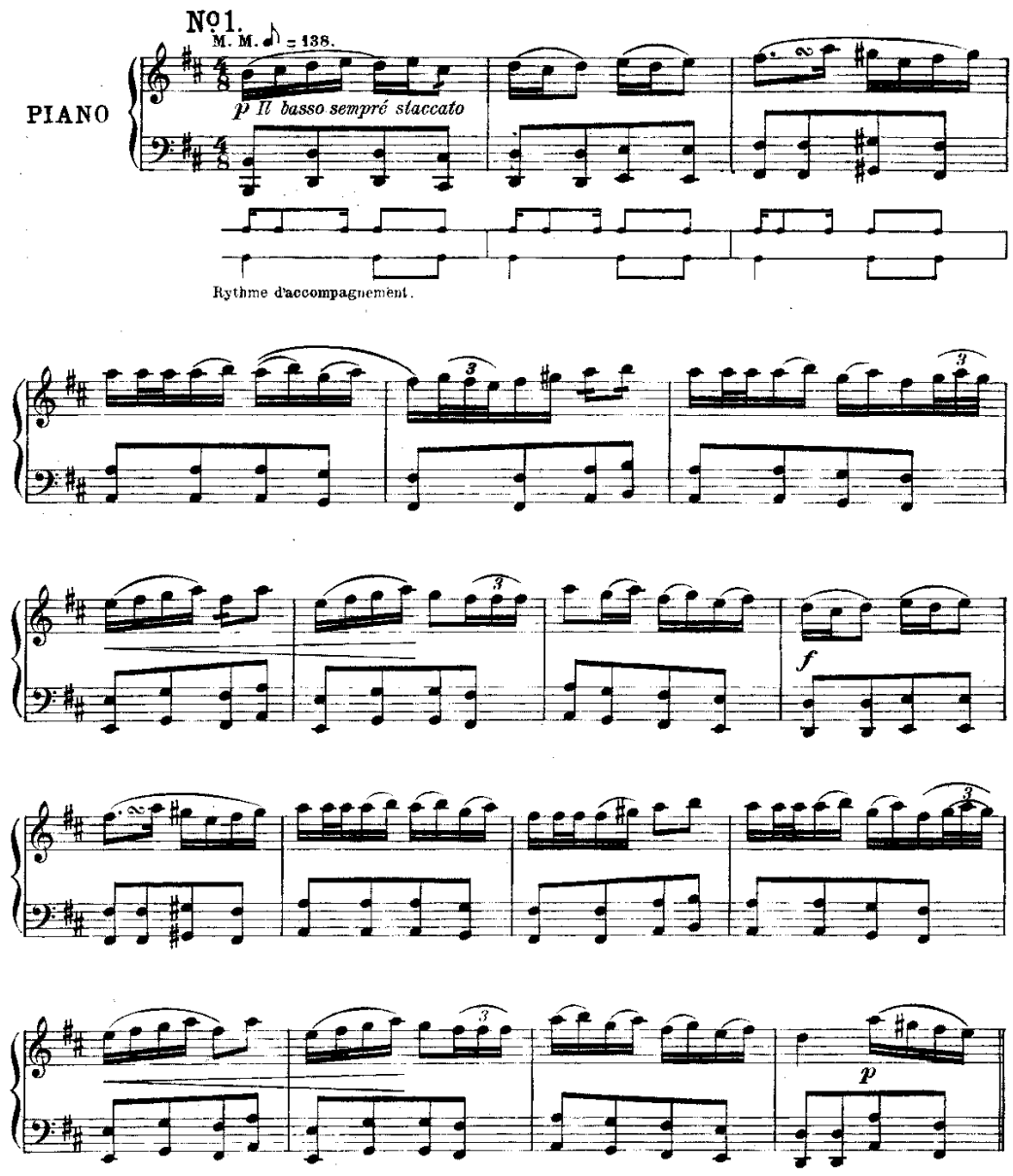
6
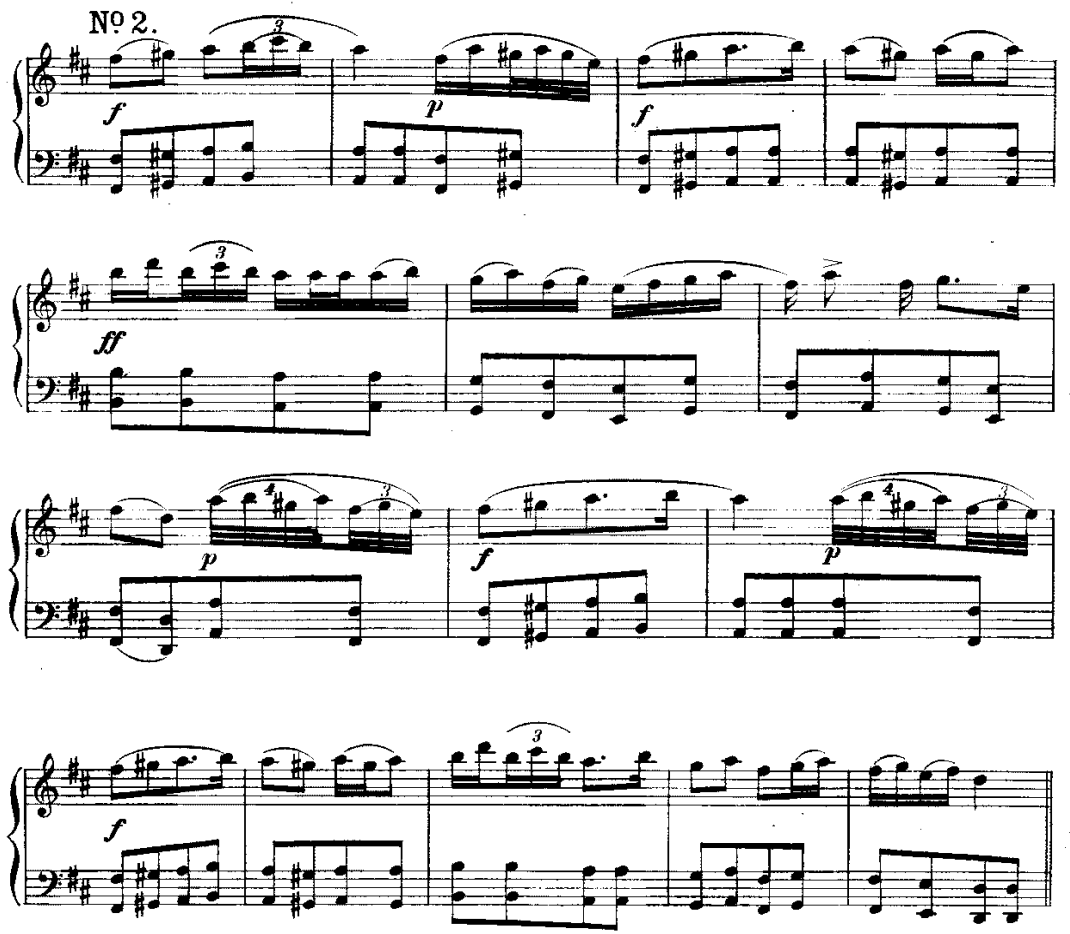

Nọ 3.

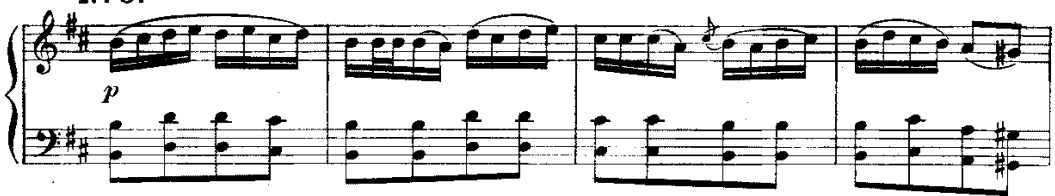




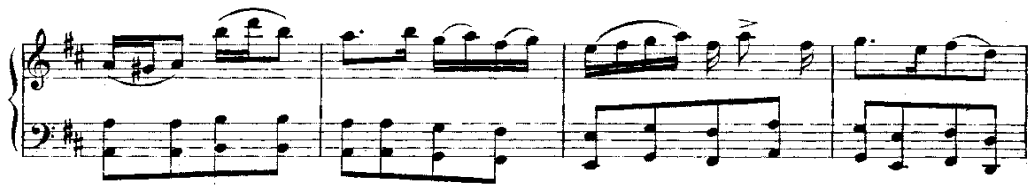

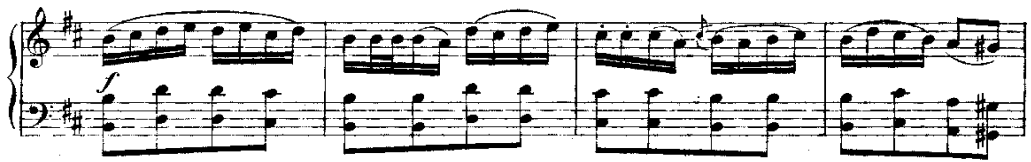

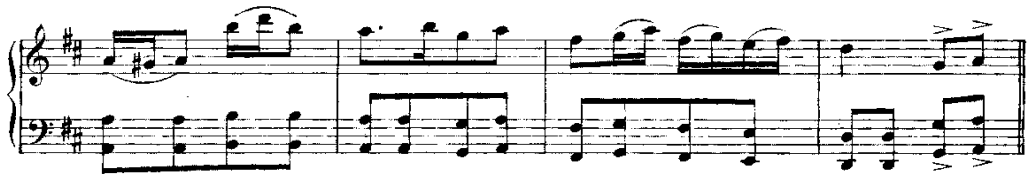

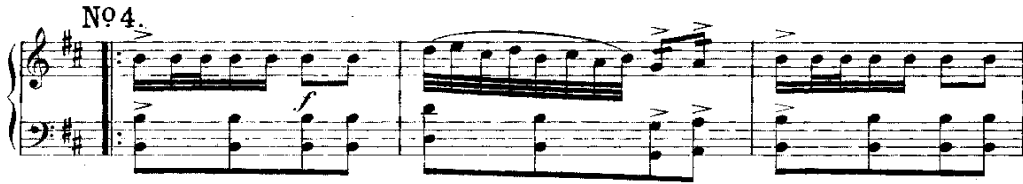

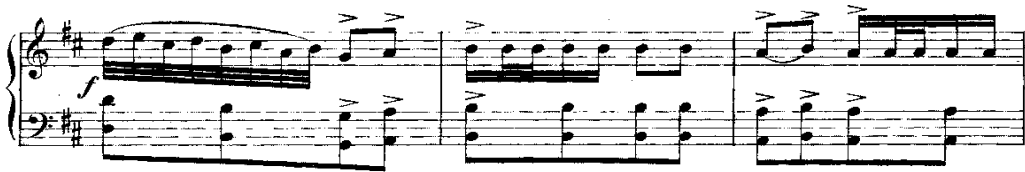

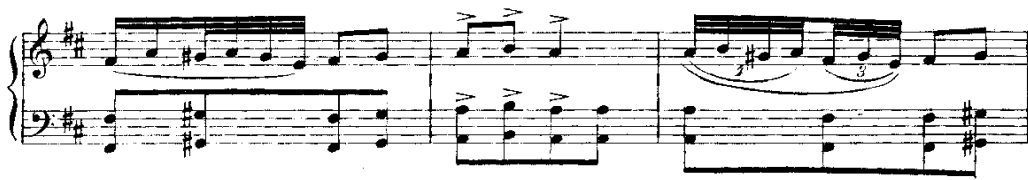



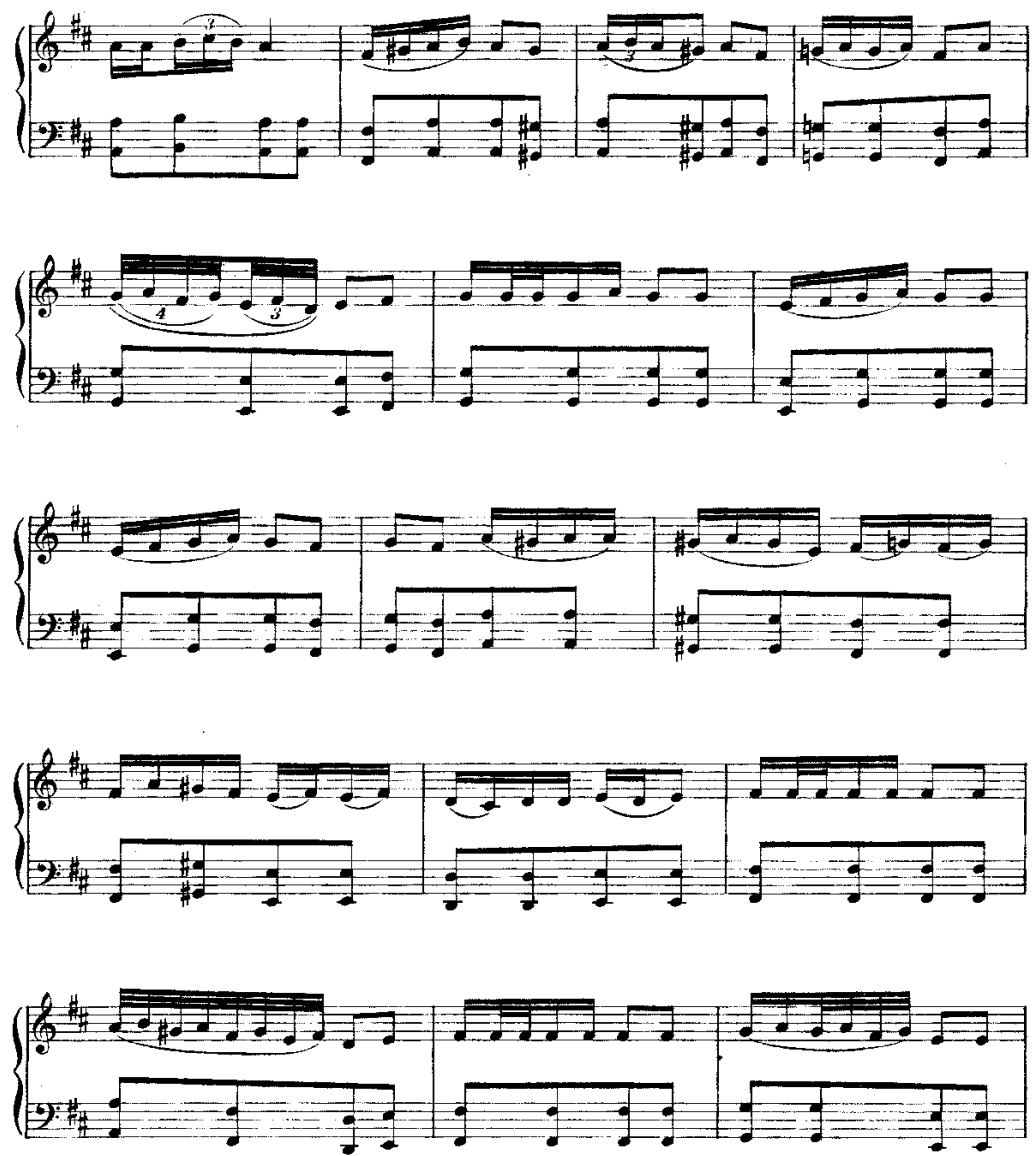


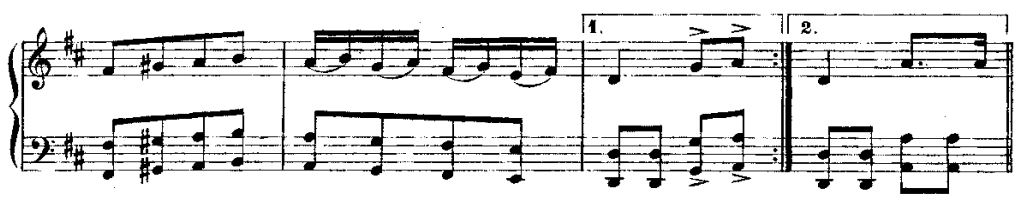

Finale.

Cette reprise $\mathbf{3}$ fois et la $\mathbf{3}$ fois pì̀ mosso
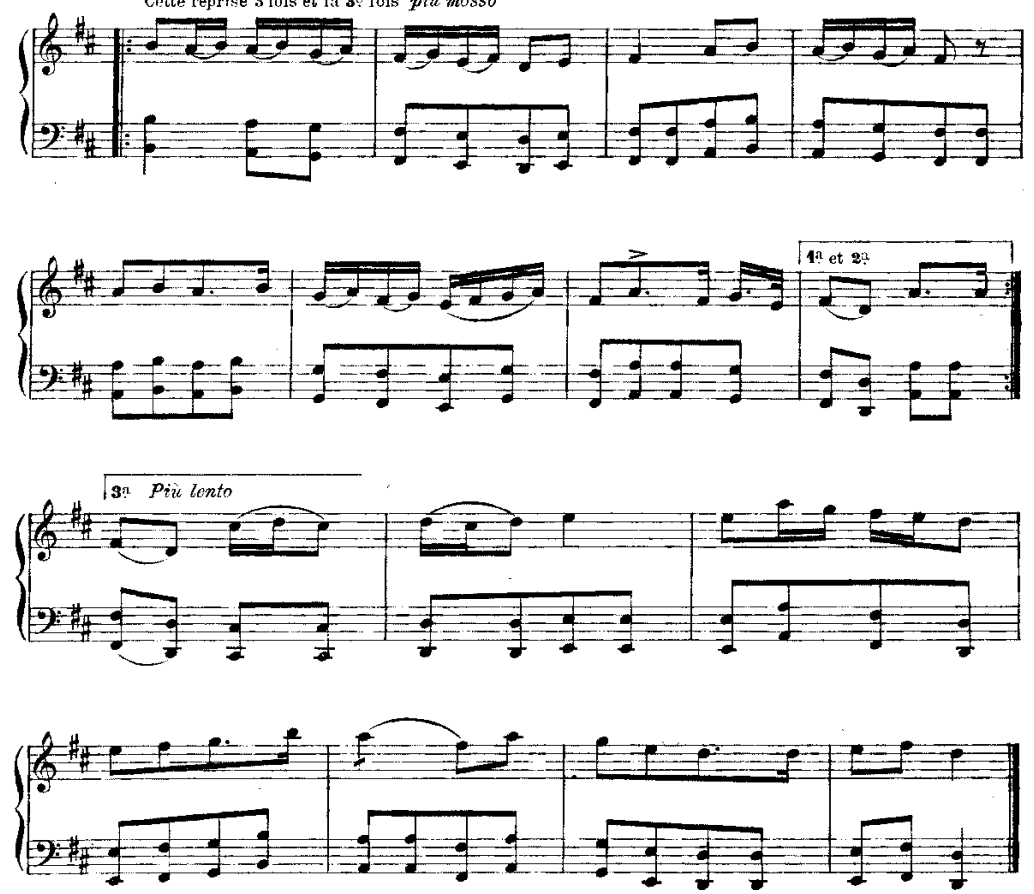


\section{REPERTOIRE DE MUSIQUE ARABE ET MAURE}

COLLECTION D'OUVERTURES, MÉLODIES, NOUBAT, $=$ CHANSONS, PRELLUDES, DANSES, ETC. =

La scule qui enohrasse trus fex genres de ta musique des Maures et des Arabes et qui présente un emsemble conplef de leur art musical depuis les temps ses pins reculés jusçn à nos jours

क्रि

\section{PREMIËRE SÉRIE}

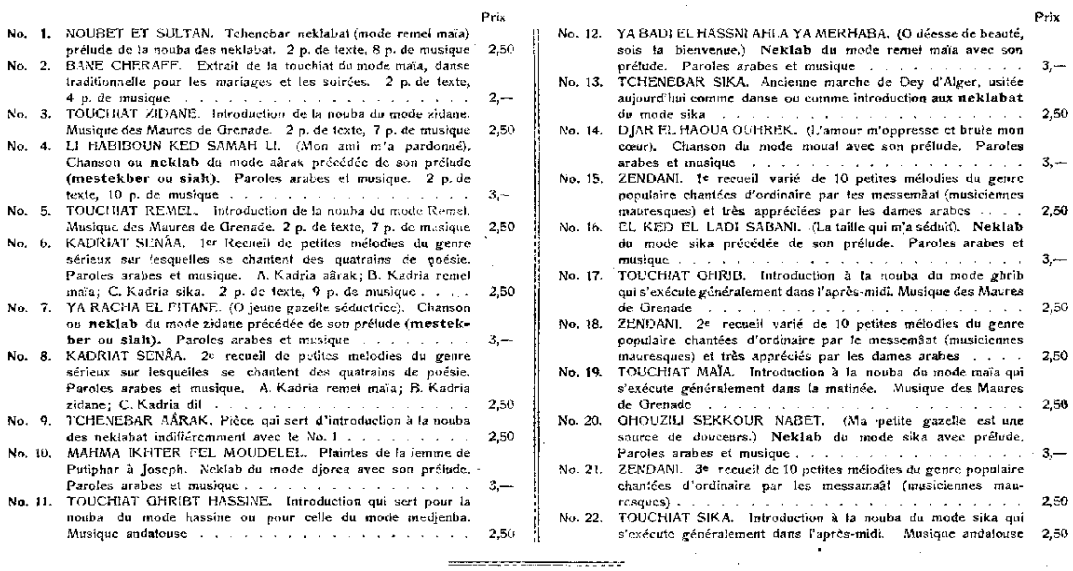

EN SOUSCRIPTION

\section{NOUBA REMEL MAIA}

Pour la premièrc fois depuis qu'existe l'art musical des Arabes, les amateurs pourront connaître une nouba tout entière, paroles et musique, avec son prélude, son ouverture, ses messeder (mélodies à mesure large), ses betaihi (mélodies langoureuses), ses derdj (melodies plus légères), ses nessraf (chants d'allure vive), son final ou moklass et ses préludes partiels ou kersi.

La nouba remel maĩa, une des rares noubat qui nous soient parvenues en entier, est un des monu. ments les plus curieux de l'ancienne musique arabe.

Elle formera un fascicule de 4 pages de texte et de 50 à 60 pages de musique, paroles et musique, du prix de $15 \mathrm{frs}$ et qui sera réservé exclusivement aux personnes qui enverront aux éditeurs une lettre de souscription avec engagement de payer la somme de 15 fres. à la livraison du fascicule.

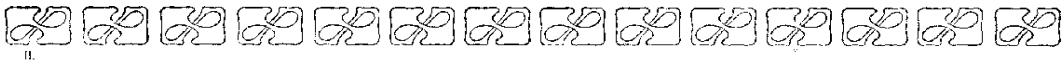




\section{Criterios de edición:}

Revista Argelina. Revista semestral de Estudios Argelinos es una publicación electrónica e impresa evaluada por pares con tres criterios de selección: 1) aceptación; 2) aceptación con cambios; 3) devolución. Se aceptan contribuciones en castellano, valenciano, árabe, francés e inglés.

Los originales se presentarán registrándose como usuario y subiendo el documento a la plataforma OJS de la página electrónica: $\underline{\text { http://argelina.ua.es }}$

El aparato crítico deberá ajustarse a las siguientes normas de edición:

-Texto en formato estándar a un espacio de interlineado.

-Fuente en Romanas (Times New Roman) a 12 puntos.

-Título del trabajo en mayúsculas a 16 puntos seguido en línea inferior por el nombre del autor en versalitas.

-Notas a pie de página a 10 puntos.

-Cita: Libro (Nombre, Titulo, Ciudad, Editorial, Año); Artículo (Nombre, "Título", en Revista, Año, vol. X, núm. X, pp. $\mathrm{XX})$.

-Sistema internacional para las citas y transcripciones del árabe. 


\section{معايير النشر :}

المجلة الجزائرية هي مجلّة علمية ومحكمة، مخصصة للدراسات المتعلقة بالجزائر، مقرّها بإِسبانيا، تطبع

$$
\text { أعدادها ورقيا وإلكترونيا كل ستة أشهر. }
$$

يستقبل المركز طلبات نشر الأبحاث والدراسات المنجزة وفق معايير الكتابة والنشر الخدّدة في متن هذه

- تخضع المواد المرسلة كلّها للتّقييم والقراءة الأكاديميّة.

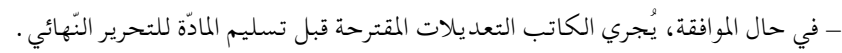

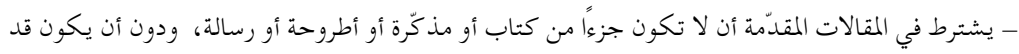
تمّ تقديمها سابقا لأي جهة علمية أخرى.

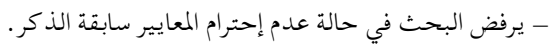

$$
\text { يمكن المساهمة باللغات التالية : العربيّة، الإسبانية، الفرنسية، الفلنسيانية والإنجليزيّة. }
$$

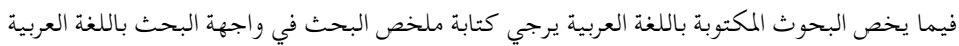

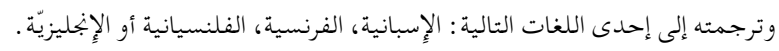

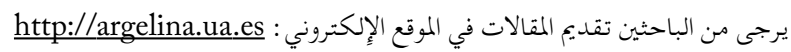

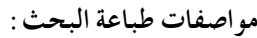

بهدف توحيد توثيق المصادر بشكل علميّ في كلّ أبحاث البجلة، يُرجى من الباحثين الكرام اعتماد أسلوب

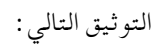

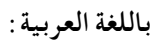

Traditional Arabic خط العناوين :بنط 16 ثقيل - خط المتن: بنط 16 عادي Traditional Arabic - خط الهوامش: حجم 12 عادي Traditional Arabic

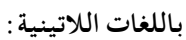
- تنسيق النص القياسي في مسافة سطر.

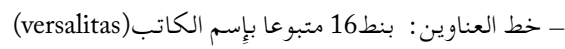
- خط المتن: بنط12 عادي(Times New Roman)

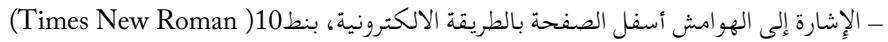

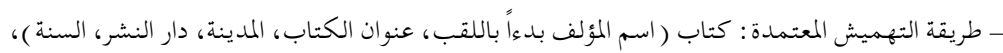

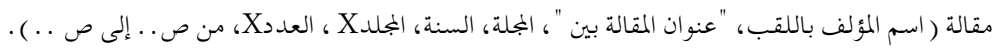

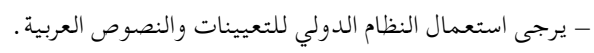

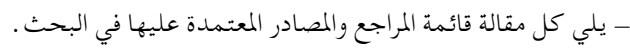




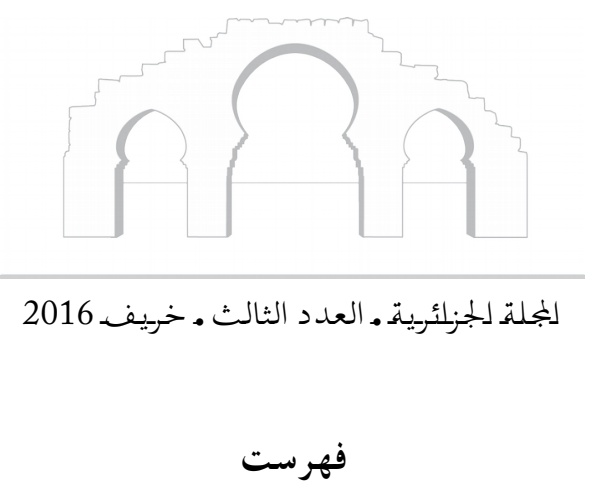

مقالات

عز الد ين تربش

الدلالات الثقافية للمو سيقى الفلكلورية : فرقة العرفة بمنطقة مسيردة أنموذجا . 29

أم هاني رحماني

51 محمد بن شنب رمز الانتماء الحضاري والتعدد الثقافي

$$
\text { العربي حسين }
$$

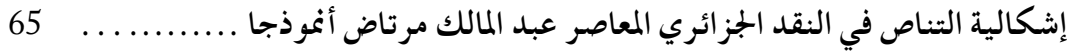

يوسفي محمد

تعارض فكرة النظام العام والاستثنـاءات العامة مـع تنفيـذ الحكم الأجنسبي في النظم المقارنسة 83 و النظام القانوني الجزز ائري . 


$$
\text { العددالثالث ـ خريف } 2016
$$

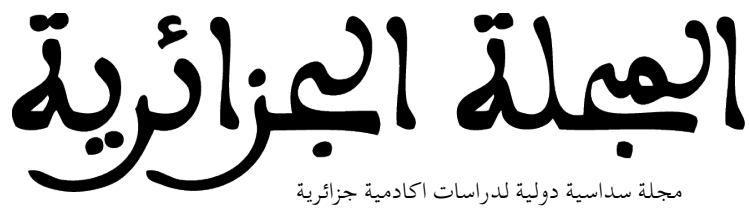




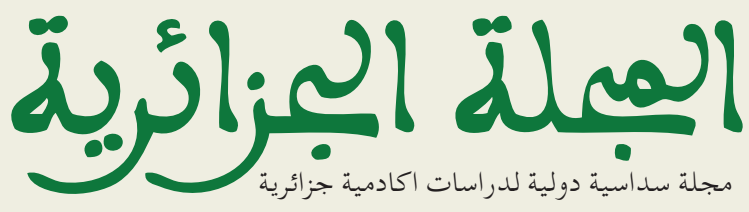

\section{ÍNDICE}

\section{Ensayo}

Luis F. Bernabé Pons

Música popular y sociedad en la Argelia actual ...

\section{Artículos y notas}

Dalila Azzi

L'identité hybride des auteurs algériens d'expression française. Le cas d'Assia Djebar

Naima Benaicha Ziani

Sobre el lenguaje en el teatro árabe argelino (II)

\section{Reseñas y comentarios bibliográficos}

IsAAC Donoso

Historia textual de la Nueva topografía de Argel de Alonso Cano

Omar Dib, Musique Algérienne. École de Tlemcen. Galerie des grands maîtres (reseña)

\section{Biblioteca}

Naima Benaicha Ziani

Kaddour el conductor. Escena dramática de la obra Los dichos de Abdelkader Alloula

Reproducción facsimil de Répertoire de musique árabe et maure.

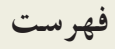

$$
\text { عز الدين تربش الد الاتش }
$$

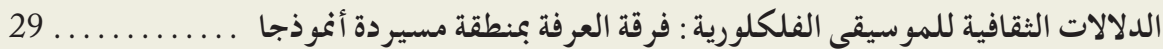

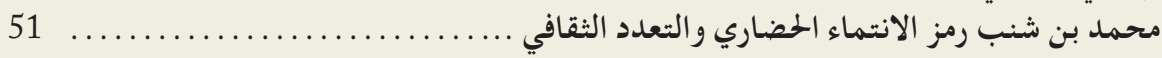

أم هاني رحماني العربي حسين

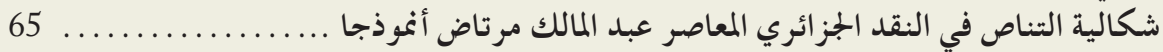
يوسفي محمد تعارض فكرة النظام العام والاستثناءات العامة مع تنفيذ الحكم الأجنبي في النظم المقارنة والنظام 83 القانوني الجززائري 